\title{
Modelling intertemporal consumer behaviour : theoretical results and empirical evidence
}

Citation for published version (APA):

Winder, C. C. A. (1988). Modelling intertemporal consumer behaviour : theoretical results and empirical evidence. [Doctoral Thesis, Maastricht University]. Free University Press.

https://doi.org/10.26481/dis.19880527cw

Document status and date:

Published: 01/01/1988

DOI:

$10.26481 /$ dis. $19880527 \mathrm{cw}$

Document Version:

Publisher's PDF, also known as Version of record

\section{Please check the document version of this publication:}

- A submitted manuscript is the version of the article upon submission and before peer-review. There can be important differences between the submitted version and the official published version of record.

People interested in the research are advised to contact the author for the final version of the publication, or visit the DOI to the publisher's website.

- The final author version and the galley proof are versions of the publication after peer review.

- The final published version features the final layout of the paper including the volume, issue and page numbers.

Link to publication

\footnotetext{
General rights rights.

- You may freely distribute the URL identifying the publication in the public portal. please follow below link for the End User Agreement:

www.umlib.nl/taverne-license

Take down policy

If you believe that this document breaches copyright please contact us at:

repository@maastrichtuniversity.nl

providing details and we will investigate your claim.
}

Copyright and moral rights for the publications made accessible in the public portal are retained by the authors and/or other copyright owners and it is a condition of accessing publications that users recognise and abide by the legal requirements associated with these

- Users may download and print one copy of any publication from the public portal for the purpose of private study or research.

- You may not further distribute the material or use it for any profit-making activity or commercial gain

If the publication is distributed under the terms of Article $25 \mathrm{fa}$ of the Dutch Copyright Act, indicated by the "Taverne" license above, 
MODELLING INTERTEMPORAL CONSUMER BEHAVIOUR

THEORETICAL RESULTS AND EMPIRICAL EVIDENCE 
Free University Press is an imprint of:

VU Boekhandel/Uitgeverij b.v.

De Boelelaan 1105

1081 HV Amsterdam

The Netherlands

Cover design: C.C.A. Winder

ISBN 90-6256-682-0 cip

NUGI 681

C C.C.A. Winder, Amsterdam, 1988.

All rights reserved. No part of this publication may be reproduced, stored in a retrieval system, or transmitted in any form or by any means, mechanically, by photocopying, recording, or otherwise, without the prior written permission of the author. 


\section{MODELLING INTERTEMPORAL CONSUMER BEHAVIOUR}

\section{THEORETICAL RESULTS AND EMPIRICAL EVIDENCE}

\section{PROEFSCHRIFT}

ter verkrijging van de graad van doctor aan

de Rijksuniversiteit Limburg te Maastricht, op gezag van de rector magnificus, Prof. Dr. F.I.M. Bonke, volgens het besluit van het College van Dekanen,

in het openbaar te verdedigen

op vrijdag, 27 mei 1988 om 14.00 uur

door

Cornelius Carolinus Andreas Winder

geboren te Alkmaar in 1958

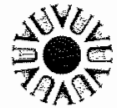

Free University Press

Amsterdam 1988 
Promotor: Prof. Dr. F.C. Palm

Beoordelingscommissie: Prof. Dr. J. Muysken Prof. Dr. H.J. Bierens

Prof. Dr. T. Kloek 


\section{ACKNOWLEDGEMENTS}

I am deeply indebted to all who contributed to the completion of this study. In particular, I wish to thank Franz Palm for his continual interest. I thank Herman Bierens for his helpful comments. The study has benefited from stimulating discussions with Aart de Vos and Rob Alessie. I am obliged to the Centraal planbureau for granting me permission to publish the data.

A special word of gratitude should be adressed to Karen. Her attention and support have made the last years the best until now. 
1. INTRODUCTION

1.1 outline 3

$\begin{array}{lr}1.2 \text { A revlew of some literature } & 12\end{array}$

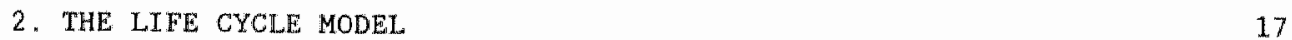

$\begin{array}{ll}2.1 \text { Theory } & 18\end{array}$

2.2 Empirical results 23

2.2.1 The income process $\quad 24$

2.2.2 The consumption process $\quad 26$

Appendix 2A The effects of structural changes 32

Appendix 2B Emplrical results for real mondurable consumption $\begin{array}{ll}\text { per capita } & 35\end{array}$

3. THE STOCHASTIC LIFE CYCLE MODEL

3.1 The model with general utility function 36

3.2 The model with the exponential utility function 40

4. THE MODEL WITH MOVING PLANNING HORTZON

4. 1 Theory $\quad 50$

4.2 Empirical results 55

4.2.1 The univariate stochastic process for consumption 56

4.2.2 The speciffcation with correction mechanism 60

Appendix 4A "The stochastic process for consumption when income follows an $\operatorname{ARIMA}(p, 1, q)$ process 68

Appendix 4B Empirical results for real nondurable consumption per capita 71

Appendix 4C "The Davidson, Hendry, Srba and Yeo model (I) 74

5. INFLATION EFFECIS

5.1 Theory 78 
Appendix 5A Empirical results for real nondurable consumption per capita

6.1 The model with infinite planing horizon

6.2 The model with finite planning horizon

6. 3 The model with moving planning horizon

6.3.1 The univariate stachastic process for consumption

6.3.2 The Davidson, Hendry, Srba and Yeo model (II)

6.4 Concluding remarks

Appendix 6A The univariate stachastic process for consunption in the model with moving planning horizon when the annual change in income follows an $\operatorname{ARM}(p, q)$ process

7. THE MODEL WITH MOVING PLANMING HORTZON UNDER VARIOUS FORMS OF HABIT FORMATION

7.2 Empirical results

Appendix 7A Empirlcal results for real nondurable consumption per capita 


\title{
Chapter 1
}

\author{
INTRODUCTION
}

Aggregate consumption is the largest component of aggregate demand. From the viewpoint of policy analysis, it is therefore important to be able to predict consumption reasonably well. So it is not surprising that the consumption function is one of the most extensively investigated relationships in economics. The most viable modern theories of the consumption function are formulated to reconclle the low marginal propensity to consume with the relative stability of the average propensity to consume observed over longer periods, a phenomenon that can not be explained by the Keynesian consumption function. Loosely speaking, in recent approaches constraint variables are introduced, which mitigate the impact of current real disposable income on the level of aggregate consumption. Important examples are Modigliani and Brumberg"s (1955) Life Cycle Hypothesis, that stresses the role of wealth, Friedman's (1957) Permanent Income Hypothesis, that claims that "permanent income" is the relevant income concept, and Brown (1952) who finds a significant impact of previous consumption, which may reflect the influence of habits.

For a successful implementation of policy applications, it ds necessary to have insight in the dynamic spectfication of the consumption function. Another reason for the continuing interest in this particular fleld of economic research is that no agreement seems to have been reached about the short run dynamic interrelationships between income and consumption. Severa1 authors (see e.g. Davidson, Hendry, Srba and Yeo (1978)) have stressed that economic theories usually yleld only information on steady. state behaviour and that an emplrical ecomometric amalysis is needed to trace the dynamic specification of the short run relationships. The multitude of econometric publications on the relationship betweer consumption and income illustrates that such a data-based approach towards dynamic specification is far from being straightforward. The category of 
economle models based on intertemporal optimization serves as an 1llustration, that economic theory is not completely uninformative about dynamic speclfication.

In this study will investigate various models of intertemporal consumer behaviour and use the dynamic implications as a guide in the specification analysis. Moreover, Sargent (1981) argues in line with Lucas (1976), that Interpreting economic time series as resulting from the cholces of private agents who are assumed to face dynamic optimlzation problems

"... offers the analyst the ability to predict how agents" behavior and the random behavior of market determined variables will each change when there are policy interventions or other changes in the environment that alter some of the agents' dynamic constraints" (op. cit. p.215).

Since we will look for emplrical evidence for the varlous models using data for the period $1968(1)-1984(4)$ and the stochastic environment in which the consumers had to take their decisions has been subject to several shocks during this perlod, we may hope that the theoretical framework will yield information on the consequences of the structural changes in the processes of the forcing wariables.

The maln objectives of the study are

1) to contribute to a better understanding of the theoretical models of intertemporal consumer behaviour under structural changes in the income process,

2) to derive the implications of these models for the univariate stachastic properties of consumption and for the relationship between income and consumption,

3) to test these implications against the information in aggregate data for the Metherlands.

To achieve these objectives we will use a wide range of different techniques, including both "econometric" and "time series" methods. Zellner and Paln (1974) have shown that univariate autoregressive integrated moving average (ARTMA) schemes can be derived for the endogenous variables of a linear simultaneous equation model when the exogenous varlables are generated by ARIMA processes. In other words, simple ARIMA processes correspond to a specific form of an econometric model called the final equation form. They are not ad-hoc specifications that are in 
contradiction with an econometric simultaneous equation model. consequently, both "econometrlc" and "tlme serles" technlques may yield valuable information about the model under consideration and may be useful in detecting specific deficlencies of the model.

In the first section of this chapter we will give an outline of the study and the second section is devoted to a discussion of some related literature.

\section{1 outline}

Since Modigliani and Brumberg (1955, 1979) put forward the life cycle consumption hypothesis, this theory has been extensively analyzed and tested, using both cross-section and time series data. Thelir work has kept a prominent position among the economic theories of consumption. Among the many articles that deal with extensions and refinements of the life cycle model, an important contribution is due to $\mathrm{Hall}$ (1978). He formulates the ife cycle hypothesis as an intertemporal decision problem under uncertainty and shows that the first order conditions for an intertemporal optimum have straightforward implications for the serial correlation properties of the time series data on consumption. Given an intertemporally additive utility function, the marginal utility of consumption is shown to be generated by a first orcler autoregressive process. Many authors have pursued and extended Hall's approach, see e.g. Bilson (1980), Flavin (1981), Hansen and Singleton (1982 "1983), Muellbauer (1983). Wickens and Molana (1983), Deaton (1985), Neusster (1987), CharpIn (1987). Campbel1 and Deaton (1987), Jager and Neusser (1987), Campbel1. (1987).

In the light of Hall's remarkable result, it may not be surprising that we will start our analysis with a similar formulation of the life cycle model. In line with Hall (1978) we make the following assumptions which will be maintained throughout the study:

1) The consumer has rational expectations about future labour income. More specifically, we assume that the subjective income expectations used in the utility maximization problem are the same as the mathematical expectations generated by an econometric mode1, whereby 
the latter is specified as a unvarlate ARIMA process. The structure and parameters of the income model are assumed to be known by the consumer. This implies among other things that we do not consider learning processes.

2) The real interest rate is constant and equal for both borrowing and lending.

3) The consumer is not 14quidity constrained, so that he is able to adjust his consumption over time in the way implied by the preference structure.

4) We refralln from a bequest motive.

5) Consumption can be regarded as a composite good. In particular, we will not make an explicit distinction between durable and nondurable goods.

Moreover, we adopt the following assumptions which will be relaxed in the subsequent chapters:

$11)$ The consumer has point expectations about future labour income. In chapter 3 we w11 analyze the life cycle mode1 in which the consumer uses in principle all information on the stochastic process of income.

2) The planning time span collncides with the expected life time. In chapter 4 we will introduce the model with moving planning horizon as an alternative for the life cycle hypothesis.

3) The consumer has full information about future prices. In chapter 5 we will investigate an extension of the model with noving planing horizon to account for inflation effects.

4) The utility function is intertemporally aditive. In chapter 6 we w11. analyze the life cycle model and the model with moving planing hortzon under rational habit formation.

5) The utility function does not depend on taste shifters. In chapter 7 we will axamine the model with moving planning horizon under various forms of habit formation: habit persistence is moclelled by means of previous consumption, past-peak income and past-peak consumption.

When a specific functional form of the utility function is required, we will use the exponentlal utillty function. This particular choice will prove to be very conventent. It will enable us to trace the consequences of structural changes in the income process in a relatively simple way and 
relate our results to other contributions on consumption theory.

In the study we w11 test the implications of the various models agalnst information in aggregate data for the Netherlands. In line with Hall (1978) and many others since then we make use of the concept of a representative consumer and estimate the various models with aggregate per capita data. Hence, we ignore the complications arising from the aggregation over individuals and changing demographic factors. In the main text we report the results for real total consumption per capita. Since the appropriate notion in the maximization problem is consumption rather than consumption expenditure, we have also estimated the model with data on nondurable consumption (including services) per capita only. The emplrical. results obtained with this consumption measure are given in an appendix at the end of the chapters. The data on real disposable labour and transfer income per capita, on real total consumption per capita and on real nondurable consumption per capita are given in Appendix $I$.

The study is organized as follows. In chapter 2 we will analyze the 1 ife cycle hypothesis. The framework is similar to that of Hall (1978). The main difference is that he assumes that the consumer takes into account the complete distribution of labour income, whereas we assume that he uses only the information on expected future labour income. Under the assumption that income is exogenous, the stachastic process of consumption is simply a transformation, accomplished by the intertemporal optimization model, of the stochastic properties of income. The analogy with physical experiments is obvious. Income is the input variable and consumption is the output variable. This observation shows that the theoretical model generates a number of restrictions between the processes for consumption and Income. Anticipated and unanticipated structural changes in the income process have for instance different speciflc effects on consumption. For rational expectations models. Lucas (1976) and Wallis (1980) have shown what the implications of a structural change in the process of the exogenous variables are for the parameters of the model for the endogenous variables and for econometric modelling. When the nature of the structural change in the process for the exogenous variables can be assessed, the implications of this change for the model can be determined. We will argue that autoregressive conditional heteroscedastic (ARCH) structures put forward by Engle (1982) may also be useful to capture the perturbations of the 
consumption process resulting from structural changes in the uncertain. stochastic ervironment in which the economic agents have to take their dectstions.

The extension of the analysis carrled out in chapter 2 with respect to Hal1's approach is obvious. The stochastic properties of consumption are analyzed in the light of those of income. In the empirical part of this chapter, way attention to the implications of structural changes in the Income process and $1 t$ is shown that the model provides a satisfactory description of the serfal correlation properties of the data, given that we are prepared to allow for a structural change in one of the parameters of the utlilty function. This assumption has to be made to account for the drop of consumption since 1979. We w11 argue however, that the empirical evidence Indicates that consumption is not smooth enough. In line with the Structurai. Econometric Mode11ing and Time Series Analysis (SEMTSA) approach put forward by Zellner and Palm (1974) and with Hendry"s (1979) criticism of ad-hoc modelling, an inconslstency between the theoretical model and the empirical evidence should lead to a reassessment and possibly a reformulation of the theoretical model. Therefore, we will try to revise the model in such a way that we do not have to appeal to this structural break.

In chapter 3 we consider the life cycle model in which the consumer is assumed to use in principle all the information on the stochastic process of income. Under the additionel assumption of normality, we derive the univariate stochastic process of consumption and we will give a closed form solution. As the drift parameter of the consumption process depends also on the variance of the income innovation, an unanticipated decrease of that varlance may explain the drop in consumption since 1979. However, under the assumption of rational expectations, information in the data sumarized by the specified income process, leads to the conclusion that the resulting model is observationally equivalent to that examined in chapter 2 . As the chosen framework in this chapter is Identical to that of Hall (1978), we discuss his model in more detail. For the model with intertemporally additive utility function, we wil also show that when the first derivative of the one-period utlity function is strictly convex, the consumer who uses all information on the stochastic process of labour income will choose a lower consumption level than the consumer who confines himself to the 
information on expected future labour income, provided that both consumers have identical preference structure and the same expected iffe time weal th.

The principal implication of the life cycle model is the separation of the consumption and income profiles. To relate the decrease in consumption to the observed decline in income in the 1980's, it seems destrable to establish a more direct link between income and consumption. In chapter 4 we introduce the model with moving planning horizon as an alternative for the life cycle model. We will axgue that it seems not unrealistic to imagine that the consumer will neglect periods far ahead in the future on which avallable information is scarce and unreliable, and will confine himself to more trustworthy information on the near future. We investigate a model of intertemporal utility maximization in which the consumer uses a planning time span that does not colncide with the expected life time When the time span differs from the life time, a mechanism that describes the adjustment of the planning horizon as time goes on has to be introduced in the model. We adopt the simplest possible solution and assume that the consumer uses a planning time span of constant length. Hence, his planning horizon is postulated to move ahead as time goes on. We will show that the drift parameter of the implied stochastic process for consumption is proportional to the one of the income process. Hence, an unanticipated change in the latter will have as a consequence that the former will alter. In other words, the model is capable of relating a change in the slope of the consumption line to a change in the income line. From the empirical analys is we conclude that the univariate process of consumption implied by the model with moving planning horizon and the assumption of rational expectations, is fully in accordance with the sample information. The model does not rely on an ad-hoc assumption about a structural change in one of the parameters of the utility function and removes in this way an important drawback of the life cycle model investigated in chapter 2. Surprisingly, the model with moving planning horizon implies a relationship between income and consumption which is highly simllar to the mechanlsm underlying the consumption function of Davidson, Hendry, Srba and Yeo (1978). More specifically, as a result of adjusting the planning horizon an error correction term has to be introduced in the consumption function. As no error is involved from the side of the consumer, we will argue that 
It is more approprlate to speak about a correction term. The introduction of a moving planning horizon provides an alternative explanation for the Inclusion of an error correction term and shows that the successful Implementation of these mechantsms in consumption functions specified and restimated from aggregate data may have 1 ts roots in a simple postulate about individual consumer behaviour. The empirical analysis using data on real total consumption per capita shows that the specification with the correction term, which is an alternative parameterization implied by the model with moving planning horlzon, is in agreement with the information in the data. The emplrical results for real nondurable constumption per capita are very satsfactory. The test for an ARCH structure in the disturbance term of the consumption function ylelds however a significant value, whereas the theoretical model and the specifled income process imply a homoscedastic stochastic process. As a possible explanation we suggest a relaxation of the assumption of rational expectations. An alternative interpretation of the significant value might of course be that it is an indication of some kind of misspecification.

In an attempt to remedy the inconsistency between the theoretical implications of the model with moving planning horizon and the empirical evidence, we direct our attention in chapter 5 to inflation effects. The chosen vehicle for incorporating inflation effects is the same as put forward by Deaton (1977). We model the consumption decision as a two stage procedure. In the first stage the consumer is assumed ta take a decision about total anticipated expenditure in the current period and conditional on this he determines in the second stage the commodity demands. When the actual prices devlate from the anticlpated prices, actual and anticipated expenditure will not colncide. The chosen model leads to a consumption function which is simflar to that of Davidson et. al. (1978). As in their specification we have to include inflation, the change in inflation and a correction term as explanatory variables. The presence of the correction term arises from the adjustment of the planning horizon as time goes on and the inflation variables are included as a result of the wrong assessments of the actual prices. The empirical results obtained for real total consumption per capita are not unsatisfactory. Information in the data, however, does not suggest that the inflation effects are present. From the empirical analysis using data on real nondurable consumption per capita we 
conclude that the model is misspecifled, We discuss several posslble explanations and suggest some extensions of the model.

One of the possible extensions suggested in chapter 5 concerns the relaxation of the assumption of an intertemporally additive utility function. In chapter 6 we will consider more general preference structures. In particular, we investigate the life cycle model and the model with moving planning horizon under rational habit formation.

Before, we noticed that the princlpal implication of the life cycle model. is the separation of the consumption and income profiles. Consequently, the dynamics of consumption are basically determined by the structure of the preferences. When we relax the assumption of separability of the utility function and impose a different structure on the preferences, a different stochastic process for consumption will arise. For the life cycle model with the exponential utility function we w111 show that an arbitrary ARIMA process for consumption can be obtained by choosing an appropriate pattern of rational habits. The model provides us with a theoretical framework for interpreting a broad category of stochastic processes for consumption. The major advantage of interpreting ARIMA processes within the context of intertemporal decision-making is that $1 t$ enables one to investigate the effects of policy interventions in the rigorous way indicated by Lucas (1976). The results of chapter 6 illustrate how simple ARIMA schemes for consumption may be used not only for forecasting purposes, but also for pollcy analysis. An illustrative example is for instance when one wants to predict the effects on consumption of a change in the tax rate on income. Given the low cost of spectfylng and estimating ARIMA processes the results of this chapter may be of practical Importance.

The model with moving planning horizon will be analyzed for a spectal form of rational habit formation that ylelds a model in the four period difference operator. We will derive the univariate stochastic process for the four period change in consumption when the annual change in income $1 \mathrm{~s}$ generated by an ARMA process. The analysis may shed some 11 ght on the frequently encountered similarities of the stochastic processes for income and consumption (see e.g. Prothero and Wallis (1976)), and we will argue that the theoretical framework can provide insight in the structures of the income and consumption processes, which may be of some use in the 
ldentification atage of a univariate modelling procedure. Moreover, It w11. be shown that when the annual change in income is generated by an autoregressive process of order 1, the model leads to a relationship between Income and consumption that is identical to the mechanism underlyling the consumption function of Davidson et. al. (1978), with the annotation that their speclfication is formulated in the logarithms of the variables whereas our mode1 reads in untransformed variables and that they use real disposable income, whereas the relevant income concept in our model is real disposable non-property income. More speciffcally, in each quarter of a year the consumer spends the same as he spent in the corresponding quarter of the previous year, modified by a proportion of the annual change in income and of the change of the annual change of income and by the correction term.

To model behawioural persistence, other predetermined variables than past consumption may be considered as well. In the 11terature on the consumption function Duessenbery (1949) and Modiglian (1949) have argued that the consumption decisfon depends also upon the highest income attained by the consumer in the past. Brown (1952) and Davis (1952) investigate a model in which past-peak consumption is used as an explanatory varlable. In chapter 7 we w11 analyze the model with moving planning horizon under a specific form of rational habit formation, in which an explicit influence of pastpeak income and past-peak consumption is recognized. We derive the consumption function and we will look for empirical evidence for the Ne therlands.

The empirical results for real total consumption per caplta are very satisfactory. Information in the data, however, does not suggest the presence of hablts. The analysis confirms the conclusion drawn in chapter 4 that the model with moving planning horlzon is fully in accordance with the sample information. These results contrast those obtained for real nondurable consumption per caplta. With this consumption measure we find a signiffcant effect of past-peak consumption. Empirical evidence suggests that neither previous consumption nor past-peak income have a significant inpact on the consumption decision. The distributional and serial correlation properties of the residuals and the predictive performance of the model are very satisfactory. In contrast to the empirical results obtained for the model without habits investigated in chapter 4 , the test 
for ARCH structures in the disturbance term of the consumption function yields an insignificant value. The absence of heteroscedasticity of the ARCH type is in agreement with the theoretical model. The direction of the influence of past-peak consumption, however, does not suggest the presence of habit persistence: its impact is contrary to habit forming. The implication of hablt hysteria casts serious doubts on the appropriateness of the model.

For the length of the planning time span we find in this chapter an estimate of 3.00 and 4.88 quarters for total and nondurable consumption respectively. The estimates obtained in previous chapters have a similar magnitude. Based on empirical evidence, Friedman (1957) draws a dividing Iine at a horizon of about 3 years (see p.221) to classify the permanent and transitory components of income. Notice that his concept of the horizon differs from ours (see on this Friedman (1963)). Obviously, information in aggregate per capita data suggests that the consumer is rather "shortsighted" and no life cycle adept.

In chapter 8 we will direct our attention to the issue of modelling seasonally unadjusted consumption series. Since we do not have quarterly seasonally unadjusted data on labour and transfer income at our disposal, we will choose for an analysis within the framework of the life cycle model. Recent1y, Miron (1986) has argued that the improper handing of seasonality might be the explanation for the frequent rejections of the life cycle theory. In the first section of this chapter we will specify and estimate a structural time series model (see e.g. Harvey and Todd (1983)), whereby the life cycle hypothesis with intertemporally additive utility function will be used to obtain a model for the trend-cycle component of consumption. As the information in the data is not in agreement with the theoretical madel, we will choose in the second section an alternative procedure and model the seasonality as a special form of rational habits. We will also indicate how a model with seasonal dumy variables may be interpreted as resulting from seasonal shocks to the preferences. However, the empirfical evidence is not fully consistent with the implications of the theoretical model. In a concluding section we will suggest some explanations and discuss some possible extensions.

Finally, chapter 9 is devoted to a summary and concluding remarks. 


\subsection{A revlew of some literature}

This section is dewoted to a discussion of some related literature. No attempt 111 be made to provide a complete survey of the 11 terature on life cycle models. For excellent reviews on various aspects of the life cycle theory, we refer to somermeyer and Bannink (1973), King (1983), Deaton (1985), Blundel1 (1986) and Muellbauer (1986). The book of Somermeyer and Bamink is recommended as a general introduction. King and Blundell consider the household life cycle labour supply and commodity demand behaviour. Deaton is concerned with aggregate savings and Muellbauer discusses the most important contributions to the research on habit formation and surveys emplxical evidence in the cross-section context. We restrict ourselves to a discussion of the models put forward by Hal1 (1978) and Davldson, Hendry, Srba and Yeo (1978) and some studies that are closely related. The concept of co-integration put forward by Engle and Granger (1987) has recently become very popular in econometrics and is tightly connected to our study. The multitude of recent papers on this topic indicates that it is a very active research area. However, a lot of intricate problems are not yet solved. We have therefore chosen to wait until the smoke clears and more insight has been acquired about the most fruitful and reliable approaches. For a recent analysis of the permanent income hypothesis using the conceptual framework of co-integrated time sexies vectors we refer to Campbell (1987).

In Hall's fanous article on consumption, the consumer is assumed to maximize at each period the expected value of an intertemporally additive ut1lity function subject to the life time budget constraint

$\operatorname{Max} \quad \operatorname{E}\left(\sum_{1=0}^{\mathbb{L}-t} \beta^{\mathbb{1}} U\left(c_{t+1}\right) \| \mathbb{I}_{t}\right)$

$S . T=\sum_{t=0}^{T-t}(1+r)^{-i} c_{t+1}=(1+r) a_{t-1}+\sum_{t=0}^{T-t}(1+r)^{-1} y_{t+1}$

with $U^{\prime}>0, U^{\prime} "<0$, where $U^{\prime}$ and $U^{\prime}$ ' are the first and second derivatives of $U$ with respect to c respectively. Real consumption and real labour income are denoted by $c_{t+1}$ and $y_{t+1}$ respectively, $a_{t-1}$ is financial wealth, $T$ 
denotes the iffe time, $\beta$ is the time preference parameter, $0<\beta<1$, and $r$ is the real interest rate, which 1 s assumed to be constant $(0<r<1)$. E is the expectations operator and $I_{t}$ denotes the information set at time $t$ used by the consumer. The only source of uncertainty concerns future labour Income and the consumer knows the value of $y_{t}$ when choosing $c_{t}$. The principal theoretical result proved by Hall is

$E\left(U^{\prime}\left(c_{t+1}\right) \mid I_{t}\right)=[\beta(1+r)]^{-1} U^{\prime}\left(c_{t}\right)$

Hence, marginal utility is generated by a first onder autoregressive process. Hall notices that a structural relation should exist between the innovation in income and consumption and tests the implication of (1.2) that information processed by the consumers when they decide on consumption in period $t$ should have no predictlve power with respect to consumption in period $t+1$. More specifically, he examines the predictive power of consumption lagged more than one period, lagged income and lagged stock prices. He finds that neither lagged consumption nor lagged income are significant. Lagged stock prices, however, do have predictive power and he argues that this finding is consistent with a modification of the hypothesis that recognizes a brief lag between the changes in permanent income and the corresponding changes in consumption. A more appropriate explanation is provided by Hansen and Singleton (1982,1983). They investigate the model (1.1) for the utility function with constant relative risk aversion and stochastic interest rates and show how a restricted bivariate autoregressive process for the logarithms of consumption and the interest rates can be obtained. The associated reduced form equation for consumption shows that past real interest rates can hawe predictive power for future consumption. In chapter 3 we will recurn to the model put forward by Hall (1978).

Bilson (1980) and Flavin (1981) discuss the permanent income-rational expectations hypothesis. In general, in this context the utility function is not explicitly specified. The permanent lncome hypothesis will arise as a special case of the model analyzed in chapter 2 . Consunption 15 defined as the sum of permanent and transitory consumption, whereby the former is postulated to be equal (or proportional) to permanent income yp, which is defined as the constant level of income which satisfies the life 
time budget constralnt. Formally, when the real interest rate is assumed to be constant wave for an infintely lived consumer (see Flavin (1981))

$y_{t}^{p} \sum_{1=0}^{\infty}(1+x)^{-1}-(1+r) a_{t-1}+\sum_{1=0}^{\infty}(1+r)^{-1} E\left(y_{t+1} \mid I_{t}\right)$

or alternatively

$y_{t}^{p}-r\left[a_{t-1}+\sum_{i=0}^{\infty}(1+r)^{-(1+1)} E\left(y_{t+1} \mid I_{t}\right)\right]$

Hence, permanent income equals the return on the consumer"s human and nonhuman wealth. Notice that in the definition of permanent income given above, It $1 \mathrm{~s}$ implicitly assumed that the consumer has point expectations about future labour income. In other words, the consumer is assuned to use only information on the conditional first moments of the stochastic process of labour income. Blison and Flavin assume that transitory consumption equals zero. Provided that consumption equals permanent income, they notice that the consumption Innovation is identical to the revision in permanent income. Bilson (1980) finds positive evidence for the U.K. and negative results for the United States and Germany. Flavin (1981) chooses an ARMA representation of the income series (in deviation from trend), and shows that the revision in permanent income is proportional to the income innovation, with the factor of proportionality determined by the parameters of the income process. She specifies a structural model of consumption and finds evidence agalnst the permanent income hypothesis. More specifically, she concludes that the response of consumption to current income is beyond that attributable to the role of current income in signaling changes in permanent Income (the so-called excess-sensitivity issue). Deaton (1985) and Campbel1 and Deaton (1987) also use the property of proportionality of the consumption and income innovation. However, they argue that the information in the data for the U.S. summarized by the income model, suggests that consumption is not sensitive enough to innovations in current Incoma.

Hall and Mishkin (1982) also examine the stochastic relationship between income and consumption and investigate the sensitivity of consumption to current fluctuations in income. Using panel data for the U.S., they reject the life cycle model and argue that the empirical evidence is consistent 
with pure life cycle behaviour for 80 per cent of consumption and proportionality of consumption and income for the remaining 20 per cent. In chapter 3 we will argue that their results hold in a more general framework.

Muellbauer (1983) and Hickens and Molana (1983) refect Hall's model on data for the U.K.. Muellbauer examines subsequently the role of real interest rates and the possibility of liquidity constraints. Wickens and Molana investigate the possible misspecification resulting from the assumption that interest rates and prices are constant. Moreover, they discuss the implications for the model when the decision interval differs from the frequency on which the data are observed (the time-aggregation problem). However, none of these extensions seems to provide a satisfactory explanation for the failure of the Hall model.

In the study of Davidson, Hendry, Srba and Yeo (1978) the role of economic theory is rather modest. They restrict themselves to the information on steady-state behaviour and use an empirical analysis to specify the $1 \mathrm{ag}$ structure of the short run consumption function. After a thorough emplrical investigation, "which was conducted on a rather intuitive basis as a "detective story" (Hendry (1983), p.194), Davidson et. all arrive at the following consumption function

$$
\begin{aligned}
\Delta_{4} \ln \left(c_{t}\right)= & .47 \Delta_{4} \ln \left(y_{t}\right)-.21 \Delta \Delta_{4} \ln \left(y_{t}\right)-.10 \ln (c / y)_{t-4}+.01 \Delta_{4} D_{t}^{0} \\
& (.04) \quad(.05) \quad(.02) \\
& =.13 \Delta_{4} \ln \left(p_{t}\right)-.28 \Delta \Delta_{4} \ln \left(p_{t}\right) \\
& (.07) \quad(.15)
\end{aligned}
$$

where $c_{t}=$ real expenditure on nondurable consumption and serwices $y_{t}=$ real disposable income

$p_{t}=$ price index of $c_{t}$

$\mathrm{D}_{\mathrm{t}}^{0}$ dummy variable for 1968 and 1973 .

The most salient feature of (1.3) is the error correction term $\ln \left(\mathrm{c} / y^{\prime}\right)_{t}-\|_{4}$ which ensures that in case of deviations from the steady state growth path, consumption will be adjusted in line with the long-run proportional relationship between income and consumption. Several authors (see e.g. 
Currie (1981). Salmon (1982), Kloek (1984)) have argued that the error correction mechanism encounters difficulties in case of a linear trending target. Hendry and Von Ungern-Stemberg (1981) argue that the consumption function (1.3) Includes deriwative and proportional control mechanisms but lacks integral correction and consider liquid assets as a proxy for Integral control. They also re-examine the role of inflation and the treatment of seasonality. Davidson and Hendry (1981) compaxe Hall's model with equation (1.3). They present tests which reject Hall's specification and show that the consumption function of Davidson et. al. (1978) encompasses Hall's model. However, we wil argue in chapter 8 that the univarfate consumption process they consider, is not the analogue of Hall's specification, but corresponds to the life cycle model under a special form of rational habit formation. Hendry (1983) reappraises relationship (1.3), using the conceptual framework presented In Hendry and Richard (1982, 1983). In Hendry and Von Ungern-Sternberg (1981), Davidson and Hendry (1981) and Hendry (1983) estimates of specification (1.3) based on the latest available data are reported. They show that the consuration function (1.3) has continued to provide a very satisfactory description of the data for the U.K.. In chapter 4 we will show that the model with moving planning horizon is capable of reproducing the basic mechanism underlying the consumption function put forward by Davidson et, al. (1978). 


\section{Chapter 2}

\section{THE LIFE CTCLE MODEL}

In this chapter we will discuss the life cycle model and will give empirfcal evidence for the Netherlands. In section 2.1 we analyze the 11 fe cycle model with the exponential utility function. The framework is similar to that proposed by Hall (1978). He formulates the 11fe cycle hypothesis as a decision problem under uncertainty with a intertemporally additive utility function and shows that the first order conditions for an optimum have straightforward implications for the serial correlation properties of the time series data on consumption. The main difference with the model discussed in this chapter is that he assumes that the consumer takes into account the complete distribution of labour incone, whereas we assume in line with Flavin (1981) and Campbe11 (1987) who investigate the Permanent Income Hypothesis, that the consumer uses only the information on expected future labour income.

Under the assumption that income is exogenous, the stochastic process of consumption is simply a transformation, accomplished by the intertemporal optimization model, of the stochastic properties of income. The analogy with physical experiments is obvious. Income is the input variable and consumption is the output variable. To put it differently, the life cycle theory generates a number of restrictions between the processes for consumption and income. In the emplrical analysis carried out in section 2.2, we will test these restrictions. The extenslon with respect to Hall"s approach is obvious. The stochastic properties of consumption are analyzed $\mathbb{i n}$ the light of those of income. Antlcipated and unanticipated structural changes in the income process have for instance different speclfic effects on consumption. For rational expectations models, Lucas (1976) and Wallis ((1980) have shown what the implications of a structural change in the process of the exogenous variables are for the parameters of the model for the endogenous variables and for econometric modeling. In the analysis of 
the life cycle hypothesis, special attention w11 be paid to these 1mplications. The emplrical analysis shows that the model provides a satisfactory description of the serial correlation properties of the data, given that we are prepared to extend it for a structural change in one of the parameters of the utility function.

\subsection{Theory}

In this section we discuss the life cycle model with a time additive utllity function. We assume that at each time period $t$, an intertemporally additive utility function is maximized subject to the life time budget constraint

$\operatorname{Max} \sum_{\mathbb{1}=0}^{\mathrm{T}-\mathrm{t}} \beta^{\mathrm{I}} \mathrm{U}\left(\mathrm{c}_{t+1}\right)$

S.T. $\sum_{1=0}^{T-t}(1+r)^{-1} c_{t+1}=(1+r) a_{t-1}+\sum_{i=0}^{T-t}(1+r)^{-1} E\left(y_{t+1} \mid I_{t}\right)$

with $U^{\prime}>0, U^{\prime} "<0$, where $U$ ' and $U^{\prime \prime}$ are the first and second derivatives of $U$ with respect to $c$ respectively. Real consumption and real labour income are denoted by $c_{t+1}$ and $y_{t+1}$ respectively, $a_{t-1}$ is accumulated real wealth, T denotes the Iife time, $\beta$ is the time preference parameter, $\quad 0<\beta<1$, and $\mathbf{r}$ is the real interest rate, that is assumed to be constant $(0<\mathrm{r}<1)$. E denotes the expectation operator, $I_{t}$ is the information set avaliable at time used by the consumer. We assume that the relevant information consists of past realizations of incone or consumption. Because consumption is a transformation of income, we may concentrate on elther the past of income or the past of consumption without changing the nature of the information set. The only source of uncextainty concerns future labour Income and $i t$ is assumed that the consumer knows the value of $y_{t}$ when taking a decision about $c_{t}$. Hence, $E\left(y_{t} \mid I_{t}\right)=y_{t}$.

To arrive at an operational model it is necessary to choose a specific functional form for $U$. In this study we examine the exponentiall utidity function 
$\mathrm{U}(\mathrm{c})=-\gamma^{-1} \exp (-\gamma \mathrm{c}), \gamma>0$

The assumptions underlying the model (2.1) differ from those often made when consumers are assumed to maximize the expected value of the utility of present and future consumption given the life time budget constraint. In chapter 3, we shall compare the two models and show that for the utility function (2.2) under the additional assumption of normality and no structural change in the variance of the income process the two models are observationally equivalent.

The first order conditions implied by (2.1) and (2.2) are

$c_{t+1}^{t}=1 \gamma^{-1} \ln [\beta(1+r)]+c_{t}^{t}, i=1, \ldots, T-t$

where $c_{t+1}^{t}$ denotes the consumption plan for period $t+i$ made at time $t$. For: period $t$, we have $c_{t}^{t}=c_{t}$ as the realization. After substitution of (2.3) into the intertemporal budget constraint, we get for $c_{t}$

$\left.\eta_{T-t^{c} t}+\gamma^{-1} \ln [\beta(1+r)] \tau_{T-t}=(1+r) a_{t-1}+\sum_{i=0}^{T-t}(1+r)^{-I_{E}} y_{t+1} \mid I_{t}\right)$

where

$\eta_{k}=\sum_{i=0}^{k}(1+r)^{-i}$ and $r_{k}=\sum_{i=1}^{k} i(1+r)^{-i}$

The parameters of the exact relationship (2.4) could be estimated provided the first moments of income are given. Moreover, to estimate (2.4) a disturbance term has to be introduced. Notice also that Friedman's (1957) Permanent Income Hypothesis and Modigliani and Brumberg's (1955) Life Cycle Hypothesis arise as a special case of (2.4), when the "constant" term on the left hand side equals zero. A necessary and sufficient condition for this to occur is $\beta(1+r)=1$. In the next chapter we will show that this result holds for any utility function satisfylng $U^{\prime}>0$ and $U^{\prime}<0$. As the restriction $\beta(1+r)=1$ implies a constant consumption level for the future (see $(2.3)$ ), we infer that the assumption $\beta(1+r)=1$ is more restrictive than the choice of the exponential utilfty function (2.2). 
To investigate the dynamics in the consumption series, it is convenient to relate $e_{t}$ to $c_{t+1}$. For pertod $t+1$ the corresponding formula for the consumption decision will be

$\eta_{T-t-1}^{c} t+1+y^{-1} \ln [\beta(1+r)] T_{T-t-1}=(1+r) a_{t}+\sum_{1=0}^{T-t-1}(1+r)^{-1} E\left(y_{t+1+1} \mid I_{t+1}\right)$.

Dividing $(2.5)$ by $1+r$, substituting $a_{t}=(1+r) a_{t-1}+y_{t}-c_{t}$, and subtracting (2.4) leads to

$$
\begin{aligned}
c_{t+1}-c_{t}= & \gamma^{-1} \ln [\beta(1+r)]+ \\
& \left.\eta_{T-t-1}^{-1} \sum_{1=0}^{T-t-1}(1+r)^{-1}\left[E\left(y_{t+1+1} \mid I_{t+1}\right)-E\left(y_{t+1+1} \mid I_{t}\right)\right]\right) .
\end{aligned}
$$

The life cycle model formulated above implies that consumption follows a random walk with drift. An advantage of the "quasi-differencing" procedure is that we have elfminated wealth. Because of the scarcity of reliable data on thls variable (see e.g. Modiglianf (1975) and Pesaran and Evans $(1984)$ ), concentrating on (2.6) wil1 probably lead to moxe reliable conclusions about the life cycle model.

To complete the model for consumption, we have to specify the process for labour income. Let us assume that the change in income is generated by a stationary process with moving average representation

$y_{t+1}=y_{t}+\delta+\sum_{1=0}^{\infty} \psi_{i} \nu_{t+1-1}, \psi_{0}=1, \sum_{1=0}^{\infty} \psi_{1}^{2}<\infty, \sigma^{2}\left(\nu_{t}\right)=\sigma_{\nu}^{2}$,

which is operatlve both in perfods $t$ and $t+1$. As the moments of $y_{t+1}$, condtionally on some intitil value, satisfy

$\mathbb{E}\left(y_{t+1} \mid I_{t+1}\right)-\mathbb{E}\left(y_{t+1} \mid I_{t}\right)=\left(\psi_{0}+\ldots+\psi_{t-1}\right) w_{t+1}, i=1, \ldots, T-t$,

substituting (2.8) into (2.6) yields the univariate process of consumption,

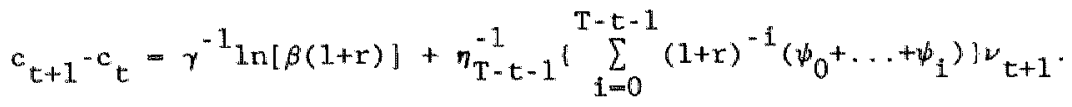

The consumption innovation $\varepsilon_{t+1}=c_{t+1}-E\left(c_{t+1} \mid I_{t}\right)$ is a Inear transformation 
of the income innovation,

$\left.\varepsilon_{t+1}=\eta_{T-t-1}^{-1} \sum_{1=0}^{T-t-1}(1+t)^{-1}\left(\psi_{0}+\ldots+\psi_{1}\right)\right) \nu_{t+1}$.

Its variance 1 s given by

$\sigma^{2}\left(\varepsilon_{t+1}\right)=\eta_{T-t-1}^{-2}\left(\sum_{i=0}^{T-t-1}(1+r)^{-1}\left(\psi_{0}+\ldots+\psi_{i}\right)\right)^{2} \sigma_{\nu}^{2}$

Equation (2.9) can also be estimated, but unlike (2.4) there is a disturbance term in (2.9). Relationship (2.10) relates consumption through its innovation $\varepsilon_{t+1}$ to income. Given the income process the stochastic process for consumption is completely specified. Notice that the life cycle model does not imply that consumption is smoother than income. From (2.11) we infer that the variance of the consumption innovation may be larger as well as smaller than that of the income innovation. When Income is generated by a random walk both variances are equal. Deaton (1985) reaches similar conclusions for the permanent income model.

Notice that in determining the expression for the consumption decision $c_{t}$, we implicitly assume that an interior solution exists. For the maximization problem (2.1) with utility function (2.2), this assumption leads to specific requirements. Since the consumption decision for periad $t$ and the implied planned consumption levels $c_{t+1}^{t}$ determined by expressions (2.3) and (2.4) respectively, should be strictly positive, we infer that it is necessary and sufficient to postulate $c_{t}>0$ when $B(1+r)>1$ and $c_{t}>0$ when $\beta(1+x)<0$. It can be easily shown that these requirements lead to the conditions

$(1+r) a_{t-1}+\sum_{1 \infty 0}^{T-t}(1+r)^{-i} E\left(y_{t+1} \| I_{t}\right)>\gamma^{-1} \ln [\beta(1+r)] \tau T-t$

iff $\beta(1+r)>1$ and

$(1+x) a_{t-1}+\sum_{i=0}^{T-t}(1+r)^{-1} E\left(y_{t+1} \mid \mathbb{I}_{t}\right)>-\gamma^{-1} \ln [\beta(1+x)] \sum_{1=0}^{T-t-1}(T-t-1)(1+r)^{-1}$

if $\beta(1+r)<1$. Notice that $(2.12)$ and $(2.13)$ imply that 1 is not sufficlent to assume that the expected walue of life time wealth is strictly positive. 
Throughout the study we assume that the particular value of life time wealth guarantes that corner solutions are excluded.

Expression (2.11) shows that the variance of the consumption innovation is age/time-dependent. When the model (2.9) has to be estimated from aggregate real per capita data, it is not sufficlent to assume that these data correspond to a representative consumer. When the age structure of the population and the income distribution over different age groups are fairly stable over time, the assumption of a constant varlance for aggregate real per capita consumption 1 s expected to be appropriate. These assumptions are closely related to the assumptions of the constancy over time of the concept of the representative consumer.

In Ifne with Lucas (1976) we can trace the effect of a change in the process of the exogenous varlable $y_{t}$ on the model for consumption. It can be easily shown by using expression (2.6) that an unanticipated change in $\delta$ in (2.7) leads for instance to a step change in the consumption level. For a derivation of this result refer to Appendix $2 \mathrm{~A}$. Because we refrain from learning processes, the adjustment in the consumption level is completed as soon as the structural shift in income arises.

Since the constancy of $\sigma^{2}\left(\nu_{t+1}\right)$ in (2.7) is not required for deriving (2.9) and (2.10), we see that any heteroscedasticfty of the income innovations should be reflected in the consumption series. For instance when $\nu_{t+1}$ in (2.7) is generated by an autoregressive conditional heteroscedasticity (ARCH) process of order p (see Engle (1982)), that is when $y_{t}$ is generated by an ARIMA process with innovations being ARCH (see Weiss (1984)), then because of (2.10), $r_{t}$ will follow an ARCH process of the same order. A feature which makes ARCH processes of great potentili interest is that they can handle outliers aristing in clusters. When we are prepared to relax the assumption of fully rational expectations, we may find consumption innovations that can be modelled as an ARCH process, even in case of absence of heteroscedasticity of the ARCH type in the income process. In Append $1 \mathrm{x} 2 \mathrm{~A}$ it is shown that a structural change in the income series leads to a step change in the consumption level. When the consumer incorrectly assesses a shift in the income process he may become aware of this after a wh1le, and adjust his consumption level accordingly (with a small correction for his error). This will lead to a new step change, but now in the opposite direction. ARCH processes can probably be used to model this 
kind of behaviour. Of course more sophisticated models allowing for gradual. learning by the consumer could be built. This will probably lead to complicated models. Moreover, the choice of a learning scheme may be arbitrary. ARCH processes are potentially useful for describing patterns in the consumption series which are the result of outliers in the income process or of a lack of rationality on the side of the consumer. However, when we stick to the assumption of rational expectations there exists a one to one correspondence between the stochastic properties of the consumption and income series.

To evaluate the theoretical model (2.1) we can analyze the random walk specification (2.9) for consumption. Moreover, a number of restrictions, arising from the fact that the stochastic behaviour of consumption is a transformation established by (2.1), of the stochastic process of income, can be tested. An empirical analysis of the consumption and income serles will be carried out in the next section.

\subsection{Emplrical results}

In this section our concerns will be to test the implications of the theoretical model (2.1) with utflity function (2.2) using quarterly seasonally adjusted data of the Netherlands. Quarterly data on real per capita disposable labour and transfer income for 1968(1)-1984(4) and on real per capita total consumption for the period 1967(1)-1984(4) and their plots are given in Appendix I. Since the appropriate notion in the life cycle theory is consumption rather than consumption expenditure, we have also estimated the model with data on nondurable consumption (fncluding services) per capita only. The empirical results ace reported in Appendix $2 B$ and the data on this serles are given in Appendix $I$. Since the stochastic behaviour of consumption is implied by both the theoretical model and the stochastic process of income, an analysis of the income series is expected to yield useful insight about the structure of the consumption model. It is therefore natural to start the empirical analysis by examining the income process. In the last subsection will discuss the empirical results for the consumption series. 


\subsubsection{The Income process}

From the plot of the income series it becomes obvious that income is not stationary and that the slope of the income line has changed. In a tentative analysis we have divided the sample period in three subperiods $1968(2)-1970(4), \quad 1971(1)-1978(4)$ and $1979(1)-1984(4)$ respectively and calculated the autocorrelation function (ACF) for $\triangle y_{t}$. For the second and third subperiod only the first order autocorrelation is significantly different from zero. In particular we have the values -.41 and -.38 respectively. For the first subperiod none of the autocorrelations is significantly different from zero. As the number of observations is only 11, this result may not be surprising. Therefore we decide to fit a MA(1) process for $\Delta y_{t}$ for the whole sample period, assuming that the drift parameter has changed over the subperiods. Estimation by the maximum likelthood (ML) -method yields

$$
\begin{aligned}
& \Delta y_{t}=\frac{40.46 d_{1 t}+\frac{25.19 d}{(7.81)} 1 t-13.01 d}{(8.56)} 2 t+\nu_{t}-\frac{.428 \nu}{(3.81)} t-1 \text { (3.72) } \\
& t(63)=2.524 ; \quad \sigma_{\nu}^{2}=809.6
\end{aligned}
$$

where $d_{1}=1$ for $1968(2)-1970(4)$

$$
\begin{aligned}
& \mathrm{d}_{2 \mathrm{t}}=1 \text { for } 1971(1)-1978(4) \\
& \mathrm{d}_{3 \mathrm{t}}=1 \text { for } 1979(1)-1984(4)
\end{aligned}
$$

and t-ratio's are reported between parentheses. The value of the $t$ statistic for the hypothesis that the coefficients in the first two subperiods are equal, denoted by $t(63)$ is significantly different from zero.

Inspection of the residuals does not show any significant correlation. We find three outliers for 1974(2), 1978(4) and 1982(1). The Box-Pierce (BP) and the LJung-Box (LB) test statistic based on s residual autocorrelations, have been computed for $s=4,8,12$ and 16 . The results can be found in Table 2.1. They are not significant at commonly used significance levels. Next, we consider the constancy of the variance of the disturbance term. We have carried out a Lagrange Multiplier (LM) test for the null hypothesis that $\nu_{t}$ in $(2.14)$ has a constant variance against the alternative hypothesis that the disturbance $\nu_{t}$ has an ARCH structure 
$\sigma^{2}\left(\nu_{t} \mid I_{t-1}\right)=\alpha_{0}+\sum_{i=1}^{p} \alpha_{i} \nu_{t-i}^{2}$

The results are reported in Table 2.1 for $p=1$ and $p=4$ as $\eta(1)$ and $\eta(4)$ respectively. Clearly, the test of an ARCH structure for the income serles is not significant. Finally, we check the normality of the income series using the test put forward by Lomnicki (1961). When we define

$m_{j}=T^{-1} \sum_{t=1}^{T} \nu_{t}^{j}, j=2,3,4 \quad$ and $\quad G_{1}=m_{3} m_{2}-3 / 2, G_{2}=m_{4} m_{2}^{-2}-3$,

then if $\nu_{t}$ is Gaussian and stationary, for large $\mathrm{T}$, both $\mathrm{G}_{1}$ and $\mathrm{G}_{2}$ are normally distributed with zero means and variances that depend on the autocorrelations of $v_{i}$. The values of the statistics $S_{1}=G_{1} / \sqrt{ } v a x G_{1}$ and $\mathrm{S}_{2}=\mathrm{G}_{2} / \sqrt{ } \operatorname{varG}_{2}$, based on the first 36 autocorrelations are given in Table 2.1. They are highly insignificant, and do not lead to rejection of normality.

TABLE 2.1 Test statistics for model $(2.14)$

$\begin{array}{rcc}\mathrm{P} & \mathrm{BP} & \mathrm{LB} \\ & & \\ 4 & 1.03 & 1.12 \\ 8 & 2.98 & 3.40 \\ 12 & 5.38 & 6.37 \\ 16 & 5.66 & 6.75\end{array}$

$\eta(1) \quad .15$

$\eta(4) \quad 3.22$

$\begin{array}{ll}\mathrm{s}_{1} & .26 \\ \mathrm{~s}_{2} & .07\end{array}$

From the results in Table 2.1 we conclude that specification (2.14), with the normality assumption of $\nu_{t}$, provides a fairly good description of the income process. Throughout the study we make the assumption that the income expectations are generated by the mode1 (2.14). More precisely, we assume that during the period $1967(1)-1970(4)$ the consumer, while determining his consumption decision, uses the income model 
$\Delta y_{t}=40.46+v_{t}-.428 v_{t-1}$

to generate his expectations of future labour income. Similarly, the expectations of future labour income calculated by the consumer during $1971(1)-1978(4)$ and $1979(1)-1984(4)$ are assumed to be generated by the income models

$\Delta y_{t}=25.19+\nu_{t}-.428 \nu_{t}-1$

and

$\Delta y_{t}=-13.01+\nu_{t}-.428 \nu_{t-1}$

respectively. The structural changes in the income process in 1971(1) and 1979(1) will have specific effects on the consumption process. The consequences will be discussed in the next section.

It is of course passible to extend the model for income by including explanatory variables. The extended model may give information on the source of the structural changes in the income process. Such an analysis is beyond the scope of this study. We want to characterize the stochastic process for consumption and judge whether the structural changes in the consumption process can be related to those of income.

\subsubsection{The consumption process}

Inspection of the consumption series reveals that it does not follow a stationary process. In particular, the slope of the consumption line becomes negative at the end of the $1970^{\prime \prime} \mathrm{s}$. This is not in accordance with the theoretical model. Since the drift parameter of the random walk process for consumption (2.9) depends on parameters that characterize consumer behavlour only, this change of the sign can only be explained within the theoretical framework by a change in the parameters of the decision problem (2.1). It seems not unrealistic to assume that the time-preference parameter $\beta$ has changed as a result of the increased uncertainty about the future. Events such as the second ofl crisis and a polfcy change alming at 
a drastic reduction of public budget deficlts can have had an impact on the time preference of the consumers. The consequences of a decrease of $\beta$ to $\beta^{*}$ can be traced by using the expressions (2.4) and (2.5). In Appendix $2 \mathrm{~A}$ it is shown that it will lead to a persistent downward adjustment of the drift parameter of (2.9), after an increase of the drift parameter in the

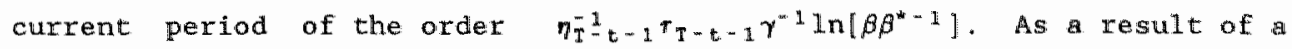
decrease of the time preference parameter, the distribution of his life time wealth over the different periods will be adjusted to the benefit of present consumption at the expense of current savings and future consumption possibilities.

In section 2.1 it was argued that the change in the constant term of the income process will give rise to a step change in the consumption model. Because of the re-evaluation of life time wealth in 1971(1) and 1979(1), we get an adjustment of the consumption level to the new perspectives. Formally, we have every perlod t a new calculation of the walue of life time wealth. This re-evaluation will imply that the chosen consumption leve $1 c_{t+1}$ will differ from the in the previous period planned level $c_{t+1}^{t}$. When in two successive periods the same income model is used to generate future income expectations, the deviation is captured by the consumption innovation (in fact, it is the source of the consumption innovation). The effects of the re-evaluation in $1971(1)$ and $1979(1)$, however, are different and will give rise to a structural change in the consumption process. In Appendix $2 \mathrm{~A}$ it is shown that when the constant term $\delta$ moves to $\delta^{*}$, the adfustment consists of a step change in the consumption model (2.6) equal. to $\left(\delta^{*}-\delta\right)\left[1+\eta_{\mathrm{T}-t-1}^{-1} \tau_{\mathrm{T}-\mathrm{t}-1}\right]$. Therefore, both in $1971(1)$ and $1979(1)$ we should expect a negative adjustment in the drift parameter of the consumption process. The perturbation of the consumption process takes the form of an innovational outlier. Notlce that since the underlying process is a random walk, the innovational outlier is equivalent to a level change (see e.g. Tsay (1988) and Box and Tiao (1965)). Obviously, the framework of intertemporal optimization provides a plausible basis for fnterpreting outliers in the consumption process.

In a first stage we investigate the correlation structure of the consumption series over different subperlods. In particular, the ACF and the partial autocorrelation function (PACF) for the periods 1967(2)$1970(4), 1971(1)-1979(4)$ and $1980(1)-1984(4)$ do not suggest that the random 
walk specification lumplied by the life cycle model (2.1) and (2.2) has to be rejected. Therefore we conclude that the correlation structure of consumption is falrly well in agreement wth the theoretical model. Let us examine the model in more detail. Estimation of the equation implied by the theory and the income process of section 2.2.1 yields the following results

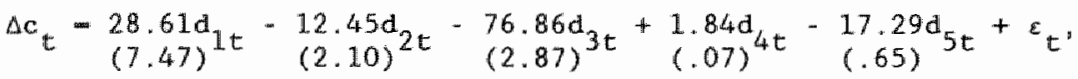

$$
\begin{aligned}
& \sigma^{2}\left(c_{t}\right)=703.7
\end{aligned}
$$

$$
\text { where } \begin{aligned}
& d_{1 t}=1 \text { for } 1967(2)-1979(4) \\
& d_{2 t}=1 \text { for } 1980(1)-1984(4) \text { for } 1971(1) \\
& d_{3 t}=1 \text { for } 1979(1) \\
& d_{4 t}=1 \text { for } 1979(4) .
\end{aligned}
$$

The dummy variables $d_{3 t}$ and $d_{4 t}$ are included as a result of the structural changes in the income process whereas $d_{2 t}$ and $d_{9 t}$ emerge because of the presumed change in the time preference parameter at the turning point in the consumption series in 1979.

The residuals do not exhibit any significant correlation. For the residual $A C F$ only $r_{16}$ takes a signiflcant value. We find significant residuals for 1977(4) and 1978(1). In Table 2.2 we give the values of the $B P$ and LB tost statistics, based on the first $4,8,12$ and 16 residual autocorrelations. They are not significant. Notice that the sharp 1ncrease when we pass from 12 to 16 is heavily influenced by the large value of $r_{16}$. To check whether the slope of the consumption line is constant during the period 1967(2)-1979(4), we have also estimated the mode1 with two separate slope coefficients $\alpha_{1}$ and $\alpha_{2}$ for the subperiods $196 \%(2)-1970(4)$ and $1971(1)-1979(4)$ respectively. The results are $\hat{\alpha}_{1}=36.00(5.28)$ and $\hat{\alpha}_{2}=25.25(5.50)$. A t-test of the equality of $\alpha_{1}$ and $\alpha_{2}$ yields an lnsignificant value: $t(65)=1.309$.

Above we found that the normality and homoscedasticity for $\Delta y_{t}$ do not have to be rejected. Given that income is normally distributed and homoscedastic, the theory predicts that consumption should follow a normally distributed and homoscedastic random walk process. In Table 2.2 
we report the test-statistics for the ARCH structure and the normality of $\varepsilon_{t}$ respectively. Both tests are insignificant, so we conclude that in this respect the empirical results are in accordance with the theory. Notice that in fact the theory has even stronger implications in the sense that the consumption innovation is identical to the income innovation up to a factor of proportionality.

TABLE 2.2 Test statistics for model (2.15)

\begin{tabular}{rrr}
$\mathrm{p}$ & $\mathrm{BP}$ & \multicolumn{1}{c}{ LB } \\
& & \\
4 & 3.05 & 3.20 \\
8 & 5.28 & 5.76 \\
12 & 9.81 & 11.29 \\
16 & 18.00 & 22.12
\end{tabular}

$\begin{array}{lc}\eta(1) & .43 \\ \eta(4) & 3.36 \\ \mathrm{~s}_{1} & -.11 \\ \mathrm{~s}_{2} & .003\end{array}$

Next, we consider the point estimates. Using expression (2.10) we find for the consumption innovation

$\varepsilon_{t}=\left(1-\theta+\theta \eta_{T-t-1}^{-1}\right) \nu_{t}$

where $\theta$ is the MA-parameter of (2.14). Since $\theta-.428$ and $0<\eta_{\mathrm{T}}^{-1} t-1<1$, we have as an implication of the theoretical model that the variance of the consumption innovation is smaller than that of the income innovation. A comparison of the values reported in $(2.14)$ and $(2.15)$ confirms the theory on this point. Using the estimates of $a_{E}^{2}, \sigma_{v}^{2}$ and $\theta$, we find for $\eta_{\mathbb{T}-t \times 1}$ the value 1.188. Since the quarterly real interest rate $r$ should be rather small, we can approximate $T-t$, that is the remaining life time of the representative consumer in period $t$, as $1.188(1+1)^{-1}$, Obviously, for reasonable values of $r$ we find embarrasingly small values for $T-t$. So although the empirical results satisfy the implication of the theoretical model and the specified income process that consumption should be smoother 
than fncome, the slze of $\sigma_{c}^{2} / \sigma_{\nu}^{2}$ leads to the conclusion that consumption is not smooth enough.

For the appraisal of the step changes, we have to keep in mind that the coefflctents of $d_{3 t}, d_{4 t}$ and $d_{5 t}$ absorb the joint effect of the adjustment in the consumption level and the transformed income innovation. From (2.14) wave an estimate of the income innovation and the MA parameter. With this knowledge we can show that the coefflclents of $d_{3 t}$ and $d_{5 t}$ should be negative and positive respectively. Because the expected step change of the constant term and the estimate of the income innovation in 1979(1) have opposite signs, we can not determine a priori the sign of the coefficient of $d_{4 t}$. Equation (2.15) shows that the adjustment in 1971(1) has the expected slgn. The size of the coefflcient of $d_{s t}$ on the contrary is different from the value predicted by the theoretical model. But as the estimate is highly insignificant we do not have to reject the theory on this point. With respect to the size and the sign of the estimated parameters, the evaluation is tentative. Apart from the fact that we wse the point estimates of $\theta, \sigma_{\nu}^{2}$ and the relevant income innovations, a reinterpretation of the formulae 1 s needed, because we estimate the model from aggregate per captta data. Since we hawe no data on the age stucture of the population and the distribution of income over different age groups at our disposal, we have adopted the procedure followed above.

From the empirlcal results we conclude that the life cycle model provides a rather good description of the serfal correlation properties of aggregate consumption data. The estimates of the variances of the income and consumption innovation, however, casts serious doubts on the appropriateness of the model. The empirical analysis does not suggest the presence of ARCH structures. A possible explanation might be aggregation: we have estimated and tested the nodel with aggregate data per capita. The results for real nondurable consumption per capita given in Appendix $2 \mathrm{~B}$ are roughly the same as those presented in this section.

A drawback is also the ad-hoc assumption of a structural change in the time preference parameter. In line with the structural econometric modelling and time series analysis (SEMTSA) approach put forward by Zellner and Palm (1974) and with Hendry"s (1979) criticism of ad-hoc modelling, an inconsistency between the theoretical model and the empirical evidence should lead to reassessment and possibly a reformulation of the 
theoretical mode1. Therefore, it seems worthwile to try to revise the model in such a way that we do not have to appeal to this structural break. In chapter 4 we will investigate a model of incertemporal optimization in which the consumer uses a planning time span that deviates from the expected life time and will show that the revised model is capable of describing the consumption series, without calling on structural changes in parameters of consumer behavtour. Before, we will discuss in the next chapter the relationship between the model examined in this chapter and the one put forward by Hall (1978) in which the consumer is assumed to maximize the expected value of life time utilfty. We will show that the empirical results of section 2.2 remain valid in the more comprehensive framework. 


\section{Append1x $2 \mathrm{~A}$ The effects of tructural changes}

In this appendix we will discuss the effects of a structural shift in the drift of the lncome process and of a change in the time preference parameter.

\section{A structural shift in the drfft of the incone process}

Suppose that the relevant income process for the consumer, while solving the naximization problem for perlod $t$ is

$\Delta y_{t}=\delta+\sum_{i=0}^{\infty} \psi_{1} \omega_{t-1}, \psi_{0}-1, \sum_{1=0}^{\infty} \psi_{1}^{2}<\infty, \sigma^{2}\left(\nu_{t}\right)-\sigma_{\nu}^{2}$.

Then we find for the expectations about future income

$E\left(y_{t+j} \| I_{t}\right)=E\left(y_{t+j-1} \mid I_{t}\right)+\delta+\sum_{\mathbb{1}=j}^{\infty} \psi_{1}^{\nu} t+j-1, j-1, \ldots, \mathbb{T}-t$.

If In perlod $t+1 \delta$ changes unexpectedly and becomes $\delta^{*}$, the relevant income expectations for the decision problem solved for period $t+1$, are generated by the income model

$\Delta y_{t}=s^{*}+\sum_{1=0}^{\infty} \psi_{1} \nu_{t-i}, \psi_{0}=1, \sum_{1=0}^{\infty} \psi_{i}^{2}<\infty, \sigma^{2}\left(\nu_{t}\right)=\sigma_{\nu}^{2}$.

Hence, we have

$\mathbb{E}\left(y_{t+j} \mid I_{t+1}\right)=E\left(y_{t+j-1} \mid I_{t+1}\right)+\delta^{* t}+\sum_{i=j-1}^{\infty} \psi_{1}^{\nu}{ }_{t+j-1}, j=2, \ldots, \mathbb{T}-t$.

Comblning (A. 1) and (A. 3) yields for $j-2, \ldots, T-t$

$E\left(y_{t+j} \mid I_{t+1}\right)-E\left(y_{t+j} \| I_{t}\right)-E\left(y_{t+j-1} \mid I_{t+1}\right)-E\left(y_{t+j-1} \mid I_{t}\right)+\delta^{*}=\delta+\psi_{j-1}{ }_{t+1}$

Using (A. 1) for $j=1$ and (A.2), we get $y_{t+1}-\mathbb{E}\left(y_{t+1} \mid I_{t}\right)=\delta^{*}-\delta+\nu_{t+1}$, Expression (A.4) yields subsequently 
$E\left(y_{t+j} \mid I_{t+1}\right)-E\left(y_{t+j} \mid I_{t}\right)=j\left(\delta^{*}-\delta\right)+\left(\phi_{0}+\psi_{1}+\ldots+\psi_{1-1}\right) \nu_{t+1}, j=1, \ldots I-t$.

When we substitute (A.5) into expression (2.6), we get

$c_{t+1}-c_{t}=\gamma^{-1} \ln [\beta(1+\mathrm{r})]+\left(\delta^{*}-\delta\right)\left[1+\eta_{\mathrm{T}-\mathrm{t}-1^{\tau}{ }^{\mathrm{T}}-\mathrm{t}-1}\right]+\varepsilon_{\mathrm{t}+1}$

with

$\varepsilon_{t+1}=\eta_{T-t-1}^{-1}\left[\sum_{i=0}^{T-t-1}(1+r)^{-i}\left(\psi_{0}+\psi_{1}+\ldots+\psi_{1}\right)\right] \nu_{t+1}$.

We conclude that the re-evaluation of life time wealth in perlod $t+1$ will lead to an adjustment of the consumption level. This correction is needed to achieve an optimal allocation of his life time wealth over the rest of his 1 ife. As we refrain from learning processes, the adjustment is completed as soon as the structural shift arises. To capture the perturbation of the stochastic process of consumption we have to introduce one dummy variable.

Along the same lines we can trace the effects of structural changes different from one in the drift of the income process. Since the consumption innovation is proportional to the income innovation, whereby the factor of proportionality depends on the parameters of the income process, we conclude that these structural changes w111 affect persistently only the propertles of the income innovation. Besides this permanent effect we have also a tenporary one resulting from the re-evaluation of Iffe time wealth. This effect will again give rise to the introduction of a dumm variable in the consumption model.

A change in the time preference parameter

To illustrate the effects of a change in the parameters of the ut1lity function, suppose that the time preference parameter has the walue $\beta$ in the maximization problem solved for period $t$ (and earlier periods), and $\beta^{*}$ in the optimization problems solved in the next periods. Hence, the preference structure in period $t$ is different from that in the following periods. For 
the consumption decislons taken in period $t$ and $t+1$, we find respectively

$\eta_{\mathbb{T}-t^{c}} c_{t}+\gamma^{-1} \ln [\rho(1+r)] \tau_{T-t}=(1+r) a_{t-1}+\sum_{1=0}^{T-t}(1+r)^{-1} E\left(y_{t+1} \mid 1_{t}\right)$

and

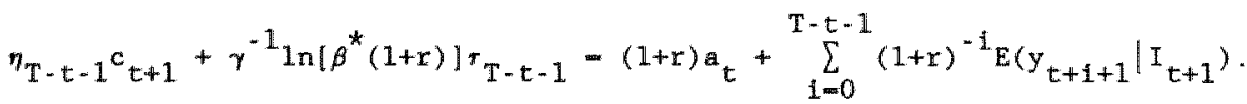

Carrying out the same operations as in the main text, we get after some rearranging

$$
\begin{gathered}
c_{t+1}-c_{t:}=\gamma^{-1} \ln [\beta(1+\mathrm{r})]+\gamma^{-1} \ln \left[\beta \beta^{*-1} \ln { }_{\mathrm{T}-\mathrm{t}-1}^{-1} \mathrm{~T}-\mathrm{t}-1+\right. \\
\eta_{\mathrm{T}-\mathrm{t}-1}^{-1} \sum_{1=0}^{\mathrm{T}-\mathrm{t}-1}(1+\mathrm{r})^{-1}\left[\mathrm{E}\left(\mathrm{y}_{\mathrm{t}+\mathrm{i}+1} \| \mathrm{I}_{\mathrm{t}+1}\right)-\mathrm{E}\left(\mathrm{y}_{\mathrm{t}+\mathrm{i}+1} \| \mathbb{I}_{\mathrm{t}}\right)\right] .
\end{gathered}
$$

For the next period, we obtain along the same lines

$c_{t+2}{ }^{-c}{ }_{t+1}=\gamma^{-1} \ln \left[\beta^{*}(1+r)\right]+\eta_{T-t-2}^{-1} \sum_{i=0}^{T-t-2}(1+r)^{-1}\left[E\left(y_{t+i+2} \mid I_{t+2}\right)-E\left(y_{t+i+2} \mid I_{t+1}\right)\right]$

The relationship between $c_{t}$ and $c_{t-1}$ is

$c_{t}-c_{t-1}-\gamma^{-1} \ln [\beta(1+r)]+\eta_{T-t}^{-1} \sum_{i=0}^{T-t}(1+r)^{-1}\left[E\left(y_{t+1} \mid I_{t}\right)-E\left(y_{t+1} \mid I_{t-1}\right)\right]$.

Comparing the expressions (A.6), (A.7) and (A.8) shows that the consequences of the re-allocation of life time wealth implied by the change in the preference structure are twofold. Firstly, a step change in the consumption level leading to the introduction of a dumm variable in the model for $\Delta c_{t+1}$ and secondly, a persistent adjustment of the drift parameter of the consumption process. 


\section{Appendix 2B Emplrical results for real mondurable consumption per capita}

The numbers of the expressions and the table in this appendix correspond to those used in the main text. A prime refers to nondurable consumption. With respect to the evaluation of the size and sign of the parameter estimates we refer to the discussion of the empirical results for total consumption in section 2.2.2. The empirical evidence indicates again that the life cycle theory provides a satisfactory description of the serfal correlation properties of the serfes, but also that consumption is not smooth enough.

$$
\begin{aligned}
& \Delta c_{t}=20.60 d_{1 t}-5.85 d_{2 t}-49.66 d_{3 t}+11.71 d_{4 t}-.57 d_{5 t}+\varepsilon_{t} \\
& \left.\begin{array}{lllll}
(6.67) & (1.22) & (2.30) & (.54) & (.03)
\end{array}\right)
\end{aligned}
$$

$\sigma^{2}\left(\varepsilon_{\mathrm{t}}\right)=457.8$.

The model with two separate slope coefficients $\alpha_{1}$ and $\alpha_{2}$ for the subperiods $1967(2)-1970(4)$ and $1971(1)-1979(4)$ yields estimates $\alpha_{1}^{*}-26.38(4.80)$ and $\hat{\alpha}_{2}=17.97$ (4.85). A t-test for the equalfty of $\alpha_{1}$ and $\alpha_{2}$ has an insignificant value, $t(65)=1.268$. Using the estimates of $\sigma_{\varepsilon}^{2}, \sigma_{\nu}^{2}$ and $\theta$ we can approximate $T-t$ as $2.378(1+r)^{-1}$.

Table 2.2' Test statistics for model (2.15)'

$$
\mathrm{p}
$$

BP

LB

$\begin{array}{lrr}4 & 2.63 & 2.74 \\ 8 & 3.91 & 4.20 \\ 12 & 7.29 & 8.30 \\ 16 & 15.76 & 19.49\end{array}$

$\begin{array}{lr}\eta(1) & .18 \\ \eta(4) & .99 \\ \mathrm{~S}_{1} & -.18 \\ \mathrm{~S}_{2} & .09\end{array}$




\section{Chapter 3}

\section{THE STOCHASTIC LIFE CYCLE MODEL.}

In this chapter we discuss Hall's (1978) model and compare it with the mode1 studied in chapter 2 . In contrast to the consumer of the previous chapter who uses only information on expected future income, we are now interested in the consumer who uses in principle all information on the stochastic process for labour income. To economize space we label in the sequel the two consumers as naive and sophisticated respectively.

In the first section we discuss the models for the naive and sophisticated consumer for a general one-period utility function U. We will show that when $U^{*}$ is strictly convex the sophisticated consumer will choose a lower consumption level than the naive consumer, provided that both consumers have an identical preference structure and the same expected income profile and initial endowments. In the second section we study the model with the exponential utility function and show that under the additional assumption of normality and no structural change in the variance of the income process, the resulting model is observationally equivalent to the one studied in chapter 2. The analysts of section 3.2 extends Hall's approach because ft lllustrates how gtructural changes in the income process can be handled.

\subsection{The model wh general at11tty function}

We start the analysis with a discussion of the model for the naive consumer. The model is the same as studied in the previous chapter except for the fact that we do not choose a speciflc functional form for $U$. Each time period the nalve consumer is assumed to solve the following utility maximization problem 
$\operatorname{Max} \sum_{i=0}^{T-t} \beta^{i} u\left(c_{t+1}\right)$

S.T. $\sum_{i=0}^{T-t}(1+r)^{-1} c_{t+1}=(1+r) a_{t-1}+\sum_{i=0}^{T-t}(1+r)^{-1} E\left(y_{t+1} \| I_{t}\right)$

with $U^{\prime}>0$ and $U^{\prime \prime}<0$. The first order conditions implied by (3.1) are

$U^{\prime}\left(c_{t+i}\right)=[\beta(1+r)]^{-I_{U^{\prime}}\left(c_{t}\right), \quad 1=1,2, \ldots, T-t .}$

Since $U^{\prime \prime}$ is strictly negative, $U^{-1}$ exists and after substitution of into the life time budget constraint we get for the consumption decision $c_{t}^{*}$

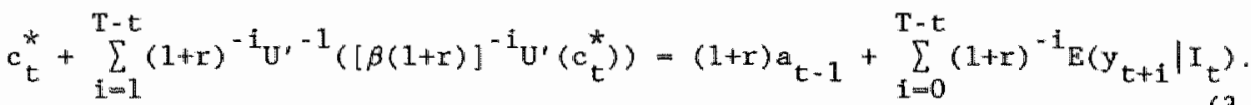

Obviously, Friedman"s (1957) Permanent Income Hypothesis and Modigllani and Brumberg's (1955) Life Cycle Hypothesis arise as a special case of (3.3) when $\beta(1+r)=1$. Notice that the assumption $\beta(1+r)=1$ is very restrictive, because it implies that preferred consumption for the rest of his life is constant (see (3.2)).

The sophisticated consumer uses in principle all the information on future labour income. Therefore, he is assumed to maximize each time period the expected value of the utility of life time consumption subject to the budget constraint

$\operatorname{Max} E\left(\sum_{i=0}^{T-t} \beta^{i} U\left(c_{t+1}\right) \| I_{t}\right)$

S.T. $\sum_{i=0}^{\mathbb{T}-t}(1+r)^{-i} c_{t+i}=(1+r) a_{t-1}+\sum_{i=0}^{T-t}(1+r)^{-i} y_{t+1}$.

Rewriting the life time budget constraint of (3.4) as $T-t+1$ pertod-byperiod budget constraints 
$c_{t+1}=\cdots t+1+(1+r) a_{t+1-1}+y_{t+1}, 1=0,1, \ldots, T-t$,

with $a_{n}=0$ reflecting the absence of a bequest motive, we get after substitution into the objective function of (3.4)

$\operatorname{Max} E\left(\sum_{i=0}^{T-t} \beta^{1} U\left(-a_{t+1}+(1+r) a_{t+1-1}+y_{t+1}\right) \mid I_{t}\right)$.

The first order conditions implied by (3.5) are

$$
\begin{aligned}
& E\left(U^{\prime}\left(-a_{t+1+1}+(1+r) a_{t+1}+y_{t+1+1}\right) \mid I_{t}\right)= \\
& \quad[\beta(1+r)]^{-1} E\left(U^{\prime}\left(-a_{t+1}+(\mathbb{1}+r) a_{t+1-1}+y_{t+1}\right) \mid I_{t}\right), 1=0,1, \ldots, \mathbb{T}-t-1 .
\end{aligned}
$$

For $1=0$ find Hall's result that marginal utility follows an AR(1) prociss. For alternative derivations of the result (3.6), we refer to Hall (1978) and Charpin (1987). Notice that we do not assume stationarity of the income process. We only require the existence of the conditional moments appearing in the first order conditions (3.6). The choice of a specific utility function leads to specific requirements for the income process. Notice also that the first order conditions (3.6) specify which part of the information on the income process is actually used. Although the maximization problem (3.4) 1 s formulated in such a way that the consumer has knowledge of all Information on income, the chosen utility function posstbly restricts the amount of information which is actually needed and used to solve the intertemporal optimization problem. When the sophisticated consumer uses for instance a quadratic utility function $U$, the first order conditions $(3,6)$ show that wave to require only the existence of the conditional moments $E\left(y_{t+1} \mid I_{t}\right)$. In other words, he takes into account the same information on the income process as the naive consume $x$ and the mathematical models $(3.1)$ and $(3.4)$ are equivalent. This is of course nothing but a restatement of the wellknown notion of certainty equivalence. Hall and Mishkin (1982) investigate the Iffe cycle model (3.4) with a quadratic utility function under the assumption of $\beta(1+r)=1$. From the foregoing, it follows that their empirical results hold for every 
consumer solving the life cycle model (3.1).

Without additional assumptions it is in general impossible to find an explicit solution for the consumption decision, say $t_{t}$. It is however not difficult to give a simple decision rule to compare the optimal consumption level $c_{t}$ with the consumption decision taken by the naive consumer, $c_{t}^{*}$. It proves to be sufficient to check the conwexity or concavity of the marginal utility function $U^{\prime}$. The first order conditions (3.6) can be rewritten as

$E\left(U^{\prime}\left(c_{t+i}\right) \mid I_{t}\right)=[\beta(1+r)]^{-i_{U}} U^{\prime}\left(c_{t}\right), i=1, \ldots, T-t$.

If $U^{\prime}$ is convex, Jensen's inequality implies

$U^{\prime}\left(E\left(c_{t+1} \mid I_{t}\right) \leq E\left(U^{\prime}\left(c_{t+1}\right) \| I_{t}\right), i=1, \ldots, T-t\right.$.

Because $U^{\prime}$ is a monotonically decreasing function, $U^{\prime-1}$ has this property too. Hence

$U^{\prime-1}\left(U^{\prime}\left(E\left(c_{t+1} \mid I_{t}\right)\right)\right)-E\left(c_{t+1} \mid I_{t}\right) \geq U^{\prime-1}\left([\beta(1+r)]^{-1} U^{\prime}\left(c_{t}\right)\right), 1-1, \ldots, T-t$.

Substitution of (3.7) for $c_{t}=c_{t}$ into the expected value of the 1 ife time budget constraint of $(3.4)$ yields

$\tilde{c}_{t}+\sum_{i=1}^{T-t}(1+r)^{-i_{U^{\prime}}-1}\left([\beta(1+r)]^{-i_{U}} U^{\prime}\left(\tilde{c}_{t}\right)\right) \leq(1+r) a_{t-1}+\sum_{i=0}^{T-t}(1+r)^{-1} E\left(y_{t+1} \mid \mathbb{I}_{t}\right)$.

Combining (3.3) and (3.8) leads to

$\bar{c}_{t} \sum_{i=1}^{T-t}(1+r)^{-i_{U^{\prime}}-1}\left([\beta(1+r)]^{-1} U^{\prime}\left(\tilde{c}_{t}\right)\right) \leq c_{t}^{*}+\sum_{i=1}^{T-t}(1+r)^{-1} U^{-1}\left(\left[\beta\left(1+x^{\prime}\right)\right]^{-1} U^{\prime}\left(c_{t}^{*}\right)\right)$

Since the derivative of the left hand side of $(3.9)$ with respect to $c_{t}$ is positive, we conclude $\tau_{t} \leq c_{t}^{*}$. When $U^{\prime}$ is strictly convex, the sophisticated consumer will choose a lower consumption level then the nalve consumer, given that they have the same preference structure and the same expected life time wealth. This result holds for any strictly convex marginal utility function $U^{\prime}$. When $U^{\prime}$ is strictly concave it can be easily 
shown that the conclusions are reversed.

\subsection{The model ith the exponentlal ut111ty function}

In this section we discuss the life cycle madel (3.4) with the exponential utility function

$U(c)=-y^{-1} \exp (-\gamma c), \gamma>0$.

As argued in the former section, the specific functional form for the utility function $U$ possibly restricts the amount of stochastic information on income whlch $1 \mathrm{~s}$ actually used by the consumer. For the utility function with constant absolute risk aversion (3.10), the first order conditions (3.6)

$E\left(\exp \left(-\gamma\left[-a_{t+1}+(1+r) a_{t+1-1}+y_{t+1}\right]\right) \mid I_{t}\right)=$

$$
[\beta(1+r)]^{-1} E\left(\exp \left(-\gamma\left[-a_{t+1-1}+(1+r) a_{t+1-2^{+y_{t+1-1}}}\right]\right) \mid I_{t}\right), \mathbb{1}=1, \ldots, T-t
$$

can be rewritten as

$$
\begin{aligned}
& \gamma a_{t+1}-\gamma(2+r) a_{t+1-1}+\gamma(1+r) a_{t+1-2}=-\ln [\beta(1+r)] \\
& \left.+\ln \left[\operatorname{E(exp}\left(-\gamma y_{t+1-1}\right) \mid I_{t}\right)\right]-\ln \left[\operatorname{E}\left(\exp \left(-\gamma y_{t+1}\right) \| I_{t}\right)\right], 1=1, \ldots T-t_{n}
\end{aligned}
$$

Hence, we require the existence of the moments $\operatorname{E}\left(\exp \left(-\gamma y_{t+1}\right) \mid I_{t}\right), \gamma>0$, $i \neq 1, \ldots, T-t$. When for instance $\left(y_{t+1}, \ldots, y_{T}\right)$ is normally distributed conditional on the information avallable at time $t$, we have

$y_{t+1} \mid I_{t}-N\left(E\left(y_{t+1} \mid I_{t}\right), \sigma_{t}^{2}\left(y_{t+1}\right)\right)$

where $\sigma_{t}^{2}\left(y_{t+i}\right)$ denotes the conditional variance, and 
$E\left(\exp \left(-\gamma y_{t+1}\right) \mid I_{t}\right)=\exp \left(-\gamma E\left(y_{t+1} \mid I_{t}\right)+\gamma_{t}^{2} \sigma_{t}^{2}\left(y_{t+1}\right)\right)$.

It follows from (3.12) and (3.13) that the optimal $a_{t}$ is $a$ linear combination of $E\left(y_{t+1} \mid I_{t}\right), \quad \sigma_{t}^{2}\left(y_{t+1}\right), \quad i=1, \ldots, T-t, y_{t}$ and $a_{t-1}$. Because $E\left(y_{t+1} \mid I_{t}\right)$ is a linear transformation of the variables in the conditioning set, and $\sigma_{t}^{2}\left(y_{t+1}\right)$ is independent of the past, It follows that $c_{t}$ is a realization of a normally distributed stochastic valiable.

In the former section it is argued that whout additional assumptions, it is in general impossible to find an expllcit solution for the consumption decision $c_{t}$. Therefore, we assume that that $\left(c_{t}+1, \ldots, c_{\mathrm{T}}\right)$ conditional on the information available at time $t$ is normally distributed. Above we saw that a sufficient condition is mormality of $\left(y_{t+1}, \ldots, y_{T}\right)$ conditional on the information set $\mathbb{I}_{t}$. Notice that as a results of the nonnegativity of consumption, the normality assumption can only be an approximation. When in an empirical analysis the average of consumption is large enough, the approximation is expected to be accurate. The first order conditions $(3.11)$

$E\left(\exp \left(-\gamma c_{t+1}\right) \mid T_{t}\right)=[\beta(1+r)]^{-1} \exp \left(-\gamma c_{t}\right), 1-1, \ldots, T-t$

can be expressed as

$E\left(c_{t+1} \mid I_{t}\right)=c_{t}+i \gamma^{-1} \ln [\beta(1+r)]+\log _{t}^{2}\left(c_{t+1}\right), i=1, \ldots, T-t$.

Similarly, the model solved for pertod $t+1$ ylelds the Euler equations

$E\left(c_{t+1} \mid I_{t+1}\right)=c_{t+1}+(1-1) \gamma^{-1} \ln [\beta(1+r)]+b_{\delta} \gamma \sigma_{t+1}^{2}\left(c_{t+1}\right), i-2, \ldots, T-t$

As a result of the conditional namality of $\left(c_{t}+\ldots, c_{T}\right), a_{t+1}^{2}\left(c_{t+1}\right)$ is independent of $c_{t+1}$. Therefore, (3.15) leads to

$E\left(c_{t+1} \mid I_{t}\right)=E\left(c_{t+1} \mid I_{t}\right)+(1-1) \gamma^{-1} \ln [\beta(1+r)]+t_{\gamma} \sigma_{t+1}^{2}\left(c_{t+1}\right), 1=2, \ldots, T-t$.

From (3.14) we get an expression for $E\left(c_{t+1} \mid I_{t}\right)$, which after substitution 
Into $(3.16)$ ylelds

$\mathrm{E}\left(c_{t+1} \mid \mathrm{I}_{t}\right)=c_{t}+i_{\gamma}^{-1} \ln [\beta(1+r)]+h_{2}\left[\sigma_{t+1}^{2}\left(c_{t+1}\right)+\sigma_{t}^{2}\left(c_{t+1}\right)\right], i=2, \ldots, T-t$.

By comparing (3.17) with (3.14), one can conclude that

$\sigma_{t}^{2}\left(c_{t+1}\right)=\sigma_{t+1}^{2}\left(c_{t+1}\right)+\sigma_{t}^{2}\left(c_{t+1}\right), i-2, \ldots, T-t$.

Along the same lines, a more general result can be derived

$\sigma_{t}^{2}\left(c_{t+1}\right)=\sigma_{t+j}^{2}\left(c_{t+i}\right)+\sigma_{t}^{2}\left(c_{t+j}\right), j=1, \ldots, T-t-1$ and $i=j+1, \ldots, T-t$.

It follows that the covariance matrix of $\left(c_{t+1}, \ldots, c_{T}\right)$ conditional on information at time $t$ is subject to the ${ }^{2}(T-t)(T-t-1)$ restrictions

$\sigma_{t}\left(c_{t+1}, c_{t+j}\right)=\sigma_{t}^{2}\left(c_{t+1}\right), i>j$,

where $\sigma_{t}\left(c_{t+1}, c_{t+j}\right)$ denotes the covariance between $c_{t+i}$ and $c_{t+j}$ conditional on the information set $I_{t}$. From (3.20) it is obvious that the conditional process of $c_{t}$ can not be stationary. Aggregation of consumption across consumers with different ages could possibly induce stationarity of the change of aggregate consumption. Now, we will give a closed form solution for the univariate process of consumption. The procedure to derive the stochastic process of consumption is simllar to that used in the previous chapter, that is we solve the model for perlod $t$ and period $t+1$ and subtract the resulting expressions for $c_{t+1}$ and $c_{t}$ in order to eliminate financial wealth. We shall express the characteristics of the process of consumption in terms of those of the income process. Substitution of (3.14) into the expected value of the life time budget constraint yields

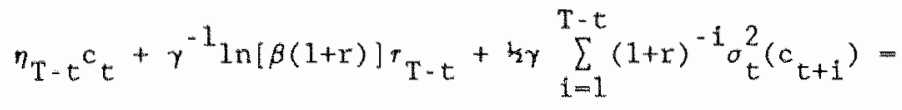

$$
\begin{aligned}
& (1+r) a_{t-1}+\sum_{i=0}^{T-t}(1+x)^{-i_{E}}\left(y_{t+i} \mid I_{t}\right)
\end{aligned}
$$


where

$\eta_{k}=\sum_{i=0}^{k}(1+r)^{-i}$ and $\tau_{k}=\sum_{i=1}^{k}(1+r)^{-i} i$.

Along the lines of deriving $(3,21)$, we get for the consumption decision for period $t+1$

$$
\begin{gathered}
\eta_{T-t-1} c_{t+1}+\gamma^{-1} \ln [\beta(1+r)] \tau_{T-t-1}+\frac{1}{2 \gamma} \sum_{i=1}^{T-t-1}(1+r)^{-i} \sigma_{t+1}^{2}\left(c_{t+1+1}\right)= \\
(1+r) a_{t}+\sum_{i=0}^{T-t-1}(1+r)^{-1} E\left(y_{t+i+1} \mid I_{t+1}\right) .
\end{gathered}
$$

Since the conditional variances $\sigma_{t+1}^{2}\left(c_{t+1+1}\right), i=1, \ldots, T-t-1$, do not depend on $c_{t+1}$, the variance of $c_{t+1}$ given information available at time $t$, expressed in terms of the moments of the income process becomes

$\sigma_{t}^{2}\left(c_{t+1}\right)=\eta_{T-t-1}^{-2} \sigma_{t}^{2}\left(\sum_{i=0}^{T-t-1}(1+r)^{-1} E\left(y_{t+i+1} \mid I_{t+1}\right)\right)$.

Dividing (3.22) by $1+r$, substituting $a_{t}=(1+r) a_{t-1}+y_{t}-c_{t}$ and subtracting (3.21) yields

$$
\begin{gathered}
c_{t+1}-c_{t}=\gamma^{-1} \ln [\beta(1+r)]+\eta_{T-t-1}^{-1} \sum_{i=1}^{T-t}(1+r)^{-i+1}\left[E\left(y_{t+1} \mid I_{t+1}\right)-E\left(y_{t+i} \mid I_{t}\right)\right] \\
-\frac{1 / 2 \gamma}{-1} \eta_{T-t-1}^{-1}\left(-\sigma_{t}^{2}\left(c_{t+1}\right)+\sum_{i=2}^{T-t}(1+r)^{-i+1}\left[\sigma_{t+1}^{2}\left(c_{t+1}\right)-\sigma_{t}^{2}\left(c_{t+1}\right)\right]\right) .
\end{gathered}
$$

When we define the consumption innovation $\epsilon_{t+1}=c_{t+1}-E\left(c_{t+1} \mid I_{t}\right)$, we get after substitution of (3.18) into (3.23)

$c_{t+1}-c_{t}=\gamma^{-1} \ln [\beta(1+r)]+1 / \frac{1}{2} \gamma \sigma_{t}^{2}\left(c_{t+1}\right)+\epsilon_{t+1}$

with 
$\left.c_{t+1}=\eta_{T-t-1}^{-1} \sum_{i=1}^{T-t}(1+t)^{-1+1}\left[E_{\left(y_{t+1}\right.} \mid I_{t+1}\right)-E\left(y_{t+1} \mid I_{t}\right)\right]$.

Comparing expressions (3.24) and (3.25) with model (2.6) for the naive consumer, shows that in both cases consumption will follow a random walk process. Notice that the expression for the consumption innovation (3.25) is Identical to that for the model of the naive consumer. As $\sigma_{\mathrm{t}}^{2}\left(\mathrm{c}_{\mathrm{t}+1}\right)-\sigma^{2}\left(\varepsilon_{\mathrm{t}+1}\right)$, we see that with a homoscedastic income process both models are observationally equivalent. The two specifications become empirically distinguishable from each other when a structural change in the variance of the income process occurs. This change will only affect the variance of the disturbance term in (2.6), but for the sophisticated consumer with model $(3.24)$, it will also have a persistent effect on the drift parameter. Along the lines of chapter 2 it can be shown that the consequences of a structural change in the drift parameter of the income process and an adjustment of the time preference parameter are the same as In the model for the naive consumer studied in chapter 2 . As the empirical analysis of the income series carried out in section 2.2.1. does not suggest the presence of any heteroscedasticity, we infer that the empirical results of section 2.2.2 hold in the more comprehensive framework of this chapter. There is an interesting possibility of relaxing the assumption of normality in favour of conditional normality of the ARCH type. In this case, the Euler equations

$E\left(c_{t+1} \| I_{t}\right)=c_{t} * \gamma^{-1} \ln [\beta(1+r)]+3_{t} \gamma c_{t}^{2}\left(c_{t+1}\right)$

will lead to an ARCH-M model (see Engle et. a1. (1987)) and we can discriminate between the two specifications. This example illustrates that Hall's conclusion that all the relevant information of the past is incorporated in $c_{t}$ is not necessarily correct. It also fllustrates that in general a different assumption about the stachastic behaviour leads to a different operational model.

Finally, we will express the chosen consumption level $c_{t}$ in terms of the income characteristics only and we will show for the special case that the change in income is generated by a stationary process, that the model is capable of explaining the high marginal propensity to save in occupations 
with an unstable income (e.g. farmers). Formula (3.21) shows that we need to find expressions for the conditional variances $a_{t}^{2}\left(c_{t+1}\right), i-1, \ldots, T-t$. Along the lines of deriving $(3.22)$, we get for the consumption dectsion for period $t+i$

$$
\begin{aligned}
& \eta_{T-t-i^{c}} c_{t+1}+\gamma^{-1} \ln [\beta(1+r)]+w^{2} \sum_{j=1}^{T-t-1}(1+r)^{-j} \sigma_{t+1}^{2}\left(c_{t+j+1}\right)= \\
& (1+r) a_{t+1-1}+\sum_{j=0}^{T-t-1}(1+r)^{-1} \mathbb{E}\left(y_{t+1+j} \mid r_{t+1}\right)
\end{aligned}
$$

and hence

$\sigma_{t+i-1}^{2}\left(c_{t+i}\right)=\eta_{T-t-1}^{-2} \sigma_{t+1-1}^{2}\left(\sum_{j=0}^{T-t-1}(1+r)^{-j} E\left(y_{t+1+j} \mid I_{t+i}\right)\right), 1-1, \ldots, T-t \cdot(3,26)$

It can be easily shown that (3.19) implies

$\sigma_{t}^{2}\left(c_{t+1}\right)=\sigma_{t+1-1}^{2}\left(c_{t+1}\right)+\sigma_{t}^{2}\left(c_{t+1-1}\right)=\sum_{k=1}^{1} a_{t+k-1}^{2}\left(c_{t+k}\right)$.

Successive substitution of $(3.26)$ into $(3.27)$ yields

$\sigma_{t}^{2}\left(c_{t+1}\right)=\sum_{k=1}^{1} \eta_{T-t-k}^{-2} \sigma_{t+k-1}^{2}\left(\sum_{j=0}^{T-t-k}(1+r)^{-j} E\left(y_{t+k+j} \mid I_{t+k}\right)\right), i=1, \ldots T-t$

After substitution of (3.28) into (3.21), we get for the consumption decistion $c_{t}$

$$
\begin{aligned}
& \eta_{\mathrm{T}-\mathrm{t}} \mathrm{c}_{\mathrm{t}}+\gamma^{-1} \operatorname{Ln}[\beta(1+\mathrm{r})] \tau_{\mathrm{T}}-\mathrm{t} \\
& +\psi_{i \gamma} \sum_{i=1}^{T-t}(1+r){ }^{-i} \sum_{k=1}^{i} \eta_{T}^{-2}-t-k^{a}{ }_{t+k-1}^{2}\left(\sum_{j=0}^{T-t-k}(1+r)^{-j} E\left(y_{t+k+j} \mid I_{t+k}\right)\right) \\
& (1+r) a_{t-1}+\sum_{i=0}^{T-t}(1+r)^{-1} E\left(y_{t+i} \mid I_{t}\right)
\end{aligned}
$$

When the change in income is generated by a stationary process with moving average representation 
$y_{t+1}-y_{t}+\delta+\sum_{i=0}^{\infty} \psi_{1} \nu_{t+1-1}, \psi_{0}-1, \sum_{1=0}^{\infty} \psi_{i}^{2}<\infty, \sigma^{2}\left(\nu \nu_{t+1}\right)=\sigma_{\nu}^{2}$,

we have

$E\left(y_{t+1} \mid I_{t+j}\right)-\mathbb{E}\left(y_{t+1} \mid T_{t+j-1}\right)-\left(\psi_{0}+\ldots+\psi_{1-j}\right) \nu_{t+j}$

for $1-j, j+1, \ldots, T-t$ and $\mathrm{J}-1,2, \ldots, T-t-1$, and hence

$a_{t+k-1}^{2}\left(\sum_{j=0}^{T-t-k}(1+r)^{-j} E\left(y_{t+k+j} \mid I_{t+k}\right)\right)=a_{\nu}^{2}\left[\sum_{j=0}^{T-t-k}(1+r)^{-j}\left(\psi_{0}+\ldots+\psi_{j}\right)\right]^{2}$.

After substitution of $(3.30)$ into $(3.29)$, we get

$$
\begin{aligned}
& \eta_{\mathrm{T}-\mathrm{t}^{\mathrm{C}}} \mathrm{t}+\gamma^{-1} \ln [\beta(1+\mathrm{r})] \tau_{\mathrm{T}-\mathrm{t}} \\
& +\frac{\gamma}{2} \sigma_{\nu}^{2} \sum_{i=1}^{\mathrm{T}-\mathrm{t}}(1+\mathrm{r})^{-i} \sum_{k=1}^{i} \eta_{\mathrm{T}-\mathrm{T}-\mathrm{k}}^{-2}\left[\sum_{j=0}^{\mathbb{T}-t-k}(1+r)^{-j}\left(\psi_{0}+\ldots+\psi_{j}\right)\right]^{2}= \\
& (1+r) a_{t-1}+\sum_{i=0}^{T-t}(1+r)^{-1} E\left(y_{t+i} \| I_{t}\right)
\end{aligned}
$$

Expression (3.31) shows that two consumers with identical preference structure, the same expected income profile and equal initial endowments $a_{t-1}$, but with a different income variance $o_{\nu}^{2}$, will choose a different consumption level $c_{t}$. The higher the variance of the income variance, the lower will be the chosen consumption level. Hence, the model discussed in this chapter can take account of the high marginal propensity to save in occupations with unstable income. Notice that the model for the naive consumer results as a limiting case. Keeping in mind the analysis of section 3.1, Infer that for a utility function with concave marginal utility the conclusion wil probably be reversed.

Expression (3.24) shows that in the model for the sophisticated consumer, a change in the slope of the consumption 1 ine does not necessarily lead to the conclusion that one of the parameters that characterize consumer 
behaviour has altered. A change in the variance of the income innovation may serve as a possible explanation. However, for a homoscedastic income process we can only explain a change in the drift of the consumption process by an adjustment of the parameters of the decision problem (3.4). Given the empirical examination of the income series carried out in the previous chapter, we conclude that the model analyzed in this chapter does not remove the ad-hoc assumption of a parameter change. In the next chapter we will put forward the model with moving planning horlizon as an alternative for the life cycle model and we will show that it is capable of relating a change in the slope of the consumption line to a change in that of the income line. 


\section{Chapter 4}

\section{THE MODEL WITH MOVING PLANNING HORIZON}

In the life cycle model the consumer is assumed to be forward looking with a planning time span that colncides with the expected lifetime. He allocates his life time wealth in an optimal way over the present and future periods. He anticipates in a rational way on expected income changes in the future such as e.g. resulting from retirement, and spreads the consequences of errors in forecasting income over the rest of his life, a feature which is used to explain the great persistence of consumption (see .g. Muelibauer (1983)). Whenever he realizes that he misinterpreted future developments, the consumer replans his future consumption in the light of the new insights. The empirical analysis carried out in chapter 2 showed that the chosen formulation of the life cycle model provides a good description of the serial correlation properties of the data" given that we are prepared to extend the model to account for a structural change in the time preference parameter $\beta$. The assumption of a decrease in $\beta$ had to be made to account for the fall in consumption since 1979. The estimates of the variances of the consumption and income innovation, however, suggested that consumption is not smooth enough. Using reasonable values of the quarterly reall interest rate $r$, we found rather small values for the expected life time of the representative consumer.

The principal implication of the Iffe cycle model is the separation of the consumption and income proflles. To relate the decrease in consumption to the observed decline in income in the $1980^{\prime \prime} \mathrm{s}$, it seems desirable to establish a more direct link between Income and consumption. Given the empirical evidence for the life cycle model, it seems promising to investelgate a model of intertemporal optimization in which the consumer uses a planning time span that does not coincide with the expected life time. It seems not unrealistic to imagine that the consumer will neglect periods far ahead in the future on which avallable information is scarce 
and unreliable, and wil confine himself to more trustworthy information on the near future. When the planning time differs from the life time, the model of intertemporal optimization needs to be extended for a mechanism that describes the adjustment of the planning horizon as time goes on. In this chapter we adopt the simplest possible solution. We assume that the consumer uses a planning time span of constant length. Hence, the planning horizon is postulated to move ahead as time goes on.

In the first section of this chapter we discuss the model with moving planning horizon and we will show that the drift parameter of the fimplied stochastic process of consumption is proportional to that of the income process. Hence, an unanticlpated change in the latter will have as a consequence that the former will alter. In ather words, the model is capable of relating a change in the slope of the consumption Iine to a change in the slope of the income line. In the first part of section 4.2 we show that the univariate process of consumption implied by the mode1 with moving planning horizon is fully in accordance with the sample information.

Surprisingly, the model leads to a relationship between consumption and income which is highly similar to the mechanism underlying the consumption function put forward by Davidson, Hendry, Sxba and leo (1978). More specifically, as a result of adjusting the planning horizon, an error correction term has to be included in the consumption function. As no error is involved from the side of the consumer, it ili be argued that it is more appropriate to speak about a correction term. The analysis of this chapter shows that the successful implementation of error correction mechanisms in consumption functions specifled and estimated with aggregate time series data, may have its roots in some slmple postulates about individual consumer behaviour. In the second part of section 4.2 we w111 show that the empirical results obtained for real total consumption per capita for the specification with the correction term, that is an alternative parameterization implied by the model with moving planning horizon, are in agrement with the theoretical model. The empirical. results for real nondurable consumption per capita are not unsatisfactory. The test for heteroscedasticity of the ARCH type for the disturbance term of the consumption function yields however a significant value, whereas the theoretical model and the specified income process imply a homoscedestic 
stochastlc process. As a possible explanation we will suggest a relaxation of the assumption of rational expectations.

\section{1 Theory}

In this section we descrlbe the theoretical model and we will derive the consumption function. The procedure to trace the relationship between consumption and income is the same as used in chapter 2, that is we solve the model for periods $t$ and $t+1$ and subtract the resulting expressions for $c_{t}$ and $c_{t+1}$ in order to eliminate financial wealth. We assume that the consumer solves at each time period the utility maximization problem

$\operatorname{Max} \sum_{i=0}^{T} \beta^{1} v\left(c_{t+1}\right)$
S.T. $\sum_{1=0}^{T}(1+r)^{-1} c_{t+1}=(1+r) a_{t-1}+\sum_{1=1}^{T}(1+r)^{-i} E\left(y_{t+1} \| I_{t}\right)$.

The only difference with the model investigated in chapter 2 is that we assume that the planning time span of $\mathbb{T}$ periods is time-independent and hence that the planning horizon shlfts as time goes on. Along the lines of chapter 2 " i.t can be easily shown that the model (4.1) with the exponential utility function $U(c)=-\gamma^{-1} \exp (-\gamma c), \quad \gamma>0$, yields for the chosen consumption level $c_{t}$

$\eta_{\mathrm{T}} c_{\mathrm{t}}+\gamma^{-1} \ln [\beta(1+\mathrm{r})] r_{\mathrm{T}}-(1+\mathrm{r}) \mathrm{a}_{\mathrm{t}-1}+\sum_{1=0}^{\mathrm{T}}(1+\mathrm{r})^{-1} \mathrm{E}\left(\mathrm{y}_{\mathrm{t}+\mathrm{i}} \mid \mathrm{I}_{\mathrm{t}}\right)$.

Using the analysis of section 3.1. it follows that for $\beta(1+r)=1$ relationship (4.2) holds for any utility function $U$ satisfying $U^{\prime}>0$ and $\mathrm{U}^{*} * 0$.

For the next perlod we find for $c_{t+1}$

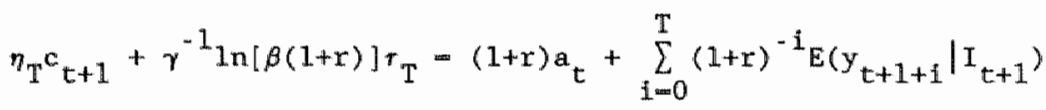

with 
$\eta_{k}=\sum_{i=0}^{k}(1+r)^{-i}$ and $\tau_{k}-\sum_{i=1}^{k}(1+r)^{-i_{1}}$

Dividing (4.3) by $1+r$, substituting $a_{\mathrm{t}}=(1+r) a_{t-1}+y_{t}-c_{t}$ and subtracting (4.2) leads after some rearranging to

$$
\begin{aligned}
c_{t+1}-c_{t}= & \gamma^{-1} \ln [\beta(1+r)]-\eta_{T}^{-1}(1+r)^{-T} \gamma^{-1}(T+1) \ln [\beta(1+r)]+ \\
& \eta_{T}^{-1}(1+r)^{-T}\left[E\left(y_{t+T+1} \mid I_{t}\right)-c_{t}\right]+ \\
& \eta_{T}^{-1} \sum_{i=0}^{T}(1+r)^{-1}\left[E\left(y_{t+i+1} \| I_{t+1}\right)-E\left(y_{t+1+1} \mid I_{t}\right)\right]
\end{aligned}
$$

Expression (4.4) is derived under the implicit assumption that both in period $t$ and $t+1$, the utility maximization (4.1) yields an intertor solution. As in chapter 2, the feasibility of such a solution depends among other things on the particular value of financial wealth. When the planning time span deviates from the expected life time, the possibility is not excluded that during one's life at a certain moment the decision problem (4.1) yields a corner solution. Because of the nonnegativity constraints on consumption, the consumer is then forced to adfust the parameters of the utility function, given that he continues to be forward looking. We 1 gnore the implications of inconsistent planning and assume that the maximlzation problem (4.1) describes consumer behaviour for at least a number of perlods and for a large part of the population, in a satisfactory way.

Notice the great resemblance of (4.4) with spectfication $(2.6)$. The main difference consists in the presence of the term

$\eta_{T}^{-1}(1+r)^{-T}\left[E\left(y_{t+T+1} \mid I_{t}\right)-c_{t}\right]$

in (4.4). In the next section we will show that it implies an error correction term. This term yielded favourable emplrical results in Davidson et. al. (1978), who derlved it along completely different lines of reasoning. The introduction of a moving planning horizon provides an alternative explanation for the inclusion of an exror correction mechanism in the consumption function. In this framework, however, it is more appropriate to call it a correction term. The solution of the decision 
problem at time te yields for the consumption "plan" for period $t+1, c_{t+1}$

$c_{t+1}^{t}-c_{t}+\gamma^{-1} \ln [\beta(1+r)]$

Provided the same income model is operative in boch period $t$ and $t+1$, it follows from expression (4.4) that

$$
\begin{aligned}
\mathbb{E}\left(c_{t+1} \mid I_{t}\right)=c_{t} & +\gamma^{-1} \ln [\beta(1+r)]-\eta_{T}^{-1}(1+r)^{-T_{Y}-1}(T+1) \ln [\beta(1+r)] \\
& +\eta_{T}^{-1}(1+r)^{-T}\left[E\left(y_{t+T+1} \mid I_{t}\right)-c_{t}\right] .
\end{aligned}
$$

Comparfing (4.5) and (4.6) shows that the "adjustment" can be expressed as

$$
\begin{aligned}
& \mathrm{E}\left(c_{t+1} \mid I_{t}\right)-c_{t+1}^{t}=-\eta_{T}^{-1}(1+r)^{-T_{\gamma}-1}(T+1) \ln [\beta(1+r)]+ \\
& \eta_{\mathrm{T}}^{-1}(1+r)^{-\mathrm{T}}\left[\mathrm{E}\left(\mathrm{y}_{\mathrm{t}+\mathrm{T}+1} \mid \mathrm{I}_{\mathrm{t}}\right)-\mathrm{c}_{\mathrm{t}}\right] \text {. }
\end{aligned}
$$

The error correction term is the result of a lag in processing information on $y_{t+T+1}$ that is already available in period $t$. The terms "plan" and "adjustment" have been written between quotation marks, because provided the consumer knows that he will replan in the next period, the quantities $c_{t}^{t}+1$ are purely instrumental in determining the current level of consumption. By solving the maximization problem (4.1) the consumer does not make an error. This is the reason why we prefer to call $E\left(y_{t+T+1} \mid I_{t}\right)$ $c_{t}$ a correction term. An advantage of the model with moving planning hortzon is that it meets the objection raised in several contributions on error correction mechanisms (see e.g. Currie (1981), Salmon (1982), Kloek (1984)) that the interpretation of the correction term as an error correction term encounters difficulties in case of a "linear trending target" or that the consumption function (4.4) lacks "integral control" (see Hendry and Von Ungern-Stemberg (1981)). In the next section we will retuin to the consumption function implied by (4.4) and the assumption of rational expectations with respect to future incone. In this section we are concerned with the unlvariate process of consumption under a moving planning horizon, and we compare the resulting model with the one derived in chapter 2. Subtracting the expression (4.4) for $\Delta c_{t}$ from (4.4) yields 


$$
\begin{aligned}
\Delta c_{t+1} & \left.-\llbracket 1-\eta_{T}^{-1}(1+r)^{-T}\right] \Delta c_{t}-\eta_{T}^{-1}(1+r)^{-T}\left[E\left(y_{t+T+1} \mid I_{t}\right)-E\left(y_{t+T} \mid I_{t-1}\right)\right] \\
& +\eta_{T}^{-1} \sum_{i=0}^{T}(1+r)^{-1}\left[E\left(y_{t+1+1} \mid I_{t+1}\right)-E\left(y_{t+1+1} \mid I_{t}\right)\right] \\
& -\eta_{T}^{-1} \sum_{i=0}^{T}(1+r)^{-i}\left[E\left(y_{t+i} \mid I_{t}\right)-E\left(y_{t+i} \| I_{t-1}\right)\right]
\end{aligned}
$$

To examine more deeply the dynamic properties of consumption, we assume that the change in income is generated by a stationary process with moving average representation

$y_{t+1}-y_{t}+\delta+\sum_{1=0}^{\infty} \psi_{i} \nu_{t+1-1}, \psi_{0}-1, \sum_{i=0}^{\infty} \psi_{i}^{2}<\infty, \sigma^{2}\left(w_{t+1}\right)=\sigma_{\nu}^{2}$.

Since the moments of $y_{t+1}$, conditionally on some infial value, satisfy

$E\left(y_{t+i} \mid I_{t+j}\right)-E\left(y_{t+i} \mid I_{t+j-1}\right)=\left(\psi_{0}+\ldots+\psi_{i-j}\right) \nu_{t+j}, j=0,1$ and $i=j, j+1, \ldots, T$.

and

$E\left(y_{t+T+1} \mid I_{t}\right)-E\left(y_{t+T} \mid I_{t-1}\right)=\left(\psi_{0}+\ldots+\psi_{T+1}\right) \nu_{t}+\delta+\sum_{j=1}^{\infty} \psi_{T+1+j} \nu_{t-j}{ }^{\prime}$

we find after substitution of $(4.8)$ into (4.7)

$$
\begin{aligned}
& \Delta c_{\mathrm{t}+1}-\left[1-\eta_{\mathrm{T}}^{-1}(1+\mathrm{T})^{-\mathrm{T}}\right] \Delta \mathrm{c}_{\mathrm{t}}=\eta_{\mathrm{T}}^{-1}(1+\mathrm{r})^{-\mathrm{T}}\left[\delta+\sum_{j-1}^{\infty} \psi_{\mathrm{T}+1+j}{ }_{\mathrm{t}-\mathrm{j}}\right] \\
& +\eta_{T}^{-1}\left[\sum_{1=0}^{T}\left(\psi_{0}+\ldots+\psi_{i}\right)(1+x)^{-1}\right] \nu_{t+1} \\
& -\eta_{\mathrm{T}}^{-1}\left[\sum_{\mathrm{i}=0}^{\mathrm{T}}\left(\phi_{0}+\ldots+\psi_{\mathrm{i}}\right)(1+\mathrm{r})^{-1}-\left(\psi_{0}+\ldots+\psi_{\mathrm{T}+\mathbb{1}}\right)(1+\mathrm{r})^{-{ }^{-T}}\right] \nu_{\mathrm{t}}
\end{aligned}
$$

Defining the consumption innovation $\varepsilon_{t+1}$ as $\varepsilon_{t+1}-c_{t+1}-E\left(c_{t+1} \| I_{t}\right)$, we have

$$
\varepsilon_{t+1}=\eta_{T}^{-1}\left[\sum_{i=0}^{T}\left(\psi_{0}+\ldots+\psi_{i}\right)(1+r)^{-i} / \nu_{t+1}\right.
$$


From (4.9) 1 tan be easly seen that when the change in income is generated by a MA process of order $q$, the change in consumption follows an ARMA(1, $\max (1 . q \cdot T))$ process. To derive the stochastic process for consurntion when Income is generated by an $\operatorname{ARIMA}(p, 1, q)$ model, it becones necessary to explore the restrictions on the $\psi^{\prime}$ 's implied by the $\mathrm{p}+\mathrm{q}$ ARMA parameters. In Appendix $4 \mathrm{~A}$ we show that in that case the change in consumption follows an ARMA $(p+1, \max (p+1, \max (p-1, q)-T)$ ) process, where the autoregressive part of the consumption process is proportional to that of income, Obvlously, the theoretical framework can provide useful insight in the structure of the income and consumption process, which may be of some use in the identification stage of a time series study.

Comparing the resulting model (2.9) for the "life cycle" consumer and (4.9) for the consumer who uses a moving planning horlzon, shows that we have a different stochastic process for the change in consumption. Another difference concerns the reaction to an unexpected structural change in the constant term of the income process. In the life cycle model discussed in chapter 2 a shift in the income drift gives rise to a step change in that of the consumption process. Along simflar lines as in chapter 2 , it can be shown that in the model with moving planning horizon we have besides a step change in the consumption level, a persistent adjustment of the constant term In the consumption process. We conclude also from expression (4.9) that the signs of the drift parameter in the consumption and income process colncide. The property of the model with moving planning horizon that the drift parameter of the stochastic process for consumption is proportional to that of the Income process opens up the possibility to drop the assumption of a structural change in the time preference parameter which we had to make in chapter 2 .

In both the life cycle model and the model with moving pleanning horizon there is a one to one correspondence between the stochastic properties of Income and consumption. Expressions (4.10) and (2.10) reveal that the consumption innovation is very similar in both cases. This may be an explanation of the Inconsistency encountered in chapter 2 . The consequences of unanticipated structural changes in the ARMA parameters and/ox the warlance of the income process, for the variance of the consumption innovation are therefore similar.

An advantage for estimation is the time-independency of the innovation 
variance. When we assume that aggregate data per capita describe the behaviour of a representative consumer, we may estinate model (4.9) with a constant variance. Notice that an adjustment of the parameters of the preference structure will lead to a step change In the consumption level for the model (4.9) too. The absence of these parameters in expression (4.7) results from the presumed constancy. The implications for the stochastic process of consumption can be traced by using expressions (4.2) and (4.3). It should be obwious that a change in $\beta$ will not lead to a permanent change of the drift parameter of the implied univariate process for consumption.

We have investigated the model (4.1) for the sophisticated consumer too. Along the lines of chapter 3 , it can be shown that for the exponential utility function under the the additional assumptions of normality and absence of structural changes in the ARMA parameters and the variance of the income process, the resulting model is observationally equivalent to the model (4.9). Hence, the results of the empirical analysis that will be carried out in the next section remain valid in the more comprehensive framework discussed in chapter 3 .

\subsection{Empirical results}

In this section will give empirical evidence for the model with moving planning horizon discussed in the previous section, using data on real per capita disposable labour and transfer income and on real per capita total consumption for the Netherlands. The empirtcal results for real nondurable consumption (Including services) per capita are reported In Appendix $4 B$. The data are the same as those used in chapter 2. An empirical examination of the Income series is carried out in section 2.2.1. In the first part of this section we will test the implications of the theoretical. model and the specified income process for the univariate stochastic process for consumption. In the second subsection we wil estintate and test the specification with the correction term, which 1 s an alternative parameterization implied by the model with moving planing hortzon. 


\subsubsection{The unlvarlate tocheste process for consumption}

Whth income being generated by a moving average process of order 1 , we find for the periods in which no structural change occured an ARA $(1,1)$ model for the change in consumption ( $\mathrm{P} \geq 1$ ):

$$
\begin{aligned}
& \left(1-p_{1} L\right) \Delta c_{t}=\eta_{T}^{-1}(1+r)^{-T^{n}} \delta+\left(1-\theta_{1} L\right) \varepsilon_{t} \\
& \text { with } \varphi_{1}=1-\eta_{\mathrm{T}}^{-1}(1+x)^{-\mathbb{T}^{4}} \text { and } \\
& \theta_{1}-1-(1-\theta)(1+x)^{-T_{n}-1}\left[1-\theta+\theta \eta_{T}^{-1}\right]^{* 1}
\end{aligned}
$$

where $\delta$ and $\theta$ denote the drift and the MA parameter of the income process respectively. It can be easily checked that the process satisfies the stability and invertibility conditions. As we have seen above, a tentative investigation of the correlation structure for consumption suggested a random walk specification. The first question we have to answer is whether this empirical finding should lead to a rejection of the model (4.11). Defining $\theta_{1}^{*}$ such that $\theta_{1} \operatorname{mop}_{1}+\theta_{1}^{*}$, it is likely that if $\theta_{1}^{*}$ is small compared with $\varphi_{1}$, cancelling of the (almost) common root can occur in small samples, so that the $\operatorname{ARMA}(1,1)$ process is empirically equivalent to the random walk model. We have calculated the values of the relevant parameters for a range of values of $\mathbb{r}$ and $T$, and the estimate of $\theta$, $0=, 428$. In Table 4.1 we give some results for $r .05$.

TABLE 4. 1

$\begin{array}{rrrrrrrc}\text { I } & \varphi_{1} & \theta_{1} & \theta_{1}^{*} & \theta_{1}^{*} / \varphi_{1} & \rho_{1} & \rho_{2} & \rho_{3} \\ 1 & .512 & .647 & .135 & .264 & -.120 & -.061 & -.031 \\ 2 & .683 & .749 & .066 & .096 & -.060 & -.041 & -.028 \\ 3 & .768 & .807 & .039 & .051 & -.036 & -.028 & -.021 \\ 4 & .819 & .845 & .026 & .031 & -.024 & -.020 & -.016 \\ 8 & .909 & .918 & .008 & .009 & -.008 & -.007 & -.006\end{array}$

We see that with a planning time span of 4 periods, $\theta_{1}^{*}$ is only 38 of $\varphi_{1}$, and with a time span of 8 periods the percentage becomes smaller than 18 . In Table 4.1 we also report the theoretical values of the first three autocorrelations. Since for large $n$ (the number of observations) the sample 
autocorrelations are uncorrelated and normally distributed with standard deviations $\mathrm{n}^{-1 / 2}$ (see Anderson (1971)), and the number of observations at our disposal is $71(1 / / 71=.119)$, we conclude from the results of Table 4.1 , that it is unlikely that we are able to detect the $\operatorname{ARMA}(1,1)$ process from the $A C F$, and that the theoretical model is not incompatsble with the empirical autocorrelations for $\Delta c_{t}$.

In section 4.1 we have argued that besides the persistent adjustment of the constant term in (4.11), a structural change in the drift parameter of the income process will lead to a step change in the consumption level. Along similar lines as in chapter 2 it can be shown that for the ARMA(1,1) process this gives rise to the introduction of two dumny variables. Using the expressions $(4.2)$ and $(4,3)$ of the former section, it can be shown that a change of $\delta$ to $\delta^{*}$ leads to a step change of the constant term in the ARMA model of size $\left[\delta^{*}-\delta\right)\left[1+\eta_{\mathrm{T}}^{-1} \tau_{\mathrm{T}}\right]$ in the first perlod and of size $\left(\delta^{*}-\delta\right)\left[-1-\eta_{\mathrm{T}}^{-1} r_{\mathbb{T}}+\eta_{\mathrm{T}}^{-1}(1+\mathrm{r})^{-\mathrm{T}}(\mathrm{T}+1)\right]$ in the next period. Therefore, for 1971 and 1979 we expect a decrease of the constant term followed by an increase. We see here an alternative explanation for the occurrence of clusters of outliers discussed in chapter 2. A correct interpretation of the outliers, based on the economic theory, can also obviate the problem. The cholice of an ARCH model can in fact be prompted by the incourect handling of structural breaks.

Maximum likelihood estimation of the equation implied by the theory and the income process of section 2.2 .1 yields the following results

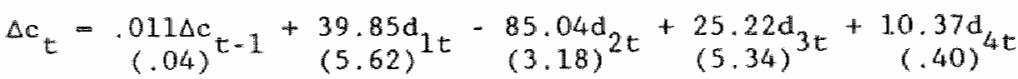

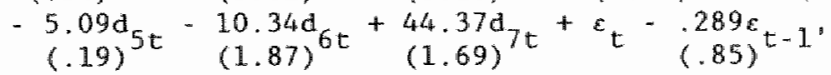

$$
\begin{aligned}
& \sigma^{2}\left(\varepsilon_{t}\right)=571.1
\end{aligned}
$$

$$
\text { where } \begin{aligned}
d_{1 t} & =1 \text { for } 1967(2)-1971(1) \\
d_{2 t} & =1 \text { for } 1971(1) \\
d_{3 t} & =1 \text { for } 1971(2)-1979(1) \\
d_{4 t} & =1 \text { for } 1971(2) \\
d_{5 t} & =1 \text { for } 1979(1) \\
d_{6 t} & =1 \text { for } 1979(2)-1984(4) \\
d_{7 t} & =1 \text { for } 1979(2)
\end{aligned}
$$


and t-ratios are reported between parentheses. The residuals do not exhibit any significant autocorrelation. The ACF and the PACF have no stgnifieant walues. We find outilers in 1975(4) and 1977(4). The values of the BP and LB cest statistic based on the first $4,8,12$ and 16 residual autocorreletions are reported in Table 4.2. They are highly insignificant. In section 2.2.1 we found that nomalty and homoscedasticity for $\Delta y_{\text {i }}$ do not have to be rejected. Given that fncome is normally distributed and homoscedastic, the theory predicts that the consumption innovation should follow a normally distributed and homoscedastic process. In table 4.2 we report the values of the test statistics for the ARCH structure and normalty of the consumption innovation. They are insignificant, so we conclude that in this respect the mpixical results are in accordance with the theory.

TABLE 4.2 Test statistics for model (4.14)

\begin{tabular}{rrr}
$\mathrm{P}$ & $\mathrm{BP}$ & \multicolumn{1}{c}{ LB } \\
4 & & \\
3 & .17 & .29 \\
12 & 3.26 & 3.40 \\
16 & 6.85 & 7.14 \\
& 10.48 & 10.94
\end{tabular}

$\begin{array}{lr}\eta(1) & .95 \\ \eta(4) & 2.22 \\ s_{1} & -.09 \\ s_{2} & -.06\end{array}$

Let us next exame the sign and slze of the parameter estimates. First we consider the walue of the consumption variance. Using expression (4.10) we have ln this instance

$e_{t}^{\infty}\left(1-\beta+\theta \eta_{\mathrm{T}}^{-1}\right) \nu$

where denotes the MA parameter of the income process. With the positive walue of glven $\ln (2.14)$ and $0<\eta_{\mathrm{T}}^{1}<1$, the variance of the income frnovation should exceed that of the consumption innovation. The values reported in $(4.12)$ and $(2.14)$ are in agreenent with the theory. Next we 
consider the values of $p_{1}$ and $\theta_{1}$. Theoretically they should be positive and smaller than 1 , a criterion which is satisfied. From the values reported in Table 4.1, we infer that the point estimates of the AR and MA parameters are rather small. Notice however that the low t-values prevent us from drawing sharp conclusions. From the estimate of $\psi_{\imath}$ we can obtain an estimate of $T$. Noting that

$\varphi_{1}=1-\eta_{\mathrm{T}}^{-1}(1+r)^{-\mathrm{T}}=1-\mathrm{r}\left[(1+\mathrm{r})^{(\mathrm{T}+1)}-1\right]^{-1}$

it follows that $T \approx\left(1-\varphi_{1}\right)^{-1}-1$. Using (4.12) we find for the estimate of $T$ the embarrassingly low value $.011(.04)$. Notice however that this estimate is highly insignificant. In section 4.1, we have shown that the sign of the constant term of the process for consumption should be the same as that for the income process. From expression (4.11) it follows that the (absolute value of the) constant term of the income process should exceed that of consumption. A comparison of (4.12) with (2.14) shows that this requirement is satisfied for the coefficients of $d_{1 t}$ and $d_{6 t}$, but not for that of $d_{3 t}$. The ratio of the constant terms equals in all cases $\eta_{T}^{-1}(1+r)^{-1}$. Empirically we find the values $.985,1.001$ and .795 respectively. The AR parameter equals $1-\eta_{\mathrm{T}}^{-1}(1+\mathrm{r})^{-T}$. Using the average of the three figures for $\eta_{\mathrm{T}}^{-1}(1+r)^{-T}$, the corresponding estinate of $\varphi_{1}$ equals .073 which is close to the value given in (4.14). These values support the statement that $r$ and/or $T$ have not undergone a structural shift. A test of the equality of the ratios can be performed when the joint (singular) process for consumption and income has been estimated. In that case an estimate of $\mathrm{T}$ can be obtained from the ratios.

To check whether the estimates of the coefficients of the dumy varlables are in accordance with the theoretical model, remember that they absorb the joint effect of the step change and the transformed income innovation. Using the estimates of the income innovation, the constant term and the MA parameter of the income process (2.14), we may infer a negative stgn for the coefficient of $d_{2 t}$ and a positive one for the coefficient of $d_{7 t}$. Because of the size of the income innovation in 1971(2) In relation to the step change, we expect a positive coefficient for $d_{4} t$. The sign of the coefficient of $d_{5 t}$ is unpredictable. Equation (4.12) shows that all these empirical results are in accordance with the implications of the theory. 
Notice however that all the estimates except that of the coefficient of $\mathrm{d}_{2 \mathrm{t}}$ are insignificant. Also, in applied work it may be deficult to pinpoint the moment of appearance of the structural change. Notwithstanding all these qualifications, it should be obvious that the theoretical framework provides a plausible basis for interpreting outliers.

From the empirtcal analysis of this section we conclude that the model for the forward lookfng consumer with a moving planning horizon provides a satisfactory description of the serial correlation properties of the consumption series. The model does not rely on an ad-hoc assumption about a structural change of the time preference parameter and removes in this way an important drawback of the 1 ife cycle model. The empirical results for real nondurable consumption per capita given in Appendix $4 \mathrm{~B}$ are roughly the same as those presented in this subsection.

Checking the Implications of the theoretical model for the univariate stochastic properties is only part of an econometric analysis. Moreover, the exanination of the consumption series carried out in this section illustrates the possible fallacies of a pure time series study. Therefore, in the next subsection we will estimate and test an alternative parameterization implied by the model with moving planning horizon. The specification of interest is the relationship between consumption and income with the correction term.

\subsubsection{The specification with correction mechanism}

To 11lustrate the concept of the correction term and to provide additional ernpirical evidence for the model with moving planning horizon, we investigate in this section the relationship between consumption and income that includes the correction mechanism. The expresston of interest is $(4.4)$. The speclfied income process of section 2.2 .1 enables us to calculate the relevant conditional expectations of (4.4). In the first lnstance we ignore the implications of the structural changes in the drift parameter of the income process. When the change in income is generated by a moving average process of order 1

$\Delta y_{\mathrm{t}}^{\prime}=\delta+\nu_{\mathrm{t}}-\theta \nu_{\mathrm{t}-1}$. 
the relevant conditional expectations of $(4.4)$ satisfy

$y_{t+1}-E\left(y_{t+1} \| I_{t}\right)=v_{t+1}$

$E\left(y_{t+i} \mid I_{t+1}\right)-E\left(y_{t+i} \mid I_{t}\right)=(1-\theta) \nu_{t+1}, 1 \geq 2$

and

$E\left(y_{t+T+1} \mid I_{t}\right)=y_{t}+(T+1) \delta-\theta \omega_{t}$.

Substituting $(4.13),(4.14)$ and $(4.15)$ into $(4.4)$ yields

$$
\begin{aligned}
\Delta c_{\mathrm{t}+1} & =\gamma^{-1} \ln [\beta(1+\mathrm{r})]\left(\mathbb{1}-(\mathrm{T}+1) \eta_{\mathrm{T}}^{-1}(1+\mathrm{r})^{-\mathrm{T}}\right)+\eta_{\mathrm{T}}^{-1}(1+\mathrm{r})^{-\mathrm{T}}\left[(\mathrm{T}+1) \delta+y_{\mathrm{t}}-c_{\mathrm{t}}\right] \\
& -\eta_{\mathrm{T}}^{-1}(1+\mathrm{r})^{-\mathrm{T}_{\theta \nu}}+\eta_{\mathrm{T}}^{-1}\left[(1-\theta) \eta_{\mathrm{T}}+\theta\right] \nu_{\mathrm{t}+1} .
\end{aligned}
$$

The last term of $(4.16)$ can be expressed as

$$
\begin{aligned}
\eta_{\mathrm{T}}^{-1}\left[(1-\theta) \eta_{\mathrm{T}}+\theta\right] \nu_{\mathrm{t}+1} & =\eta_{\mathrm{T}}^{-1} \eta_{\mathrm{T}-1}\left[1-\theta(1+\mathrm{r})^{-1}\right] \nu_{\mathrm{t}+1} \\
& +\eta_{\mathrm{T}}^{-1}(1+\mathrm{r})^{-\mathrm{T}}\left[\Delta \mathrm{y}_{\mathrm{t}+1}-\delta\right]+\eta_{\mathrm{T}}^{-1}(1+\mathrm{r})^{-\mathrm{T}} \theta \nu_{\mathrm{t}}
\end{aligned}
$$

and after substitution of $(4.17)$ into $(4.16)$ we get

$$
\begin{aligned}
\Delta c_{\mathrm{t}+1} & =\gamma^{-1} \ln [\beta(1+\mathrm{r})]\left(1-(\mathrm{T}+1) \eta_{\mathrm{T}}^{-1}(1+\mathrm{r})^{-\mathrm{T}}\right)+\eta_{\mathrm{T}}^{-1}(1+\mathrm{r})^{-\mathrm{T}} \mathrm{T} \delta+\eta_{\mathrm{T}}^{-1}(1+\mathrm{r})^{-\mathrm{T}} \Delta \mathrm{y}_{\mathrm{t}+1} \\
& +\eta_{\mathrm{T}}^{-1}(1+\mathrm{r})^{-\mathrm{T}}\left(\mathrm{y}_{\mathrm{t}}{ }^{-1} \mathrm{c}_{\mathrm{t}}\right)+\eta_{\mathrm{T}}^{-1} \eta_{\mathrm{T}-1}\left[1-\theta(1+\mathrm{r})^{-1} \| \nu_{\mathrm{t}+1}\right.
\end{aligned}
$$

The resulting consumption function is similar to that put forward by Davidson, Hendry, Srba and Yeo (1978) except for $\Delta \Delta y_{t+1}$ which does not appear as an explanatory variable in (4.18). In Appendix $4 \mathrm{C}$ we will show that when $\Delta y_{t}$ is generated by an AR(1) process, expression (4.4) reproduces the basic mechanism underlying their consumption function: in each period 
consumers spend the same amount as they spent the previous partod, modffied by a proportion of the change and the change of the change in income and by a term labeled and interpreted by Davidson et. al. as the error correction term. There renaln however important differences between specification (4.18) and the consumption function found by Davidson et. al.. The main differences relate to the role of the inflation variable and the log-linear functional form. In the next chapter we will consider the extension of the model studied in this chapter with respect to inflation effects. Moreover, the speciflcation put forward by Davidson et. al. is formulated in four period differences. In chapter 6 we will show that the model with moving planning horizon with a preference structure that exhibits a special form of rational habits, is capable of reproducing a consumption function like (4.18) in four perlod differences. Notice also that the appropriate income concept. In the model wth moving planning horizon is real disposable nonproperty income, whereas the income variable used by Davidson et. al. is real dispasable income. Finally, notice that the consumption function obtalned by Hendry (1983) for annul data displays the same lag structure as speciflcation $(4,18)$.

Under the assumption that the changes in the drift parameter of the income process were not anticlpated, the model for consumption (4.18) needs revision. Let us assume that the constant term $\delta$ moves to $\delta^{*}$. Using the closed form (4.2) and (4.3) for $c_{t}$ and $c_{t+1}$, it can be shown along similar lines as in chapter 2 that the structural change in the income process will give rise to a step change in the constant of the consumption mode1 (4.18) equal to $\left(\delta^{*}-\delta\right) \eta_{r}^{1}\left[(1+r) r_{T+1}-(1+r)^{-T}\right]$. Therefore, both in 197](1) and $1979(1)$ we expect negative adjustment in the drift parameter of the consumption model (4.18). Since the constant term in (4.18) depends on $\delta$, we also have a persistent change in the constant term of the consumption function. This completes the derivation of the estimation equation implied by the model with moving planning horizon and the assumption of rational expectations 1 th respect to future income. In conclusion, we have

$\Delta c_{t}=\sum_{i=1}^{5} \beta_{1} d_{i t}+\alpha_{1} \Delta y_{t}+\alpha_{2}\left(y_{t-1}-c_{t-1}\right)+\varepsilon_{t}$

with $d_{1 t}=1$ for $1968(2)-1971(1)$

$$
d_{2 t}=1 \text { for } 1971(1)
$$




$$
\begin{aligned}
& d_{3 t}=1 \text { for } 1971(2)-1979(1) \\
& d_{4 t}=1 \text { for } 1979(1) \\
& d_{5 t}=1 \text { for } 1979(2)-1984(4) .
\end{aligned}
$$

The coeficients of $(4.19)$ are defined as follows

$$
\begin{aligned}
& \beta_{1}=\gamma^{-1} \ln \left[\beta\left(1+r^{-}\right)\right]\left(1-(T+1) \eta_{\mathrm{T}}^{-1}(1+r)^{-\mathrm{T}}\right)+\eta_{\mathrm{T}}^{-1}(1+r)^{-\mathrm{T}_{\mathrm{T}} \delta_{1}} \\
& \beta_{2}=\left(\delta_{2}-\delta_{1}\right) \eta_{\mathbb{T}}^{-1}\left[(1+r) \tau_{\mathrm{T}+1}-(1+\mathrm{r})^{-\mathrm{T}}\right] \\
& \beta_{3}=\gamma^{-1} \ln [\beta(1+r)]\left(1-(\mathrm{T}+1) \eta_{\mathrm{T}}^{-1}(1+\mathrm{r})^{-\mathrm{T}}\right)+\eta_{\mathrm{T}}^{-1}(1+\mathrm{r})^{-\mathrm{T}_{\mathrm{T}} \mathrm{T}_{2}} \\
& \beta_{4}=\left(\delta_{3}-\delta_{2}\right) \eta_{\mathrm{T}}^{-1}\left[(1+\mathrm{r}) \tau_{\mathrm{T}+1}-(1+\mathrm{r})^{-\mathbb{I}^{2}}\right] \\
& \beta_{5}=\gamma^{-1} \ln [\beta(1+r)]\left(1-(\mathrm{T}+1) \eta_{\mathrm{T}}^{-1}(1+\mathrm{r})^{-\mathrm{T}}\right)+\eta_{\mathrm{T}}^{-1}(1+\mathrm{r})^{-\mathrm{T}_{\mathrm{T}} \delta_{3}} \\
& \alpha_{1}=\alpha_{2}=n_{\mathrm{T}}^{-1}(1+\mathrm{T})^{-\mathrm{T}}
\end{aligned}
$$

with $\delta_{1}$ being the coefficient of $d_{1 t}$ in the model (2.14) for income. The disturbance term $\varepsilon_{t}$ in (4.19) is a linear transformation of the incone innovation

$\varepsilon_{t}=\eta_{\mathrm{T}}^{-1} \eta_{\mathrm{T}-1}\left[1-\theta(1+\mathrm{r})^{-1}\right] \nu_{\mathrm{t}}$.

The mean $\operatorname{lag}$ in $(4.19)$ equals $\left(1-\alpha_{2}\right) \alpha_{1}^{-1}$ so that the restriction $\alpha_{1}$ wa does not imply a zero mean lag, which is neccessary to guarantee adjustment of the endogenous variable to its target, in case the latter 1 s "Lreat trending" (see Currie (1981)). The homogenelty condition which requires that the sum of the coefficients of the autoregressive part of (4.19) equals that of the coefficients of income is satisfled.

Since the explanatory variable $\Delta y_{t}$ is correlated with the disturbance $\varepsilon_{t}$. the model (4.19) has been estimated by instrumential variables (IV). We impose the restriction $\alpha_{1} \alpha_{2}$ and use $y_{t_{-}-1}-c_{t-2}$ as an instrument for $y_{t}$ $c_{t-1}$. For real total consumption per captea the following estrmates have been obtained 


$\begin{array}{lrr}\beta_{1} & 41.45 & (5.07) \\ \beta_{2} & -77.02 & (2.77) \\ \beta_{3} & 15.99 & (2.46) \\ \beta_{4} & 4.21 & (.16) \\ \beta_{5} & 6.71 & (.74) \\ \alpha_{1} & .24 & (2.03) \\ \sigma^{2}\left(c_{4}\right) & 669.6 & \end{array}$

wh th-values given between parentheses. Some test statistics for model (4.19) are giwen in Table 4.3.

Table 4.3 Test statistics for model (4.19)

p

$B P$

$\mathrm{L}, \mathrm{B}$

$\begin{array}{lrr}4 & 2.32 & 2.42 \\ 8 & 5.31 & 5.56 \\ 12 & 12.04 & 12.59 \\ 16 & 20.51 & 21.46\end{array}$

$\eta(1)$

2.37

$\eta(4)$

3.16

$\mathrm{S}_{1}$

$-.06$

$\mathrm{S}_{2}$

$-.09$

$\operatorname{PFCF}(8,52)$

.52

$\begin{array}{ll}\operatorname{SCE}(1) & .0004 \\ \operatorname{SCEF}(1,53) & .0004 \\ \operatorname{SCN}(1) & .0004 \\ \operatorname{SCWF}(1,53) & .0004\end{array}$

$\begin{array}{lr}\operatorname{SCE}(4) & 7.94 \\ \operatorname{SCEF}(4,50) & 1.91 \\ \operatorname{SCW}(4) & .12 \\ \operatorname{SCWF}(4,50) & .03\end{array}$

CRW (1)

.90

CRWE $(1,59) \quad .81$

CRLM (1) $\quad .92$

CRLMF $(1,59) \quad .83$ 
The residuals do not exhibit any significant correlation. The values of the BP and LB test statistic, based on the flrst $4,8,12$ and 16 residual autocorrelations are insignificant. In section 2.2.1 we found that normality and homoscedasticfty for $\Delta y_{t}$ do not have to be rejected. Since the disturbance term $\varepsilon_{t}$ is a linear transformation of the income innovation, the theory predicts that $\varepsilon_{t}$ should follow a normally distributed and homoscedastic process. The values of the test statistics for the ARCH structure and normality of $\varepsilon_{t}$, reported in table 4.3, are insignificant, so we conclude that in this respect the empirical results are in accordance with the theory.

Since the correlation between the explanatory varlables and the disturbance term jeopardizes the validity of the BP and LB test statistics, several tests put forward by Kiviet (1985) in the context of instrumental varlables estimation have been caxried out. We have adopted his notation. The statistic PFCF tests for postsample predictive failure. It lis based on predictions for the period 1983(1)-1984(4). Under the null hypothesis, it has an $F(8,52)$ distribution. SCE(p) and SCW(p) are LM- and Wald-type statistics which test for an $A R(p)$-process for the residuals. They are asymptotically $x^{2}$ (p) distributed under the null hypothesis that the disturbances are white notse. We have also computed their F-type versions, denoted by SCEF and SCWF respectively. The number of degrees of Ereedom are reported between brackets. As finstruments we used the five dumny variables, $y_{t-5}-c_{t-6}, y_{t-6}-c_{t-7}, y_{t-7}-c_{t-8}, \Delta c_{t-5}$ and $\Delta c_{t-6}$.

Finally, the model (4.19) has been estinated without the restriction $\alpha_{1}-\alpha_{2}$ using the dummy variables, $\Delta y_{t-1}$ and $y_{t-2}-c_{t-2}$ as instruments. The point estimates are $\hat{\alpha}_{1}=.128(.80)$ and $\hat{\alpha}_{2}=.160(.36)$. Several test statistles for the equality between the regression coefficients have beri computed. CRW(1) and CRLM(1) refer to the Wald - and LM-type test statistlos, whlch are asymptotically $x^{2}(1)$ distributed. In table 4.3 we mention also their $p$ type versions.

All statistics yield insignificant values and we conclude that the distributional and serial correlation properties of the IV residuals and the predictive performance of the model (4.19) is very satisfactory.

Next, we consider the point estimates. Expression (4.18) shows that we have for the disturbance term $\varepsilon_{t}$ 
$\varepsilon_{t}=\eta_{T}^{-1} \eta_{T-1}\left[1-\theta(1+\mathrm{r})^{-1}\right] \nu_{t}$

Given the estimate $0.428 \quad \ln (2.14)$, we have as an implication of the theoretical model that the variance of $\varepsilon_{\mathrm{q}}$ in $(4.19)$ is smaller than that of the income innovation. A comparison of the values reported in $(2.14)$ and (4.20) shows that the point estimates confirm the theory on this point. It is not difficult to show that the variance of $\varepsilon_{t}$ in (4.19) ought to be smaller than the variance of the disturbance term in the univariate model for consumption ( 4.12$)$, a restriction that is not satisfled by the polnt estinates of the variances.

The criterion that the coefficlent for the correction term should be positive and smaller than 1 , is met. The estimate of $\alpha_{1}$ can be used to find an estimate of $T$. It can be easily shown that $T \approx \alpha_{1}^{-1}-1$. From (4.20) we deduce for $T$ the estimate $3.17(2.03)$. Hence, the consumer takes into account the information on the next 3 quarters when taking his consumption decision. Notice that the estimate is significantly different from zero, so that we have an empirical confirmation that the consumer displays forward looking behaviour.

From (4.18) and (4.19) it follows that the sign of $\beta_{1}, \beta_{3}$ and $\beta_{5}$ depends on that of $\gamma^{-1} \ln [\beta(1+r)]\left[1-(T+1) n_{T}^{-1}(1+r)^{-T}\right]$. However, with the point estimates of the $\delta_{1}$ 's given in (2.14) the following Inequality has to hold: $\beta_{5}<\beta_{3}<\beta_{1}$, which is indeed the case for the point estimates in $(4,20)$. With the point estimates of the $\delta_{1}$ "s and given in (2.14) and the estimate of the Income innovation, It can be shown that $\beta_{2}$ ought to be negative. This requirement is satisfied by the point estimate reported in (4.20). The sign of $\beta_{\text {i }}$ is not determined as a result of the opposite signs of the expected step change in the constant term and the estimate of the income innowation in 1979(1). It can be shown that for the parameters of (4.19) the following restriction has to hold

$$
\left(\beta_{3}-\beta_{1}\right)\left(\delta_{2}-\delta_{1}\right)^{-1}-\left(\beta_{5}-\beta_{3}\right)\left(\delta_{3}-\delta_{2}\right)^{-1}=\mathrm{T} \alpha_{1}
$$

With the point estimates of $\beta_{1}, \beta_{3}$ and $\beta_{5}$ of $(4.20)$ and the estimates of the $\delta_{1}$ "s given $\mathbb{1 n}(2.14)$, we find for the first two expressions of (4.21) the values 1.67 and .24 respectively. Using the average of the two figures 
and the point estimate of $\alpha_{1}$ given in (4.20), the corresponding estimate of $T$ equals 3.98 , which is close to the value given above. A test of the restrictions (4.21) can only be performed when the joint (singular) process of consumption and income has been estimated.

From the empirical analysis of this section, we conclude that the model with moving planning horizon provides a very satisfactory description of the data. For the length of the planning time span we find an estimate of 3.17 quarters. In contrast to the result obtained by the univariate analysis carried out in section 4.2.1, the estimate of I is significantly different from zero. Based on empirical evidence, Friedman (1957) draws a dividing line at about 3 years (see p. 221), to classify the permanent and transitory components of income. Obviously, our empirical results suggest that the consumer is more "shortsighted" than in Friedman's model.

Davidson and Hendry (1981) among others have stressed the (almost) observational equivalence of models based on forward looking behaviour and those based on feedback control rules. The models studied in this chapter provide a new illustration of this observation. The only possibility to discriminate between the two interpretations seems to occur when structural breaks appear in the processes of the forcing variables. When the agents display full capacity of anticipatory behaviour, the model for consumption differs from that of an agent who bases his decision on a feedback rule.

The empirical results for real nondurable consumption reported in Appendix 4B are approximately the same as those presented in this subsection, with the important exception that the test for an ARCH structure yields a significant value. A possible explanation may be the lack of rationality from the side of the consumer discussed in chapter 2. An alternative interpretation of the significant value might of course be that it is an Indication of some kind of misspecification. In the next chapters we will. investigate more extensive models of consumer behaviour and we will try to remedy the inconsistency between the theoretical implications of the model and the empirical evidence. After a careful empirical examination Davidsori et. al. (1978) arrive at an ultimate specification, in which the basic mechanism between consumption and income is extended for the effects of inflation. In the next chapter we will consider the extension of the model. investigated in this chapter with respect to inflation effects. 
Appendix 4 the stochastlo process for consumption when Income follows an ARTMA $(p, 1, q)$ process

In this appendix will derive the stochastic process of consumption implied by the model investigated in this chapter when the change in income is generated by an ARMA $(p, q)$ process. We consider a stationary invertible $\operatorname{ARTMA}(p, 1, q)$ process for income

$\Phi(L) \Delta y_{t}=\theta(L) \nu_{t}$, with $E \nu_{t}=0$ and $\sigma^{2}\left(\nu_{t}\right)-\sigma^{2}$.

The lag polyromials are defined as

$$
\Phi(\mathbb{L})=\varphi_{0}-\varphi_{1} \mathrm{~L} \cdots-\varphi_{\mathrm{p}} \mathrm{L}^{\mathrm{p}}, \varphi_{0} 1
$$

and $\theta(L)=\theta_{0}-\theta_{1} L-\ldots-\theta_{q} L^{q}, \theta_{0}=1$

respectively. The MA( $\infty)$-representation is denoted as

$\Delta y_{t}-\Psi(L) \nu_{t}$

with $\Psi(\mathrm{L})=\sum_{\mathbb{1}=0}^{\infty} \psi_{1} \mathrm{~L}^{\mathbb{1}}, \psi_{0}=1$.

From (A.1) and (A.2) follows

$\Psi(\mathrm{L}) \Psi(\mathrm{L})=\theta(\mathrm{L})$.

Expression (A.3) can be used to trace the restrictions on the parameters $\psi_{i}$, implied by the $\mathrm{p}+\mathrm{q}$ ARMA parameters. It is straightforward to show that (A.3) implies

$\psi_{j}=\varphi_{1} \psi_{j-1}+\ldots+\varphi_{p} \psi_{j-p} \quad$ for all $j \geq \max (p, q+1)$. 
Therefore, for $j \geq \max (p, q+1)$ the parameters $\psi_{j}$ are generated by a $p^{\text {th }}$ order homogeneous difference equation. When we define $\mu_{t}$ 果 the MA part of $(4.9)$, we have

$$
\begin{aligned}
\mu_{t} & =\eta_{\mathrm{T}}^{-1}\left[\sum_{i=0}^{\mathrm{T}}(1+\mathrm{r})^{-i}\left(\psi_{0}+\ldots+\psi_{i}\right)\right] \nu_{t} \\
& -\eta_{\mathrm{T}}^{-1}\left[\sum_{i=0}^{\mathrm{T}}(1+\mathrm{r})^{-i}\left(\psi_{0}+\ldots+\psi_{1}\right)-(1+\mathrm{r})^{-\mathrm{T}} \sum_{i=0}^{\mathrm{T}+1} \psi_{\mathrm{i}}\right] \nu_{t-1} \\
& +\eta_{\mathrm{T}}^{-1}(1+\mathrm{r})^{-\mathrm{T}} \sum_{j=2}^{\infty} \psi_{\mathrm{T}+\mathrm{j}}^{\nu} \mathrm{t}-\mathrm{j} .
\end{aligned}
$$

Calculating the autocovariance function for $\mu_{t}$ ylelds for all $1 \geq 2$

$$
\begin{aligned}
& E\left(\mu_{t} \mu_{t-1}\right)=\sigma^{2}\left[\psi_{T+\mathbb{1}}(1+\mathbb{r})^{-T} \eta_{T}^{-2}\left[\sum_{j=0}^{T}(1+r)^{-j}\left(\psi_{0}+\ldots+\psi_{j}\right)\right]\right. \\
& \left.-\psi_{T+i+1}(1+r)^{-T} \eta_{T}^{-2}\left[\sum_{j=0}^{T}(1+r)^{-j}\left(\psi_{0}+\ldots+\psi_{j}\right)-(1+r)^{-T^{T+1}} \sum_{j=0}^{T} \psi_{j}\right)\right] \\
& \left.+\eta_{\mathrm{T}}^{-2}(1+\mathrm{r})^{-2 \mathrm{~T}} \sum_{j=2}^{\infty} \psi_{\mathrm{T}+\mathbf{i}+\mathbf{j} !} \psi_{\mathrm{T}+\mathrm{j}}\right) \text {. }
\end{aligned}
$$

For every 1 sacisfying. $T+1 \geq \max (p, q+1)$ we can use (A.4) to rewrite (A.5) as

$$
\begin{aligned}
& E\left(\mu_{t} \mu_{t-1}\right)=\sigma^{2} \sum_{j=1}^{P} \varphi_{j}\left(\psi_{T+1-j}(1+r)^{-T} \eta_{T}^{-2}\left[\sum_{k=0}^{T}(1+r)^{-k}\left(\psi_{0}+\ldots+\psi_{k}\right)\right]-\right.
\end{aligned}
$$

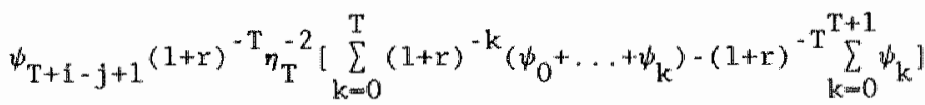

$$
\begin{aligned}
& \left.+\eta_{\mathbb{T}}^{-2}(I+r)^{-2 T} \sum_{k=2}^{\infty} \psi_{T}^{\infty} T+i-j+k^{\psi} T+k\right)
\end{aligned}
$$


For every 1 satisylng $\mathbb{1 n}$ addicion $T+1-p \geq T+2$, substitution of (A.5) in (A.6) gives as a result

$E\left(\mu_{t}^{\mu}{ }_{t-1}\right)=\varphi_{1} E\left(\mu_{t}^{\mu} t-(1-1)\right)+\ldots+\varphi_{p} E\left(\mu_{t}{ }_{t}^{\mu}-(1-p)\right)$

From the requirements in (A.5), (A.6) and (A.7), we see that for all $i \geq$ $\max (p+2, \max (p, q+1)-T)$ the autocovariances of $\mu_{t}$ are generated by a $p^{t h}$ order homogeneous difference equation. For an ARMA $(r, s)$ process the autocovarlances $\gamma_{\mathfrak{l}}$ are generated for all $\mathrm{j} \geq \mathrm{s+1}$ by a $\mathrm{r}^{\mathrm{t}}$ order homogeneous difference equation (see Box and Jenkins (1976)). Because the autocowarlance function determines the order of a stationary stochastic process, we conolude from (A.7) that $\mu_{\mathrm{t}}$ follows an ARMA(p, max $(p+1$, max $(p-1, q)-T)$ process, where the AR part coincides with the one for the income process. Say

$\Phi(L) \mu_{t}=\tilde{\theta}(L) \zeta_{t}, \quad E_{t}=0$ and $\sigma^{2}\left(\zeta_{t}\right)=a_{\zeta}^{2}$

or in the MA representation

$\mu_{\mathrm{t}} \Phi^{-1}(\mathrm{~L}) \tilde{\theta}(\mathrm{L}) \zeta_{\mathrm{t}}$

Substituting (A.B) Into (4.9) 1eads to the conclusion that $c_{t}$ is generated by an $\operatorname{ARIMA}(p+1,1, \max (p+1, \max (p-1, q)-T))$ process, with the autoregressive part including that of the income process. 


\section{Appendix 4B Empirical results for real nondurable consumption per caplta}

The numbers of the expressions and tables in this appendix correspond to those used in the main text. A prime refers to nondurable consumption. With respect to the evaluation of the size and sign of the parameter estimates we refer to the discussion in section 4.2 .

Maximum likelihood estimation of the univariate stochastic process for consumption implied by the theory and the income process of section 2.2.1 yields the following results

$$
\begin{aligned}
& \Delta \mathrm{c}_{\mathrm{t}}=.12 \Delta \mathrm{c}_{\mathrm{t}-1}+31.37 \mathrm{~d}_{\mathrm{t} t}-56.83 \mathrm{~d}_{2 \mathrm{t}}+17.04 \mathrm{~d}_{3 \mathrm{t}}+21.14 \mathrm{~d}_{4 \mathrm{t}}+ \\
& \begin{array}{lllll}
(.49) & (5.11)(2.77) & (4.23) & (1.27)
\end{array} \\
& 10.47 \mathrm{~d}_{5 \mathrm{t}}-3.52 \mathrm{~d}_{6 \mathrm{t}}+27.36 \mathrm{~d}_{7 \mathrm{t}} * \varepsilon_{\mathrm{t}}-.44 \varepsilon_{\mathrm{t}-1} \\
& \begin{array}{llll}
(.52)(1.35) \quad(1.37) & (1.61)
\end{array} \\
& \sigma^{2}\left(\varepsilon_{t}\right)=332.7 \text {. }
\end{aligned}
$$

Table $4.2^{\prime}$ Test statistics for model (4.12)'

\begin{tabular}{lrr} 
P & \multicolumn{1}{c}{ BP } & \multicolumn{1}{c}{ LB } \\
4. & .60 & .63 \\
8 & 1.60 & 1.67 \\
12 & 7.10 & 7.41 \\
16 & 10.11 & 10.55
\end{tabular}

$\begin{array}{ll}\eta(1) & .0003 \\ \eta(4) & 5.38 \\ s_{1} & -.14 \\ s_{2} & -.03\end{array}$

The theoretical implications are satisfied by the test situstics and the parameter estimates. The estimate of $\mathrm{T}$ derived from the one of the AR patameter of (4.12)' yields again a rather small value and is imsignificant: $.14(.49)$.

IV-estimation for real nondurable consumption per capita of the 
speciflcation wh correction mechanlsm investigated in section 4.2 .2 , ylelds the following results

$\begin{array}{lrr}\beta_{1} & -11.72 & (.47) \\ \beta_{2} & -62.49 & (2.93) \\ \beta_{3} & -40.21 & (1.27) \\ \beta_{4} & 4.79 & (.23) \\ \beta_{5} & -55.21 & (1.90) \\ \alpha_{1} & .07 & (1.84) \\ \alpha^{2}\left(c_{t}\right) & 413.3 & \end{array}$

Table 4.3' Test statistics for model (4.19)'

\begin{tabular}{lrr} 
P & BP & \multicolumn{1}{c}{ LB } \\
4. & 4.36 & 4.56 \\
8 & 5.72 & 5.98 \\
12 & 10.36 & 10.83 \\
16 & 18.40 & 19.25
\end{tabular}

$\begin{array}{lrll}\eta(1) & .13 & & \\ \eta(4) & 12.74 & & \\ S_{1} & -.19 & & \\ S_{2} & -.02 & & \\ \operatorname{PFCF}(8,52) & .62 & \operatorname{SCE}(4) & 9.23 \\ & & \operatorname{SCEF}(4,50) & 2.27 \\ \operatorname{SCE}(1) & 2.10 & \operatorname{SCW}(4) & .05 \\ \operatorname{SCEF}(1,53) & 1.92 & \operatorname{SCWF}(4,50) & .01 \\ \operatorname{SCW}(1) & 2.06 & & \\ \operatorname{SCWF}(1,53) & 1.82 & & \\ & & & \\ \operatorname{CRW}(1) & 1.48 & & \\ \operatorname{CRWP}(1,59) & 1.32 & & \\ \operatorname{CRLM}(1) & 1.55 & & \\ \operatorname{CRMME}(1,59) & 1.42 & & \end{array}$


The model without the restriction $\alpha_{1}-\alpha_{2}$ yields the IV-estimates $\hat{\alpha}_{1}=055$ $(1.32)$ and $\hat{\alpha}_{2}=-.192 \quad(.84)$. The empirical results roughly confirm the appropriateness of the theoretical model. The conclusions with respect to the sign and size of the parameter estimates are similar to those drawn in section 4.2. From the estimate of the coefficient of the correction term we can derive an estimate of $T: 13.29$ (1.84).

All values of the test statistics reported in table 4.3" are insignificant. except the one for $\eta(4)$. Since the presence of heteroscedasticity of the ARCH type jeopardizes the consistency of the estimates of the t-ratios in $(4.20)^{\prime}$, we have to be careful in interpreting the estimation results in $(4.20)^{\prime}$ 
Appendix $4 C$ The Dayldson, Hendry, Srba and Yeo model (I)

In this append1x, we 11 show that if the change in income follows an aturegressive process of order 1 , the model presented in this chapter ylelds a relationship between income and consumption that is highly similar to the mechanism put fordard by Davidson et. al. (1978). We assume that

$\Delta y_{t}-\Delta y_{t-1}+\nu \nu_{t}$

For the sake of simplicity we omit the constant term, which does not change the conclusilons. The expression of interest is $(4,4)$. To calculate the relevant conditional expectations we can call on formula (4.8) with

$\psi_{1}=\varphi^{*}$ for all $\mathbb{1}$

It is however more convenfent to calculate the conditional expectations directly as follows

$y_{t+1}-E\left(y_{t+1} \mid I_{t}\right)=\Delta y_{t+1}-\varphi \varphi^{*} \Delta y_{t}$

$E\left(y_{t+1} \mid I_{t+1}\right)-E\left(y_{t+1} \mid \mathbb{I}_{t}\right)=\sum_{j=0}^{i-1} \varphi^{* j}\left[y_{t+1}-E\left(y_{t+1} \mid I_{t}\right)\right], i \geq 2$

$E\left(y_{t+T+1} \| I_{t}\right)=y_{t}+\sum_{j=1}^{T+1} \varphi^{m} \|_{t}$.

Substituting (C.1), (C.2) and (C.3) into expression (4.4) gives after some rearranging

$\Delta c_{t+1}-\alpha_{0}+\left(\alpha_{1}-\alpha_{2}\right) \Delta y_{t+1}+\alpha_{2} \Delta \Delta y_{t+1}+\alpha_{3}\left(y_{t}-c_{t}\right)$

with

$\alpha_{0}=\gamma^{-1} \ln (\theta(1+r)]\left[1-(\mathrm{T}+1) \eta_{\mathrm{T}}^{-1}(1+\mathrm{r})^{-\mathrm{T}}\right]$ 


$$
\begin{aligned}
& \alpha_{1}=\eta_{\mathrm{T}}^{-1} \sum_{i=0}^{\mathrm{T}}(1+\mathrm{r})^{-1} \sum_{j=0}^{\mathrm{i}} \varphi^{\mathrm{j}} \\
& \alpha_{2}=\eta_{\mathrm{T}}^{-1} \sum_{i=0}^{\mathrm{T}-1}(1+r)^{-1} \sum_{j=0}^{1} \varphi^{* j+1} \\
& \alpha_{3}=\eta_{\mathrm{T}}^{-1}(1+\mathrm{r})^{-\mathrm{T}}
\end{aligned}
$$

Expression (C.4) shows that for $\beta(1+r)=1$, we have the same mechanism as found in Davidson et. al. Using the analysis of section 3.1. 1t can be easily shown that for $\beta(1+\mathrm{r})=1$, the relationship (C.4) holds for any utility function $U$ satisfying $U^{\prime}>0$ and $U^{\prime \prime}<0$. Hence, the model with moving planning horizon is capable of reproducing the basic mechanism underlying the consumption function of Davidson et. al. irrespective of the chosen functional form of $U$. In each period consumers spend the same as they spent the period before, modified by a proportion of the change and the change of the change in income, and by the correction term. Matice that the relevant income concept in our model is real disposable labour income, whereas the income variable used by Davidson et. al. is real disposable income. With our economic model we can determine the sign and size of the coefficients. For $\alpha_{3}$ we find that it should be positive and smaller than 1. The sign and the size of both $\alpha_{1}-\alpha_{2}$ and $\alpha_{2}$ depend on the sign of $\varphi^{*}$. It is easy to show that if $0<\varphi^{*}<1$ we have $0<\alpha_{1}-\alpha_{2}<1$ and $\alpha_{2}<0$, and when $-1<\varphi^{*}<0: \quad 1<\alpha_{1}-\alpha_{2}$ and $\alpha_{2}<0$. In their emplrical analysis, Davidson et. al. have found a coefficient for the change in income between 0 and 1 and a negative coefflcient for the change of the change in income. Obviouslyt. their estimation results are at variance with the implications of the theoretical model analyzed in this chapter. 


\section{Chapter 5}

\section{IMPLATION EEFECTS}

In this chapter we will extend the model with moving planning horizon investigated in the previous chapeer for inflation effects and we will glve empirical evidence for the Netherlands. The chosen vehicle for incorporating inflation effects is similar to that put forward by Deaton (1977).

In the first section we will discuss the theoretical model. In line with Deaton (1977) we model the consumption decision as a two stage decision problem. In the first stage the consumer is assumed to solve an intertemporal optimization problem. The decision taken about real consumption determines together with the anticipated price level for the current period total antloipated expenditure. To describe the decision procedure in the first stage we adopt the model with moving planning horizon investigated in the previous chapter. Given total anticipated expenditure and anticipated prices of the individual goods, the consumer determines in the second stage the commodity demands. To model this decision we choose a linear expenditure system. When actual and anticipated prices deviate the actual and anticipated expenditure will not coincide. To determine the actual expenditure on a certain commodity, we assume in line with Deaton (1.977) that the consumer remains on the demand curve for that good implied by the model for the second stage of his decision problem. This assumption enables us to find actual total expenditure in the current period. Together with the result obtained for the first stage of the comsumption declsion we find the consumption function which depends among other things on future income expectations and anticipated prices. The resulting consumption function differs from Deaton's because the model used to describe the first stage of the decision procedure deviates from that chosen by Deaton.

We assume that the consumer has rational expectations about the future real 
income stream. Following Deaton (1977), it may be argued that the greater stablitty of real income changes compared with the nominal changes make them more easily predictable. The difficulties with predicting future real income seem to be most severe in times of high and changing inflation rates. Hence, we may expect problems when model11ng the 1970 's, However, during that period the wages and salaries in the Netherlands were automatically corrected for inflation effects. In the $1980^{\prime} \mathrm{s}$ this indexation system was no longer malntained, but the movements of the inflation rates during that period were much less turbulent. Therefore, it seems not unrealistic to assume that the consumers were able to assess future reail income.

To complete the model we postulate some mechanisms concerning the anticlpated prices. The framework does not preclude the incorporation of rational expectations with respect to anticipated prices. This will however complicate the estimation equation considerably. Since we want to establish a link with the specification put forward by Davidson, Hendry, Srba and Yeo (1978), we choose therefore a much simpler procedure for modelling the anticipated prices. More specifically, we assume that the anticipated price level for the current period equals the price level of the previous period. It will be argued that when the time span between two successive two stage decision problems is short enough, the mechanism may yield a satisfactory prediction. Notice that we preclude the possibllity that real income expectations are formed indirectly from expectations on money income and prices. Because of the assumption concerning anticipated prices, we must doubt in that case whether the consumer is able to make rational expectations of future real income.

With the assumptions about future real income expectations and anticlpated prices, we obtain a consumption function whlch is simllat to the one of Davidson et. al. (1978). As $\mathbb{1 n}$ thelr specification we have to include inflation, the change in inflation and the correction term as explanatory variables.

The empirical analysis carried out in the second section shows that the results for real total consumption are not unsatisfactory. Information in the data, however, does not suggest that the inflation effects are present. These results contrast those for real nondurable consumption. With this consumption measure, we find a signiflcant effect of inflation, but the 
milspecification analysis indicates that the model has to be rejected.

\subsection{Theory}

In this section we 111 describe the theoretical model and derive the consunption function. The procedure to trace the relationship between income, consurption and inflation is the same as used before, that is we solve the model for perlods $t$ and $t+1$ and subtract the resulting expressions for $c_{t}$ and $c_{t+1}$ in order to eliminate financial wealth. In IIne with Deaton (1977) we assume that at each period the consumer makes his decision in two parts. In the first stage he determines total expenditure In the current period by solving an intertemporal optimization problem and in the second stage the demands of the various comodities are determined. Since we study a model with incomplete price information, it becomes necessary im the sequel to distinguish actual and anticipated variables.

To describe the dectision taken in the first stage, we choose the spectfication put forward in chapter 4. More particularly, at each period $t$ the consumer is assumed to solve

$\operatorname{Max} \sum_{i=0}^{T} \beta^{i} U\left(c_{t+i}^{*}\right)$

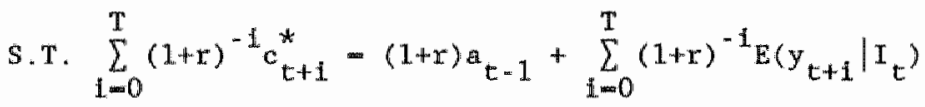

w th

$U(c)=-\gamma^{-1} \exp (-\gamma c), \gamma>0$

and anticlpated real consumption is denoted by $c_{t+i}^{*}$. The first order conditions implied by (5.1) yield

$c_{t+1}^{*}=c_{t}^{*}+i \gamma^{-1} \ln [\beta(1+\mathrm{r})], 1=1,2, \ldots, \mathrm{T}$ 
After substitution of (5.2) into the budget constralnt of (5.1), we get for $c_{t}^{*}$

$c_{t}^{*} \eta_{T}+\gamma^{-1} \ln [\beta(1+r)] \tau_{T}=(1+r) a_{t-1}+\sum_{i=0}^{T}(1+r)^{-1} E\left(y_{t+i} \mid I_{t}\right)$

where

$\eta_{k}=\sum_{i=0}^{k}(1+r)^{-i}$ and $r_{k}-\sum_{i=1}^{k} i(1+r)^{-i}$

Using the analysis of section 3.1 , it can easily be shown that for $\beta(1+x)=1$ (5.3) holds for any utility function $U$ satisfying $U^{\prime}>0$ and $U^{\prime}$ ' $<0$. Denoting the anticipated price level by $p_{t}^{*}$, it follows from (5.3) that anticipated total expenditure is given by

$\mathrm{p}_{\mathrm{t}}^{*} \mathrm{c}_{\mathrm{t}}^{*} \mathrm{\eta}_{\mathrm{T}}+\gamma^{-1} \ln [\beta(1+\mathrm{r})] \tau_{\mathrm{T}^{\mathrm{p}}}^{\mathrm{p}_{\mathrm{t}}^{*}}-(1+\mathrm{r}) \mathrm{a}_{\mathrm{t}-1} \mathrm{p}_{\mathrm{t}}^{*}+\sum_{\mathrm{i}=0}^{\mathrm{T}}(1+\mathrm{r})^{-\mathrm{i}} \mathrm{p}_{\mathrm{t}}^{*} \mathrm{E}\left(\mathrm{y}_{\mathrm{t}+\mathrm{i}} \mid \mathrm{I}_{\mathrm{t}}\right)$.

Given the total amount $p_{t}^{*} c_{t}^{*}$, the consumer determines in the second stage the purchases of individual goods. We assume that the preference ordering may be described by a stone-Geary utility function. The implied linear expenditure system will prove to be convenient. Formally, the consumer solves

$\max \prod_{k=1}^{n}\left(q_{k t}^{*}-\gamma_{k}\right)^{\beta_{k}}$

S.T. $\sum_{k=1}^{n} p_{k t}^{*} q_{k t}^{*}=c_{t}^{*} p_{t}^{*}$

with $\beta_{i} \in(0,1), i=1, \ldots, n, \sum_{i=1}^{n} \beta_{1}-1$ and $\gamma_{i}>0,1-1, \ldots, n$.

Anticipated acquisitions and prices of good $k$ are denoted by $q_{k t}^{*}$ and $p_{k}^{*}$ respectively, the parameters $\gamma_{\mathrm{k}}$ may be interpreted as "necessary" quantities and $\mathbf{n}$ is the number of goods. We assume that the purchases take place sequentially and rank the goods in the order of purchase. The utility maximization problem (5.5) leads to the wellknown linear: 
expendicure system

$p_{1 t}^{*} q_{1 t}^{*}-p_{1 t}^{*} \gamma_{1}+\beta_{1}\left(c_{t}^{*} p_{t}^{*}-\sum_{k=1}^{n} p_{k t}^{*} \gamma_{k}\right), i=1, \ldots, n$

and hence we have for the demand curves $f_{i}\left(p_{1}^{*}, \ldots, p_{n}^{*}, c_{t}^{*} p_{t}^{*}\right)$

$f_{1}\left(p_{1 t}^{*}, \ldots, p_{n t}^{*} c_{t}^{*} p_{t}^{*}\right)-\gamma_{1}+p_{i t}^{*-1} \beta_{i}\left(c_{t}^{*} p_{t}^{*}-\sum_{k=1}^{n} p_{k t}^{*} \gamma_{k}\right), i=1, \ldots, n$

At an instant in perlod $t$, assume the consumer is purchasing good 1 . On the basis of the anticipated prices $p_{t}^{*}$ and $p_{k t}^{*}, k=1, \ldots, n$, he plans to buy the quantity $q_{1 t}^{*}$. At the time of purchase, the actual price $p_{i t}$ is observed. The consumer has also knowledge of the actual prices pjt, $j=1, \ldots, 1-1$. In contrast to Deaton (1977) we assume that he incorporates this knowledge in his decision about $q_{t}$. When one of the actual values of $\mathrm{P}_{\mathfrak{j} t}, f_{m} 1, \ldots, \mathbb{1}$, differs from the anticlpated prices $\mathrm{p}_{j \mathrm{t}}^{*}, j=1, \ldots, 1$, the consumer will buy a quantity of good 1 that deviates from the anticipated value. In line with Deaton (1977) we assume that the consumer remains on his demand curve and hence $(5,6)$ determines the actual acquisition of good 1. say $\mathrm{q}_{1 \mathrm{t}}$

$q_{i t}=\gamma_{i}+p_{i t}^{-1} \beta_{i}\left(c_{t}^{*} p_{t}^{*}-\sum_{k=1}^{n} p_{k t}^{*} \gamma_{k}+\sum_{k=1}^{i}\left(p_{k t}^{*}-p_{k t}\right) \gamma_{k}\right)$

Thus we have for the actual expenditure on good 1

$p_{1 t} q_{1 t}=p_{1 t}^{*} q_{1 t}^{*}+x_{1}\left(1-\beta_{1}\right)\left(p_{1 t}-p_{1 t}^{*}\right)$

and

$p_{1, t} q_{1 t}=p_{i t}^{*} q_{i t}^{*}+\gamma_{1}\left(1-\beta_{i}\right)\left(p_{i t}-p_{i t}^{*}\right)+\beta_{i} \sum_{k=1}^{i-1}\left(p_{k t}^{*}-p_{k t}\right), i \geq 2$.

When we define actual total expenditure

$p_{t} c_{t}=\sum_{i=1}^{n} p_{1: t} q_{1:}$

we have from $(5.8)$ 
$p_{t} c_{t}=p_{t}^{*} c_{t}^{*}+\sum_{i=1}^{n} \gamma_{i}\left(1-\beta_{i}\right)\left(p_{i t}-p_{i t}^{*}\right)+\sum_{i=2}^{n} \beta_{i} \sum_{k=1}^{i-1}\left(p_{k t}^{*}-p_{k t}\right) \gamma_{k}$

It can easily be shown that $(5.6)$ and (5.7) imply

$\gamma_{i}\left(1-\beta_{i}\right)=q_{i t}\left(1+\frac{p_{i t}}{q_{i t}} \frac{\partial f_{i}}{\partial p_{i t}^{k}}\right)$

where $\partial f_{1} / \partial p_{1 t}^{*}$ is evaluated in $\left(p_{1 t}, \ldots, p_{1 t}, p_{i t+1}^{*}, \ldots, p_{n t}^{*}, c_{t}^{*} p_{t}^{*}\right)$.

Substitution of (5.10) into (5.9) yields

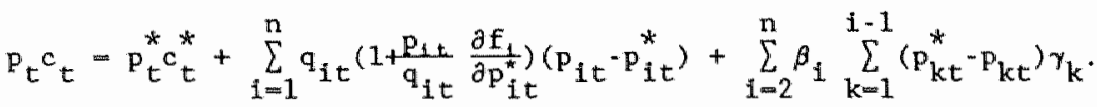

Expression (5.11) generalizes the result obtained by Deaton (eq.7). The difference concerns the last term of (5.11) which results from incorporating the information on the actual prices $p_{j t}, j=1, \ldots f-1$, in his decision about $q_{1 t}$. Instead of focussing on the saving ratio, we want to establish a link with the consumption function of chapter 4 . Therefore we substitute (5.9) into (5.4) and we get for total expenditure in period $t$

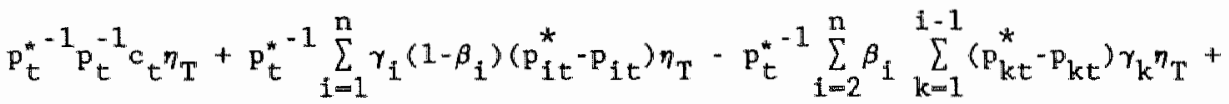

$$
\begin{aligned}
& \left.\gamma^{-1} \ln [\beta(1+r)] r_{T}=(I+r) a_{t-1}+\sum_{1 \rightarrow 0}^{T}(1+r)^{-i_{E}}{\left(y_{t+\mathbb{1}}\right.}_{t} \mid I_{t}\right)
\end{aligned}
$$

To investigate the dynamics in consumption, it is conventent to relate $c_{t}$ to $c_{t+1}$. Along the same Innes as before, we find for total consumption expenditure in the next period

$$
\begin{aligned}
& \mathrm{p}_{\mathrm{t}+1}^{*} \mathrm{p}_{\mathrm{t}+1} \mathrm{c}_{\mathrm{t}+1} \eta_{\mathrm{T}}+\mathrm{p}_{\mathrm{t}+1}^{*-1} \sum_{\mathrm{i}=1}^{\mathrm{n}} \gamma_{\mathrm{i}}\left(1-\beta_{1}\right)\left(\mathrm{p}_{\mathrm{it}+1}^{*}-\mathrm{p}_{1 \mathrm{t}+1}\right) \eta_{\mathrm{T}}+\gamma^{-1} \ln [\beta(1+\mathrm{r})] \tau_{\mathrm{T}} \\
& -p_{t+1}^{*}-1 \sum_{i=2}^{n} \beta_{i} \sum_{k=1}^{i-1}\left(p_{k t+1}^{*}-p_{k t+1}\right) \gamma_{k} \eta_{T}= \\
& (1+r) a_{t}+\sum_{i=0}^{T}(1+r)^{-i} E\left(y_{t+1+i} \mid I_{t+1}\right) .
\end{aligned}
$$


In 1ine wh the analysis of Deaton (1977), we assume that the difference between actual and anticipated expenditure w11 be (dis)saved. With the assumption of a constant real interest rate we have therefore $a_{t}=(1+r) a_{t-1}+y_{t}-c_{t}$. Dividing $(5.13)$ by $1+r$, substituting $a_{t}=(1+r) a_{t-1}+y_{t}-c_{t}$ and subtracting $(5,12)$ leads to

$$
\begin{aligned}
& \mathrm{p}_{\mathrm{t}+1}^{*-1} \mathrm{p}_{\mathrm{t}+1} c_{\mathrm{t}+1}(1+\mathrm{r})^{-1} \eta_{\mathrm{T}}-\mathrm{p}_{\mathrm{t}}^{*-1} \mathrm{p}_{\mathrm{t}} c_{\mathrm{t}} \eta_{\mathrm{T}+1}=\gamma^{-1} \ln \left[\beta(1+\mathrm{r}) \rrbracket \eta_{\mathrm{T}}(1+\mathrm{r})^{-1}\right. \\
& -c_{t}+\sum_{i=1}^{T+1}(1+r)^{-1}\left(E\left(y_{t+1} \mid I_{t+1}\right)-E\left(y_{t+1} \mid I_{t}\right)\right) \\
& -\mathrm{p}_{\mathrm{t}+1}^{*-1}(1+r)^{-1} \eta_{\mathrm{T}} \sum_{1=1}^{\mathrm{n}} \gamma_{1}\left(1-\beta_{1}\right)\left(\mathrm{p}_{\mathrm{it}+1}^{*}-\mathrm{p}_{1 \mathrm{t}+1}\right) \\
& +\mathrm{P}_{t+1}^{*-1}(1+\mathrm{r})^{-1} \eta_{\mathrm{T}} \sum_{1=2}^{\mathrm{n}} \beta_{i} \sum_{k=1}^{1-1}\left(\mathrm{p}_{k t+1}^{*}-\mathrm{p}_{k t+1}\right) \gamma_{k} \\
& +\mathrm{p}_{t}^{*-1} \eta_{\mathrm{T}} \sum_{1=1}^{\mathrm{n}} \gamma_{1}\left(1-\beta_{1}\right)\left(\mathrm{p}_{1 \mathrm{t}}^{*}-\mathrm{p}_{1 \mathrm{t}}\right)-\mathrm{p}_{\mathrm{t}}^{*-1} \eta_{\mathrm{T}} \sum_{i=2}^{\mathrm{n}} \beta_{1} \sum_{\mathrm{k}=1}^{1-1}\left(\mathrm{p}_{\mathrm{kt}}^{*} \mathrm{p}_{\mathrm{kt}}\right) \gamma_{\mathrm{k}} \\
& +(1+r)^{-(T+1)}\left(\mathrm{E}\left(y_{t+T+1} \mid \mathbb{I}_{\mathbb{T}}\right)-\mathrm{p}_{t}^{*} \mathrm{p}_{t} c_{t}-(\mathrm{T}+1) \gamma^{-1} \ln [\beta(1+r)]\right) .
\end{aligned}
$$

Notice that the mistakes made in the previous period will influence the consumption level in the current period. This can easily be seen, when we reformulate $(5.14)$ in terms of anticlpated consumption $c_{t+1}^{*}$ and $c_{t}^{*}$. Substituting (5.9) and the simllar expression for $c_{t+1}^{*} p_{t+1}^{*}$ into (5.14) ylelds after some rearranging

$$
\begin{aligned}
& c_{\mathrm{t}+1}^{*}{ }^{-c_{\mathrm{t}}^{*}}-\gamma^{-1} \ln [\beta(1+\mathrm{r})]\left(1-\eta_{\mathrm{T}}^{-1}(1+\mathrm{r})^{-\mathrm{T}}(\mathrm{T}+1)\right) \\
& +\eta_{\mathrm{T}}^{-1} \sum_{1=0}^{\mathrm{T}}(1+\mathrm{r})^{-1}\left(\mathrm{E}_{\mathrm{T}}\left(\mathrm{y}_{\mathrm{t}+\mathrm{i}+1} \mid \mathrm{I}_{\mathrm{t}+1}\right)-\mathrm{E}\left(\mathrm{y}_{\mathrm{t}+\mathrm{i}+1} \mid \mathrm{I}_{\mathrm{t}}\right)\right) \\
& +\eta_{\mathrm{T}}^{-1}(1+\mathrm{r})^{-\mathrm{T}}\left(\mathbb{E}\left(\mathrm{y}_{\mathrm{t}+\mathrm{T}+1} \mid \mathrm{I}_{\mathrm{t}}\right)-\mathrm{c}_{\mathrm{t}}^{*}\right)+\eta_{\mathrm{T}}^{-1}(1+\mathrm{r})\left(c_{\mathrm{t}}^{*}-\mathrm{c}_{\mathrm{t}}\right) .
\end{aligned}
$$

The last term expresses the influence of the mistakes in period $t$ induced by the wrong assessment of the price level, on the decision with respect to anticipated consumption in period $t+1$. Because of the assumption that the 
difference between anticipated and actual consumption expenditure will be (dis)saved, the error in period $t$ will only affect the decision in the next period. Obviously, when anticipated and actual prices colncide, expression (5.15) passes into the consumption function (4.4) put forward in chapter 4. In order to complete the model, we must specify mechanisms linking anticipated prices to actual values. The assumption of rational expectations about anticipated prices may be incorporated by substituting $p_{t}-p_{t}^{*}=\zeta_{t}, \quad E\left(\zeta_{t} \mid I_{t-1}\right)=0$ into (5.14). The resulting estimation equation wi11. however be rather complicated and display an intricate form of heteroscedasticity. An alternative is to specify a model for the prices, and next calculate the one step ahead prediction. This procedure will lead to a nonlinear (in the variables) specification and will make the comparison with the consumption function of Davidson et. A1. (1978) intransparent. Therefore, we look for a simple but not inrealistic alternative. Since we want to concentrate on general inflation effects, it becomes necessary to make assumptions concerning the price changes of the individual goods. The most simple way is to postulate

ASSUMPTION 1: $\pi_{1}^{*}=\pi_{t}^{*}, \pi_{1 t}=\pi_{t}, 1=1, \ldots, n$ for a11 $t$

where $\pi_{i t}^{*}=\left(p_{i t}^{*}-p_{1 t-1}\right) / p_{1 t-1}$ and $\pi_{1 t}-\left(p_{1 t}-p_{1 t-1}\right) / p_{\| t-1}$ denote the anticipated and actual relative price change of good 1 respectively and $\pi_{t}^{*}$ and $\pi_{t}$ are defined in a similar way. Following Deaton (1977), assumption 1 may be rationalized by the argument that the dominant effect of the (anticipated) relative price change is ascribed to general (anticlpated) inflation. Finally, we must specify a model for anticipated inflation $\pi_{t}^{\prime \prime}$. In contrast to Deaton (1977), who assumes that $\pi_{\mathrm{t}}^{*}$ is an arbitrary comstant, we postulate

ASSUMPTION 2: $\pi_{t}^{*} 0$ for all $t$.

Clearly, (5.17) is the simplest possible assumption about $\pi_{t}^{*}$. The plausibility of assumption 2 depends crucially on the time span between two successive two stage decision problems. When it is short enough (e.g. a week), the resulting errors will be small. This argument becomes stronger when we notice that price changes of the individual goods take place 
discontinuously and uswally unexpectedy. of course over longer periods the curiulated exrors may become large, but the natural way to remedy the wrong assessments is to extend the Intertemporal decision problem for inflation effects. This is an alternative way to incorporate inflation effects. We refrain from this possiblity and use the intertemporal model (5.1) to describe the decistor for the first stage. A nice feature of assumption 2 is that 1 simplifles expression (5.14) considerably. From (5.1.7) we have

$p_{t}^{-1} p_{t}-\left(1+\pi_{t}\right)$ for all $t$

and $1 t$ can be shown that $(5.16)$ and $(5.17)$ imply

$p_{t}^{*-1} \sum_{i=1}^{n} \gamma_{i}\left(1-\beta_{1}\right)\left(p_{i, t}^{*}-p_{i, t}\right)--\pi \sum_{t=1}^{n} \gamma_{i}\left(\mathbb{1}-\beta_{i}\right) \xi_{1}$ for all $t$

and

$\mathrm{p}_{t}^{*} \sum_{1=2}^{\mathrm{n}} \beta_{1} \sum_{k=1}^{i-1}\left(\mathrm{p}_{k t}^{*}-\mathrm{p}_{k t}\right) \gamma_{k}--\pi \sum_{i=2}^{n} \beta_{1} \sum_{k=1}^{i-1} \xi_{k} \gamma_{k}$ for all $t$.

where $\xi_{i} p_{i t} / p_{t}$, which is time independent because of assumption 1 .

Substituting (5.18), (5.19) and (5.20) into (5.14) leads after some rearranging to

$$
\begin{aligned}
& \Delta c_{t+1}=-\pi_{t+1} c_{t+1}+(1+r) \pi_{t} c_{t}+\gamma^{-1} \ln [\beta(1+r)]\left(1-\eta_{T}^{-1}(1+r)^{-T}(T+1)\right) \\
& -1 \lambda \pi_{t+1}+(1+r) \lambda \Delta \pi_{t+1}+\eta_{T}^{-1}(1+r)^{-T}\left(E\left(y_{t+T+1} \mid I_{t}\right)-c_{t}\right) \\
& +m_{T}^{-1} \sum_{1=0}^{T}(1+x)^{-1}\left(E\left(y_{t+1+1} \mid I_{t+1}\right)-E\left(y_{t+1+1} \mid I_{t}\right)\right)
\end{aligned}
$$

where

$$
\lambda=\sum_{i=1}^{n} \gamma_{i}\left(1-\beta_{i}\right) \xi_{i}-\sum_{i=2}^{n} \beta_{i} \sum_{k=1}^{i-1} \xi_{k} \gamma_{k}=\sum_{i=2}^{n} \gamma_{i} \xi_{i} \sum_{k=1}^{i-1} \beta_{k} .
$$

Expression (5.21) shows that we have a consumption function that is 
similar to the one put forward in chapter 4. In particular, we have the error correction term $E\left(y_{t+r+1} \mid I_{t}\right)-c_{t}$. Its presence arises from the adjustment of the planning horizon as time goes on. The inflation variables are included as a result of the wrong assessments of the anticipated prices. An important difference between our analysis and that of Deaton (1977) is that we make the assumption of rational expectations with respect to real incone, whereas he postulates a deterministic adjustment mechanism which does not necessarily correspond to the one of a rational expectations formulation. This approach is very similar to the feedback control rules discussed by for instance Davidson and Hendry (1981). It is interesting, however, to investigate such a feedback rule. When we assume that the generating mechanism of the conditional expectations corresponds to the one when the change in income follows an autoregressive (AR) process of order 1 , (5.21) implies a relationshtp between consumption, income and inflation which is similat to the consumption function put forward by Davidson et. al. (1978). Let us as sume

$\Delta y_{t}=\varphi y_{t-1}+\nu_{t}$

For the sake of simplicity we omit the constant term, which does not change the conclusions. It is straightforward to calculate from (5.22) the relevant conditional expectations of (5.21), which read like

$y_{t+1}-E\left(y_{t+1} \mid I_{t}\right)=\Delta y_{t+1}-\Delta \Delta y_{t}$

$E\left(y_{t+1} \mid I_{t+1}\right)-E\left(y_{t+i} \mid I_{t}\right)=\sum_{j=0}^{i-1} \varphi^{j}\left(y_{t+1}-E\left(y_{t+1} \mid I_{t}\right)\right), \mathbb{1}=2, \ldots, T+1$

$\mathbb{E}\left(y_{t+T+1} \| I_{t}\right)=y_{t} \sum_{j=1}^{T+1} \varphi^{j} \Delta y_{t}$.

Substituting $(5.23),(5.24)$ and $(5.25)$ into $(5.21)$ gives after some rearranging 


$$
\begin{aligned}
& \Delta c_{t+1}=\alpha_{0}-\pi_{t+1} c_{t+1}+(1+r) \pi_{t} c_{t}+\alpha_{1} \pi_{t+1}+\alpha_{2} \Delta \pi \\
& t+1+ \\
&+\left(\alpha_{3}-\alpha_{4}\right) \Delta y_{t+1}+\alpha_{4} \Delta \Delta y_{t+1}+\alpha_{5}\left(y_{t}-c_{t}\right)
\end{aligned}
$$

$$
\begin{aligned}
& \text { with } \alpha_{0}=\gamma^{-1} \ln [\beta(1+\mathrm{r})]\left(1-\eta_{\mathrm{T}}^{-1}(1+\mathrm{r})^{-\mathrm{T}}(\mathrm{T}+1)\right) \\
& \alpha_{1}=-\mathrm{r \lambda} \\
& \alpha_{2}=(1+\mathrm{r}) \lambda \\
& \alpha_{3}=\eta_{\mathrm{T}^{r}}^{-1} \sum_{1=0}^{\mathrm{T}}(1+\mathrm{r})^{-1} \sum_{j=0}^{1} \varphi^{j} \\
& \alpha_{4}=\eta_{\mathrm{T}}^{-1} \sum_{\mathrm{i}=0}^{\mathrm{T}=1}(1+\mathrm{r})^{-1} \sum_{j=0}^{1} \varphi^{j+1}
\end{aligned}
$$

and $\alpha_{5}=\eta_{\mathrm{T}}^{-1}(1+r)^{-\mathrm{T}}$.

Expression (5.26) shows that apart from the cerm $-\pi_{t+1} c_{t+1}+(1+r) \pi_{t} c_{t}$, we have a similar mechanism as found in Davidson et. al. (1978). In each period the consumer spends the same as he spent the previous period, modified by proportion of the inflation and the change in income, and by whether the change in those variables is itself increasing or decreasing, and by the error correction term. As argued in chapter 4 we prefer to label it as a correction term. Notice that the relevant income concept in our model is real disposable labour income, whereas the income variable used by Davidson et. a1. is real disposable income. With our theoretical model we can determine the $\mathbf{s i g n}$ and the size of the coefficients. For $\alpha_{5}$ we find that it should be positive and smaller than 1 . For $\alpha_{1}$ and $\alpha_{2}$ we infer a negative and a positive sign respectively. The sign and the size of both $\alpha_{3}-\alpha_{4}$ and $\alpha_{4}$ depend on the sign of $\varphi$. It is easy to show that If $0<\varphi<1$ we have $0<\alpha_{3}-\alpha_{4}<1$ and $\alpha_{4}>0$, and when $-1<\varphi<0$ we have $\alpha_{3}-\alpha_{4}>1$ and $\alpha_{4}<0$. In their empirical analysis, Davidson et, al. (1978) found a coefflcient for the change in income between 0 and 1 , and negative coefficients for 
inflation, for the change in inflation and for the change in the change in income. Obviously, their empirical findings are at variance with the implications of our theoretical model.

Since we want to establish a link with the model. Investigated in the previous chapter we make the assumption of rational expectations with respect to real income. Therefore, before we can estimate and test the consumption function (5.21), it becomes necessary to investigate the income series. An empirical analysis of the model with moving planning horizon extended for inflation effects will be carried out in the next section.

\subsection{Empirical results}

In this section our concerns will be to test the limplications of the theoretical model described in the previous section using quarterly seasonally adjusted data for the Netherlands. The data on real per capita disposable labour and transfer income and on real consumption per capta are the same as those used in chapters 2 and 4. The inflation series has been constructed from the data on the price index of total consumption and is given in Appendix. I. In the main text we report the results obtained for total consumption and the empirical results for nondurable consumption are given in Appendix 5A.

The income series is investigated in section 2.2.1. The specified income process enables us to calculate the relevant conditional expectations of (5.21). Moreover, the analysis of the income series may yield information on possible structural changes in the income process. Notice that the postulate of incomplete price information does not preclucle the possibility of rational expectations with respect to anticipated prices. We assume however that the model for the anticipated prices chosen in section 5.1 is valid during the whole sample perlod.

We start the analysis by deriving the estimation equation for the model discussed in the previous section. The procedure is the same as used in section 4.2.2. In the first instance we ignore the implications of the structural changes in the drift parameter of the income process. When the change in income is generated by a mowing average process of order 1 
$\Delta y_{t}=\delta+\nu t-\theta \nu_{t-1}$

the relevant conditional expectations of $(5.21)$ satisfy

$y_{t+1}-\mathbb{E}\left(y_{t+1} \mid I_{t}\right)=\nu_{t+1}$

$E\left(y_{t+1} \mid I_{t+1}\right)-E\left(y_{t+1} \mid I_{t}\right)=(1-\theta) \nu_{t+1}, 1 \geq 2$

$E\left(y_{t+T+1} \mid I_{t}\right)=y_{t}+(T+1) \delta=\theta \nu{ }_{t}$

Substituting $(5.27),(5.28)$ and $(5.29)$ into $(5.21)$ yields

$$
\begin{aligned}
& \Delta c_{t+1}+\pi_{\mathrm{t}+1} c_{\mathrm{t}+1}-(1+\mathrm{r}) \pi_{\mathrm{t}} c_{\mathrm{t}}+\gamma^{-1} \mathbb{1}[\beta(1+\mathrm{r})]\left(1-\eta_{\mathrm{T}}^{-1}(1+\mathrm{r})^{-\mathrm{T}}(\mathrm{T}+1)\right)-\mathrm{r} \lambda \pi_{\mathrm{t}+1}+ \\
& (1+\mathrm{r}) \lambda \Delta \pi_{\mathrm{t}+1}+\eta_{\mathrm{T}}^{-1}(1+\mathrm{r})^{-\mathrm{T}}\left[\delta(\mathrm{T}+1)+\mathrm{y}_{\mathrm{t}}=\mathrm{c}_{\mathrm{t}}\right]-\eta_{\mathrm{T}}^{-1}(1+\mathrm{r})^{-\mathrm{T}} \theta \nu_{\mathrm{t}}+\eta_{\mathrm{T}}^{-1}\left[(1-\theta) \eta_{\mathrm{T}}+\theta\right] \nu_{\mathrm{t}+1}
\end{aligned}
$$

The last term of $(5.30)$ can be expressed as

$$
\begin{aligned}
& \eta_{\mathrm{T}}^{-1}\left[(1-\theta) \eta_{\mathrm{T}}+\theta\right] \nu_{\mathrm{t}+1}=\eta_{\mathrm{T}}^{-1} \eta_{\mathrm{T}-1}\left[1-\theta(1+\mathrm{r})^{-1}\right] \nu_{\mathrm{T}+1}+ \\
& \eta_{\mathrm{T}}^{-1}(1+\mathrm{r})^{-\mathrm{T}}\left[\Delta y_{\mathrm{t}+1}{ }^{-\delta]}+\eta_{\mathrm{T}}^{-1}(1+\mathrm{r})^{-\mathrm{T}_{\theta \nu}}\right.
\end{aligned}
$$

and after substitution of $(5.31)$ into (5.30) we get

$$
\begin{gathered}
\Delta \mathrm{c}_{\mathrm{t}+1}+\pi_{\mathrm{t}+1} \mathrm{c}_{\mathrm{t}+1}-(1+\mathrm{r}) \pi_{\mathrm{t}} \mathrm{c}_{\mathrm{t}}+\gamma^{-1} \ln [\beta(1+\mathrm{r})]\left(1-\eta_{\mathrm{T}}^{-1}(1+\mathrm{r})^{-\mathrm{T}}(\mathrm{T}+1)\right)-\mathrm{r} \lambda \pi_{\mathrm{t}+1}+ \\
(1+\mathrm{r}) \lambda \Delta \pi_{\mathrm{t}+1}+\eta_{\mathrm{T}}^{-1}(1+\mathrm{r})^{-\mathrm{T}_{\mathrm{T}}}+\eta_{\mathrm{T}}^{-1}(1+\mathrm{r})^{-\mathrm{T}} \Delta \mathrm{y}_{\mathrm{t}+1}+ \\
\eta_{\mathrm{T}}^{-1}(1+\mathrm{r})^{-\mathrm{T}}\left(\mathrm{y}_{\mathrm{t}}-\mathrm{c}_{\mathrm{t}}\right)+\eta_{\mathrm{T}}^{-1} \eta_{\mathrm{T}-1}\left[1-\theta(1+\mathrm{r})^{-1}\right] \nu_{\mathrm{t}+1} .
\end{gathered}
$$

Under the assumption that the changes in the drift parameter of the income process were not anticipated, the model for consumption (5.32) needs 
revision. Let us assume that the constant term $\delta$ moves to $\delta^{*}$ " Using the closed form solutions for $c_{t}$ and $c_{t+1}$ derived in section 5.1 , 1 t can be shown along the same lines as in chapter 2 that the structural change in the income process will give rise to a step change in the consunption model (5.3.2) equal to $\left.\left(\delta^{*}-\delta\right) \eta_{\mathrm{T}}^{-1} \llbracket(1+\mathrm{r}) r_{\mathrm{T}+1}-(1+\mathrm{r})^{-\mathrm{T}}\right]$. Therefore, both $\operatorname{In} 1971(1)$ and $1979(1)$ we should expect a negative adjustment in the drift parameter of the consumption model (5.32). Moreover, because the constant term in (5.32) depends on $\delta$, we have also a persistent change of the constant term of the consumption function. This completes the derivation of the estimation equation. In conclusion, we have

$\Delta c_{t}+\pi_{t} c_{t}=\sum_{i=1}^{5} \beta_{1} d_{i t}+\alpha_{1} \pi_{t-1} c_{t-1}+\alpha_{2} \pi_{t}+\alpha_{3} \Delta \pi_{t}+\alpha_{4} \Delta y_{t}+\alpha_{5}\left(y_{t-1}-c_{t-1}\right)+\varepsilon_{t}$

with $d_{1 t}=1$ for $1968(2)-1971(1)$

$$
\begin{aligned}
& d_{2 t}=1 \text { for } 1971(1) \\
& d_{3 t}=1 \text { for } 1971(2)-1979(1) \\
& d_{4 t}=1 \text { for } 1979(1) \\
& d_{5 t}=1 \text { for } 1979(2)-1984(4) .
\end{aligned}
$$

The coefficients $\alpha_{1}$ given in expression (5.32) and for the $\beta_{1}$ 's we have

$$
\begin{aligned}
& \beta_{1}=\gamma^{-1} \ln [\beta(1+\mathrm{r})]\left(1-\eta_{\mathrm{T}}^{-1}(1+\mathrm{r})^{-\mathrm{T}}(\mathrm{T}+1)\right)+\eta_{\mathrm{T}}^{-1}(1+\mathrm{r})^{-\mathrm{T}} \mathrm{T} \delta_{1} \\
& \beta_{2}=\left(\delta_{2}{ }^{-\delta_{1}}\right) \eta_{\mathrm{T}}^{-1}\left[(1+\mathrm{r}) r_{\mathrm{T}+1^{-(1+r)}}{ }^{-\mathrm{T}}\right] \\
& \beta_{3}=\gamma^{-1} \ln [\beta(1+\mathrm{r})]\left(1-\eta_{\mathrm{T}}^{-1}(1+\mathrm{r})^{-\mathrm{T}}(\mathrm{T}+1)\right)+\eta_{\mathrm{T}}^{-1}(1+\mathrm{r})^{-\mathrm{T}_{\mathrm{T}}} \delta_{2} \\
& \beta_{4}=\left(\delta_{3}-\delta_{2}\right) \eta_{\mathrm{T}}^{-1}\left[(1+\mathrm{r}) \mathrm{T}_{\mathrm{T}+1}-(1+\mathrm{r})^{-\mathrm{T}}\right] \\
& \beta_{5}=\gamma^{-1} \ln [\beta(1+\mathrm{r})]\left(1-\eta_{\mathrm{T}}^{-1}(1+\mathrm{r})^{-\mathrm{T}}(\mathrm{T}+1)\right)+\eta_{\mathrm{T}}^{-1}(1+\mathrm{r})^{-\mathrm{T}} \mathrm{T} \delta_{3}
\end{aligned}
$$

with $\delta_{i}$ being the coefficient of $d_{i t}$ in the model (2.14) for income. The resulting consumption function is similar to the specification put forward by Hendry (1983), except for $\Delta \pi_{t+1}$. Since the explanatory variables are correlated with the disturbance term $\varepsilon_{t}$, the model (5.33) has been 
estimated by instrumental variables (IV). We impose the restriction $\alpha_{4}=\alpha_{5}$ and use the flve dumy variables, $\pi_{t-1} c_{t-1}, \pi_{t-1}, \Delta \pi_{t-1}, \Delta y_{t-1}$ and $y_{t-1}-$ $c_{t-1}$ as instruments. For total consumption, the following estimates have been obtalned

$\begin{array}{lrl}\beta_{1} & 93.87(2.60) \\ \beta_{2} & -31.50(.67) \\ \beta_{3} & 87.18(2.16) \\ \beta_{4} & -33.26(.75) \\ \beta_{5} & 83.51(1.95) \\ \alpha_{1} & -.68(.49) \\ \alpha_{2} & .76(.18) \\ \alpha_{3} & -3.45(.71) \\ \alpha_{4} & .57(2.49) \\ \sigma^{2}\left(c_{t_{t}}\right) & 1348.3\end{array}$

with t-values glven between parentheses. Some test statistics for model (5.33) are given in Table 5.1. The residuals do not exhibit any significant correlation. The values of the BP and LB test statistic based on the first $4,8,12$ and 16 residual autocorrelations are insignificant. In chapter 2 we found that normallty and homoscedasticity for $\Delta y_{t}$ do not have to be rejected. Given that income is normally distributed and homoscedastic, the theory predicts that the disturbance term $\varepsilon_{t}$ should follow a normally distributed and homoscedastic process. In Tabje 5.1 we repote the test statsics for the ARCH structure and rormality of $c_{4}$ respectively, both tests are insigniflcant, so we conclude that in this respect the emplicical resure are in accordance wh the theory.

Since the correlation betwen the explantory variables and the disturbatee

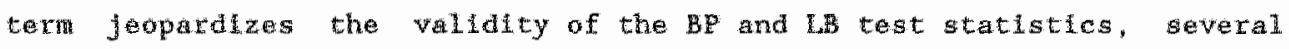
tests put forward by kivlet (1985) in the context of wnstrumental variabies wstmation have been carrued out. We adopt his notation. The statistic PFCF tests for postsanple predictive fallure. It is based on predictions for the period 1983(1)-1984(4). Under the null hypothesis, it has an F(8,49)-distrbution. SCE(p) and Sw(p) are W-and Wald-type statstics which test for an $A R(p)$ process for the residuals. They are asymptotically $x^{2}(p)$ distrbuted under the null hypothesis that the disturbances are white 
noise. We have also computed their F-type versions, denoted by SCEF and SCWF with the number of degrees of freedom reported between brackets. As

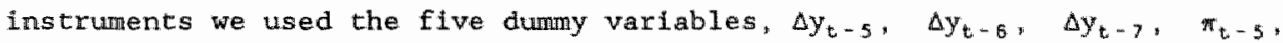
$\pi_{t-6}, \pi_{\mathrm{t}-7}, \Delta \mathrm{c}_{\mathrm{t}-5}$ and $\Delta \mathrm{c}_{\mathrm{t}-6}$.

Finally, the model (5.33) has been estimated without the restriction $\alpha_{4}=\alpha_{5}$. The point estimates are $\hat{\alpha}_{4}=-.11(.22)$ and $\hat{\alpha}_{5}=.56(2.33)$. Several test statistics for the equality between the regression coefflctents have been computed. CRW(1) and CRLM(1) refer to the Wald and LM-type test statistics, which are asymptatically $\chi^{2}(1)$ distributed, In Table 5.1 we mention also their F-type versions. All statistics yleld insignificant

Table 5.1 Test statistics for model (5.33)

\begin{tabular}{|c|c|c|c|c|}
\hline $\mathrm{p}$ & $\mathrm{BP}$ & LB & & \\
\hline 4 & .88 & .92 & & \\
\hline 8 & 10.62 & 11.10 & & \\
\hline 12 & 14.19 & 14.85 & & \\
\hline 16 & 23.10 & 24.17 & & \\
\hline$\eta(1)$ & 1.16 & & & \\
\hline$n(4)$ & 3.34 & & & \\
\hline $\mathrm{s}_{1}$ & -.48 & & & \\
\hline $\mathrm{s}_{2}$ & .29 & & & \\
\hline $\operatorname{PFCF}(8,49)$ & .094 & & & \\
\hline $\operatorname{SCE}(1)$ & .26 & & $\operatorname{SCE}(4)$ & 1.59 \\
\hline $\operatorname{SCEF}(1,50)$ & .21 & & $\operatorname{SCEF}(4,47)$ & .32 \\
\hline $\operatorname{SCW}(1)$ & .12 & & $\operatorname{sct}(4)$ & .08 \\
\hline $\operatorname{SCWF}(1,50)$ & .17 & & $\operatorname{SCWE}(4,47)$ & .02 \\
\hline $\mathrm{CRW}(1)$ & 2.95 & & & \\
\hline $\operatorname{CRWF}(1,56)$ & 2.50 & & & \\
\hline $\operatorname{CRLM}(1)$ & 3.22 & & & \\
\hline $\operatorname{CRLMF}(1,56)$ & 2.87 & & & \\
\hline
\end{tabular}


values for the one-sided tests and we conclude that the distributional and scrial correlation properties of the IV residuals and the predictive performance of the model (5.33) are very satisfactory.

Mext we consider the point estimates. From expression (5.32) we deduce for the disturbance term $\varepsilon_{t}$

$c_{t}=\eta_{\mathrm{T}}^{-1} \eta_{\mathrm{T}-1}\left[1-\theta(1+\mathrm{r})^{-1}\right]_{\mathrm{t}+1}$.

As $0=.428$, we have as an implication of the theoretical model that the varlance of $\varepsilon_{t} 1$ s smaller than that of the income innovation. A comparison of the values reported in (2.14) and (5.34) shows that the estimates do not confirm the theory on this point. From (5.32) and (5.33) it follows that the sign of $\beta_{1}, \quad \beta_{3}$ and $\beta_{5}$ depends on that of $\gamma^{-1} \ln [\beta(1+r)]\left(1-\eta_{T}^{-1}(1+r)^{-T}(T+1)\right)$. However, with the point estimates of the $\delta_{1}$ 's in (2.14) the following inequality has to hold: $\beta_{5}<\beta_{3}<\beta_{1}$. This restriction is indeed satisfied by the point estimates of $(5.34)$. For the appralsal of the step changes we have to keep in mind that $d_{2 t}$ and $d_{4 t}$ absorb the joint effect of the adjustment in the consumption level and the transformed income innovation. From (2.14) we have an estimate of the income innovation and the MA parameter. With this knowledge we can show that the coefficient of $d_{2 t}$ should be negative. This requirement is satisfied. Because the expected step change in the constant term and the astimate of the income inrovation in 1979(1) have opposite signs, we can not determine a priori the sign of $\beta_{4}$. From (5.32) we Infer that $\alpha_{1}$ should siatisfy $1<\alpha_{1}<2$, an Implication that 1 s not satisfied. The $t$-value for the hypothes $1 \mathrm{H} H_{0}: \alpha_{1}=1$ is 1.21 , which $1 \mathrm{~s}$ insigniflcant. The coefficients $\alpha_{2}$ and $\alpha_{3}$ ought to be negative and posteive respectively. This criterion is vilolated by the point estinates in (5.34). Notice however that the estimates are highly insignificant. Finally, the criterion that the coefficlent for the correction term should be positive and smaller than 1 is met. From the estimate of $\alpha_{4}$ we may infer an estimate of $T$. Noting that

$\alpha_{4}=\eta_{\mathrm{T}}^{-1}(1+\mathrm{r})^{-\mathrm{T}}=\mathrm{r}\left[(1+\mathrm{r})^{(\mathrm{T}+1)}-1\right]^{-1}$

it can be easily shown that $T \approx \alpha_{4}^{-1}-1$. Using $(5,34)$ we find for $T$ the 
estimate $.75(2.49)$. This estimate is somewhat smaller than that found in the previous chapter. Notice that the estimate is significantly different from zero, so that we have an empirical confirmation that the consumer displays forward looking behaviour.

From the empirical analysis we conclude that the model describes the data not unsatisfactorily. The values of the diagnostic test statistics do not suggest the presence of misspecification. Notice that we do not find a significant effect for inflation and the change in inflation. The wrong signs of the estimates of the coefficients of the inflation variables leads to the conclusion that the information in the data does not unequivocally confirm the theoretical model.

From the empirical results for real nondurable consumption per capita reported in appendix $5 \mathrm{~A}$, we infer that the model is misspecifled. The test for the equality of the coefficients of the change in income and the correction term is (marginally) significant. More important however, is that the estimates of the coefficlents of the inflation variables have the wrong sign and, in contrast to the results obtained for total consumption, are significant. Since we used the data on the price index of total consumption, a possible explanation might be the inappropriateness of the inflation series. Another explanation may be the fact that we estlmated the model with quarterly data. Possibly, the length of the time span between two successive two stage decision problems invalidates the assumption that the anticipated inflation equals zexo. A solution might be the incorporation of time aggregation effects (see e.g. Muellbauer (1986)). We showed how the assumption of rational expectations with respect to anticipated prices may be incorporated in the model. For the functional forms of the preference structure chosen in this chapter, this will lead to a rather complifated estimation equation. Since we wated to relate our specification to the consumption function put forward by Davidson et. a1. (1978), we refrained from this possibility. It seems however not superfluous to investigate more realistic mechanlsms for the anticipated prices.

Possible extensions axe dropplang the assumption of a constant real interest rate and, possibly along the lines of Hendry and Von Ungern-Sternberg (1981) and Pesaran and Evans (1984), taking into account the effects of inflation induced capital losses. Another extension deals with relaxing 
the assumption of an intertemporally additive utility function. The results of chapters 2 to 5 are obtained under a specific assumption concerning the preference structure. In the next chapter we will consider alternative speciflcations. More particularly, we w11 investigate the Iffe cycle model and the model with moving planning horizon under rational habit formation and we wl1 look whether the results obtalned in the prevlous chapters can be generalized. 
Appendix 5A Empirical results for real nondurable consumption per capita

In this appendix we present estimation results for real nondurable consumption per capita. The numbers of the expressions and the table correspond to those used in the main text. A prime refers to nondurable consumption. With respect to the evaluation of the sign and size of the parameter estimates we refer to the discussion of section 5.2 .

$\begin{array}{lrr}\beta_{1} & -160.39 & (3.55) \\ \beta_{2} & -51.09 & (2.06) \\ \beta_{3} & -192.49 & (3.86) \\ \beta_{4} & -13.98 & (.53) \\ \beta_{5} & -168.95 & (4.12) \\ \alpha_{1} & -6.45 & (3.29) \\ \alpha_{2} & 16.20 & (3.88) \\ \alpha_{3} & -16.59 & (3.32) \\ \alpha_{4} & .29 & (4.13) \\ \sigma^{2}\left(\varepsilon_{t}\right) & 516.8 & \end{array}$

When the restriction $\alpha_{4}=\alpha_{5}$ is not imposed, the IV estimates for $\alpha_{4}$ and $\alpha_{5}$ are $\hat{\alpha}_{4}=-21(.74)$ and $\hat{\alpha}_{5}=.28(3.63)$. The test statistics for the hypothesis $H_{0}: \alpha_{4}=\alpha_{5}$ axe significant at a 58 level, but not at a significance level of .025 .

The inequality between the varlances in $(5.34)^{*}$ and $(2.14), \sigma_{5}^{2}<\sigma_{i}^{2}, 4 . s$ satisfied. The restrictions $\beta_{2}<0$ and $0<\alpha_{4}<1$ are again satisfied by the point estimates. From $\hat{\alpha}_{4}$ we infer an estimate of $\mathbb{T}: 2.48$ (4.13). The restrictions $\beta_{5}<\beta_{3}<\beta_{1}, \quad 1<\alpha_{1}<2, \quad \alpha_{2}<0$ and $0<\alpha_{3}$ are violated. From these results we conclude that the model is misspectefed. 
Table 5.1' Test statistics of modeI $(5.33)^{\prime}$.

\begin{tabular}{|c|c|c|c|}
\hline $\mathrm{p}$ & $\mathrm{BP}$ & $L B$ & \\
\hline 4 & 3.40 & 3.56 & \\
\hline 8 & 8.36 & 8.74 & \\
\hline 12 & 12.14 & 12.71 & \\
\hline 16 & 22.59 & 23.63 & \\
\hline$n(1)$ & .72 & & \\
\hline$\eta(4)$ & .96 & & \\
\hline $\mathrm{S}_{1}$ &. .28 & & \\
\hline$s_{2}$ & .21 & & \\
\hline $\operatorname{PFCF}(8,49)$ & .23 & & \\
\hline $\operatorname{SCE}(1)$ & .27 & $\operatorname{SCE}(4)$ & 1.69 \\
\hline $\operatorname{SCEF}(1,50)$ & .22 & $\operatorname{SCEF}(4,47)$ & .3 .4 \\
\hline $\operatorname{SCN}(1)$ & .20 & $\operatorname{SCW}(4)$ & .06 \\
\hline $\operatorname{SCNF}(1,50)$ & .16 & $\operatorname{SCWF}(4,47)$ & .01 \\
\hline CRW (1) & 3.84 & & \\
\hline $\operatorname{CRWF}(1,56)$ & 3.26 & & \\
\hline $\operatorname{CRLM}(1)$ & 4.57 & & \\
\hline $\operatorname{CRLMF}(1,56)$ & 4.17 & & \\
\hline
\end{tabular}




\section{Ghepter 6}

\section{RATIONAL HABIT FORMATION}

In the models investigated in the previous chapters we postulated a preference structure with intertemporally additive utility function. In this chapter we will consider more general preference structures. More specifically, we will investigate the life cycle model studied in chapter 2 and the model with moving planning horizon exanined in chapter 4 under rational habit formation. The analysis extends that of Muellbauer (1986), because we consider more general patterns of rational habit formation.

In the first section we analyze the life cycle model extended for the presence for habits, in which the planning horizon is assumed to be infinite. We adopt the infinte horizon formulation because it is more conventent. Gale (1.967) gives a more positive argument for the choice of an infinite horizon formulation. He argues that the choice of an infinite plan will affect very crucially what one does the very near future and describes the situation figuratively as follows

"One is guiding a ship on a long journey by keeping it lined up with a point on the horizon even though one knows that long before that point is reached the weather wil change (but in an unpredictable wy) and it will be necessary to plck up a new course with a new reference point, agalin on the horlzon rather than just a short distance ahead" (op. cit. p.2).

We will show that for the exponential utility function, an arbitrary autoregressive integrated moving average (ARIMA) process is obtalned by choosing an appropriate pattern of rational habits. Many authors (see e.g. King (1983)) have stressed that an empirical analysis of the life cycle theory tests the joint hypothesis of the life cycle model and the chosen functional form of the utility function. In line with Hall's (1978) approach, the life cycle model has frequently been tested by examining the 
predictive power of the information set assumed to be used by the consumer. The result of section 6.1 suggests that ignoring habits may explain the frequent rejection of the life cycle hypothesis and that checking the signiffcance of past realizations of consumption is not so much a test of the life cycle model as a test of rational habit formation. In this section we will also indicate how the preference structure exhibiting rational hablts may be used to model consumption of durable goods.

In the second section we will Investigate the Iffe cycle consumption model under rational habit formation in which the consumer uses a finite planning horizon. An obvious reason for postulating a finite life time is the observation of mortality and this section asks whether the assumption of a finite planning horizon affects the conclusions of section 6.1. It w11 be shown that the only difference with the result for an infinite time horizon is that the drift parameter and the variance of the ARIMA process for consumption become age/time dependent.

In the third section we will analyze the model with moving planning horizon for a spectal pattern of rational habits that yields a model in the four period difference operator. In chapter 4 we argued that it is not. unrealistic to lmagine that the consumer will neglect periods far ahead in the future on which avallable information is scarce and unreliable, and will confine himself to more trustworthy information on the near future. We assume that the consumer shifts the planning horizon further ahead as time goes on. In the first subsection we will dertve the consumption function for an arbitrary income process. The only requirement is that the first (conditional) moments of the Income process extst. As a consequence of adjusting the planning horizon, a correction term has to be included in the consumption function. Next, we will derive the univariate stochastic process for the four pertod change in consumption when the annual change in income i.s generated by an ARMA $(p, q)$ process. The analysis may provide the skeleton of simple ARIMA schemes fot consumption with economic flesh and may shed some light on the frequently encountered similartities of the stachastic processes for income and consumption (see e.g. Prothero and Wallis (1976)). Obviously, the theoretical interrelationships between the consumption and income processes may be of some use in the identification stage of a time series modelling procedure. It is shown that the drift parameter of the consumption process is proportional to that of the income 
pracess. Hence, the model is capable of relating change in the slope of the consumption line to a change in the income line. In the second subsection we will show that when the annual change in income follows an autoregressive process of order 1 , the model leads to a relationship between income and consumption that is similar to the mechanism underlying the consumption function of Davidson, Hendry. Srba an Yeo (1978). More specifically, in each quarter of a year the consumer spends the same as he spent in that quarter of the previous year, modified by a proportion of the annual change in income and by whether that change is itself increasing or decreasing, and by the correction term.

Finally, section 6.4 is devoted to concluding remarks.

\subsection{The model with infinite planning horizon}

In this section we discuss the implications of the 1 ife cycle consumption model when the preference structure exhibits rational habits and the consumer uses an infinite planning horizon. The procedure to dertve the consumption function is the same as before, that is we solve the model for periods $t$ and $t+1$ and subtract the resulting expressions for $c_{t}$ and $c_{t+1}$ in order to eliminate financial wealth. In the first instance we assume that the preference structure depends on a finite number of past realizations of consumption. At time the representative consumer is assumed to maximize his life time utility subject to the life time budget constraint

$\operatorname{Max} \sum_{i=0}^{\infty} \beta^{i} \mathrm{U}\left(\Phi(L) c_{t+1}\right)$

S.T. $\quad \sum_{i=0}^{\infty}(1+r)^{-1} c_{t+i}=(1+r) a_{t-1}+\sum_{i=0}^{\infty}(1+r)^{-1} E\left(y_{t+1} \mid I_{t}\right)$,

with $U^{\prime}>0$ and $U^{\prime}<0$, where $U^{\prime}$ and $U^{\prime}$ ' are the first and second derivatives of $U$, and $\Phi(L)$ is polynomial of order $p$ in the lag operator $L$

$\Phi(L)=1-\varphi_{1} L-\cdots-\varphi_{p} L^{P}$ 
with factorization

$(L)=\left(1-\pi_{1} L\right)\left(1-\pi_{2} L\right) \ldots\left(\mathbb{L}-\pi_{p} L\right)$.

The gubsequent analysis 111 show that wave to impose the condition that the roots of $\Phi(L)=0$ must lie on or outside the unit circle, that $i s\left|\pi_{i}\right| \leq 1$, $1=1, \ldots, \mathrm{p}$.

Madel (6.1) shows that the current dectsion $c_{t}$ is affected by past cholces of consumption. Muellbater (1986) discusses the stochastic version of madel (6.1) in which expected utility is maximized for the case that (L) Is of order 1. We assume however that the consumer uses only infomation on the first (conditional) moments of the income process.

A few comments are in order. Firstly, the life time budget constraine in (6.1) results from successive substitution of the period by period budget constraints

$a_{t+1}=(1+r) a_{t+1-1}+E\left(y_{t+1} \mid I_{t}\right)=c_{t}, i=0,1, \ldots$

and the boundary condition

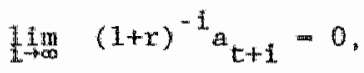

which is the transversality condition (see d'Autume and Michel (1987)). Secondly, the life time budget constraint as formulated in (6.1) is meaningless, unless the infinite sums converge. This leads to the requirement that $c_{t+1}$ and $E\left(y_{t+1} \mid I_{t}\right)$ are of exponential order less than $(1+x)$. A sequence $z_{t+1}$ will be termed of exponential order less than $(1+r)$, when there exist $\mathbb{1}_{0}$ and $K>0$ such that for every $i>1_{0}$

$\left|z_{t+1}\right|<\mathrm{Kx}^{1}$ for some $\mathrm{x} \in[1,1+\mathrm{r})$.

It is also required that the life cycle utility determined by (6.1) does not dlverge to infinity. When $U$ is bounded from above, the convergence of the target function is guaranteed.

Thirdly, although the discussion of model (6.1) is presented within the 
context of rational habit formation, the preference structure determined in (6.1) may be used to model consumption of durable goods. When we 1 ump all goods together and assume an average 1ife time of $\mathrm{N}$ periods, a depreciation rate $\delta \mathrm{N}^{-1}$ and that the stock of durable goods ylelds a consumption service flow which is proportional to 1 ts magnitude, it follows that

$s_{t+i}=\theta K_{t+1}=\theta N^{-1} \sum_{j=0}^{N-1}(N-j) L^{j} c_{t+1}$

where $s_{t+1}$ and $k_{t+i}$ denote the service flow and the stock of durable goods in period t+i respectively, and is the proportionality factor relating the service flow to the stock of durable goods. Given an intextemporally additive life time utility function with arguments $s_{t+1}$, we conclude that (after normalization) a special case of model (6.1) arises. Notice that other schemes of depreciation may be considered and that the extension to

$s_{t+1}=\theta(L) K_{t+1}$

is straightforward, as long as the $\mathrm{lag}$ polynomial $\Phi(L)$ in (6.1) satisfies the requirement that the roots of $\Phi(L)-0$ lie on or outside the unit circle. The first order conditions of (6.1) consist of a system of difference equations

$\frac{\partial}{\partial c_{t+1}}\left[\sum_{i=1}^{1+p} \beta^{i} U\left(\Phi(L) c_{t+i}\right)\right]=\frac{1}{1+r} \frac{\partial}{\partial c_{t+1-1}}\left(\sum_{i=1-1}^{1+p-1} \beta^{i} U\left(\Phi(L) c_{t+i}\right)\right] 1=1,2, \ldots$

Determining the solution of (6.1) corresponds to solving the $(p+1)^{\text {th }}$ order difference equation $(6.4)$ subject to the $(p+1)$ inttial conditions $c_{t-1}, c_{t-2}, \ldots, c_{t-p}$ and

$\sum_{i=0}^{\infty}(1+r)^{-i} c_{t+1}-(1+r) a_{t-1}+\sum_{i=0}^{\infty}(1+r)^{-i} E\left(y_{t+i} \mid I_{t}\right)$

Substituting

$\frac{\partial}{\partial c_{t+1}}\left[\sum_{i=1}^{1+p} \beta^{i} U\left(L(L) c_{t+1}\right)\right]=\sum_{i=1}^{1+p} \beta^{i} U^{\prime}\left(\Phi(L) c_{t+1}\right) \frac{\partial\left(\Phi(L) c_{t+1}\right)}{\partial c_{t+1}}$

and 
$\frac{\partial}{\partial c_{t+1-1}}\left(\sum_{1=1-1}^{1+p-1} \beta^{I} v\left(\Phi(L) c_{t+1}\right)\right)-\sum_{1=1}^{1+p} \beta^{1-1} v^{\prime}\left(\Phi(\mathbb{L}) c_{t+1-1}\right) \frac{\partial\left(\Phi(L) c_{t+1}\right)}{\partial c_{t+1}}$

Into (6.4) leads to

$\sum_{1=1}^{1+\mathrm{p}} \beta^{1}\left[U^{\prime \prime}\left(\Phi(L) c_{t+1}\right)-\frac{1}{\beta(1+\tau)} U^{\prime}\left(\Phi(L) c_{t+1-1}\right)\right] \frac{\partial\left(\Phi(L) c_{t+1}\right)}{\partial c_{t+1}}=0,1-1,2, \ldots$

A suffictent condition for $(6.6)$ to hold true is

$U^{\prime \prime}\left(\Phi(L) c_{t+\mathbb{H}}\right)=\beta^{-1}(\mathbb{1}+\mathrm{r})^{-1} U^{\prime}\left(\Phi(L) c_{t+1-1}\right), 1=1,2, \ldots$

To arrive at an operational mode1, it is necessary to choose a specific functional form for the utilty function $U$. We will investigate the exponential utility function

$\mathbb{v}(\mathrm{c})=-\gamma^{-1} \exp (-\gamma c), \gamma>0$

obviously, the utility function (6.8) is bounded from above. For the exponential utility function the optimal consumption path corresponds to the solution of the linear difference equation of order $(p+1)$

$\Phi(L)(1-L) c_{t+1 .}=\gamma^{-1} \ln [\beta(1+r)], i=1,2, \ldots$

with inftal conditions $c_{t-1}, c_{t-2}, \ldots, c_{t-p}$ and the life time budget constraint $(6.5)$.

A conventent altarnative procedure to obtain a closed-form solution of the utility maximization problem (6.1) is imposing the restriction $\beta(1+r)=1$. In chapter 31 was shown that for the life cycle model (6.1) without habits" $\beta(1+x)=1$ 1: a sufficient condition to obtain Friedman"s (1957) Permanent Incone Hypothesis. Using expression $(6.7)$, it follows that for any utility function $U$ satisfying $U^{\prime}>0$ and $U^{\prime \prime}<0$, the first order conditions consist of a system of linear homogeneous difference equations of order $(p+1)$. Since the resulting difference equation arises as a special case of $(6,9)$, we conclude that the assumption $\beta(1+r)=1$ is more restrictive than the choice 
of the exponential utility function. It should be obvious that the subsequent analysis remains valld for an arbitrary utility function $u$ satisfying $U^{\prime}>0$ and $U^{\prime \prime}<0$ under the alternative restriction $\beta(1+r)-1$.

The literature on linear difference equations (see e.g. Sargent (1979)) provides us immediately the form of the solution of (6.9). When we assume in the first instance that the roots of $\Phi(L)=0$ are distinct and do not lie on the unit circle, $(6.9)$ yields as a solution

$c_{t+i}=k_{0} i+\sum_{j=1}^{p} k_{j} \pi_{j}^{i}+k_{p+1} 1^{i}$

with $k_{j}, j=1,2, \ldots, p+1$, determined by the $(p+1)$ infitial conditions, and $\pi_{1}$, $i=1, \ldots p$, given by $(6.2)$. Imagine the situation 1 in which one of the roots, say $1 / \pi_{1}$, lies inside the unt circle. For $\left|\pi_{1}\right| \geq 1+r$ we have a solution of the difference equation that is in contradiction with the requirement that $c_{t+1}$ is of exponential order less than $(1+r)$. Since we do not want to exclude any value of $r \in(0,1)$, we require that the ultimate result has to hold for every $r \in(0,1)$. Hence, we conclude from (6.3) and (6.10) that all the roots must lie on or outside the unit circle. In general, when the first $n$ roots are equal and do not lie on the unit circle, the difference equation ylelds the solution

$c_{t+i}=k_{0} i+\sum_{j=1}^{n} k_{j} i^{j-1} \pi_{1}^{i}+\sum_{j=n+1}^{p} k_{j} \pi_{j}^{i}+k_{p+1} 1^{i}$.

This shows that the case of multiple roots does not lead to Incompatibility with requirement (6.3), as long as the roots lie outside the unit circle. obviously, multiple roots equal to 1 do not lead to difficulties. In conclusion, to avold a contradiction between condition (6.3) for any value of the real interest rate between 0 and 1 , and the solution of the difference equation, it is necessary to impose the restrictions

$\left|\pi_{i}\right| \leq 1, i=1,2, \ldots, p$.

We proceed by examining (6.9). It is convenient to define auxiliary variables $c_{t+1}^{*}$ as 
$c_{t+1}^{*}-1(L) c_{t+\mathbb{1}}, 1=0,1, \ldots$

Solving the difference equation (6.9) subject to the $(p+1)$ initial conditions 1s equivalent to solving the linear first order difference equation

$c_{t+1}^{*}=c_{t+1-1}^{*}+\gamma^{-1} \ln [\beta(1+r)], \quad 1=1,2, \ldots$

with one boundary condition, namely the life time budget constraint expressed in terms of $c_{t+1}^{*}$. Using $a_{t-1}(1+r) a_{t-2}+y_{t-1}-c_{t-1}$, it can be easily shown that

$\sum_{1=0}^{\infty}(1+r)^{-1} c_{t-1+1}=(1+r) a_{t-2}+\sum_{i=0}^{\infty}(1+r)^{-1} E\left(y_{t-1+1} \mid I_{t}\right)$

is equivalent to (6.5). By repeated argument we find for the transformed life time budget constralnt

$$
\sum_{i=0}^{\infty}(1+r)^{-1} c_{t+i}^{*}=(1+r) \Phi(L) a_{t-1}+\sum_{i=0}^{\infty}(1+r)^{-1} E\left(\mathbb{L}(\mathbb{L}) y_{t+1} \mid I_{t}\right)
$$

It can be easily checked that (6.13) is only equivalent to (6.5) in case of an infinite planning horizon. In the next section we discuss an alternative procedure which enables us to tackle the model with finite time horizon. Expression (6.12) can be rewritten as

$c_{t+i}^{*}=c_{t}^{*}+i \gamma^{-1} \ln [\beta(\mathbb{1}+r)], \quad i=1,2, \ldots$

and substitution of $(6.14)$ into the life time budget constraint (6.13) yields

$c_{t}^{*} \frac{1+r}{r}+\gamma^{-1} \ln \left[\beta\left(1+\mu^{*}\right)\right] \frac{1+r}{r^{2}}=(1+r) \Phi(L) a_{t-1}+\sum_{t=0}^{\infty}(1+r)^{-1} E\left(\Phi(L) y_{t+1} \mid I_{t}\right)(6.15)$

Substitcuting $c_{t}=(L) c_{t}$, Formula (6.15) expresses the decision $c_{t}$ as a function of current income, future income expectations, wealth and past 
consumption. In line with Brown (1952) the latter may be interpreted as the influence of habits.

To investigate the dynamics in consumption, it is convenient to relate $c_{t}$ to $c_{t+1}$. Carrying out the same operations as before for the model solved for period $t+1$ leads to

$c_{t+1}^{*} \frac{1+r}{r}+\gamma^{-1} \ln [\beta(1+r)] \frac{1+r}{r^{2}}=(1+r) \Phi(L) a_{t}+\sum_{i=0}^{\infty}(1+r)^{-i} E\left(\Phi(L) y_{t+1+i} \mid I_{t+1}\right)$

Dividing $(6.16)$ by $1+r$, substituting $a_{t}=(1+r) a_{t-1}+y_{t}-c_{t}$ and subtracting (6.15) yields

$c_{t+1}^{*}-c_{t}^{*} \gamma^{-1} \ln [\beta(1+r)]+\frac{r}{1+r} \sum_{1=0}^{\infty}(1+r)^{-i}\left[E\left(\Phi(L) y_{t+1+1} \mid I_{t+1}\right)-E\left(\Phi(L) y_{t+1+1} \mid I_{t}\right)\right]$.

When we substitute $(1-L) c_{t+1}^{*} \Phi(L) \Delta c_{t+1}$ and define the consumption innovation $\varepsilon_{t+1}$ as $\varepsilon_{t+1}-c_{t+1}-E\left(c_{t+1} \mid I_{t}\right)$, we have

$\Phi(L) \Delta c_{t+1}=\gamma^{-1} \ln [\beta(1+r)]+\varepsilon_{t+1}$

with

$\varepsilon_{t+1}=\frac{r}{1+r} \sum_{i=0}^{\infty}(1+r)^{-i}\left[E\left(\Phi(L) y_{t+i+1} \mid I_{t+1}\right)-E\left(\Phi(L) y_{t+i+1} \| I_{t}\right)\right]$.

Consumption follows an autoregressive integrated (ARI) stochastic process. Since unit roots are permitted the order of integration nay be larger than one for an appropriate choice of the lag polynomial $\Phi(L)$ (obviously. integration of order zero is excluded). Notice also that a model in the speriod difference operator $\Delta_{3}$ may be obtained by the choice of (L) $=1+\mathrm{L}+\ldots+\mathrm{L}^{\mathrm{s}-1}$.

Unanticipated changes in the process of the exogenous varlable $y_{t}$ have definite effects on the model for consumption. Along similar lines as in chapter 2, the implications can be traced by using the closed form solutions (6.15) and (6.16). In chapter 9 we w111 investigate the 11fe cycle model with a special form of rational habits. The empirical analysis of that model will illustrate how structural changes can be handled.

As an 111 ustration we give two examples. The first one corresponds to the 
model discussed by Mullbauer (1986), where it is assumed that the current consumption decision. is only influenced by previous consumption. In the second one we use a lag polynomial with unit roots. Since it generates a model in the annual difference of consumption, it illustrates the rich posslbflities of the chosen polynomial for modelling seasonally unadjusted consumption sertes.

Example 1 (L) -1 -al.

Substitution of $\Phi(L)-1-a L$ into $(6.17)$ and (6.18) leads after some rearrangling to

$\varepsilon_{t+1}-\left(1-\frac{1}{1+r}\right)\left(1-\frac{a}{1+r}\right) \sum_{i=0}^{\infty}(1+r)^{-1}\left[E\left(y_{t+1+1} \mid I_{t+1}\right)-E\left(y_{t+1+1} \mid I_{t}\right)\right]$

and

$(1-\mathrm{aL}) \Delta c_{\mathrm{t}+1}-\gamma^{-1} \ln [\beta(1+\mathrm{r})]+\varepsilon_{\mathrm{t}+1}$.

Example $2 \Phi(\mathrm{L})=1+\mathrm{L}+\mathrm{L}^{2}+\mathrm{L}^{3}$.

Noting that $\left(1+\mathrm{L}+\mathrm{L}^{2}+\mathrm{L}^{3}\right)(1-\mathrm{L})=1-\mathbb{L}^{4}$, we have for the consumption process

$\Delta_{4} c_{\mathrm{t}+1}=\gamma^{-1} \ln [\beta(1+r)]+\varepsilon_{\mathrm{t}+1}$

where $\varepsilon_{t+1}$ is equal to

$E_{t+1}-\left(1-\frac{1}{(1+r)^{4}}\right)\left(\sum_{i=0}^{\infty}(1+r)^{-1}\left[E\left(y_{t+1+1} \| I_{t+1}\right)-E\left(y_{t+i+1} \mid I_{t}\right)\right]\right)$

as can be verified by substitution of $\Phi(L)=1+L+L^{2}+L^{3}$ into $(6.17)$ and $(6.18)$.

In the model discussed above the consumer is assumed to use a finite memory with respect to past realizations of consumption. Pollak (1970) mentions the possiblitity of a preference structure that depends on an inflnite number of past realizations of consurption and the utility function in (6.1) may be generalized by replacing the one-period utflity function argument $\Phi(\mathbb{L}) c_{t+1}$ by $\Phi(L) \Theta(L)^{-1} c_{t+1}$, where $\theta(L)$ is a finfte order lag polynomial. It seems reasonable to impose the additional restriction that the roots of $\theta(L)=0$ lie outside the unit circle. By this restriction we 
are assured that the consumer attaches declining weights to the very past of consumption. When we carry out the same operations as before, the first arder conditions yield

$\theta(\mathrm{L})^{-1} \Phi(\mathrm{L})(1-\mathrm{L}) c_{t+i}=\gamma^{-1} \ln [\beta(I+\mathrm{r})]$

The only difference between (6.19) and its "finite memory" counterpart (6.9) is that we have $\theta(L)^{-1} \Phi(L)$ instead of $\Phi(L)$. Solving the model for period $t$ and period $t+1$ leads to the ultimate result

$\Phi(L)(1-L) c_{t+1}=\theta(L) \gamma^{-1} \ln [\beta(1+r)]+\theta(L) \varepsilon_{t+1}$

with

$\varepsilon_{t+1}=\frac{r}{1+r} \sum_{i=0}^{\infty}(1+r)^{-1}\left[E\left(\Phi(L) \theta(L)^{-1} y_{t+i+1} \mid I_{t+1}\right)-E\left(\Phi(L) \theta(L)^{-1} y_{t+i+1} \mid I_{t}\right)\right]$.

Hence, consumption will follow an arbitrary invertible ARIMA process.

The model with infinite memory may be used to describe consumption behaviour with respect to durable goods with an infinite life time. When we assume that the stock of durable goods $K_{t+1}$ evolves according to

$k_{t+1}=(1-\delta) K_{t+1-1}+c_{t+1}$

we have for the service flows $s_{t+1}$

$s_{t+1}-\theta \mathrm{K}_{\mathrm{t}+\mathrm{i}}=(1-(1-\delta) \mathrm{L})^{-1} \theta \mathrm{c}_{\mathrm{t}+1}$

Hence, $s_{t+1}$ depends on the acquisition of durable goods irfinitely far into the past. Given an intertemporally additive utility function with arguments $s_{t}+1$. the resulting model is a speclall case of $(6,20)$.

Expression (6.20) shows that the constant term of the ARIMA process for consumption depends on parameters of the preference structure only. Hence, a change in the slope of the consumption line can only be explained within this theoretical framework by a change of the parameters of the decision 
problem (6.1). In the 1ight of the analysis of chapter 4, the model with moving planning horizon may explain a change in the drift of the consumption process by a change of the constant term of the income process. Mowever, in order to Investigate this model under rational habit formation it becomes necessary to solve the model with finite planning horizon. Since the procedure used in this section to reformulate the life time budget constraint in terms of $\mathrm{c}_{\mathrm{t}+1}^{*}$ depends cructally on the assumption of an Infinite planning horizon, it becomes necessary to establish an alternative way to tackle the finite horizon formulation. In the next section we develop such a procedure and ask whether the assumption of a finfte time horizon affects the results of this section.

\subsection{The model with finite planning horfzon}

In this section we discuss the life cycle model with finite time horizon under rational habit farmation. The procedure to derive the consumption function is the same as used before, that is we solve the model for periods $t$ and $t+1$ and subtract the resulting expressions for $c_{t}$ and $c_{t+1}$ in order to eliminate financial wealth. At each time period $t$, the consumer is assuned to maximize his life time utility subject to the life time budget constraint.

$\operatorname{Max} \tilde{\mathrm{H}}\left(c_{t}, c_{t+1} \ldots, c_{\mathrm{T}}\right)=\sum_{i=0}^{T-t} \beta^{1} U\left(\Phi(L) c_{t+1}\right)$

S.T. $\sum_{1=0}^{T-t}(1+r)^{-1} c_{t+1} \leq(1+r) a_{t-1}+\sum_{i=0}^{T-t}(1+r)^{-i} E\left(y_{t+i} \| I_{t}\right)$

$$
c_{t+1} \geq 0, \quad 1 \neq 0, \ldots, T-t,
$$

with $U^{\prime}>0$ and $U^{*}<0$, where $U^{\prime}$ and $U^{\prime \prime}$ are the Elrst and second derivatives of $U$ respectively, and $\Phi(L)$ is a polynomial of order $p$ in the lag operator L.

$\omega(\mathrm{L})=1-\varphi_{1} \mathrm{~L} \cdots \cdots-\varphi_{\mathrm{p}} \mathrm{L}^{\mathrm{p}}$.

Later we discuss the generalization of $(6.21)$ to the case that the 
preference structure depends on an infinite number of past realizations of consumption. In the previous section we studied the utility function (6.21) with infinite planning horizon, that is $T=0$. In chapter 2 we examined the model (6.21) without habits, that is $\Phi(\mathbb{L})-1$. Notice that a may depend on additional predetermined variables. Examples are for instance taste shifters or, in case of habit formation, past realizations of consumption. In the next chapter we will consider past-peak Income and past-peak consumption as taste shifters. The utility function (6.21) shows that the decision $c_{t}$ is affected by past choices of consumption. Past consumption is assumed to influence current consumption in a way that corresponds to the rational habits formulation.

When $\mathfrak{u}$ is quasi-concave and the consumer is never satiated in at least one $c_{t+1}$, the quasi saddle point (QSP) characterization for an optimum yields a necessary and sufficient condition for a global maximum (see e.g. Takayama (1985), p.135). When we restrict ourselves to an interior solution the QSP characterization reduces to the familfar condition

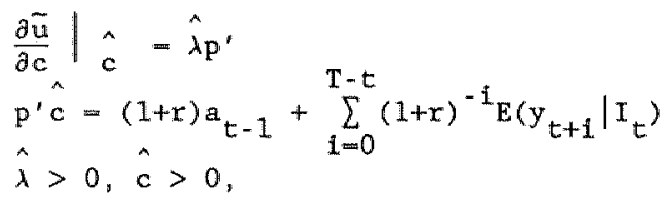

where $\lambda$ is the multiplier associated with the life time budget constraint, $c$ and $p$ denote the (T-t+1)-vectors $\left(c_{t}, c_{t+1}, \ldots, c_{T}\right)^{\prime}$ and $\left(1,(1+r)^{-1}\right.$ $\left., \ldots,(1+r)^{-T+t}\right)^{\prime}$ respectively, and $(\hat{c}, \hat{\lambda})$ represents the solution of (6.22). Moreover, when $a$ is strictly quasi-concave $\hat{c}$ is a unlque glober 1 maximum.

Motice that

$\left.\frac{\partial \tilde{u}}{\partial c_{T}}=\beta^{T-t_{U}\left(\Phi(L) c_{T}\right.}\right)>0$,

so that the consumer is never satiated in at least one commodity. It can be easily seen that condition (6.22a) implies

$\frac{\partial \bar{u}}{\partial c_{t+i}}=(1+r)^{T-i} \frac{\partial \tilde{u}}{\partial c_{t+T}}, i=0,1, \ldots, T-t-1$.

Hence, the necessary condition for the existence of an intertor solution, 
that $1 \mathrm{~g}$

$\left.\frac{\partial \vec{u}}{\partial c_{t+1}}\right|_{c} \quad>0,1-0,1, \ldots, T-t$

is satisfied. This condition is of course not sufficient to guarantee that corner solutions are excluded. As argued in chapter 2 the existence of an interfor solution 111 depend on the particular value of life time wealth and the parameters of the utility function. In case of rational habit formation it 111 also depend on past realizations of consumption. Derivation of the specific requirements resulting from the "interior solution postulate" in case the preference structure is described by (6.21) is however far from belng stralghtforward. Hence, we Implicitly assume that the conditions for the existence of an interior solution are satisfied. For the subsequent analysis it proves conventent to define

$c_{t+1}^{*}=\Phi(L) c_{t+1}$

and

$c^{*}=\left(c_{t}^{*}, c_{t+1}^{*}, \ldots, c_{T}^{*}\right)^{\prime}$

When we define

$\Pi(L)=\Phi(L)^{-1}=\sum_{i=0}^{\infty} \pi_{i} \mathbb{L}^{i}, \pi_{0}-1$

we have

$c_{t+1}=\Pi(I) c_{t+1}^{*}-\sum_{j=0}^{1} \pi x-j c_{t+j}^{*}+\sum_{j=i+1}^{\infty} \pi_{j} c_{t+1-j}^{*}$

or In matrix notation

$c=A c^{*}+\bar{c}$

where $A$ is the lower triangular matrix with $A_{1 j} \infty \pi_{i-j}, i \geq j$ and $i$ is the $(\mathrm{T}=\mathrm{t}+1)$-vector $\left(\mathrm{c}_{\mathrm{t}}, \mathrm{c}_{\mathrm{t}+1}, \ldots, \mathrm{c}_{\mathrm{T}}\right)^{\prime \prime}$ with 
$\bar{c}_{t+i}=\sum_{j=i+1}^{\infty} \pi_{j} c_{t-j+i}^{*}$

Notice that $\bar{c}$ depends only on past realizations of consumption.

When we define

$\tilde{u}^{*}\left(c^{*}\right)=\tilde{u}\left(A c^{*}+\tilde{c}\right)-\sum_{i=0}^{\mathbb{T}-t} \beta^{i} U\left(c_{t+1}^{*}\right)$

we have

$\frac{\partial \tilde{u}}{\partial c}=\frac{\partial \tilde{u}^{*}}{\partial c^{*}} \frac{\partial c^{*}}{\partial c}=\frac{\partial \tilde{u}^{*}}{\partial c^{*}} A^{-1}$

and condition $(6.22)$ passes into

$\left.\frac{\partial \vec{u}^{*}}{\partial c^{*}}\right|_{c^{*}=A^{-1}(\hat{c}-\bar{c})}=\hat{\lambda p^{\prime} A}$

$p^{\prime} A c^{*}=(1+r) a_{t-1}+\sum_{i=0}^{T-t}(1+r)^{-1} E\left(y_{t+1} \mid I_{t}\right)-p^{\prime} \dot{c}$

Mareover, because

$\frac{\partial^{2} \tilde{u}}{\partial c \partial c}=A^{,-1} \frac{\partial^{2} \tilde{u}^{*}}{\partial c^{*} \partial c^{j *}}, A^{-1}$ and $\frac{\partial^{2} \tilde{u}^{*}}{\partial c^{*} \partial c^{*}}$, is negative definite, we conclude that $a(c)$ is strictly concave and hence strictly quasi-concave.

We proceed by examining (6.24), which yields $T-t+2$ equations to solve the $\mathrm{I}-\mathrm{t}+2$ unknown variables $\hat{\mathrm{c}}_{\mathrm{t}}, \ldots, \hat{\mathrm{c}}_{\mathrm{T}}, \hat{\mathcal{A}}$. The $(i+1)^{\mathrm{t} h}$ equation of $(6,24 a)$ reads as

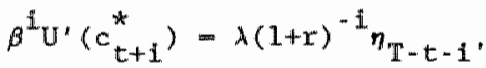

where

$\eta_{k}=\sum_{j=0}^{k}(1+r)^{-j} \pi_{j}$

Using expression (6.25) for $i=0$, we find 
$A^{1} U^{\prime}\left(c_{t+1}^{*}\right)=(1+r)^{-1} \eta_{T-t-1} \eta_{T-t^{-1}}^{-1}\left(c_{t}^{*}\right), i-1,2, \ldots, T-t$

For the exponential utility function

$U(c)=-\gamma^{-1} \exp (-\gamma c), \gamma>0$

expression $(6.26)$ can be rewritten as

$c_{t+1}^{*}=c_{t}^{*}+1 \gamma^{-1} \ln [\beta(1+r)]-\gamma^{-1} \ln \left[\eta_{T}-t-1 \eta_{T-t}^{-1}\right], \mathbb{1}-1, \ldots, \mathbb{T}^{*}-t$

After substitution of (6.28) into the 11 fe time budget constraint $(6.24 b)$, we get for the decision $c_{t}^{*}$

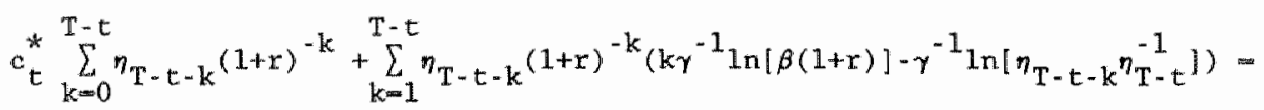

$$
(1+r) a_{t-1}+\sum_{i=0}^{T-t}(1+r)^{-1} E\left(y_{t+1} \mid I_{t}\right)-\sum_{k=0}^{T-t}(1+r)^{-k} \sum_{j=k+1}^{\infty} \pi_{j} c^{*} t+k-j
$$

Substituting $\quad c_{t}^{*}=\Phi(L) c_{t_{t}}$ into formula (6.29) ylields the current consumption decision $c_{t}$ as a function of current income, future income expectations, wealth and past consumption. In line with Brown (1952), the latter may be interpreted as the influence of habits on corsumer behaviour.

It is implicitly assumed that the consumption decision $c_{\text {it }}$ determined by expression (6.29), is positive. The feasibility of an interior solution depends among other things on the specific values of life time wealth and past consumption levels. Notice also that it is required that the implied planned consumption levels $c_{t+1}$ determined by $(6.28)$, correspond to an Interior solution. Expression (6.28) reveals in this respect that we need to impose the necessary condition

$\eta_{T-t-\mathbb{L}^{-1}} \eta_{\mathrm{T}}^{-1}>0, \quad 1-1, \ldots, T+t$

This leads to restrictions on the $\pi$-coefficients of (6.23) and hence on the 
p-coefficients of the utility function (6.21). We have not been successful in deriving the form of the restrictions in the model with a general pattern of rational habits. For the specific form of rational hablts discussed in the next section, the restrictions (6.30) are satisfied. To investigate the dynamics in consumption, it is convenient to relate $c_{t}$ to $c_{t+1}$. Carrying out the same operations as before for the model for the next period leads to

$c_{t+1}^{*} \sum_{k=0}^{T-t-1}(1+r)^{-k} T_{T-t-1-k}$

$$
\begin{aligned}
& \left.+\sum_{k=1}^{\mathbb{T}-t-1}(1+r)^{-k} \eta_{T-t-1-k^{(k \gamma}}{ }^{-1} \ln [\beta(1+r)]-\gamma^{-1} \ln \left[\eta_{T-t-1-k^{\eta} \mathrm{T}-\mathrm{t}-1}\right]\right)= \\
& (1+r) a_{t}+\sum_{i=0}^{T-t-1}(1+r)^{-i} E\left(y_{t+1+i} \mid I_{t+1}\right)-\sum_{k=0}^{T-t-1}(1+r)^{-k} \sum_{j=1 k+1}^{\infty} \pi_{j} c_{t+1+k-j}^{*}
\end{aligned}
$$

Dividing $(6.31)$ by $(1+x)$, substituting $a_{t}=(1+r) a_{t-1}+y_{t}-c_{t}$, subtracting (6.29) and using

$$
\begin{aligned}
& -c_{t}-(1+r)^{-1}\left[\sum_{k=0}^{T-t-1}(1+r)^{-k} \sum_{j=m+1}^{\infty} \pi j^{*} c_{t+1+k-j}^{*}\right] \\
& \text { * } \sum_{k=0}^{T-t}(1+r)^{-k} \sum_{j=k+1}^{\infty} \pi j c^{*} c_{t+k-j}=-c^{*}{ }^{\eta} T-t
\end{aligned}
$$

and

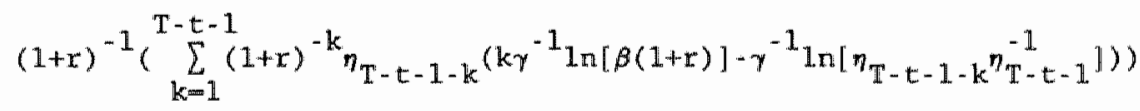

$$
\begin{aligned}
& \left.-\sum_{k=1}^{T-t}(1+x)^{-k} \eta_{T-t-k^{(k \gamma}}{ }^{-1} \ln [\beta(1+r)]-\gamma^{-1} \ln \left[\eta_{T-t-k^{\eta} T-t}\right]\right)= \\
& -\sum_{k=1}^{T-t}(1+r)^{-k} \eta_{T-t-k^{(\gamma}}\left(\gamma^{-1} \ln [\beta(1+r)]-\gamma^{-1} \ln \left[\eta_{\left.T-t-I^{2} T-t\right]} \eta^{-1}\right)\right.
\end{aligned}
$$


Leads to

$c_{t+1}^{*}-c_{t}^{*}-\gamma^{-1} \ln [\beta(1+r)]-\gamma^{-1} \ln \left[n_{T-t-1}{ }^{-1} T-t\right]+$

$\left.\sum_{k=0}^{T-t-1}(1+x)^{-k} T_{T-t-1-k}\right)^{-1}\left(\sum_{i=0}^{T-t-1}(1+x)^{-1}\left[E\left(y_{t+1+1} \mid I_{t+1}\right)-E\left(y_{t+1+1} \mid I_{t}\right)\right]\right) \cdot(6.32)$

When we substitute next

$c_{t+1}^{*}-c_{t}^{*}=\Phi(L) \Delta c_{t+1}$

into (6.32) and define the consumption fnnovation $\varepsilon_{t+1}$ as $\varepsilon_{t+1}=c_{t+1}$ $E\left(c_{t+1} \mid I_{t}\right)$, we have

$\Phi(L) \Delta c_{t+1}=\gamma^{-1} \ln [\beta(1+r)]-\gamma^{-1} \ln \left[\eta_{T-t-1} \eta_{T-t}^{-1}\right]+\varepsilon_{t+1}$

with

$\varepsilon_{t+1}=\left(\sum_{k=0}^{T-t-1}(1+r)^{-k}{ }_{\eta} T-t-1-k\right)^{-1}\left(\sum_{i=0}^{T-t-1}(1+r)^{-i}\left[E\left(y_{t+1+i} \mid I_{t+1}\right)-E\left(y_{t+1+i} \mid I_{t}\right)\right]\right)$.

Consumption follows an autoregressive integrated (ARI) process. If unit roots are not incompatible with the assumption that an interior solution exists, the order of integration may be larger than 1 for an appropriate cholice of the lag polynomial $\Phi(L)$ (only integration of order zero is excluded).

Expressions (6.33) and (6.34) reveal that both the drift parameter of the stochastic process and the variance of the consumption innovation tre age/time dependent. Estimation of model (6.33) with a constant variance and a constant drift is expected to be appropriate when the age structure of the population and the income distribution over different age groups are falrly stable over time.

In chapter 2 we investigated the model (6.21) with utility function (6.27) without habit formation. In that case $\Phi(\mathrm{L})=\eta_{\mathrm{k}} \mathrm{m}$ for $\mathrm{a} 1 \mathrm{l} \mathrm{k}$ and $(6.33)$ and $(6.34)$ spectalize to 
$\Delta c_{t+1}=\gamma^{-1} \ln [\beta(1+r)]+\varepsilon_{t+1}$

with

$\varepsilon_{t+1}=\left(\sum_{k=0}^{T-t-1}(1+r)^{-k}\right)^{-1}\left(\sum_{i=0}^{T-t-1}(1+r)^{-i}\left[E\left(y_{t+1+1} \mid I_{t+1}\right)-E\left(y_{t+1+1} \mid I_{t}\right)\right)\right)$.

In the model discussed above the consumer is assumed to have a preference structure that depends on a finite number of past realizations of consumption. Pollak (1970) mentions the possibility that the utility function includes all past walues of consumption and (6.21) may be generalized by replacing the one-period utility function argument $\Phi(L) c_{t+1}$ by $(L) \theta(L)^{-1} c_{t+1}$, where $\theta(L)$ is a finite order lag polynomial. It seens reasonable to impose the additional restriction that the roots of $\theta(L)=0$ lie outside the unit circle. By this restriction we are assured that the consumer attaches declining weights to the very past of consumption. When we define $\mathbb{I}(\mathrm{L})$ in $(6.23)$ as

$\mathbb{H}(\mathrm{L})=\Phi(\mathrm{L})^{-1} \Theta(\mathrm{L})$

it can be easily seen that the foregoing analysis remains valld. The ultimate result $(6.33)$ passes into

$\Phi(\mathrm{L}) \Delta \mathrm{c}_{\mathrm{t}+1}=\theta(\mathrm{L})\left(\gamma^{-1} \ln [\beta(1+\mathrm{L})]-\gamma^{-1} \ln \left[\eta_{\mathrm{T}-\mathrm{t}-1^{\eta} \mathrm{T}-\mathrm{t}}\right]\right)+\theta(\mathrm{L}) c_{\mathrm{t}+1}$

where $\varepsilon_{\mathrm{t}+1}$ is given by $(6.34)$. Hence, consumption w11 follow an ARIMA process, the parameters of which correspond to the weightg attached to past consumption in the utility function. The results of this section correspond with those obtained in section 6.1 for the infinite hor 1 zon model. The only difference consists in the age-dependency of the drift parameter of the stochastic process and the variance of the consumption innovation for the model with flnite planning horizon. In both models, the drift parameter depends only on parameters that characterize consumer behaviour. A change in the slope of the consumption line can only be explained in this framework by a change in the parametexs of the decision 
problem determined by $(6.21)$. In chapter 4 it was show that in the model with moving planning horizon whout rational habit formation, the drift parameter of the consumption process is proportional to that of the income process. Hence, an unanticipated change in the slope of the income lime will imply a change of the constant term of the consumption model. The next section asks whether this implication remains valid for the extended model with habit formation.

\subsection{The model with moving planning hor 1 zon}

In chapter 4 the model with moving planning horizon was introduced as an alternative for the life cycle model. The modifled model is capable of relating a change in the slope of the consumption line to a change in the drift parameter of the income process. An attractive feature of the model is that it leads to a corisumption function with a correction term. This term was found to yield favourable emplrical results in Davidson, Hendry, Srba and Yeo (1978), where it was derived along completely different lines of ressoning. In this section, we ask whether the assumption of a moving plaming horizon together with hablt formation will produce a consunption function with correction term in annual differences. In the light of the analysis carried out in the previous sections, the special form of rational habits that leads to a model in the four perlod difference operator $\Delta_{4}$ is of particular interest. In the first subsection we describe the model and derive the consumption function for an arbitrary income process. The procedure to trace the relationship between income and consumption is the same as used before, that is we solve the model for perlods $t$ and $t+1$ and subtract the resulting expressions for $c_{t}$ and $c_{t+1}$ in order to eliminate financial wealth. Next, we examine the implied univariate stochastic process for consumption when the annual change in income follows an ARMA(p, q) process. In the second subsection we show that when the annual change in income is generated by an AR(1) process, the model leads to a relationship between consumption and income that is highly similar to that of Davidson et. al. (1978). 


\subsubsection{The unfrariate stochastic process for consumption}

We assume that the consumer solves at each time period the utility maximization problem

$\operatorname{Max} \sum_{i=0}^{T} \beta^{i} U\left(\Phi(L) c_{t+i}\right)$

$S \cdot T \cdot \sum_{i=0}^{T}(1+r)^{-1} c_{t+1}^{T}=(1+r) a_{t-1}+\sum_{i=0}^{T}(1+r)^{-1} E\left(y_{t+1} \mid I_{t}\right)$

with

(L) $=1+L+L^{2}+L^{3}$.

The difference with the model (6.21) is that now the length of the planning time span is time-independent and the time horizon shifts as time goes on. It is straightforward to show that

$\Phi(L)^{-1}=1-L+L^{4}-L^{5}+L^{8}-L^{9}+\ldots$

and accordingly we have for the $\pi$-coefficients of (6.23)

$\pi_{4: 1}=1$

$\pi_{41+1}=-1$

$\pi_{4 i+2}=\pi_{4 i+3}=0, i=0,1,2, \ldots$

Along the lines of section 6.2, it can be shown that for the utility function ( 6.27$)$, we have for the consumption dectsion

$c_{t}^{*} \sum_{i=0}^{T} n_{T-1}(1+r)^{-1}+a=(1+r) a_{t-1}+\sum_{i=0}^{T}(1+r)^{-1} E\left(y_{t+i} \mid T_{t}\right)$

$$
-\sum_{i=0}^{T}(1+x)^{-i} \sum_{j=1+1}^{\infty} \pi_{j} c_{t+1-j}^{*}
$$

where 
$x=\sum_{1=1}^{\pi}(1+r)^{-1} \eta_{T-1}\left(1 \gamma^{-1} \ln [\beta(1+r)]-\gamma^{-1} \ln \left[\eta_{T}-1^{\eta} T^{-1}\right]\right)$

and

$c_{t+1}^{*}-\Phi(L) c_{t+1} \quad$ for a11 $i$

As a consequence of the restrictions on the $\pi$-coefficients, it becomes necessary to make an additional assumption on the length of the planning time span. Here we make the additional assumption that the consumer uses a time hortzon of 1 years, that is $T=4$.

After some simple manipulations with the lag polynomial $\Phi(L)$, we find

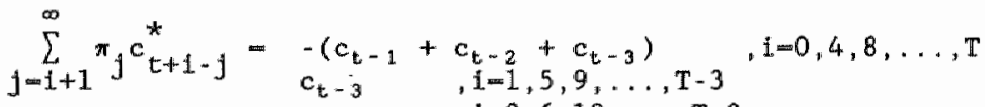

$$
\begin{aligned}
& c_{t-2} \quad, 1-2,6,10, \ldots, T-2 \\
& c_{t-1} \quad, 1=3,7,11, \ldots, T-1
\end{aligned}
$$

and hence after some rearranging

$$
\begin{aligned}
& \sum_{1=0}^{T}(1+r)^{-1} \sum_{j=1+1}^{\infty} \pi c_{t+1-j} c_{t+1}^{*}=-(1+r)^{-T}\left(c_{t-1}+c_{t-2}+c_{t-3}\right) \\
& \quad+\quad(T-4)\left[\left(-1+\frac{1}{\left.(1+r)^{3}\right)} c_{t-1}+\left(-1+\frac{1}{(1+r)^{2}}\right) c_{t-2}+\left(-1+\frac{1}{1+r}\right) c_{t-3}\right],\right.
\end{aligned}
$$

where

$r(4 k)=\sum_{1=0}^{k}(1+x)^{-41}$

Also, tt follows for the $\pi$-coefficients given by $(6.37)$ that

$$
\sum_{1 \rightarrow 0}^{T}(1+x)^{-1} \eta_{T-1}=F(T)
$$

Substitution of $(6.39)$ and $(6.40)$ into (6.38) yields for the decision $c_{t}^{*}$ 


$$
\begin{gathered}
\pi(T) c_{t}^{*}+\alpha=(1+r) a_{t-1}+\sum_{i=0}^{T}(1+r)^{-1} E\left(y_{t+1} \mid I_{t}\right)+(1+r)^{-T}\left(c_{t-1}+c_{t-2}+c_{t-3}\right) \\
+r(T-4)\left[\left(1-\frac{1}{(1+r)^{3}}\right) c_{t-1}+\left(1-\frac{1}{(1+r)^{2}}\right) c_{t-2}+\left(1-\frac{1}{1+r}\right) c_{t-3}\right]
\end{gathered}
$$

For the next period, the expression for the decision $c_{t+1}^{*}$ reads 11 ke

$$
\begin{gathered}
\tau(T) c_{t+1}^{*}+\alpha=(1+r) a_{t}+\sum_{1=0}^{T}(1+r)^{-1} E\left(y_{t+1+i} \mid I_{t+1}\right)+(1+r)^{-T}\left(c_{t}+c_{t-1}+c_{t-2}\right) \\
+r(T-4)\left[\left(1-\frac{1}{(1+r)^{3}}\right) c_{t}+\left(1-\frac{1}{(1+r)^{2}}\right) c_{t-1}+\left(1-\frac{1}{1+r}\right) c_{t-2}\right] .
\end{gathered}
$$

Dividing $(6.42)$ by $1+r$, substituting $a_{t} m(1+r) a_{t-1}+y_{t}-c_{t}$ and subtracting (6.41) leads to

$$
\begin{aligned}
& \left(c_{t+1}^{*}-c_{t}^{*}\right) r(T)(1+r)^{-1}=\left(1-\frac{1}{1+r}\right) \alpha+\sum_{i=1}^{T+1}(1+r)^{-i}\left[E\left(y_{t+1} \mid I_{t+1}\right)-E\left(y_{t+1} \mid I_{t}\right)\right] \\
& +(1+r)^{-(T+1)}\left[E\left(y_{t+T+1} \mid I_{t}\right)-c_{t-3}\right]
\end{aligned}
$$

where we have used.

$$
\begin{aligned}
-c_{t}+r(T-4)(1+r)^{-1}\left[\left(1-\frac{1}{(1+r)^{3}}\right) c_{t}+\left(1-\frac{1}{(1+r)^{2}}\right) c_{t-1}+\left(1-\frac{1}{1+r}\right) c_{t-2}\right] \\
\left.+(1+r)^{-(T+1)}\left(c_{t}+c_{t-1}+c_{t-2}\right)-(1+r)^{-T} c_{t-1^{+}}+c_{t-2}+c_{t-3}\right) \\
-r(T-4)\left[\left(1-\frac{1}{(1+r)^{3}}\right) c_{t-1}+\left(1-\frac{1}{(1+r)^{2}}\right) c_{t-2}+\left(1-\frac{1}{1+r}\right) c_{t-3}\right]= \\
-\left(r(T)-(1+r)^{-1} r(T)\right) c_{t}^{*}-(1+r)^{-(T+1)} c_{t-3} .
\end{aligned}
$$

Substitution of $\Delta c_{t+1}^{*}=\Delta_{4} c_{t+1}$ into (6.43) and multiplying with $(1+r) / \tau(T)$ yields finally

$$
\left.\Delta_{4} c_{t+1}=\tau(T)^{-1} r \alpha+r(T)^{-1} \sum_{i=0}^{T}(1+r)^{-i}\left[E_{\left(y_{t+1+1}\right.} \mid I_{t+1}\right)-E\left(y_{t+1+i} \mid I_{t}\right)\right]
$$




$$
\left.+r(T)^{-1}(1+x)^{-T}\left[E_{(y+T+1} \mid I_{T}\right)-c_{t-3}\right]
$$

An interesting feature of the consumption function (6.44) is the appearance of the correction term $\mathrm{E}\left(\mathrm{y}_{t+\mathrm{T}+1} \mid \mathrm{I}_{t}\right)-\mathrm{c}_{\mathrm{t}-3}$. Its presence arises from the adjustment of the plaming horizon as time goes on. The introduction of a moving planning horlzon provides an alternative explanation for the Inclusion of an error correction mechanism in the consumption function. To complete the model for consumption, we have to specify the process for income. In the mext subsection we show that when the annual change of income follows an $\operatorname{AR}(1)$ process, $(6.44)$ passes into the consumption Eunction of Davidson et. al. (1978). In this subsection our concerns will be to derive the implications of the model (6.36) for the univariate stochastic process of $c_{t}$.

The corresponding expression for the consumption decision in periad t-3 reads like

$$
\begin{aligned}
& \Delta_{4} c_{t-3}=\tau(T)^{-1} r \alpha+\tau(T)^{-1} \sum_{i=0}^{T}(1+r)^{-i}\left[E\left(y_{t-3+i} \mid I_{t-3}\right)-E\left(y_{t-3+i} \mid I_{t-4}\right)\right. \\
& +r(\mathrm{~T})^{-1}(1+\mathrm{r})^{-\mathrm{T}}\left[\mathrm{E}\left(\mathrm{y}_{\mathrm{t}+\mathrm{T}-3} \mid \mathrm{I}_{\mathrm{t}-4}\right)-c_{\mathrm{t}-7}\right] \text {. }
\end{aligned}
$$

Subtracting $(6.45)$ from $(6.44)$ ylelds

$$
\begin{aligned}
& \Delta_{4} c_{t+1}-\left[1-(1+r)^{\left.-T_{T}(T)^{-1}\right] \Delta_{4} c_{t-3}}=\right. \\
& r(T)^{-1} \sum_{i=0}^{T}(1+r)^{-1}\left[E\left(y_{t+1+1} \mid I_{t+1}\right)-E\left(y_{t+1+1} \mid I_{t}\right)\right] \\
& -r(T)^{-1} \sum_{t=0}^{T}(1+r)^{-1}\left[E\left(y_{t-3+1} \mid I_{t-3}\right)-E\left(y_{t-3+1} \mid I_{t-4}\right)\right] \\
& +r(T)^{-1}(\mathbb{1}+r)^{-T}\left[E\left(y_{t+T+1} \mid I_{t}\right)-E\left(y_{t+T-3} \mid I_{t-4}\right)\right] .
\end{aligned}
$$

Let us assume that the annual change in income is generated by a stationary process with moving average representation 
$\Delta_{4} y_{t+1}=\delta+\sum_{i=0}^{\infty} \psi_{i} \nu_{t+1-1}, \psi_{0}-1, \sum_{i=0}^{\infty} \psi_{1}^{2}<\infty, \sigma^{2}\left(\nu_{t+1}\right)=\sigma_{\nu}^{2}$.

It can be easily verifled from (6.47) that the relevant conditional expectations in (6.46) satisfy

$E\left(y_{t+1+4 i+j} \mid I_{t+1}\right)-E\left(y_{t+1+4 i+j} \mid I_{t}\right)=\sum_{k=0}^{1} \psi_{4 k+j} \nu_{t+1}$

$E\left(y_{t-3+41+j} \mid I_{t-3}\right)-E\left(y_{t-3+4 i+j} \mid I_{t-4}\right)=\sum_{k=0}^{1} \psi_{4 k+j} \nu_{t-3}$

with $j=0,1,2,3$ and $i=0,1,2, \ldots$, and

$E\left(y_{t+T+1} \mid I_{t}\right)-E\left(y_{t+T-3} \mid I_{t-4}\right)=\sum_{j=1}^{4} \sum_{k=0}^{T / 4} \psi_{4 k+j} \nu_{t+1-j}+\psi_{0}{ }^{\nu} t-3+\sum_{i=T+5}^{\infty} \psi_{1}{ }_{t+T+1-1}+\delta$.

Substitution of $(6.48)$ into $(6.46)$ yields after some rearranging

$$
\begin{aligned}
& \Delta_{4} c_{t+1}-\left[1-(1+r)^{-T} \tau(T)^{-1}\right] \Delta_{4} c_{t-3}=r(T)^{-1}(1+r)^{-T_{\delta}} \\
& +r(T)^{-1}\left[\sum_{i=0}^{(T-4) / 4} \sum_{j=0}^{3}(1+r)^{-(4 I+j)} \sum_{k=0}^{i} \psi_{4 k+j}+(1+r)^{-T} \sum_{k=0}^{T / 4} \psi_{4 k}\right] \nu_{t+1} \\
& +r(T)^{-1}(1+r)^{-T} \sum_{j=1}^{3} \sum_{k=0}^{T / 4} \psi_{4 k+j} \nu t+1-j \\
& -r(T)^{-1}\left[\sum_{i=0}^{(T-4) / 4} \sum_{j=0}^{3}(1+r)^{-(4 i+j)} \sum_{k=0}^{1} \psi_{4 k+j}\right] \nu_{t-3} \\
& +r(T)^{-1}(1+r)^{-T} \sum_{i=4}^{\infty} \psi_{T+1+1^{\nu} t-1} .
\end{aligned}
$$

From (6.49) we infer that when the annual change of Income 1s generated by a MA process of order $q, \Delta_{4} c_{t}$ follows an $\operatorname{ARMA}(4$, max $(4, q-T))$ process. Notice that the ARMA process for $\Delta_{4} c_{t}$ in (6.49) is subject to exclusion restrictions. This can be easily seen for the AR part which equals 1-[1-(1+r $\left.)^{-T} T(T)^{-1}\right] L^{4}$. Conditionally on the speciflc form of the lncome process, one or more MA parameters may be equal to zero. When $\Delta_{4} y_{t}$ satisfies 
$\Delta_{u_{k}} y_{t+1}=v+\sum_{1=0}^{k} w_{d+1}{ }^{\nu} t+1-41$

with $k \in\{0,1,2, \ldots,(T+4) / 4)$, formula $(6.49)$ passes into

$$
\begin{aligned}
& \Delta_{4} c_{\mathrm{T}+1}-\left[1-(1+\mathrm{r})^{-T} \pi(T)^{-1}\right] \Delta_{4} c_{t-3}=\tau(T)^{-1}(1+r)^{-T_{\delta}} \\
& +\tau(T)^{-1}\left[\sum_{i=0}^{(T-4) / 4}(1+r)^{-4 i} \sum_{k=0}^{1} \psi_{4 k}+(1+r)^{-T} \sum_{k=0}^{T / 4} \psi_{4 k}\right] \nu_{t+1} \\
& \quad=\tau(T)^{-1}\left[\sum_{i=0}^{(T-4) / 4}(1+r)^{-41} \sum_{k=0}^{i} \psi_{4 k}\right] \nu_{t-3}
\end{aligned}
$$

Hence, $\Delta_{4} c_{t}$ follows an ARMA $(4,4)$ process with only the coefficients of the highest lags of the AR and MA parts unequal to zero. To derive the stochastic process for $\Delta_{4} c_{t}$ when $\Delta_{4} y_{t}$ is generated by an $\operatorname{ARMA}(\mathrm{p}, \mathrm{q})$ model, 1t becomes necessary to explore the restrictions on the $\psi^{\prime \prime}$ s implied by the p+q ARMA parameters. In appendix $6 \mathrm{~A}$ it is shown that in that case $\Delta_{4} c_{t}$ follows an $A R M A(p+4, \max (p+4, \max (p-1, q)-T))$ process, where the autoregressive part is proportional to that of income.

Madels like (6.50) are frequently encountered in time series studies and the analysis of this section may shed some light on the economic story behind the ARMA specifications. Obviously, the theoretical framework can provide insight in the structures of the income and consumption process, which may be of some use in the identification stage of the modeling procedure. Moreover, Lucas (1976) has convincingly argued that a theoretical framework enables one to trace the effects of structural changes in the forcing variables on the endogenous variables. Expression (6.49) shows in this respect that a change in the income 1 ine will lead to a change in the constant term of the consumption model. A11 these results are very similar to those obtained in chapter 4. Notice however that this property does not hold for any ARMA process for the amnual change in consumption. Expression (6.49) shows that the highest lag of the autoregressive part of the stochastlc process is at least 4. 


\subsubsection{The Davidson, Hendxy, Srba and Yeo model (II)}

In this subsection we will show that if the annual change in income is generated by an autoregressive process of order 1 , the consumption function (6.44) is highly similar to the mechanism put forward by Davidson et. al. (1978). More specifically, we assume that

$\Delta_{4} y_{t+1}=\varphi \Delta_{4} y_{t}+\nu_{t+1}$

For the sake of simplicity we omit the constant term, which does not change the conclusions. It is straightforward to calculate the relevant conditional expectations, which read as

$E\left(y_{t+4 i+j} \mid I_{t+1}\right)-E\left(y_{t+4 i+j} \mid I_{t}\right)=\varphi^{j-1} \sum_{k=0}^{1} \varphi^{4 k}\left(\Delta_{4} y_{t+1}-\varphi \Delta_{4} y_{t}\right), \quad \begin{aligned} & j=1,2,3,4 \\ & i=0,1,2, \ldots\end{aligned}$

and

$E\left(y_{t+T+1} \mid I_{t}\right)=y_{t-3}+\varphi \sum_{k=0}^{T / / 4} \varphi^{4 j} \Delta_{4} y_{t}$

Substitution of $(6.51)$ into (6.44) leads after some rearranging to

$\Delta_{4} c_{t+1}=\alpha_{0}+\left(\alpha_{1}-\alpha_{2}\right) \Delta_{4} y_{t+1}+\alpha_{2} \Delta_{4} y_{t+1}+\alpha_{3}\left(y_{t-3}-c_{t-3}\right)$

with

$$
\begin{aligned}
& \alpha_{0}=\pi(T)^{-1} r \alpha \\
& \alpha_{1}=\tau(T)^{-1}\left[\sum_{i=0}^{(T-4) / 4} \sum_{j=1 .}^{4}(1+r)^{-(4 i+j-1)} \varphi^{j-1} \sum_{k=0}^{1} \varphi^{4 k}+(1+r)^{-T} \sum_{k=0}^{T / 4} \varphi^{4 k}\right] \\
& \alpha_{2}=\tau(T)^{-1} \varphi\left[\sum_{i=0}^{(T-4) / 4} \sum_{j=1}^{4}(1+r)^{-(4 i+j-1)} \varphi_{\varphi}^{j-1} \sum_{k=0}^{1} \varphi^{4 k}\right] \\
& \alpha_{3}=\tau(T)^{-1}(1+r)^{-T} .
\end{aligned}
$$

Expression (6.52) shows that we have the same mechanism as found in 
Davidson et. al. (1978). Notice that the income variable they use is real disposible fncome, whereas the relevant income concept in the model with moving planning horizon is real disposable non-property income. With our theoretical model we can determine the sign and size of the coefficients. For $a_{3}$ we find that it should be positive and smaller than 1 . The sign and size of both $\left(\alpha_{1}-\alpha_{2}\right)$ and $\alpha_{2}$ depend on the sign of $\varphi$. It can easily be shown that if $0<x p<1$ we have $0<\alpha_{1}-\alpha_{2}<1$ and $0<\alpha_{2}$, and when $-1<\phi<0$ we have $\alpha_{2}<0$ and $\alpha_{1} * \alpha_{2}>1$. In the consumption function of Davidson et. al. the coefficient for the annual change in income has a value between 0 and 1 , and the coefficlent for the change of that change is negative. Clearly, their point estimates do not satisfy the plausibility requirements of our theoretical mode 1.

We have also investigated the model under various assumptions concerning the length of the planning span. The ultimate consumption function differs only from (6.52) with respect to the lag of the correction term. It can be shown that for a time horizon $T$ such that there is an $i_{0}$ with $T=4 i_{0}+k$, $k=0,1,2,3$, the correction term reads like $\left(y_{t-3+k}-c_{t-3+k}\right)$. The coefficients of (6.52) need slight revision for a choice of $k$ unequal to 0 but leaves the inference with respect to the sign and size of the coefficients intact.

\subsection{Concluding remarks}

In this chapter we considered both the 11 fe cycle model and the model with novlng planning hotizon under rational habit formation. In the first two sections we examined the life cycle model and it was show that for the exponential utlity function an arbitrary ARIMA process for consumption is obtained by choosing an appropriate pattern of rational hablts. The model provides us with a theoretical framework for interpreting a broad category of stochastic processes for consumption. A major advantage of interpreting ARIMA processes within the context of intertemporal decision-making is that it enables one to Investigate the effects of policy interventions in the rigorous way indicated by Lucas (1976). The results of this chapter 11lustrate how simple ARIMA schemes for consumption may be used not only for forecasting purposes, but also for policy analysis. An illustrative 
example is when one wants to predict the effects on consuntion of a change in the tax rate on income. Given the low cost of specifying and estimating ARIMA processes the results of this chapter may be of practlcal Importance.

The principal implication of the life cycle model is the separation of the Iffe time consumption and income profiles. Consequently, the dynamics of consumption are basically determined by the preference structure. This observation reveals that structural changes in the ARMA parameters of the consumption process can only be interpreted within this framework by the assumption of a change in the preference structure. Noting that the consumption innovation is a transformation of the income innovation, it becomes clear that structural changes in the income process will affect persistentiy only the properties of the consumption innovation. It may be desirable however to establish a more direct link between the consunption and income processes. The model with moving planning horizon investigated in chapter 4 furnishes such a 1ink. In this chapter that model was analyzed for a special form of rational habits that yields a consumption function in the four pertod difference operator and it was shown that the model can reproduce the basic mechanism underlying the consumption function of Davidson et. a1. (1978).

Davidson and Hendry (1981) among others have stressed the (almost) observational equivalence of models based on forward looking behaviour and those based on feedback control rules. The models studied in this chapter provide a new illustration of this observation. Notice that the models of consumer behaviour undex rational habit formation, effectively establish a synthesis between forward and backward looking behaviour. In making his decision, the consumer is assumed to incorporate information on expected future labour income and Information consisting of past realtzations of consumption. We modelled the influence of past consumption by means of the utility function. The choice of the rational habits formulation corresponds to a specific case and can be viewed as an attractive way of limposing regularity on the preference structure in order to arrive at concrete results.

It should be remarked that the question what habits are remains unanswered. Muellbauer (1986) raises this issue and concludes that the use of aggregate data is unlikely to help very much in distinguishing exactly what habits 
represent. However some kind of behavioural persistence seems not unceasonably and in this chapter we have shown how this may be incorporated In the preference structure of an economic agent. To model behavioural persistence other predetermined variables may of course be considered as well. In the 1iterature on the consumption function, Duesemberry (1949) and Modigliani. (1949) have suggested that the consumption decision depends also upon the highest income attained by the consumer in the past. Davis (1952) and Brown (1952) consider past-peak consumption as an explanatory variable. In the next chapter we will analyze the model with moving planing horizon under spectfic form of rational habits, in which an expliclt influence of past-peak income and past-peak consumption is recognized and we w11 give empirical evidence for the Netherlands. 
Appendix 6A The unfvarlate stochastlc process for consumption in the model with noving planning horlzon when the anmual. change in Incone follows an ARM $(P, q)$ process

In this appendix we will derive the stachastic process of consumption implied by the model investigated in section 6.3 when the annual change in income is generated by an ARMA $(p, q)$ process. We consider a stationary invertible $\operatorname{ARMA}(p, q)$ process for the anmul change in income

$\Phi(L) \Delta_{4} y_{t}=\theta(L) \nu_{t}$, with $E\left(\nu_{t}\right)=0$ and $\sigma^{2}\left(\nu_{t}\right)-\sigma_{\nu}^{2}$.

The lag polynomials $\Phi(\mathbb{L})$ and $\theta(L)$ are defined as

$\Phi(L)=\varphi_{0}-\varphi_{1} L \cdots \varphi_{p} L^{p} \cdot \varphi_{0}{ }^{m 1}$

and

$\theta(\mathrm{L})=\theta_{0}-\theta_{1} \mathrm{~L}-\ldots-\theta_{\mathrm{q}} \mathrm{L}^{\mathrm{q}}, \theta_{0}-1$

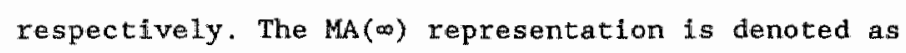

$\Delta_{4} y_{t}=\Psi(L) \nu_{t}$

with

$\Psi(\mathbb{L})=\sum_{i=0}^{\infty} \psi_{i} L^{1}, \psi_{0}=1$

From (A.1) and (A.2) follows

$\Phi(L) \Psi(L)=\theta(L)$.

Relationship (A.3) can be used to trace the restrictions on the parameters $\psi_{1}$ implied by the $p+q$ ARMA parameters. It is straightforward to show that 
$-128$.

(A.3) implies

$$
\psi_{j}-\varphi_{1} \psi_{j-1}+\ldots+\varphi_{p} \psi_{j-p} \text { for all } j \geq \max (p, q+1) \text {. }
$$

The parameters $\psi_{j}, \quad j \geq \max (p, q+1)$, are generated by a $\mathrm{p}^{\mathrm{th}}$ order homogeneous difference equation. When we define $\mu_{\mathrm{t}}$ as the MA part of $(6.49)$, we have

$$
\mu_{t}-\sum_{j=0}^{\infty} \alpha_{j} \nu_{t-j}
$$

with

$$
\begin{aligned}
& \alpha_{0}=\tau(T)^{-1}\left[\sum_{1=0}^{(T-4) / 4} \sum_{j=0}^{3}(1+r)^{-(41+j)} \sum_{k=0}^{1} \psi_{4 k+j}+(1+r)^{-T} \sum_{k=0}^{T / 4} \psi_{4 k}\right] \\
& \alpha_{j}=r(T)^{-1}(1+r)^{-T} \sum_{k=0}^{T / 4} \psi_{4 k+j}, j=1,2,3 \\
& \alpha_{4}=-r(T)^{-1}\left[\sum_{i=0}^{(T-4) / 4} \sum_{j=0}^{3}(I+r)^{-(41+j)} \sum_{k=0}^{1} \psi_{4 k+j}\right] \\
& \alpha_{j}=\tau(T){ }^{-1}(1+r)^{-T} \psi_{T+j}, j \geq 5 .
\end{aligned}
$$

Calculating the autocovariance function for $\mu_{t}$ yields for all $i \geq 5$

$$
\mathrm{E}\left(\mu_{\mathrm{t}} \mu_{\mathrm{t}-1}\right)-\sigma_{\nu}^{2},(\mathrm{~T})^{-1}(1+\mathbb{T})^{-\mathrm{T}} \sum_{j=0}^{\infty} \psi_{\mathrm{T}+1+\mathrm{j}^{\prime}} \alpha_{\mathrm{j}}
$$

For avery 1 satisfying $T+i \geq \max (p, q+1)$, we can use (A.4) to rewrite (A.5) as

$$
\begin{aligned}
E\left(\mu_{t} \mu_{t-1}\right) & =\sigma_{\nu}^{2} r(\mathbb{T})^{-1}(1+r)^{-T} \sum_{j=0}^{\infty} \sum_{k=1}^{p} \varphi_{k} \psi_{T+1+j-k^{\alpha} j} \\
& =\sum_{k=1}^{P} \varphi_{k}\left[\sigma_{\nu}^{2} r(\mathbb{T})^{-1}(1+r)^{-T} \sum_{j=0}^{\infty} \psi_{T+1+j-k^{\alpha}}\right] .
\end{aligned}
$$


For every i satisfying in addition $\mathrm{T}+\mathbb{1}-\mathrm{p} \geq \mathrm{T}+5$, substitution of (A.4) into (A.6) gives as a result

$E\left(\mu_{t} \mu_{t-1}\right)-\sum_{k=1}^{p} \varphi_{k} E\left(\mu_{t} \mu_{t-(\mathbb{1}-k)}\right)$

From the requirements in (A.5), (A.6) and (A.7), we see that for all $1 \geq \max (p+5, \max (p, q+1)-T)$ the autocovarlances of $\mu_{t}$ are generated by a $p^{t h}$ order homogeneous difference equation. For an ARMA $(r, s)$ process the autocovariances $\gamma_{j}$ are generated by an $r^{\text {th }}$ order homogeneous difference equation for all $\mathrm{j} \geq \mathrm{s}+1$. Because the autocovariance function determines the order of a stationary stochastic process, we conclude from (A.7) that $\mu_{\mathrm{t}}$ follows an ARMA $(p, \max (p+4, \max (p-1, q)-T))$ process, where the AR part coincides with that of the income process. Say

$\Phi(L) \mu_{t}=\bar{\theta}(L) \zeta_{t}, E\left(\zeta_{t}\right)=0$ and $\sigma^{2}\left(\zeta_{t}\right)=\sigma_{\zeta}^{2}$

or in MA representation

$\mu_{t}=\Phi(L)^{-1} \bar{\theta}(L) S t$

Substitution of (A.8) in (6.49) leads to the conclusion that $\Delta_{4} c_{t}$ is generated by an $\operatorname{ARMA}(p+4, \max (p+4, \max (p-1, q)-T))$ process. Notice that this ARMA process is subject to exclusion restrictions. The AR part factorizes as

$\Phi(L)\left(1-\left[1-r(T)^{-1}(1+r)^{-T}\right] \mathbb{L}^{4}\right)$

and the example discussed in section 6.3 illustrates that conditionally on the specific form of the income process (A.1) one or more of the MA parameters may be equal to zero. 
Chapter 7

THE MODEL WITH MOVING PLANMING HORIZON

DNDER VARIOUS FORMS OF HABIT FORMATION

In the previous chapter we analyzed models of intertemporal consumer behavlour in which a special kind of hablt persistemce was incorporated. We investigated the life cycle model and the model with moving plamning horizon under rational habit formation. Hence, the influence of past living standards was modelled by means of past consumption. This model may be considered as a generalization of that investigated by Brown (1952), in which habit persistence is captured by means of previous consumption. In the literature on the consumption function other varlables have been put forward to incorporate the effects of habit persistence. Duesenberry (1949) and Modigliani (1949) have suggested that the consumption decision deperds also upon the highest income attained by the consumer in the past. Davis (1952) and Brown (1952) have investigated the variant in which past-peak consumption is substituted for past-peak income. An attractive feature of modelling habits by means of these two variables is that it implies an asymmetrical relationship between income and consumption. Duesenberry (1949) argues that

"II... It is harder for a fandly to reduce its expenditure from a high level than for a fanfly to refrain from making high expenditure in the first place" (op. cit. p.85)

and that

"families are willing to sacrifice saving in order to protect their living standard" (op. cit. p.85).

The last quotation suggests that the impact of past-peak lincome should be incorporated by means of the preference structure. Duesenberry (1949) and Modigliani (1949) believe that the effect of past living standards on the current consumption level can be captured by means of past-peak income. 
Davis (1952) notices that the consumption hablts can only be bullt up when consumption actually takes place and argues that the relevant variable should be past-peak consumption. Brown (1952) investigates also the Impact of past-peak consumption, but his empirical analysis favours the influence of previous consumption. Since aggregate data on past-peak consumption and previous consumption usually coincide, it might be difficult to discriminate between the two hypotheses on the basis of empirical evidence. However, we have seen that since 1980 consumption and income move in a downward direction. Hence, we may expect that the data at our disposal contains information that sheds some light on the most suitable form of habit formation.

In the first section we will analyze the model with moving planning horlzon under a specific form of rational habit formation, that recognizes an impact of previous consumption on the current consumption decision. We also incorporate an explicit influence of past-peak income and past-peak consumption. As a result of adjusting the planning horizon as time goes on, a correction term as proposed by Davidson, Hendry, Srba and Yeo (1978) has to be included in the consumption function. The model provides us with an integrated framework to examine the different hypotheses concerning habit formation originally put forward by Brown (1952), by Duesenberry (1949) and Modigliani (1949) and by Davis (1952) and Brown (1952). For a review of recent contributions to the research on habit formation, we refer to Mue1lbauer (1986).

In section 7.2 we will look for empirical evidence using data for the Netherlands. We will test for the existence of habits in the consumption function and will try to isolate the particular form that is in accordance with the sample information. The model with moving planning horlzon investigated in chapter 4 is nested in the model analyzed in this chapter. Therefore, the empirical analysis carried out in section 7.2 will ylelld additional evidence with respect to the conclusions drawn fin chapter 4.

The empirical results for real total consumption per capita are very satisfactory. Information in the data, however, does not suggest the presence of habits. The analysis confirms the conclusion drawn in chapter 4 that the model with moving planning horizon is fully ln accordance with the sample information. These results contrast those obtained for real. nondurable consumption pex capita. With this consumption measure find a 
signlficant effect of past-peak consumption. Empirical evidence suggests that neither previous consumption nor past-peak income have a significant Impact on the consumption level. The distributional and serial correlation properties of the residuals and the predictive performance of the model are very satisfactory. In contrast to the empirical results obtained for the radel wh moving planning horizon investigated in chapter 4, the test for heteroscedasticity of the ARCH type in the disturbance term of the consumption function ylelds an insignificant value. This finding is in agreement with the theoretical model. Obviously, the inclusion of past-peak income remedies the inconsistency encountered in chapter 4. The examination of the point estimates indicates however that the higher pastpeak consumption the lower wil be current consumption (and vice versa). In other words, the Impact of the highest preceding level of consumption is the opposite of habit forming. The implication of habit hysteria makes it hard to qualify the empirical results as theory-consistent.

\subsection{Theory}

In this section we w11 discuss the theoretical model and we will derive the consumption function. The procedure we will follow is the same as used before, that is we solve the model for periods $t$ and $t+1$, and subtract the resulting expressions for $c_{t+1}$ and $c_{t}$ in order to eliminate financial wealth. At each time period $t$, the consumer is assumed to solve the following utilty maximization problem

$\operatorname{Max} \pi\left(c_{t}, \ldots, c_{t+T}\right)$

S.T. $\sum_{1=0}^{T}(1+r)^{-1} c_{t+1} \leq(1+r) a_{t-1}+\sum_{1=0}^{T}(1+r)^{-i_{E}}\left(y_{t+1} \mid I_{t}\right)$

$$
c_{t+1} \geq 0, \quad 1-0, \ldots T
$$

with

$$
\tilde{u}\left(c_{t} \ldots c_{t+T}\right)=u\left(c_{t}-a c_{t-1}-\alpha^{n} x_{t}\right)+\sum_{t=1}^{T} \beta^{i} u\left(c_{t+1}-a c_{t+1-1}\right)
$$


where $x_{t}$ denotes a k-vector of taste shifters, that are assumed to be known by the consumer, and $\alpha$ is the corresponding vector of coefficients. The consumption decision $c_{t}$ will be affected by past cholces of consumption. In order to establish a 1 ink between the model investigated in chapter 6 we assume that previous consumption influences current consumption in a way that corresponds to the rational habits formulation. The current consumption decision will also depend on the values of the vector of taste shifters $x_{t}$. Expression (7.2) shows that the preference ordening is chosen such that the additional variables influence only the one-period utility function of the current period. In the emplrical examination carried out in the next subsection we will consider the effects of past-peak income and past-peak consumption on current consumption.

There are of course mumerous ways of incorporating the taste shifters $x_{t}$ in the preference structure. One possibility is for instance a formulaton that corresponds to myopic habit formation (see Muelibauer (1986)). In that case the argument of the one-period utility function for period t+i reads like $c_{t+1}-a c_{t+1-1}-\alpha^{\prime} x_{t}$. However, in the sequel we w111 examine the exponential utility function. In case of myopic habit formation, the intertemporal utility function factorizes as

$-\gamma^{-1} \exp \left(\gamma \alpha^{\prime} x_{t}\right) \sum_{i=0}^{T} \beta^{i} \exp \left(-\gamma\left[c_{t+i}-a c_{t+i-1}\right]\right)$

and the resulting consumption decision and consequently the fimplied consumption function will be identical to that generated by a preference structure without taste shifters $x_{t}$. We have therefore decided to use the functional form (7.2). The value of $a c_{t-1}+\alpha^{\prime} x_{t}$ may be interpreted as necessary consumption (notice the correspondence with the Linear Expenditure System). This observation shows that $c_{t-1}$ and $x_{t}$ model habit persistence when $\alpha>0$ and $\alpha>0$. For negative values of a and $\alpha$, previous consumption and the taste-shifters reflect habit hysteria.

When $a$ is quasi-concave and the consumer is never satiated in at last one $c_{t}+$, the quasi-saddle polnt (QSP) characterization for an optimum yields a necessary and sufficient condition for global maximum (see e.g. Takayama (1985), p. 135). When we restrict ourselves to an interior solution the QSP characterlzation reduces to the familiar condition 
$\frac{\partial u}{\partial c} \mid \hat{c}=\hat{k} p^{\prime}$

$p^{\prime \prime c}-(1+r) a_{t-1}+\sum_{i=0}^{T}(1+r)^{-1} E\left(y_{t+1} \mid I_{t}\right)$

$\hat{x}>0, \hat{c}>0$

where $\lambda$ is the multiplier associated th the budget constraint, $c$ and $p$ denote the $(T+1)$-vectors $\left(c_{t}, \ldots, c_{t+T}\right)^{\prime}$ and $\left(1,(1+r)^{-1}, \ldots,(1+r)^{-I}\right)^{\prime}$ respectively and $(\hat{c}, \hat{\lambda})$ represents the solution of (7.3). Moreover, when a is strictly quasi-concave, $\hat{c}$ is a unique global maximum.

When we define

$c_{t+1}^{*}=c_{t+1}-a c_{t+1-1}$

and

$c^{*}=\left(c_{t}^{*}, \ldots, c_{t+\mathbb{T}}^{*}\right)^{\prime}$

it can be easily shown that

$c=A c^{*}+b c_{t-1}$

where $A$ is the $(\mathbb{T}+1) \times(\mathbb{T}+1)$ lower triangular matrix with $A_{1}-a^{1-j}$, $1 \geq j$, and $b$ is the $(T+1)$-vector $\left(a, a^{2}, \ldots, a^{T+1}\right)^{\prime}$. When we define

$a^{*}\left(c^{*}\right)-u\left(A c^{*}+b c c_{t-1}\right)-U\left(c_{t}^{*}-\alpha^{\prime} x_{t}\right)+\sum_{i=0}^{T} \beta^{i} U\left(c_{t+1}^{*}\right)$

1t follows that

$\frac{\partial \mathrm{u}}{\partial \mathrm{c}}=\frac{\partial \mathrm{u}^{*}}{\partial \mathrm{c}^{*}} \frac{\partial \mathrm{c}^{*}}{\partial \mathrm{c}}=\frac{\partial \mathrm{a}^{*}}{\partial \mathrm{c}^{*}} \mathrm{~A}^{-1}$.

and condition (7,3) becomes

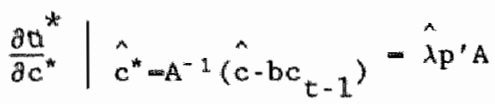




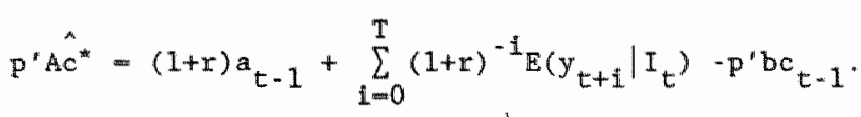

Along the lines of section 6.2, it can be easily shown that the necessary condition for the existence of an interior solution, that is

$\left.\frac{\partial u}{\partial c_{t+1}}\right|_{\hat{c}} ^{\wedge}>0, \quad I=0, \ldots . T$,

is satisfied and that $\mathrm{a}(\mathrm{c})$ is strictly quasi-concave.

We proceed by examining (7.4), which yields $(\mathrm{T}+2)$ equations to solve the $(T+2)$ unknown variables $\hat{c}_{t}, \hat{c}_{t+1}, \ldots, \hat{c}_{t+T}, \hat{\lambda}$. Expression $(7.4 a)$ reads as

$\frac{\partial a^{*}}{\partial c_{t+1}^{*}} \mid \hat{c}^{*}=\hat{\lambda(1+x)^{-1} \eta_{T-1}, i=0, \ldots, T}$

where

$n_{k}=\sum_{i=0}^{k}(1+x)^{-i} a^{i}$

Noting that

$\frac{\partial u}{\partial c_{t}^{*}}=U^{\prime}\left(c_{t}^{*}-\alpha^{\prime} x_{t}\right)$

and using expression (7.5) for $i=0$, it follows that

$\beta^{1} U^{*}\left(c_{t+1}^{*}\right)=(1+r)^{-1} \eta_{T-1} \eta_{T}^{-1} U^{*}\left(c_{t}^{*}-\alpha^{\prime} x_{t}\right), \quad 1=1, \ldots, T$.

For the exponential utility function

$\mathrm{U}(\mathrm{c})=-\gamma^{-1} \exp (-\gamma \mathrm{c}), \gamma>0$,

we can rewrite expression $(7,6)$ as

$c_{t+i}^{*}=c_{t}^{*}-\alpha^{\prime} x_{t}+i \gamma^{-1} \ln [\beta(1+r)]-\gamma^{-1} \ln \left[\eta T_{-i} T^{-1}\right], \quad 1=1, \ldots, T$ 
After substitution of (7.7) Into the budget constraint (7.4b), we get for the decision $c_{t}^{*}$

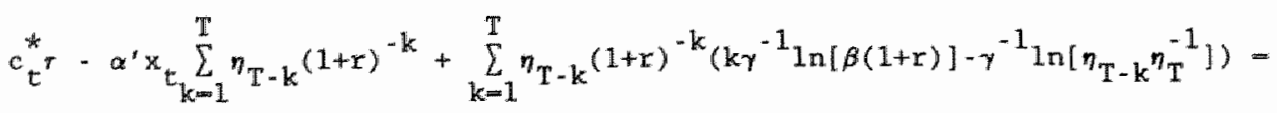

$$
\begin{aligned}
& (1+r) a_{t-1}+\sum_{1=0}^{T}(1+r)^{-1} E\left(y_{t+1} \mid I_{t}\right) \cdot a c_{t-1} T^{n}
\end{aligned}
$$

where

$\tau \sum_{k=0}^{T} \eta_{T}-k(1+x)^{-k}$

Substituting $c_{t}^{*} c_{t}-a c_{t-1}$ into formula (7.8) yields the current consumption deciston $c_{t}$ as a function of current income, future income expectations, wealth, previous consumption and the actual values of the taste shifters. When we consider past-peak income and past-peak consumption as taste shifters, the model examined in this chapter may be considered as a synthesis between the hypotheses concerning habit persistence originally put forward by Brown (1952), by Duesenberry (1949) and Modiglianl (1949), and by Davis (1952) and Brown (1952).

As before, it is implicitly assumed that the maximization problem (7.1) and (7.2) yields an interior solution. Expression (7.6) reveals in this respect that we have to impose the necessary condition

$\eta_{T-1} \eta_{T}^{-1}>0,1-1, \ldots, T$

It is straightforward to show that this restriction is satisfied for $a-(1+r)$. When do not want to exclude any value of $r \in(0,1)$, it is sufficient to require that $a \geq-1$.

To investigate the dynamics in consumption and to el.iminate financial wealth $a_{t-1}$, it is convenient to relate $c_{t}$ to $c_{t+1}$. Carrying out the same operations as before for the model solved for the next period leads to

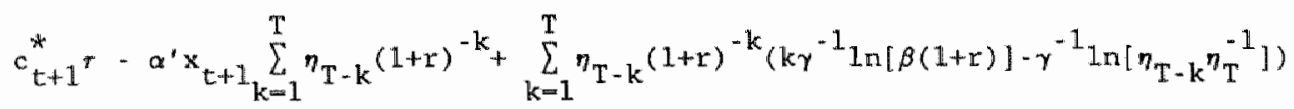


$-137$.

$$
=(1+r) a_{t}+\sum_{i=0}^{T}(1+r)^{-\mathbb{I}_{E}}\left(y_{t+i+1} \mid I_{t+1}\right)-a c_{t} \eta_{T}
$$

Dividing (7.9) by $1+r$, substituting $a_{t}-(1+r) a_{t-1}+y_{t}-c_{t}$ and subtracting (7.8) leads to

$$
\begin{aligned}
& \left(c_{t+1}^{*}-c_{t}^{*}\right)(1+r)^{-1} \tau=\left[1-(1+r)^{-1}\right]^{-1} \sum_{k=1}^{T} \eta_{T-k}(1+r)^{-k}\left(k \gamma-1 \ln [\beta(1+r)]-\gamma^{-1} \ln \left[\eta_{T}-k^{\eta} T^{-1}\right]\right) \\
& +\alpha^{\prime} x_{t+1}(1+r)^{-1}\left[\tau-\sum_{k=0}^{T}(1+r)^{-k_{a} k}\right]-\alpha^{\prime} x_{t}(1+r)^{-1}\left[\tau-(1+r)^{-T} \sum_{k=0}^{T} z^{k}\right] \\
& +(1+r)^{-(T+1)}\left[E\left(y_{t+T+1} \mid I_{t}\right)-c_{t}\right]-a(1+r)^{-(T+1)} \sum_{i=0}^{T} a^{i} \Delta c_{t} \\
& +(1+r)^{-1} \sum_{i=0}^{T}(1+r)^{-i}\left[E\left(y_{t+i+1} \mid I_{t+1}\right)-E\left(y_{t+i+1} \mid I_{t}\right)\right]
\end{aligned}
$$

where we have used

$$
\begin{aligned}
& r=(1+r)^{-1}+\eta_{T}-(1+r)^{-(T+1)} \sum_{i=0}^{T} a^{i}, \\
& (1+r)^{-1} \sum_{k=1}^{T} \eta_{T-k}(1+r)^{-k}=(1+r)^{-1} \tau-(1+r)^{-1} \sum_{i=0}^{T}(1+r)^{-1} a^{1}, \\
& \sum_{k=1}^{T} \eta_{T}-k^{(1+r)^{-k}}=(1+r)^{-1}-(1+r)^{-(T+1)} \sum_{i=0}^{T} a^{i}
\end{aligned}
$$

and

$$
c_{t}^{*}\left[-\eta_{T}+(1+r)^{-(T+1)} \sum_{i=0}^{T} a^{i}\right]=-c_{t}-(1+r)^{-1} a c_{t} \eta_{T}+a c_{t-1} \eta_{T}+(1+r)^{-(T+1)}\left[c_{t}+a \Delta c_{t} \sum_{i=0}^{T} a^{i}\right]
$$

Substitution of $\Delta c_{t+1}^{*}=\Delta c_{t+1}-a \Delta c_{t}$ into (7.10) and multiplying with $r(1+r)^{-1}$ yields finally

$$
\Delta c_{t+1}=r r^{-1} \sum_{k=1}^{T} \eta_{T-k}(1+r)^{-k}\left(k \gamma^{-1} \ln [\beta(1+r)]-\gamma^{-1} 1 n\left[\eta_{T}-k^{\eta_{T}-1}\right]\right)
$$




$$
\begin{aligned}
& +a^{\prime} x_{t+1}\left[1-\tau^{-1} \sum_{1=0}^{T}(1+r)^{-1} a^{1}\right]-a^{\prime} x_{t}\left[1-\tau^{-1}(1+r)^{-T} \sum_{i=0}^{T} a^{\mathbb{I}}\right] \\
& +r^{-1}(1+r)^{-T}\left[E\left(y_{t+T+1} \mid I_{t}\right)-c_{t}\right]+a\left[1-r^{-1}(1+r)^{-T} \sum_{i=0}^{T} a^{i}\right] \Delta c_{t} \\
& +r^{-1} \sum_{1=0}^{T}(1+r)^{-1}\left[E\left(y_{t+1+1} \mid I_{t+1}\right)-E\left(y_{t+1+1} \mid I_{t}\right)\right] .
\end{aligned}
$$

According to (7.11), $\Delta c_{t+1}$ is a linear function of $x_{t+1}, x_{t}, E\left(y_{t+1+1} \mid I_{t}\right)$. $c_{t}, \Delta c_{t}$ and the income innovation. The inclusion of $\Delta c_{t}$ is a result of rational habit formation, the appearance of the $x^{\prime} s$ is a consequence of allowing for taste shifting and the correction term $E\left(y_{t+I+1} \mid I_{t}\right)-c_{t}$ is Introduced because of the adjustment of the planning horizon as time goes on.

In chapter 4 we analyzed the model (7.1) and $(7.2)$ without habits. In that case we have $\alpha m 0$ and $a m 0$. Noting that $\eta_{k}=1$ for $a 11 k$ and

$\pi \sum_{i=0}^{T}(1+r)^{-1}$

expression (7.11) specializes to

$$
\begin{aligned}
\Delta c_{t+1} & =r\left[\sum_{k=0}^{T}(1+r)^{-k}\right]^{-1} \sum_{k=1}^{T}(1+r)^{-k_{k \gamma}}-1 \text { In }[\beta(1+r)] \\
+ & {\left[\sum_{k=0}^{T}(1+r)^{-k}\right]^{-1}(1+r)^{-T}\left[E\left(y_{t+T+1} \mid I_{t}\right)-c_{t}\right] } \\
& +\left[\sum_{k=0}^{T}(1+r)^{-k}\right]^{-1} \sum_{i=0}^{T}(1+r)^{-1}\left[E\left(y_{t+i+1} \mid I_{t+1}\right)-E\left(y_{t+i+1} \| I_{t}\right)\right] .
\end{aligned}
$$

It can be easily checked that formula (7.12) is identical to expression $(4,4)$ of chapter 4. Consequently, the empirical analysis of consumption finction (7.11) will yield information on the correctness of the conclusions drawn in chapter 4. The model analyzed in this section provides us with an integrated framework to investigate the various forms of habits. We will ask whether the information in the data suggests the presence of habits, and if so, which form is the most appropriate one. 


\subsection{Empirfical results}

In this section we will look for empirical evidence for the model described in the previous section using quarterly seasonally adjusted data for the Netherlands. The data on real disposable labour and transfer income per capita and on real consumption per capita are the same as those used in chapters 2, 4 and 5 . In the main text we report the results obtained for total consumption and those for nondurable consumption are given in. Appendix 7A.

The income series is investigated in section 2.2.1. The specified income process enables us to calculate the relevant conditional expectations of (7.11). Moreover, the analysis of the income series may yield information on possible structural changes in the income process.

We start the analysis by deriving the estimation equation for the model discussed in the previous section. In the first instance we ignore the implications of the structural changes in the drift parameter of the income process. When the change in income is generated by a moving average process of order 1

$\Delta y_{t}=\delta+\nu \nu_{t}-\theta \nu_{t-1}$

the relevant conditional expectations of (7.11) satisfy

$y_{t+1}-E\left(y_{t+1} \mid I_{t}\right)=w_{t+1}$

$\mathbb{E}\left(y_{t+1} \mid I_{t+1}\right)-E\left(y_{t+1} \mid I_{t}\right)=(1-\theta) \nu_{t+1}, i \geq 2$,

$E\left(y_{t+T+1} \mid I_{t}\right)=y_{t}+(T+1) \delta \cdot \theta \nu_{t}$.

Substituting (7.13), (7.14) and (7.15) into (7.11) yields

$\Delta \mathrm{c}_{\mathrm{t}+1}=\mathrm{r \tau} \tau^{-1} \sum_{\mathrm{k}=1}^{\mathrm{T}} \eta_{\mathrm{T}-\mathrm{k}}(1+\mathrm{r})^{-\mathrm{k}}\left(\mathrm{k \gamma}{ }^{-1} \ln [\beta(1+\mathrm{r})]-\gamma^{-1} \ln \left[\eta_{\mathrm{T}-\mathrm{k}^{\eta} \mathrm{T}}-1\right]\right)$ 


$$
\begin{aligned}
& +\alpha^{\prime} x_{t+1}\left[1-r^{-1} \sum_{i=0}^{T}(1+r)^{-1} a^{i}\right]-\alpha^{\prime} x_{t}\left[1-\tau^{-1}(1+r)^{-T} \sum_{i=0}^{T} a^{i}\right] \\
& +r^{-1}(\mathbb{1}+r)^{-T}\left[(T+1) \&+y_{t}{ }^{-c_{t}}\right]-r^{-1}(1+r)^{-T} \theta \nu_{t}+a\left[1-\tau^{-1}(1+r)^{-T} \sum_{i=0}^{T} a^{i}\right] \Delta c_{t} \\
& +r^{-1}\left[\mathbb{1}+(I-\theta) \sum_{i=1}^{T}(\mathbb{I}+r)^{-1}\right] \nu_{t+1} .
\end{aligned}
$$

The last term of $(7.16)$ can be expressed as

$$
\begin{aligned}
\tau^{-1}[1+(1-\theta) & \left.\sum_{t=1}^{T}(1+r)^{-1}\right] \nu_{t+1}=\tau^{-1}(1+r)^{-T}\left(\Delta y_{t+1}-\delta\right)+\tau^{-1}(1+r)^{-T} \nu_{t} \\
+\tau^{-1} & \sum_{1=0}^{T-1}(1+r)^{-1}\left[1-\theta(1+r)^{-1}\right] \nu_{t+1},
\end{aligned}
$$

and after substitution of $(7.17)$ into $(7.16)$ we get

$$
\begin{aligned}
& \Delta c_{t+1}=r r^{-1} \sum_{k=1}^{T} \eta_{T-k^{(1+r)}}{ }^{-k}\left(k \gamma^{-1} \ln [\beta(1+r)]-\gamma^{-1} \ln \left[\eta T-k^{\eta} T^{-1}\right]\right) \\
& +\tau^{-1}(T+1)(1+r)^{-T} \hat{b}+a\left[1-\tau^{-1}(1+r)^{-T} \sum_{1=0}^{T} a^{1}\right] \Delta c_{t} \\
& +\alpha^{\prime} x_{t+1}\left[1-\tau^{-1} \sum_{i=0}^{T}(1+r)^{-1} a^{i}\right]-\alpha^{\prime} x_{t}\left[1-\tau^{-1}(1+r)^{-T} \sum_{i=0}^{T} a^{i}\right] \\
& +\tau^{-1}(1+x)^{-T} \Delta y_{t+1}+\tau^{-1}(1+x)^{-T}\left(y_{t}-c_{t}\right) \\
& +\pi^{-1}\left[1-\theta(1+r)^{-1}\right] \sum_{1=0}^{\mathbb{T}-1}(\mathbb{1}+r)^{-1}{ }_{t+1}
\end{aligned}
$$

Undex the assumption that the changes in the drift parameter of the income process were not antlcipated, the model for consumption (7.18) needs revision. Let us assume that the constant term $\delta$ moves to $\delta^{*}$. Using the closed form solutions (7.8) and (7.9), it can be shown along similar lines as in chapter 2 that the structural change in the income process will give rise to a step change in the consumption model (7.18) equal to 
$\left(\delta^{*}-\delta\right) \tau^{-1}\left[\sum_{i=0}^{T}(i+1)(1+r)^{-1}-(1+r)^{-T}\right]$.

Therefore, both in $1971(1)$ and $1979(1)$ we should expect a negatiwe adjustment in the drift parameter of the consumption model (7.18). Moreover, because the constant term in (7.18) depends on $\delta$, we have also a persistent change of the drift parameter of the consumption function. When we define $\alpha=\left(\alpha_{1}, \alpha_{2}\right)^{\prime}$ and $x_{t}=\left(y_{t}^{\max }, c_{t}^{\max }\right)^{\prime}$, where $y_{t}^{\max }$ and $c_{t}^{\max }$ denote the highest preceding level of income and consumption respectively, we find for the estimation equation

$$
\begin{aligned}
\Delta c_{t} & =\sum_{i=1}^{5} \beta_{1} d_{1 t}+\gamma_{1} \Delta c_{t-1}+\gamma_{2} \Delta y_{t}+\gamma_{3}\left(y_{t-1}-c_{t-1}\right)+\gamma_{4} y_{t}^{\max }+\gamma_{5} c_{t}^{\max }+ \\
& +\gamma_{6} y_{t-1}^{\max }+\gamma_{7} c_{t-1}^{\max }+\varepsilon_{t}
\end{aligned}
$$

with $d_{1 t}=1$ for $1968(2)-1971(1)$

$$
\begin{aligned}
& d_{2 t}=1 \text { for } 1971(1) \\
& d_{3 t}=1 \text { for } 1971(2)-1979(1) \\
& d_{4 t}=1 \text { for } 1979(1) \\
& d_{5 t}=1 \text { for } 1979(2)-1984(4) .
\end{aligned}
$$

The coefficlents of (7.19) are defined as follows

$$
\begin{aligned}
& \beta_{1}=r \tau^{-1} \sum_{k=1}^{\mathrm{T}} \eta_{\mathrm{T}-\mathrm{k}}(1+\mathrm{r})^{-\mathrm{k}}\left(\mathrm{k} \gamma^{-1} \ln [\beta(1+\mathrm{r})]-\gamma^{-1} \ln \left[\eta_{\left.\left.\mathrm{T}-\mathrm{k} \eta^{-1}\right]\right)+\tau^{-1}(\mathrm{~T}+1)(1+\mathrm{r})^{-\mathrm{T}_{\delta}}}\right.\right. \\
& \beta_{2}=\left(\delta_{2}-\delta_{1}\right) r^{-1}\left[\sum_{i=0}^{T}(i+1)(1+r)^{-1}-(1+r)^{-T}\right] \\
& \beta_{3}=\beta_{1}+\left(\delta_{2}-\delta_{1}\right) \tau^{-1}(\mathrm{~T}+1)(1+\mathrm{r})^{-\mathrm{T}} \\
& \beta_{4}=\left(\delta_{3}-\delta_{2}\right) \pi^{-1}\left[\sum_{i=0}^{T}(i+1)(1+r)^{-i}-(1+r)^{-T}\right] \\
& \beta_{5}=\beta_{3}+\left(\delta_{3}-\delta_{2}\right) \tau^{-1}(\mathbb{T}+1)(1+r)^{-T} \\
& \gamma_{1}=a\left[1-r^{-1}(1+r)^{-T} \sum_{i=0}^{T} a^{1} \rrbracket\right.
\end{aligned}
$$




$$
\begin{aligned}
& \gamma_{2}=\gamma_{3}=\pi^{-1}(1+r)^{-T} \\
& \gamma_{4}=\alpha_{1}\left[1-\pi^{-1} \sum_{1=0}^{T}(1+r)^{-1} a^{1}\right] \\
& \gamma_{5}=\alpha_{2}\left[1-T^{-1} \sum_{1=0}^{T}(1+r)^{-1} a^{1}\right] \\
& \gamma_{6}=a_{1}\left[r^{-1}(1+r)^{-T} \sum_{i=0}^{T} a^{i}-1\right] \\
& \gamma_{7}=a_{2}\left[\tau^{-1}(1+r)^{-T} \sum_{i=0}^{T} a^{i}-1 \rrbracket\right.
\end{aligned}
$$

with $\delta_{1}$ being the coefficient of $d_{1 t}$ in the income model (2.14) and

$$
\varepsilon_{t}=r^{-1}\left[1-\theta(1+r)^{-1}\right] \sum_{1=0}^{T-1}(1+r)^{-1} \nu_{t} .
$$

The resulting consumption function is similar to the specification investigated in chapter 4. The correction term appears as a result of the adjustment of the planning horizon, and the explanatory variables $\Delta c_{t-1}$, $y_{t}^{m a x}, y_{t}^{m a x}, c_{t}^{m a x}$ and $c_{t}^{m a x}$ are included to capture the influence of the various forms of habits. The dummy variables appear as a result of the structural changes in the drift parameter of the income process, which, because of replanning and the forward looking behaviour of the consumer w11. have distorting Impact on the consumption function.

The analysis of consumption function (7.19) will yleld additional empirical evidence on the model investigated in chapter 4 , because the model without habits 4.5 nested in specification (7.19). Notice that the parameters in (7.19) are subject to one restriction, $\gamma_{4} \gamma_{7}-\gamma_{5} \gamma_{6}$. For the time being we w11 however ignore thls restriction. Since the explanatory variables are correlated with the disturbance term $c_{t}$. the model (7.19) has been estimated by Instrumental variables (IV). We inpose the restriction $\gamma_{2}-\gamma_{3}$ and use the five dummy variables, $\Delta c_{t-1}, \Delta y_{t-1}, y_{t-1}-c_{t-1}, y_{t}^{m a x}, c_{t}^{m x}$, $y_{t}=1$ and $c_{t}-1$ as instruments. For total consumption the following estimates have been obtalned 


$\begin{array}{lrl}\beta_{1} & -15.45 & (.30) \\ \beta_{2} & -79.20 & (2.84) \\ \beta_{3} & -59.42 & (.93) \\ \beta_{4} & -25.08 & (.82) \\ \beta_{5} & -84.69 & (1.14) \\ \gamma_{1} & .09 & (.38) \\ \gamma_{2} & .17 & (1.34) \\ \gamma_{4} & .25 & (1.39) \\ \gamma_{5} & -.48 & (1.31) \\ \gamma_{6} & -.14 & (.81) \\ \gamma_{7} & .39 & (1.13) \\ \sigma^{2}\left(\varepsilon_{t}\right) & 657.8 & \end{array}$

with t-values reported between parentheses. Some test statistics for model (7.19) are given in Table 7.1. The residuals do not exhibit any significant correlation. The values of the $B P$ and $L B$ test statistics based on the first $4,8,12$ and 16 residual autocorrelations are insigniflcant. In section 2.2.1 we found that normality and homoscedasticity for $\Delta y_{t}$ do not have to be rejected. Given that income is nomally distributed and homoscedastic, the theory predicts that the disturbance term $\varepsilon_{\mathrm{t}}$ should follow a normally distributed and homoscedastic process. In Table 7.11 the values of the test statistics for an ARGH structure of order 1 and order 4, and for normality of $\varepsilon_{t}$ are reported as $\eta(1), \eta(4)$ and $s_{1}, s_{2}$ respectively. All test statistics are insignificant, so we conclude that in this respect the empirical results are in accordance with the theory.

since the correlation between the explanatory variables and the disturbance term jeopardizes the validity of the statistics discussed above, we have also carried out several tests put forward by Kiviet (1985) in the context of Instrumental variable estimation. The statistic PFCF tests for post sample predictive power. It is based on predictions for the period 1983(1)-1984(4). Under the null hypothesis, it has an $F(8,47)$ distribution. SCE(p) and SCW(P) are LM- and Wald-type statistics for an AR(p) process for the residuals. They are asymptotically $x^{2}$ (p) distributed under the null hypothesis that the disturbances are white noise. We have also computed. their F-type versions, denoted by SCEF and SCWF with the number of degrees of freedom reported between brackets. As instruments we used the five dumy 
varlables, $\Delta y_{t-5}, \Delta y_{t-6}, \Delta y_{t-7}, \Delta c_{t-5}, \Delta c_{t-6}, \Delta c_{t-7}, \quad y_{t}^{m}-y_{t}^{m}, x_{5}$,

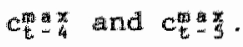

Table 7.1 Test statistics for model (7.19)

\begin{tabular}{lrr}
$\mathrm{P}$ & $\mathrm{BP}$ & \multicolumn{1}{c}{$\mathrm{LB}$} \\
4 & 1.66 & 1.73 \\
8 & 5.32 & 5.57 \\
12 & 11.06 & 11.57 \\
16 & 17.58 & 18.39
\end{tabular}

$\begin{array}{lcll}n(1) & 1.25 & & \\ \eta(4) & 1.68 & & \\ \mathrm{~S}_{1} & -.14 & & \\ \mathrm{~S}_{2} & -.17 & & \\ \operatorname{PFCF}(8,47) & .59 & \operatorname{SCE}(4) & 2.29 \\ \operatorname{SCE}(1) & 1.44 & \operatorname{SCEF}(4,45) & .45 \\ \operatorname{SCEF}(1,48) & 1.12 & \operatorname{SCW}(4) & 1.34 \\ \operatorname{SCW}(1) & .75 & \operatorname{SCWF}(4,45) & .25 \\ \operatorname{SCWF}(1,48) & .56 & & \\ & & & \\ \operatorname{CRW}(1) & .003 & & \\ \operatorname{CRWF}(1,54) & .003 & & \\ \operatorname{CRLM}(1) & .003 & & \\ \operatorname{CRLMF}(1,54) & .003 & & \end{array}$

Finally, the model (7.19) has been estimated without the restriction $\gamma_{2}=\gamma_{3}$. The point estimates are $\hat{\gamma}_{2}=.14(.26)$ and $\hat{\gamma}_{3}=.17(1.22)$. Several test statistics for the equality of the coefficients have been computed. CRW(1) and CRLM(1) refer to the Wald and LM-type statistics, which are asymptotically $x^{2}(1)$ distributed. In Table 7.1 we give also their F-type versions. All test statistics yield insignificant values for the one sided tests and we conclude that the distributional and serial correlation properties of the IV-residuals and the predictive performance of the model 


\section{(7.19) are very satisfactory.}

The results given in (7.20) show that only the estimate of $p_{2} 1 \mathrm{~s}$ significant and that a more restricted consumption function might be in accordance with the sample information. Therefore, we proceed by simplifylng the model (7.19) and by asking whether the information in the data indicates a significant effect of habit formation. When the answer is confirmative, the empirical evidence may suggest which form of habit formation is most appropriate. In Table 7.2 we report the values of the statisties for several hypotheses considered in the specification amalysis.

Table 7.2

$\left.H_{0}: \quad a-\alpha_{1}=\alpha_{2}=0 \quad \Leftrightarrow \gamma_{1}=\gamma_{4}-\gamma_{5}=\gamma_{6}=\gamma_{7}=0\right)$

$\begin{array}{llllll}\operatorname{CRW}(5) \quad 5.19 & \operatorname{CRWF}(5,55) & .86 & \operatorname{CRLM}(5) \quad 4.64 & \operatorname{CRLMF}(5,55) \quad .83\end{array}$

$\mathrm{H}_{0}: \mathrm{a}=\mathrm{O} \quad\left(\Rightarrow \gamma_{1}=0\right)$

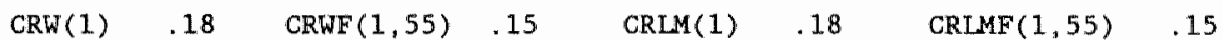

$\left.\mathrm{H}_{0}: \quad \alpha_{1}=0 \Leftrightarrow \gamma_{4}=\gamma_{6}=0\right)$

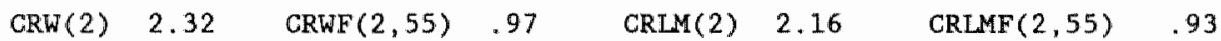

$\left.H_{0}^{\prime}: \quad \alpha_{2}=0 \quad \Leftrightarrow \gamma_{5}=\gamma_{7}=0\right)$

$\begin{array}{lllllll}\operatorname{CRW}(2) & 2.12 & \operatorname{CRWF}(2,55) & .88 & \operatorname{CRLM}(2) & 2.01 & \operatorname{CRLMF}(2,55)\end{array}$

$\left.H_{0}: \tau^{-1}(1+r)^{-T} \Sigma_{1=0}^{T} a^{1}=1 \Leftrightarrow \gamma_{1}=\gamma_{6}=\gamma_{7}=0\right)$

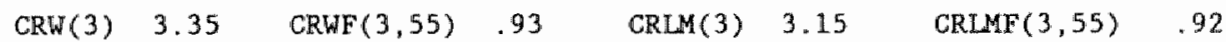

$H_{0}: \tau^{-1} \Sigma_{i=0}^{\mathrm{T}}\left[(1+r)^{-1} a\right]^{1}=1 \quad\left(\Rightarrow \gamma_{4}=\gamma_{5}=0\right)$

$\operatorname{CRW}(2) \quad 3.90 \quad \operatorname{CRWF}(2,55) \quad 1.64 \quad$ CRTM(3) $3.51 \quad \operatorname{CRLMF}(2,55) \quad 1.55$ 
To check whether the data indicate the presence of hablts, we direct our attention in the first instance to the restriction $a=\alpha_{1}=\alpha_{2}=0$. The values of the statistics which test the model examined in chapter 4 (i.e. $H_{0}$ : $a=\alpha_{1}=\alpha_{2}=0$ ) against the specification (7.19) are all insignificant. In Table 7.2 we also report a number of separate hypotheses constituting the joint hypothesis $H_{0}: \quad \gamma_{1}-\gamma_{4}-\gamma_{5}-\gamma_{6}-\gamma_{7}=0$. The values of the statistics for the different hypotheses that we have considered are all insignificant and we infer that the model without habits is not in contradiction with the sample information.

When we impose the restrictions $\gamma_{1}=\gamma_{4}=\gamma_{5}=\gamma_{8}=\gamma_{7}=0$, the consumption function (7.19) specializes to that investigated in chapter 4 . To check the robustness of the empirical results obtained in that chapter with respect to the chosen IV-set, we have also estimated the model with moving planning horfizon wh the Instrumental variables used in this chapter. For total consumption we find the following results

$\begin{array}{lrl}\beta_{1} & 41.45 & (5.05) \\ \beta_{2} & -76.27 & (2.77) \\ \beta_{3} & 15.45 & (2.73) \\ \beta_{4} & 4.15 & (.16) \\ \beta_{5} & 7.58 & (1.01) \\ \gamma_{2} & .25 & (3.04) \\ \sigma^{2}\left(\varepsilon_{t}\right) & 673.9 & \end{array}$

The results are very similar to those reported in section 4.2 .2 . Notice that the t-ratio of the coefficient of the correction term increases from 2.03 to 3.04 . The estimate of $\gamma_{2}$ can be used to find an estimate of $T$. It Is stralghtforward to show that $T \approx \gamma_{2}^{-1}-1$. From (7.21) we deduce for $T$ the estimate 3.0 (3.04). With respect to the evaluation of the sign and the size of the parameter estimates we refer to the discussion in section 4.2.2. Since the point estimates given in (7.21) only differ marginally from those reported in chapter 4, it may not be surprising that the conclusion remains intact that the model with moving planning horizon is in agreement with the sample information.

In Table 7.3 we give the values of some statistics for the restricted 
Table 7.3 Test statistics for model (7.21)

\begin{tabular}{lrr}
$\mathrm{p}$ & \multicolumn{1}{c}{$\mathrm{BP}$} & \multicolumn{1}{c}{$\mathrm{LB}$} \\
4 & 2.42 & 2.53 \\
8 & 5.78 & 6.05 \\
1.2 & 12.71 & 13.30 \\
16 & 21.25 & 22.23
\end{tabular}

$\begin{array}{lrlr}\eta(1) & 2.33 & & \\ \eta(4) & 2.87 & & \\ \mathrm{~S}_{1} & -.06 & & \\ \mathrm{~S}_{2} & -.09 & & \\ \operatorname{PFCF}(8,52) & .84 & \operatorname{SCE}(4) & 3.79 \\ & & \operatorname{SCEF}(4,50) & .84 \\ \operatorname{SCE}(1) & .08 & \operatorname{SCW}(4) & 2.49 \\ \operatorname{SCEF}(1,53) & .07 & & .52 \\ \operatorname{SCW}(1) & .08 & & \\ \operatorname{SCWF}(1,53) & .07 & & \\ & & & \\ \operatorname{CRW}(1) & .16 & & \\ \operatorname{CRWF}(1,59) & .14 & & \\ \operatorname{CRLM}(1) & .15 & & \\ \operatorname{CRLMF}(1,59) & .14 & \end{array}$

mode1. The results given in Table 7.3 do not suggest that the model is misspecified. The results of the tests for heteroscedasticity of the ARCH type and for the normality of $\varepsilon_{\mathrm{t}}$ are in accordance with the theoretical implications. IV-estimation of the model without the restriction $\gamma_{2}-\gamma_{3}$ yields the estimates $\hat{\gamma}_{2} .15(.54)$ and $\hat{\gamma}_{3}=24(2.75)$. The values of the (modified) Wald- and LM-statistics reported in Table 7.3 Indicate that the restriction $\gamma_{2}=\gamma_{3}$ is in accordance with the sample information.

From the empirical analysis carried out in this section we conclude that the model with moving planning horizon provides a satisfactory description 
of the data. The distributional and serial correlation properties of the IV-residuals and the predictive performance of the model are all in accordance with the theory. Sample information, however, does not suggest the presence of habits. The specification analysis leads to the same model as investigated in chapter 4 and provides additional evidence for that specification. Moreover, the empirical evidence given in this section shows that the results are falrly robust with respect to the cholice of the instrumental variables.

These conclusions contrast those obtained for real nondurable consumption. With this consumption measure we find a significant effect of past-peak consumption. Given the results for cotal consumption, this finding is rather surprising. Intultively, one would expect some inertia in consumers." behaviour when we consider consumption including durables. Contrary to this intuition, the empirical analysis suggests the opposite. Empirical. evidence $\mathbb{A n d}$ icates that nelther previous consumption nor past-peak income have a signiflcant impact on current consumption. The misspecification analysis shows that the model is in agreement with the sample information. The distributional and serial correlation properties of the residuals and the predictive performance of the model are very satisfactory. In contrast to the results obtained for the model without hablts investigated in chapter 4, the test for an ARCH structure in the disturbance term af the consumption function yields an insignificant value. The absence of heteroscedasticity of the ARCH type is in accordance with the theoretical implications. Obviously, the inclusion of past-peak consumption seems to remedy the inconsistency encountered in chapter 4. The examination of the polnt estimates, however, indicates that the impact of past-peak consumption is contrary to habit forming. The implication of habit hysteria makes 1 t hard to consider the empirical results as theoryconsistent.

Final1y, following King (1983) it should be stressed that the empirical analysis tests the joint hypothesis of the model with moving planning horizon extended for various forms of habit persistence and the chosen functional form of the preference structure. All the inferences and conclusions are therefore conditional on this jolint hypothesis. 


\section{Appendix 7 Ampirical results for real nondurable consumption per caplta}

In this appendix we present estimation results for teal nondurable consumption per capita. IV-estimation of the consumption function (7.19) yields the following results

$\begin{array}{lrl}\beta_{1} & 92.92 & (2.13) \\ \beta_{2} & -50.24 & (2.49) \\ \beta_{3} & 64.30 & (1.31) \\ \beta_{4} & -1.07 & (.05) \\ \beta_{5} & 78.21 & (1.34) \\ \gamma_{1} & -.26 & (1.25) \\ \gamma_{2} & .09 & (1.76) \\ \gamma_{4} & .23 & (1.87) \\ \gamma_{5} & -.29 & (.83) \\ \gamma_{6} & -.02 & (.15) \\ \gamma_{7} & -.04 & (.12) \\ \sigma^{2}\left(\varepsilon_{\mathrm{t}}\right) & 34 . .4 & \end{array}$

where $t$-values are reported between parentheses. We have used the IV-set consisting of the five dumny variables, $\Delta c_{t-1}, \Delta y_{t-1}, y_{t-1}-c_{t-1}, y_{t}^{m a x}$, $c_{t}^{m a x}, \quad y_{t}^{m a x}, \quad c_{t}^{m}-\frac{x}{1}$.

Several test statistics for model (A.1) are given in Table 7.A.1. Estimation without the restriction $\gamma_{2}=\gamma_{3}$ yllelds the estlmates $\hat{\gamma}_{2}-1.16$ (.51) and $\hat{\gamma}_{3}=.09$ (1.69). The values of the (modifled) Wald and LM-test statistics indicate that the restriction $\gamma_{2}=\gamma_{3}$ is not in contradiction with the sample information. All statistics reported in Table 7.AL yleld insignificant values and we conclude that the model with moving planning horizon extended for the effects of varlous forms of habit formation provides a satisfactory description of the data. Notice that in contrast to the results obtained in chapter 4, the tests for heteroscedasticity of the ARCH type yield insignificant values.

The estimates given in (A.1) suggest that a more restricted model might be 
Table 7.Al Test statistics for model (A.1)

\begin{tabular}{lrr} 
P. & \multicolumn{1}{c}{ BP } & \multicolumn{1}{c}{ LB } \\
4 & 1.29 & 1.35 \\
8 & 2.43 & 2.54 \\
12 & 10.44 & 10.92 \\
16 & 14.86 & 15.54
\end{tabular}

$\begin{array}{ll}\eta(1) & 1.22 \\ \eta(4) & 3.46 \\ s_{1} & -.11 \\ s_{2} & -.13 \\ \operatorname{PFCF}(8,47) & 1.06\end{array}$

$\begin{array}{lllr}\operatorname{SCE}(1) & .53 & \operatorname{SCE}(4) & 3.87 \\ \operatorname{SCEF}(1,48) & .43 & \operatorname{SCEF}(4,45) & .78 \\ \operatorname{SCW}(1) & .50 & \operatorname{SCW}(4) & .05 \\ \operatorname{SCWF}(1,48) & .40 & \operatorname{SCWF}(4,45) & .01\end{array}$

$\begin{array}{ll}\operatorname{CRW}(1) & .06 \\ \operatorname{CRWF}(1,54) & .05 \\ \operatorname{CRLM}(1) & .06 \\ \operatorname{CRLMF}(1,54) & .05\end{array}$

appropriate to decribe the data. In Table 7.A2 we report the values of the statistics for the varfous hypotheses considered in an attempt to obtain a more parsimonious parameterization of the consumption function. The test for absence of habit effects (1.e. $H_{0}: \quad a_{1}=\alpha_{2}=0$ ) leads unequivocally to the conclusion that the restriction $\gamma_{1}-\gamma_{4}=\gamma_{5}=\gamma_{6}=\gamma_{7}=0$ is at variance with the sample information. Given the results abtained for total consumption, the strong rejection of this hypothesis is rather surprising. It seems quite natural to expect some inertia in consumers' behaviour when we 
Table $7 . A 2$

\begin{tabular}{|c|c|c|c|c|c|c|c|}
\hline GRW (5) & 20.66 & $\operatorname{GRWF}(5,55)$ & 3.44 & $\operatorname{CRLM}(5)$ & 15.77 & $\operatorname{CRLMF}(5,55)$ & 3.45 \\
\hline \multicolumn{8}{|c|}{$H_{0}: \quad a=0 \quad\left(\Rightarrow \gamma_{1}=0\right)$} \\
\hline $\operatorname{CRW(1)}$ & 1.8 .8 & $\operatorname{CRWF}^{\prime}(1,55)$ & 1.57 & GRLM(1) & 1.82 & $\operatorname{CRLMF}(1,5,5)$ & 1.56 \\
\hline \multicolumn{8}{|c|}{$\left.H_{0}: \alpha_{1}=0 \quad \Leftrightarrow \gamma_{4}=\gamma_{6}=0\right)$} \\
\hline CRW (2) & 6.73 & CRWF $(2,55)$ & 2.80 & $\operatorname{CRLM}(2)$ & 5.91 & $\operatorname{CRLMF}(2,55)$ & 2.70 \\
\hline \multicolumn{8}{|c|}{$\left.H_{0}: \quad \alpha_{2}=0 \quad \Leftrightarrow \gamma_{5}=\gamma_{7}=0\right)$} \\
\hline CRW(2) & 6.93 & $\operatorname{CRWF}(2,55)$ & 2.89 & GRLM(2) & 6.11 & $\operatorname{CRLMF}(2,55)$ & 2.81 \\
\hline \multicolumn{8}{|c|}{$H_{0}: \tau^{-1}(1+r)^{-T} \Sigma_{i=0}^{T} a^{1}=1 \quad\left(\Leftrightarrow \gamma_{1}=\gamma_{6}=\gamma_{7}=0\right)$} \\
\hline CRW(3) & 5.66 & $\operatorname{CRWF}(3,55)$ & 1.57 & CRLM(3) & 5.21 & $\operatorname{CRLMF}(3,55)$ & 1.57 \\
\hline
\end{tabular}

$\operatorname{CRH}(2) \quad 5.41 \quad \operatorname{CRWF}(2,55) \quad 2.25 \quad \operatorname{CRLM}(2) \quad 4.93 \quad \operatorname{CRLMF}(2,55) \quad 2.22$

consider consumption including durables. This would probably less the case for consumption of nondurables. Contrary to this Intuition, the emptrical evidence suggests the opposite. In an attempt to trace the particular restriction that is responsible for the decisive rejection of $H_{\mathfrak{b}}$ : $\gamma_{1}=\gamma_{4}=\gamma_{5}=\gamma_{5}=\gamma_{7}=0$, we examine a number of separate hypotheses. Whe results given in Table 7.A2 suggest that past-peak consumption and past-peak fncome have a significant impact on current consumption and that the restriction 
amo is not resporisible for the rejection of the hypothesis of no habit formation. Therefore, we impose the restriction aw0 and find the following results

$\begin{array}{lrl}\beta_{1} & 93.85 & (2.13) \\ \beta_{2} & -48.28 & (2.38) \\ \beta_{3} & 63.37 & (1.28) \\ \beta_{4} & .05 & (.002) \\ \beta_{5} & 77.90 & (1.33) \\ \gamma_{2} & .10 & (1.97) \\ \gamma_{4} & .19 & (1.62) \\ \gamma_{5} & -.63 & (2.82) \\ \gamma_{6} & .003 & (.02) \\ \gamma_{7} & .31 & (1.76) \\ \sigma^{2}\left(\varepsilon_{t}\right) & 349.3 & \end{array}$

When we subsequently test the signiflcance of past-peak income and pastpeak consumption, we find the following values

Table $7 . \mathrm{A}^{3}$

$\begin{array}{lrlr}\left.\mathrm{H}_{0}: \alpha_{1}=0 \Leftrightarrow \gamma_{4}=\gamma_{6}=0\right) & \left.\mathrm{H}_{0}: \alpha_{2}=0 \Leftrightarrow \gamma_{5}=\gamma_{7}=0\right) \\ \operatorname{CRW}(2) & 5.48 & \operatorname{CRW}(2) & 10.05 \\ \operatorname{CRWF}(2,56) & 2.32 & \operatorname{CRWF}(2,56) & 4.26 \\ \operatorname{CRIM}(2) & 4.91 & \operatorname{CRLM}(2) & 8.55 \\ \operatorname{CRLMF}(2,56) & 2.25 & \operatorname{CRLMF}(2,56) & 4.16\end{array}$

Obviously, the results of Table 7.A3 indicate that the restriction $\alpha_{2}=0$ is not supported by the information in the data. The restriction $\alpha_{1}=0$ however does not seem to be at varlance with the sample information. When we Limpose the restriction $\alpha_{1}=0$ we obtain the following model 
$\Delta c_{t}=\sum_{1=1}^{5} \beta_{i} d_{i t}+\gamma_{2} \Delta y_{t}+\gamma_{3}\left(y_{t-1}-c_{t-1}\right)+\gamma_{5} c_{t}^{\max }+\gamma_{7} c_{t-1}^{\max }+c_{t}$

with $\gamma_{2}=\gamma_{3}$ and $d_{1 t}=1$ for $1968(2)-1971(1)$

$$
\begin{aligned}
& d_{2 t}=1 \text { for } 1971(1) \\
& d_{3 t}=1 \text { for } 1971(2)-1979(1) \\
& d_{4 t}=1 \text { for } 1979(1) \\
& d_{5 t}=1 \text { for } 1979(2)-1984(4)
\end{aligned}
$$

and $d_{i t}=0$ otherwise. The expressions for the coefficlents can be found by substituting $a m 0$ and $\alpha_{1}=0$ into (7.19). Notlce that for $a m 0$ the expression for $r$ specializes to

$\tau \sum_{1=0}^{T}(1+r)^{-1}$

When we impose the restriction $\gamma_{2}-\gamma_{3}$ and use the same instrumental variables as before, we find the following results

$\begin{array}{lrl}\beta_{1} & 70.38 & (1.69) \\ \beta_{2} & -46.08 & (2.19) \\ \beta_{3} & 46.88 & (.94) \\ \beta_{4} & 6.48 & (.31) \\ \beta_{5} & 59.82 & (1.01) \\ \gamma_{2} & .17 & (3.69) \\ \gamma_{5} & -.39 & (2.13) \\ \gamma_{7} & .32 & (1.76) \\ \sigma^{2}\left(\varepsilon_{t_{2}}\right) & 376.6 & \end{array}$

where t-ratios are given between parentheses. In Table 7. A4 we report some statistics for mode1 (A.4) When we do not impose the restriction $\gamma_{2}-\gamma_{3}$, IVestimation yields $\hat{\gamma}_{2}-.005(.03)$ and $\hat{\gamma}_{3} .16(3.48)$. The values of the (modified) Wald-and LM-type statistics reported in Table 7. A4 cloarly do not suggest that the restriction $\gamma_{2} \gamma_{3}$ is in contradiction with the sample information. Obviously, the results of the test for the exclusion of pastpeak consumption (i.e. $\alpha_{1}=0$ ) do not permit us to impose the restriction $\gamma_{5}-\gamma_{7}=0$. All other statistics yield insignificant values and we conclude that the distributional and serial correlation propertles of the IV. 
Table 7.A4 Test statistlcs for model (A.4)

$\mathbb{R}$

BP

LB

$\begin{array}{lrr}4 & .56 & .59 \\ 8 & 1.21 & 1.26 \\ 12 & 8.51 & 8.90 \\ 16 & 14.11 & 14.76\end{array}$

$\begin{array}{lr}\eta(1) & .87 \\ \eta(4) & 4.31 \\ \mathrm{~S}_{1} & -.12 \\ \mathrm{~S}_{2} & -.08 \\ \operatorname{PFCF}(8,50) & 1.74\end{array}$

$\begin{array}{lclr}\operatorname{SCE}(1) & .29 & \operatorname{SCE}(4) & 8.95 \\ \operatorname{SCEF}(1,51) & .25 & \operatorname{SCEF}(4,48) & 2.10 \\ \operatorname{SCW}(1) & .29 & \operatorname{SCW}(4) & 1.70 \\ \operatorname{SCWF}(1,51) & .25 & \operatorname{SCWF}(4,48) & .3 .4 \\ & & & \\ \mathrm{H}_{0}: \gamma_{2}=\gamma_{3} & & \left.H_{0}: \alpha_{2}=0 \Leftrightarrow \gamma_{5}=\gamma_{7}=0\right) \\ & & & \\ \operatorname{CRW}(1) & 1.02 & \operatorname{CRW}(2) & 11.38 \\ \operatorname{CRWF}(1,57) & .88 & \operatorname{CRWF}(2,58) & 5.00 \\ \operatorname{CRLM}(1) & .96 & \operatorname{CRLM}(2) & 10.02 \\ \operatorname{CRLMF}(1,57) & .84 & \operatorname{CRLMF}(2,58) & 5.19\end{array}$

residuals and the predictive performance of the model (A.4) are very satisfactory. Notice that in contrast to the empirical results obtained for the model without hablts investigated in chapter 4 , the test for an ARCH structure $\mathbb{1 n}$ the disturbance term of the consumption function $y$ fields an insignificant value. The absence of heteroscedasticity of the ARCH type is in agreement with the theoretical implications. Obviously, the 
empirical findings reported in this appendix suggest that the inclusion of past-peak consumption remedies the inconsistency encountered in chapter 4. Finally, we consider the point estimates. For $\varepsilon_{\mathrm{t}}$ we have

$\varepsilon_{t}=\tau^{-1}\left[\tau-(1+r)^{-T}\right]\left[1-\theta(1+r)^{-1}\right] \nu_{t}$.

As $\theta=.428$, we have as an implication of the theoretical madel that the variance of $\varepsilon_{\mathrm{t}}$ is smaller than that of the income innovation. A comparison of the values reported in (2.14) and (A.4) shows that the point estimates confirm the theory on this point. The criterion that the coefficient of the correction term should be positive and smaller than 1 is met. The estimate of $\gamma_{2}$ can be used to find an estimate of $T$. It can be easlly shown that $T=\gamma_{2}^{-1}-1$. From (A.4) we deduce for $T$ the estimate 4.88 (3.69).

From (A.3) and (7.19) it follows that the sign of $\beta_{1}, \beta_{3}$ and $\beta_{5}$ depends on that of $\gamma^{-1} \ln [\beta(1+r)]\left[1-(T+1)(1+r)^{-T} \tau^{-1}\right]$. However, with the point estimates of the $\delta_{i}$ 's given in (2.14) the following lnequality has to hold: $\beta_{5}<\beta_{3}<\beta_{1}$. The results of (A.4) show that the point estimates are at variance with this theoretical implication.

When $a=\alpha_{1}=0$, the expressions for $\gamma_{5}$ and $\gamma_{7}$ read like $\gamma_{5}-\alpha_{2}\left[1-\tau^{-1}\right]$ and $\gamma_{7}=\alpha_{2}\left[(1+r)^{-T_{T}-1}-1\right]$. The estimates of $\gamma_{5}$ and $\gamma_{7}$ are compatible with a negative value of $\alpha_{2}$. This finding is consistent with habit hysteria. From the estimates of $\gamma_{2}$ and $\gamma_{7}$ we can easily deduce point estimate of $\alpha_{2}$ : $\hat{\alpha}_{2}=-39$. The implication of habit hysteria casts serfous doubts on the appropriateness of the model. 


\section{Chapter 8}

\section{SRASONAL RLUCTUATIONS IN CONSUMPTION}

In this chapter we wil show how the implications from the life cycle model can be incorporated in univarlate autoregressive integrated moving average (ARTMA) processes of seasonally unadjusted consumption and that they can be tested by means of univarlate time serles procedures. Recently, Miron (1986) has suggested that the improper handling of seasonality might be the explanation for the frequent rejections of the 1 ife cycle model. Above we paid already some attention to the issue of modelling seasonally unadjusted data on consumption. In chapter 6 we analyzed the model with moving planning horizon under a specific form of rational habit formation and showed that It was capable of reproducing the basic mechanism underlying the consumption function of Davidson, Hendry, Srba and Yeo (1978).

Modelling seasonal patterns may be of interest for instance in short-term forecasting and pollcy analysis. Hence, it seems worthwile to see whether the framework developed in the previous chapters can be used to model consumption data that are subject to seasonal fluctuations. Unfortunately, we do not have quarterly seasonally unadjusted data on labour and transfer incone at our disposal. Since the model with moving planning horizon limplies that the dymamics in consumption are closely related to those of Lncome, the absence of unadjusted income data impedes an analysis within that framework. We have therefore chosen for an examination within the context of the life cycle model. Because we do not want to ignore the possible effects of structural changes in the income process, we used the same income series as in the previous chapters. An empirical analysis of that series fis carried out in section 2.2.1. Although the choice of an adjusted income series may be a poor one, the use of it is not prohibitive since the rational consumer is capable of anticipating on and incorporating in his consumption decision the seasonal fluctuations of income (see also Miron $(1986)$ ). 
The ARIMA processes investigated by Box and Jenkins (1976) provide a broad class of models for univariate time series forecasting and seasonal adjustment. In the Box-Jenkins approach the basic tools for specifying a suitable model are the autocorrelation and partial autocorrelation functions. More recently, structural time series models (STMs) have been introduced and used in forecasting (see e.g. Harvey and Todd (1983), Gersch and Kitagawa (1983), Steyn and De Vos (1987)) and in the decomposition of economic time series into trend, cyclical and seasonal components (see e.g. Engle (1978), Nerlove et. al. (1979), Nelson and Plosser (1982), Harvey (1985) and Maraval1 (1985)). STMs are formulated in terms of simple ARIMA schemes for the trend, cyclical, seasonal and irregular components of the series. The processes for the components are specifled in such a way that the resulting model for the series is in accordance with the sample information. An advantage of formulating the model. directly in terms of the components is that the implied process for the observed variable satisfles plausible requirements concerning the type of forecast function and the type of time series structure. Although STMs are derived from prior information, the implications from economic theory are usually not explicitly incorporated into the specification of STMs. In the previous chapters we have seen how a model of intertemporal decision-making can be brought to bear on the serial correlation properties of a single economic time series. The interpretation of the components as resulting from a dynamic optimization problem opens up the possibility to incorporate in the model the perturbations caused by structural changes in the environment fin which the agents have to take their decisions. In chapter 2 tt was argued that the framework of intertemporal maximization is an appropriate one for interpreting outliers, the appearance of which can heavily affect the parameter estimates and hence hinder a correct examination of the structure of the series. For the life cycle model analyzed in that chapter it was also shown that an unanticipated structural change in the drift of the income process will glve accasion to a level change in the consumption series. Obviously. the structural changes have an limportant impact on the forecast function.

In the first section we will specify a basic STM for consumption. We will use the life cycle model with intertemporally additive utility function to obtain a model for the trend-cycle component of aggregate consumption. The 
seasonal component: are assumed to sun to a white nolse. We will give mpirlcal evidence for the Netherlands using seasonally unadjusted data on real nondurable consumption per caplta. The series and a short description of the data are given in appendix $\mathbb{I}$.

STMs can be estlmated by state space methods. Instead, we apply the method of asymptotic least squares (see e.g. Gourieroux et. al. (1985) and Kodde and Palm (1986)) to get efficient parameter estimates, standard errors and test statistics for the restrictions implied by the theoretical model. This computationally convenient method is briefly outlined in Appendix $8 \mathrm{~A}$. The highly parstmonious model implied by the 1 ife cycle theory and the stochastic specification for the seasonals takes the form of a restricted MA process of order 3 for the annual change in consumption. To account for the drop in consumption since 1980, we assume that one of the parameters of the utility function has changed. The estimation results are not fully in accordance with the theoretical implications and the calculated autocorrelation function for the subperiods suggests that an AR(1) process for the annual change in consumption seems to be more appropriate.

In chaptex 6 we discussed the 1 ffe cycle model under rational habit formation and we showed how an arbitrary ARIMA process for consumption can be obtalned by choosing an appropriate pattern of rational habits. In the second section we will therefore model the seasonality as a special form of rational habits. We will also indicate how a model with seasonal dumm varlables may be interpreted as resulting from seasonal shocks to the preferences. In the empirical analysis, we will choose a specification that 1.5 very sinflar to the one investigated by Davidson and Hendry (1981), and whlch they present as the analogue of Hel1's model. The empirical evidence indicates that the implications of the theoretical model are not fully in accordance with the information in the data. The test for heteroscedasticity of the ARCH type for the consumption innovation yields a significant value, whereas a homoscedastic process is in agreement with the theoretical model.

Section 8.3 is devoted to concluding remarks. We suggest a possible remedy to bring the theoretical model in agreement with the empirical evidence and discuss some possible extensions. 


\subsection{A structural time series model}

In this section our concerns will be to specify a structural time series model for consumption, whereby the life cycle hypothesis with intertemporally additive utility function is used to obtain a model for the trend-cycle component of aggregate consumption, and to give empirical evidence for the Netherlands.

The basic structural model put forward by Harvey and Todd (1983) has the following form

$x_{t}=\delta_{t}+\gamma_{t}+\varepsilon_{1 t}$

where $x_{t}$ is the observed variable and $\delta_{t}, \gamma_{t}$ and $\varepsilon_{1 t}$ are the trend, seasonal and frregular components respectively. The process generating the trend is specified as

$\delta_{t}=\delta_{t-1}+\beta_{t-1}+\varepsilon_{2 t}$ and $\beta_{t}=\beta_{t-1}+\varepsilon_{3 t}$

where $\varepsilon_{2 t}$ and $\varepsilon_{3 . t}$ are normally and independently distributed white nolse processes with zero means and variances $\sigma_{2}^{2}$ and $\sigma_{3}^{2}$ respectively. The seasonal component is defined as

$\sum_{i=0}^{s-1} \gamma_{t-i}=\varepsilon_{4 t}$,

where $s$ is the number of "seasons" in a year and $\varepsilon_{4} \mathrm{t}$ is normally distributed white noise with varlance $\sigma_{4}^{2}$. The disturbances $\varepsilon_{2 t}, \varepsilon_{3 t}$ and $\varepsilon_{4}$ are independent of each other and of the irregular component that is a normally distributed white noise with varlance $\sigma_{1}^{2}$.

In the basic structural model, the trend has both its level $\delta_{t}$ mand 1 ts slope $\beta_{\mathrm{t}}$ slowly changing over time. The seasonal pattern is also changing over time. Various partially deterministic models arise as special cases of the basic structural model. An example is the seasonal random walk with drift, i.e. 
$\Delta x_{t}-\beta+\sum_{1=1}^{s-1} \beta_{1} d_{1 t}+\varepsilon_{2 t}$

where $\beta$ is the trend parameter " the $d_{10}$ "s are the seasonal dummies and the $\beta_{1}^{\prime} s$ are their coefficlents. This model is obtained when we impose the restrictions $\sigma_{1}^{z}=\sigma_{3}^{2}=\sigma_{4}^{2}=0$, and has been found to fit many economic time series remarkably well (see e.g. Pierce (1978)). Notice that $\sigma_{1}^{2}$ ) 0 implies that no irregular component is introduced.

In this section we assume that

$c_{t}=\tilde{c}_{t}+s_{t^{\prime}}$

where $c_{t}$ and $s_{t}$ are the trend and seasonal components respectively, that are assumed to be independent of each other. For the trend component $x_{t}$ we assume that it is generated by the life cycle model with exponential utility function analyzed in chapter 2 . Hence, we have

$\Delta \tilde{\mathrm{c}}_{t}=\gamma^{-1} \ln [\beta(1+\mathrm{r})]+\varepsilon_{t}$

where $\varepsilon_{\mathrm{t}}$ is a linear transformation of the income innovation and the slope of the trend is deterministic. As we have quarterly data at our disposal, the seasonal component $s_{t}$ is assumed to be such that the sum over four subsequent quarters is white nolse. Formally, we have

$\Psi(L) s_{t}-\mu_{t}, \Psi(L)=1+L+L^{2}+L^{3}, \mu_{t}-\operatorname{IID}\left(0, \sigma_{\mu}^{2}\right)$

and $\mu_{\mathrm{t}}$ is Independent of $\varepsilon_{\mathrm{t}}$. For the change in consumption we have $\Delta c_{t}-\gamma^{-1} \ln [\beta(1+\mathrm{r})]+\Delta s_{t}+\varepsilon_{t}$

When $\sigma_{k=0}^{2}=(8.2)$ implies $\Delta \mathbf{s}_{t}=\Delta \mathbf{s}_{\mathrm{t}-4}$ and we obtain a seasonal random walk with drift. For a nondeterministic seasonal pattern, we get after multelplying by $v(L)$ 
$\Delta_{4} c_{t}=\Psi(\mathrm{L}) \gamma^{-1} \ln [\beta(1+r)]+\Psi(L) \varepsilon_{t}+\Delta \mu_{t}$.

According to (8.3) the annual change of $c_{t}$ is generated by a restricted third order MA process with mean $(L) \gamma^{-1} \ln [\beta(1+r)]$. Notice that when $\mu_{t}$ is autocorrelated up to order 2, 1.e. $\mu_{\mathrm{z}}$ is generated by a MA(2) process, the disturbance of $\Delta_{4} c_{t}$ in (8.3) can still be represented by a MA(3) process, though its error component structure is different from that implied by (8.1) and (8.2). Notice also that a reinterpretation of the life time budget constraint in the model of chapter 2 is necessary, since we assume that only the trend-cycle component is generated by the life cycle model. In line with the analysis carried out in chapter 2 , we assume that the time preference parameter $\beta$ has changed to account for the drop in consumption since 1979. Under the assumption that the changes in the drift parameter of the income process (2.14) were not anticipated, the model for consumption (8.3) needs reviston. Then we incorporate the distortions of the consumption model caused by these structural changes in the process of the nonseasonal component $c_{t}$, we find in line with chapter 2

$$
\Delta \mathrm{c}_{\mathrm{t}}=\beta_{1} \mathrm{~d}_{1 \mathrm{t}}+\beta_{2} \mathrm{~d}_{2 \mathrm{t}}+\beta_{3} \mathrm{~d}_{3 \mathrm{t}}+\beta_{4} \mathrm{~d}_{4 \mathrm{t}}+\beta_{5} \mathrm{~d}_{5 \mathrm{t}}+\varepsilon_{\mathrm{t}}
$$

$$
\text { with } \begin{aligned}
d_{1 t} & =1 \text { for } 1967(2)-1979(4) \\
d_{2 t} & =1 \text { for } 1980(1)-1984(4) \\
d_{3 t} & =1 \text { for } 1971(1) \\
d_{4 t} & =1 \text { for } 1979(1) \\
d_{5 t} & =1 \text { for } 1979(4)
\end{aligned}
$$

and $\mathrm{d}_{1 \mathrm{t}}=0$ otherwise. In chapter 2 it is shown that $\beta_{3}$ and $\beta_{4}$ are expected to be negative and $\beta_{9}$ to be positive. After substitution, we get for total. consumption

$$
\Delta_{4} c_{t}=\beta_{1} d_{1 t}+\beta_{2} d_{2 t}+\beta_{3} d_{3 t}+\beta_{4} d_{4 t}+\beta_{5} d_{5 t}+\Psi(L) \varepsilon_{t}+\Delta \mu_{t}
$$

with $\mathrm{d}_{1 \mathrm{t}}-4$ for $1968(1)-1979(4)$

$$
\begin{aligned}
& =3 \text { for } 1980(1) \\
& =2 \text { for } 1980(2) \\
& =1 \text { for } 1980(3)
\end{aligned}
$$




$$
\begin{aligned}
& d_{2 t}=1 \text { for } 1980(1) \\
&-2 \text { for } 1980(2) \\
&-3 \text { for } 1980(3) \\
&-4 \text { for } 1980(4)-1984(4) \\
& d_{3 t}-1 \text { for } 1971(1)-1971(4) \\
& d_{4 t}=1 \text { for } 1979(1)-1979(4) \\
& d_{5 t}-1 \text { for } 1979(4)-1980(3)
\end{aligned}
$$

and $d_{i t}=0$ otherwise.

The disturbance of model (8.5) has an exror component structure which can be expressed a (restricted) third order MA process, say

$v(L) \varepsilon_{t}+\Delta \mu_{t}-\left(1-\theta_{1} L-\theta_{2} L^{2}-\theta_{3} L^{3}\right) \eta_{t}$, with $\eta_{t}-\operatorname{IID}\left(0, \sigma_{\eta}^{2}\right)$

Estimates of the unrestricted model have been obtained by Maximum Likelthood (ML) method. Fully efficient estimates of the restricted model (8.5) have subsequently been obtalned by the method of Asymptotic Least squares (ALS) based on the ML estimates. The method of ALS is briefly outlined in Appendix 8A. For more detalls, we refer to Gourieroux et. al. (1985) and Kodde and Palm (1986). Results for model (8.5) are reported in Table 8.1 and t-ratios are given between parentheses. The Box-Pierce (BP) and the Ljung-Box (IB) statistics based on the first p residual serial correlations of the unrestricted model are given for several valus of $p$, and the Wald test statistic for the 2 restrictions implied by the error component structure of $(8.5)$ are given in Table 8.1.

Several comments are in order about the results in Table 8.1. In terms of the residual serial correlation, the model behaves fairly we11. The restrictions implied by the error components are not rejected at conventional signiflcance levels. Notice that under the null hypothesis the Wald statistic is $x^{2}$-distributed with 2 degrees of freedom in large samples. The variance of the trend-cycle component is highly significant. For the seasonals, the vartance is not significant suggesting that a deterministic specification for the seasonals might be in accordance with the sample information. We 1 ike to notice however that the model with seasonal dummy varlables performs badly in terms of diagnostic tests and parameter estimates, so that on the basis of the information in the data, the model with stochastic seasonals is preferred to that with a 
Table 8.1 Emplrical results for model (8.5)

$$
\text { ML(unrestricted) }
$$

ALS

$\beta_{1}$

$\beta_{2}$

$\beta_{3}$

$\beta_{4}$

$\beta_{5}$

$\theta_{1}$

$\theta_{2}$

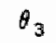

$\sigma_{n}^{2}$

$a_{c}^{2}$

$a_{\mu}^{2}$

Waldtest

$4.15-x^{2}(2)$

p

$\mathrm{BP}$

.38

3. 50

4.8 .4

15.27

$\begin{array}{lrr}4 & .38 & .40 \\ 8 & 3.50 & 3.65 \\ 12 & 4.84 & 5.06 \\ 16 & 15.27 & 15.95\end{array}$

$16.2(4.80)$

$-8.6(1.58)$

$62.5(2.06)$

43.9 (1.46)

$-18.2(.46)$

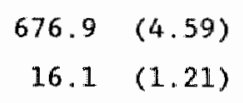

deterministic seasonal component. The $t$-value for the hypothesis: $H_{0}: \beta_{1}=\beta_{2}$ is 3.878 . Hence, the assumption of a structural change in the time preference parameter $\beta$ to account for the change in the consumption line is supported by the Information in the data.

Next, we consider the point estimates. In chapter 2 it was shown that 
$\varepsilon_{\mathrm{t}}=\left(1-0+\eta_{\mathrm{T}-\mathrm{t}-1}^{-1}\right) \mathrm{w}^{n}$

where $\nu_{t}$ is the income innovation and $\theta$ is the the MA process of $(2,14)$. As $\theta=.428$ and $0<\eta_{\mathrm{T}}^{*}-1-1<1$, we have as an implication of the theoretical model that $\sigma^{2}\left(c_{t}\right)<\sigma^{2}\left(\nu_{t}\right)$. A comparison of the values reported in Table 8.1 and (2.14) shows that this restriction is satisfled by the point estimates. Using the point estimates of $\sigma^{2}\left(\varepsilon_{t}\right), \sigma^{2}\left(\nu_{t}\right)$ and $\theta$, we find for $\eta_{T-t-1}$ the value 1.250. Since the quarterly real interest rate $r$ should be rather small, we can approximate $T-t$, that is the remaining life time of the representative consumer in period $t$, as $1.250(1+r)^{-1}$. As in chapter 2 we find for reasonable values of $r$ embarrasingly small values for $T-t$.

The estimates of $\beta_{3}, \beta_{4}$ and $\beta_{5}$ do not have the expected signs. Notice that $\beta_{3}$ is signiflcant. However, one has to notice that the parameters $\beta_{3}, \beta_{4}$ and $\beta_{5}$ are estimated from a few data points (see the specification of the dumy variables in (8.5)). Moreover, a reinterpretation of the formulae for the parameters is needed, because we estimate the model from aggregate per capita data. Notwithstanding all these considerations, we conclude from the empirical results that the data need further investigation. We find a confirmation of this observation when we consider the autocorrelation function of the annulal change of consumption. In Table 8.2 we report the correlograms for $\Delta_{4} c_{t}$ over the perlods $1968(1)-1979(4)$ and $1980(1)-1984(4)$.

Table 8.2 Correlograms for $\Delta_{4} c_{t}$

$\begin{array}{lcccccccc}\operatorname{Lag} & 1 & 2 & 3 & 4 & 5 & 6 & 7 & 8 \\ 1968(1)-1979(4) & .70 & .43 & .19 & -.07 & -.22 & -.22 & -.15 & -.16 \\ 1980(1)-1984(4) & .14 & .20 & .08 & .02 & -.06 & -.24 & -.04 & -.37 \\ & & & & & & & & \\ \operatorname{Lag} & 9 & 10 & 11 & 12 & 13 & 14 & 15 & 16 \\ 1968(1)-1.979(4) & -.04 & .05 & .13 & .12 & .06 & -.07 & -.30 & -.42 \\ 1980(1)-1984(4) & -.07 & -.18 & -.26 & .01 & & & & \end{array}$

From the results given in Table 8.2 we conclude that a time serles analyst 
would only reluctantly decide on a MA(3) process. The correlogram obtalned for the pertod 1968(1)-1979(4) suggests that an AR(1) process might be more appropriate. None of the autocorrelations over the period $1980(1)-1984(4)$ is significant. However, the number of observations is rather small. A possibility to proced consists in adjusting the specifled processes for the trend-cycle and/or seasonal components of consumption. However, in chapter 6 we analyzed the life cycle model under rational habit formation and we showed that an arbitrary ARIMA process for consumption may be obtained by choosing an approprlate pattern of rational habits. An advantage of using that model for incorporating information on economic theory is that no reinterpretation of the life time budget constraint is necessary. In the next section we will therefore model the seasonal fluctuations by means of the preference structure.

\subsection{Seasonal fluctuations as a form of rational habits}

In this section we will show how the life cycle hypothesis under rational habit formation can be used to model seasonal fluctuations in consumption by means of the preference structure. In section 6.1 we analyzed among other things the model

$\operatorname{Max} \sum_{i=0}^{\infty} \beta^{i} U\left(\Phi(L) c_{t+1}\right)$

S.T. $\sum_{1=0}^{\infty}(1+r)^{-1} c_{t+1}(1+r) a_{t-1}+\sum_{i=0}^{\infty}(1+r)^{-1} E\left(y_{t+1} \mid I_{t}\right)$

for the exponential utility function

$U(c)=-\gamma^{-1} \exp (-\gamma c), \gamma>0$

(L) is a lag polynomial of order $p$

$\Phi(\mathrm{L})=\mathbb{1}-\varphi_{1} \mathrm{~L}-\ldots-\varphi_{\mathrm{p}} \mathrm{L}^{\mathrm{P}}$ 
and the roots of $\Phi(L)=0$ lie on or outside the unit circle. It was shown that the utility maximization problem (8.6) lmplied the following autoregressive integrated process for consumption

$\Psi(\mathrm{L}) \Delta \mathrm{C}_{\mathrm{t}}-\gamma^{-1} \ln [\beta(1+\mathrm{r})]+c_{\mathrm{t}+\mathrm{I}}$

wth

$\varepsilon_{t+1}=\frac{r}{1+r} \sum_{1=0}^{\infty}(1+r)^{-1}\left[E\left(\Phi(L) y_{t+1+1} \mid I_{t+1}\right)-E\left(\Phi(L) y_{t+1+1} \mid I_{t}\right)\right]$

In example 2 at p. 106, we showed that the use of the lag polynomial $\$(L)=1+L+L^{2}+L^{3}$ ylelds a model in the four perlod difference operator. Box and Jenkins (1976) advocate the use of the $\Delta_{4}$-filter to achieve stationarity of quarterly seasonalily unadjusted series. In many studies it has proven to be an effective way to eliminate the seasonal fluctuations. The consumption function of Davidson, Hendry, Srba and Yeo (1978) is an 11lustrative example, Hendry and Von Ungern-Sternberg (1981) however, present estimation results which show that the use of the $\Delta_{4}$-operator may not be sufficient. They find significant coefficients for the seasonal dummy varlables. Hansen and singleton (1983) discuss the possibility of a preference structure which is liable to shocks. A deterministic seasonal pattern may be incorporated in the maximization problem $(8.6)$ and be interpreted as "seasonal shocks to the preferences" or, equivalently, as taste shifters. More particularly, when we assume that the consumer solves every time perlod the optimization problem

$\operatorname{Max} \sum_{1=0}^{\infty} \beta^{1} \mathrm{v}\left(\Phi(L) c_{t+1}{ }^{-5} t+1\right)$

S. TH. $\sum_{1=0}^{\infty}(1+r)^{-1} c_{t+1}-(1+r) a_{t-1}+\sum_{1=0}^{\infty}(1+r)^{-1} E\left(y_{t+1} \mid I_{t}\right)$

It can be easily shown along the lines of chapter 6 that with the exponential utility function, the following consumption model results 
$\Phi(L) \Delta c_{t+1}=\gamma^{-1} \ln [\beta(1+r)]+s_{t+1}-s_{t}+\varepsilon_{t+1}$

with $\varepsilon_{t+1}$ given by (8.9). When $\left(1+L+L^{2}+L^{3}\right) s_{t+1}=s^{\circ}$, that is the sum over four subsequent quarters equals $s^{\circ}$, the consumption model (8.10) displays a deterministic seasonal pattern. Notice that when $s^{\circ}$ equals zero, we have the deterministic equivalent of the model for the seasonal components postulated in the previous section. Notice also that in the model without habits, that is $\Phi(L)=1$, and $s^{\circ}>0$ the interpretation of the seasonal component as "subsistence" or "necessary" consumption is straightforward. Instead of deriving satisfaction from total consumption, the consumer is assumed to attach utlitity to consumption in excess of the necessary seasonal component of total consumption. Expression (8.10) shows that in that case we have a seasonal random walk with drift. For the lag polynomial $\Phi(L)=1+L+L^{2}+L^{3}$, the result corresponding to (8.10) w111 be

$\Delta_{4} c_{t+1}=\gamma^{-1} \ln [\beta(1+r)]+s_{t+1}-s_{t}+\varepsilon_{t+1}$

with $\varepsilon_{t+1}$ equal to

$\varepsilon_{t+1}=\left(1-\frac{1}{(1+r)^{4}}\right) \sum_{i=0}^{\infty}(1+r)^{-i}\left[E\left(y_{t+1+1} \mid \mathbb{I}_{t+1}\right)-E\left(y_{t+1+1} \mid I_{t}\right)\right]$,

as can be verified by substituting of $\Phi(L)=1+L+L^{2}+L^{3}$ into (8.9). This illustrates how a model in annul differences with a deterministic sasonal pattern can be obtained.

since the autocorrelation function suggests that an AR(1) process for $\Delta_{4} c_{t}$ might be compatible with the information in the data, we choose for the lag polynomial (L) In (8.7)

$(L)=(1-a L)\left(1+L+L^{2}+L^{3}\right)$.

Substituting (8.11) into (8.8) and (8.9) yields after some rearrangements

$\left(1-\right.$ aL) $\Delta_{4} c_{t}=\gamma^{-1} \ln [\beta(1+x)]+\varepsilon_{t}$ 
with

$$
\epsilon_{t}=\left(1-\frac{a}{1+r}\right)\left(1-\frac{1}{(1+r)^{4}}\right) \sum_{1=0}^{\infty}(1+r)^{-1}\left[E\left(y_{t+1} \| I_{t}\right)-E\left(y_{t+1} \mid I_{t-1}\right)\right]
$$

When we assume that the change in income is generated by a stationary and invertible ARTMA process, it is straightforward to show that the consumption Innovation is a linear transformation of the income innovation. Notlce that the proportionality factor depends not only on the parameters of the income process but also on those that reflect the impact of rational habits.

The drift parameter of the consumption process ( 8.12 ) depends only on parameters that characterize consumer behaviour and the change of the slope of the consumption line from positive to negative is not in accordance with the theoretical model. It can only be interpreted within this framework by the assumption of a structural change of the parameters. In line with chapter 2 we assume that the preference parameter $\beta$ has changed as a result of the increased uncertainty about the future. The consequences of a decrease of $\beta$ to $\beta *$ can be traced by using the closed form solutions (6.15) and (6.16). Along the same lines as in chaptex 2, it can be shown that it wi11 lead to a persistent downward adjustment of the drift parameter in (8.12) after an increase of the drift parameter in the current period of order $\gamma^{-1} \mathrm{r}^{-1} \mathbb{Z}\left[\beta\left[\beta \boldsymbol{*}^{-1}\right]\right.$.

Under the assumption that the changes in the drift parameter of the Income process were not anticipated, the model for consumption (8.12) needs revision. Let us assume that the constant term $\delta$ moves to $\delta *$. Using expressions (6.15) and (6.16) it can be shown along similar lines as in chapter 2 that 1t w11 give rise to a step change in the consumption model (8.12) equal to $(\delta+\delta)(1+r-a)\left(1-(1+r)^{-4}\right)(1+r) r^{-2}$. Therefore, both in 1971(1) and 1979(1) we should expect a negative adjustment in the drift parameter of consumption. A similar mechanism was found in chapter 2 . For the model without habits, the perturbation takes the form of an Innovational outlier. Notice that as the underlying time series is in that case a randon walk the Lnnovational outlier is equivalent to a level change (see e.g. Tsay (1988) and Box and Tiao (1965)). The disturbance in the model with habit formation investigated here implies on the other hand a 
gradual response before the permanent change is reached, obwlously, this mechanism reflects the role of habits. Surprisingly, the consequences far the stochastic process of consumption are in both cases the same: introduction of one dunimy variable obviates the problem.

The following estimation equation is in accordance with the theoretical. model and the empirical findings for the income process

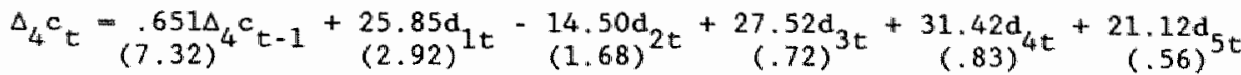

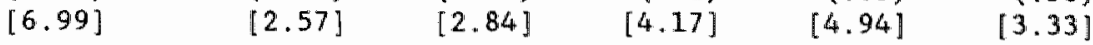

$$
\begin{aligned}
& a_{c}^{2}=1413.6
\end{aligned}
$$

$$
\text { where } \begin{aligned}
d_{1 t}=1 \text { for } 1967(2)-1979(4) \\
d_{2 t}=1 \text { for } 1980(1)-1984(4) \\
d_{3 t}=1 \text { for } 1971(1) \\
d_{4 t}=1 \text { for } 1979(1) \\
d_{5 t}=1 \text { for } 1979(4) .
\end{aligned}
$$

The dumny variables $d_{3 t}$ and $d_{4 t}$ are included as a result of the structural changes in the income process, whereas $d_{2 t}$ and $d_{5 t}$ emerge because of the change in the time preference parameter which is timed at the turning point of the consumption series. The values between parentheses are the t-values calculated in the conventional way and those reported between square brackets correspond to the t-ratios calculated as in white (1980) (see also Domowitz and White (1982) and Blerens (1984)). The latter are robust with respect to any form of heteroscedasticity.

The residuals of the model have been analyzed. They do not oxhlbit significant serlal correlation. The ACF takes only slgniflcant values for $r_{15}$ and $r_{17}$ and the $B P$ and $L B$ test statistics yield values that are insignificant at commonly used signiflcance levels. In section 1.2.1 we saw that normality and homoscedasticlty of the process for $\Delta y_{t}$ are not rejected. The theoretical implications are that $\Delta_{4} c_{t}$ follows normally distributed homoscedastic process. Inspection of the values reported in Table 8.3 shows that the emplrical findings are not in agreement with the theory. In particular, the significant values of the LM test statistic for the hypothesis of homoscedasticity against the alternative hypothesis of an ARCH structure is in contradiction with the empirical results for the income process. 
Since the regressors include a lagged dependent variable, the presence of heteroscedasticlty of the ARCH type Implies that ordinary least squares (OLS) w11 no longer give correct standard errors (see e.g. Welss (1984)). The consistency of the OLS estimates is however not affected. The reported $t$-vallues in (B.14) illustrate that ignoration of the heteroscedasticity may lead to incorrect inference. Since the presence of ARCH structures Jeopardizes the validity of the BP and LB test statistics, we have also carrled out test for serial correlation in the residuals put forward by Bierens (1984). When the data generating process is strictly stationary, this test is consistent with respect to any deviation from the nu1I hypothes1s. The values of the simplifled form of the test statistics for the null hypothesis that the errors are martingale differences against the alternative hypothesis that the null is false, are reported in Table 8.3 as $r\left(L_{n}, \varepsilon\right)$, where $L_{n}$ and $\varepsilon$ are chosen in line with Bierens" simulation results. For detalls we refer to Blerens (1984, sections 7 and 8 ). obviously, the results indicate no deviation from the hypothesis of zero residual serial correlation.

Table 8.3 Test statistics of mode1 (8.14)

\begin{tabular}{lrr}
$P$ & \multicolumn{1}{c}{ BP } & \multicolumn{1}{c}{ LB } \\
4 & 4.03 & 4.22 \\
8 & 10.10 & 10.56 \\
12 & 11.57 & 12.10 \\
16 & 18.71 & 19.56 \\
$\eta(1)$ & 8.97 & \\
$\eta(4)$ & 9.72 & \\
$S_{1}$ & -.26 & \\
$S_{2}$ & .27 & \\
$\tau(20, .5)$ & 100.83 & \\
$\tau(20,1.5)$ & 3.54 &
\end{tabular}

We proceed by examining the point estimates. Substitution of $y_{t}$ $\mathbb{E}\left(y_{t} \mid I_{t-1}\right)=w_{t}$ and $\mathbb{E}\left(y_{t+1} \| I_{t}\right)-E\left(y_{t+1} \mid I_{t-1}\right)=(1-\theta) \nu_{t}$, $1 \geq 2$ into (8.13) leads to $\varepsilon_{t}-(1+r-a)\left(1-\frac{1}{(1+r)^{4}}\right)\left(1-\frac{\theta}{1+r}\right) \frac{1}{r} \nu_{t}$

and hence 
$\sigma^{2}\left(\varepsilon_{t}\right)=(1+r-a)^{2}\left(1-\frac{1}{(1+r)^{4}}\right)^{2}\left(1-\frac{\theta}{1+r}\right)^{2} \frac{1}{r^{2}} \sigma^{2}\left(L_{t}\right)$.

With the point estimates -428 obtained in section 1.2 .1 for the MA parameter of the income process and $\hat{a}=.650$, expression (8.15) shows that the variance of the consumption innovation may be smaller as well as larger than the variance of the income innovation. For small values of $x$ the proportionality factor is smaller than 1 . With $r=05$ we find for instance .71. Hence, it seems reasonable to expect the variance of the consumption innovation to be smaller than that of the income innovation. Comparison of the reported values in $(2.14)$ and (8.14) shows that the estimates contradict this implication. When the appropriate income series is the seasonally unadjusted one, a plausible explanation might be that the method of seasonal adjustment has led to a smoothed series. Consequently, the relevant residual variance would be larger than the value glven in (2.14). Notice that the appearance of an ARCH process does not obviate the contradiction. The effects of an ARCH structure will increase the variance of the consumption innovation (see Engle (1982), theorem 2).

For the appraisal of the step changes, we have to keep in mind that the dumy variables absorb the joint effect of both the adjustment of the consumption level and the transformed income innovation. From (2.14) we have an estimate of the income innowation and the MA parameter from which we can infer a negative sign of the coeffictent of $d_{3 t}$ and a positive one of $d_{s_{t}}$. This implication is comfirmed for $d_{s t}$, but violated for $d_{3 t}$. Because of the opposite sign of the adjustment of the constant term and the estimate of the transformed income innovation, we can not determine a priori the sign of the coefficient of $d_{4 t}$. With respect to the evaluation of the size and sign of the parameter estimates it should be remarked that the analysis is highly tentative. Apart from the fact that we use the point estimates of $a, \theta, \sigma^{2}(x)$ and the income innovation, $a$ reinterpretation of the formulae is required since we estimate the model from aggregate per capita data.

Finally, notice that Davidson and Hendry (1981) investigate the log-linear version of model (8.14), that they present as the analogue of Hall's (1978) consumption function. Their analysis tempted Hal1 (1981, p.193) to comment 
it found theix tests unconvincing because of their treatment of seasona11ty".

The foregoing analysis suggests that their model is not the analogue of Hall's model, but also that their specification is not necessarily incompatible with the life cycle theory extended for the presence of habits.

\section{3 Concluding remarks}

In this chapter we showed how information on economic theory can be incorporated in unlvariate ARIMA schemes for seasonally unadjusted data on consumption. In section 8.1 we specified a simple STM, in which the life cycle hypothesis with intertemporally additive utility function was used to obtain a model for the trend-cycle component of consumption. However, we concluded that the sample information was not in accordance with the theoretical inplications. As an alternative procedure we investigated in the second section the life cycle model under rational habit formation and modelled the seasonality by means of the preference structure.

Special attention was pald to the implications of structural changes in the Income process, which because of replanning, will have an impact on the process of consumption. For the model investigated in section 8.2 , it was shown that the only adjustment consisted of the fnclusion of one dummy variable in the consumption model. This illustrates the gradual adaptation of the consumption level to the new perspectives, which is of course a result of the presence of habits. We conclude that the framework of intertemporal optimization is an appropriate one for interpreting outliers In the consumption process. Moreover, the relationship with the appearance of structural changes in the income process may be of some use in detecting the time point of the occurrence of structural breaks. A preliminary analysis along the lines of Tsay (1988) is expected to yield useful Information in this respect.

The observation that the stochastic process of consumption is a transformation of that of income led to the examination of a number of implications of the theoretical model. Since the empirically observed heteroscedasticity of the $\mathrm{ARCH}$ type in the consumption process is in 
contradiction with the homoscedasticity of the income process, we concluded that the madel was not in full agreement with the information in the data. In chapter 2 we gave an economic argument for the plaustbility of the appearance of ARCH processes. We argued that when we are prepared to relax. the assumption of fully rational expectations, may find consumption innovations that can be modelled as an ARCH process although the income innovations are homoscedastic. We have seen that a structural change in the income process leads to the introduction of a dumy variable in the consumption model. When the consumer incorrectly assesses a shift in the income process, he will become aware of this after a whlle, and adjust his consumption level accordingly. This will lead to new step change, but now in the opposite direction. An interesting feature of ARCH processes is that they can handle outliers arising in clusters. The significant value of the LM test statistics may be interpreted as a confirmation of temporary incorrect assessment of the expected walue of future income by the consumer. However, when we stick to the assumption of rational expectations there exists a one to one correspondence between the stochastic properties of the income and consumption innovation. In that case we have to consider the significant values of the $L$ test for ARCH structures as being in contradiction with the properties of the income process.

An alternative explanation might be the inappropriateness of the income series. We used a seasonally adjusted series, and it seems not imaginary that the used adjustment method has eliminated the heteroscedasticity. When the stochastic process of the seasonally unadjusted income series exhibyts heteroscedasticity of the ARCH type, the empirical resultis of section 8.2 are not necessaxily incompatible with the theoretical model. Unfortunately, the lack of seasonally unadjusted income data hampers a further analysis. From the analysis carried out in the previous chapters, it should be obvious that the interpretation of the inconsistency as an indication of some kind of misspecification can not be ignored. In the 11 ght of the empirical results of chapter 7 , a logical step is to investigate the possible effects of past-peak consumption.

A drawback of the life time models investigated in this chapter is that we had to make the assumption of structural change in the time preference parameter $\beta$ to account for the drop in consumption since 1980. A $\log 1$ cal way to modify the model is to investigate the model with moving planning 
horizon. Notice however that wen quarterly seasonally unadjusted income data re modelled by means of an ARMA process for the annual change, the model wh moving planning horizon under rational hablt formation Investigated in section 6.3 is not capable of obviating the ad-hoc assumption of a change in $\beta$. In chapter 6 we showed that the highest lag of the autoregressive part of the trmpled stochastic process for the annual change in consumption is at least four.

Motice finally, that the property of the theoretical models examined in this chapter, that the consumption innovation is a 1 inear transformation of the income innovation opens up the posslbility to investigate alternative parameterizations. The analysis carried out in chapter 4 may serve as an illustration. Such an examination is of course also possible with the data series used in this chapter. However, we feel that it is more plausible to investigate the rellationship between income and consumption when both series are seasonally unadjusted. Because we do not have seasonally unadjusted labour and transfer income data at our disposal we refrained from this possibility and restricted ourselves to a univariate analysis of consumption.

From all these considerations, it should be clear that the issue of modelling seasonally unadjusted consumption data deserves further investigation and that there is considerable scope for further research. However, a more thorough examination has to be postponed until seasonally unadjusted income data are avallable. We have good hopes, that when this will be undertaken, the analysis carried out for seasonally adjusted data may be of valuable use. 
Appendix 8A An example of ALS estimation

To outline the method of asymptotic least squares (ALS), we consider the univariate model (8.5) with error components

$\Delta_{4} c_{t}=\sum_{i=1}^{5} \beta_{i} \tilde{\mathrm{d}}_{i t}+\Psi(L) c_{t}+\Delta \mu_{t}$.

When we ignore the error component structure, $\Delta_{4} c_{t}$ can be expressed as a third order MA process

$\Delta_{4} c_{t}-\sum_{i=1}^{5} \beta_{1} \tilde{\mathrm{d}}_{1 \mathrm{t}}+\left(1-\theta_{\mathbb{L}} \mathrm{L}-\theta_{2} \mathrm{~L}^{2}-\theta_{3} \mathbb{L}^{3}\right) \eta \eta_{\mathrm{t}}$

where $\eta_{t}$ is white noise with variance $a^{2}(\eta)$. The mode1 (A.2) can be estimated by ML yielding an estimate $\hat{\gamma}_{M L}$ of $\gamma=\left(\beta^{*}, \theta_{1}, \theta_{2}, \theta_{3}, \sigma^{2}(\eta)\right)^{*}$, wth $\beta^{\prime}=\left(\beta_{1}, \beta_{2}, \beta_{3}, \beta_{4}, \beta_{5}\right)^{\prime}$. The parameters $\gamma$ are related to the parameters of interest $\alpha^{=}\left(\beta^{n}, \sigma^{2}(\varepsilon), \sigma^{2}(\mu)\right)^{\prime \prime}$ by the followling (use the second moments)

$$
\left[\begin{array}{l}
\beta \\
\left(1+\theta_{1}^{2}+\theta_{2}^{2}+\theta_{3}^{2}\right) \sigma^{2}(\eta) \\
\left(-\theta_{1}+\theta_{2} \theta_{1}+\theta_{3} \theta_{2}\right) \sigma^{2}(\eta) \\
\left(-\theta_{2}+\theta_{3} \theta_{2}\right) \sigma^{2}(\eta) \\
-\theta_{3} \sigma^{2}(\eta)
\end{array}\right]=\left[\begin{array}{cc|cc}
I_{5} & -1 & 0 \\
-\cdots & - & -2 & - \\
0 & & -1 \\
& & 2 & 0 \\
& & 1 & 0
\end{array}\right]\left(\begin{array}{c}
\beta \\
\sigma^{2}(\varepsilon) \\
\sigma^{2}(\mu)
\end{array}\right]
$$

ox alternatively in matrix notation

$\mathrm{g}(\gamma)=\mathrm{A} \alpha$,

where $g$ is a vector of functions in $\gamma$ and $A$ is the $\operatorname{matrix}$ in (A.3) with known coefficlents.

Given a consistent estimate of $\gamma, \hat{\gamma}$, ALS minimizes the distance of $g(\hat{\gamma})-A \alpha$ in the metric of a nonsingular matrix $s, i . e$. 
$\left.\min _{\alpha} \ln [g(\gamma)-A \alpha]^{\prime} \mathrm{S} \llbracket g(\gamma)-A \alpha\right\rfloor$

which yields the AIs estimate

$\hat{\alpha}=\left(\mathrm{A}^{\prime} \mathrm{SA}\right)^{-1} \mathrm{~A}^{\prime} \mathrm{Sg}(\hat{\gamma})$.

The optimal cholce of $\mathrm{S}$ is

$S^{*}=\left[\frac{\partial g}{\partial \gamma^{\prime}}, \frac{\partial g}{\partial \gamma}\right)^{-1}$,

where $\Omega$ is the asymptotic covarilance matrix of $\hat{\gamma}$. When $S^{*}$ is used and $\hat{\gamma}$ has a large sample normal distribution, the large sample distribution of $a$ is

$\left.\mathrm{T}^{-\mathrm{s}}(\hat{\alpha}-\alpha) \sim \mathrm{N}\left(0,\left[\mathrm{~A}^{\prime} \mathrm{s}^{*} \mathrm{~A}\right]\right]^{-1}\right)$.

When $\hat{\gamma}_{M L}$ is used with the corresponding optimal weighting matrix $s^{*}$, the ALS method ylelds an estimator of $\alpha$ which is asymptotically equivalent with the ML estimator. In the present example, the efficient ALS estimator can be obtained as a generallzed least squares estimator of the model

$g\left(\gamma_{M L}\right)=A \alpha+u$, with weighting matrix $s^{*}$.

In applled work, a consistent estimate has to be substituted for $n$. Notice flnally that the milnimun value of the objective function (A.5) multiplied by the number of observations $T$ yields a Wald statistic for testing the two restrictions implied by the error components structure. 


\section{Chapter 9}

\section{SURAARY AND CONGLUDING REMARKS}

In this study we investigated models of forward looking consumption behaviour, whereby the consumer replans his consumption and savings each period. We used the information on the dynamic structure implied by the intertemporal optimization problems as a guide in the specification analysis.

For various theoretical models we derived the corresponding consumption function and for most of them we also determined the implied univarlate process for consumption. These implications were tested against the information in aggregate quarterly data for the period 1968(1)-1984(4). During the sample period the stachastic environment in which the consumers had to take their deciclons, has been subject to several structural shocks. Examples are for instance the occurrence of two ofl crises, the move from fixed to flexible exchange rates and a policy change afining at a drastic reduction of public budgets deficits. All these changes have probably had an impact on consumer behaviour and altered certaln economic relationships. Sargent (1981) has argued in line with Lucas (1976) that the models in which private agents are assumed to solve dynamic optimization problems can be used to predict how agents" behaviour w11. alter as a result of the structural changes in the processes of the forcing variables. In the models we analyzed, income has been assumed to be the only forcing variable. An objective of the research project was to contribute to a better understanding of the theoretical models of intertemporal consumer behaviour under structural changes in the forcing variables. Throughout the study special attention was devoted to the consequences of these structural changes.

We started our analysis with the life cycle hypothesis. The chosen formulation was similar to that of Hall (1978). The only difference was that we assumed in line with Flavin (1981) and others who investigated the 
permanent income hypothesis, that the consumer uses only the information on expected future labour income, whereas Hall assumes that the consumer takes into account the complete distribution of income. In chapter 2 we investigated the life cycle model for the exponential utility function. The model has the property that under the assumption that income is exogenous, the stochastic process for consumption is a transformation, accomplished by the intertemporal optimization model, of the stochastic process of income. Therefore, the theoretical model generates a number of restrictions between the stochastic processes of consumption and income. Structural changes in the income process have for instance definite effects for the consumption function. Once the nature of the structural changes in the Income process can be assessed, theoretical framework enables one to determine the Implifations of this change for the model of consumption. We argued that the ARCH structures put forward by Engle (1982) may also be useful to capture the perturbations of the consumption process resulting from structural changes in the forcing variables of the maximization problem. In the empirical analysis we paid attention to the consequences of these structural changes and we showed that the model provtdes satisfactory description of the serial correlation properties of the consumption data, glven that we are prepared to extend the model to allow for a structural change in one of the parameters of the utility function. This assumption had to be made to account for the drop in consumption since 1979. The empirical analysis indicates however that consumption is not smooth enough. Using reasonable values for the quarterly real interest rate, we found rather small values for the expected life time of the representative consumer.

In chapter 3 we dropped the assumption of point expectations about future labour incone. We assumed that the consumer uses in principle all the Information on the stochastic process of income. Under the additional assumption of normality we derived a closed form siolution and the stochastic process of consumption. Since the framework of this chapter is Identical to that of Hall (1978), we discussed his model in more detail. Our analysis extended Hall's approach because it illustrated how the effects of unanticipated structural changes in the income process can be handled. Since the drift parameter of the implied consumption process depends also on the variance of the income innovation, an unanticipated 
decrease in that variance may explain the drop fin consumption in the Netherlands since 1979. However, under the assumption of rationel expectations, the information in the data sumarized by the speciffed income process, led to the conclusion that the resulting model is observationally equivalent to that investigated chapter 2 .

The principal implication of the life cycle model is the separation of the consumption and income profiles. In order to relate the decrease in consumption to the observed decline in income during the $1980 \mathrm{~s}$, we intraduced in chapter 4 the model with moving pianing horizon. We maintained the concept of forward looking behaviour, but dropped the assumption that the planning horizon coincides with the expected life time. When the time horizon used in the intertemporal utility maximization problem deviates from the lifetime, a mechanism that describes the adjustment of the planning horizon as time goes on has to be introduced in the mode1. We adopted the simplest possible solution and assumed that the consumer uses a planning time span of constant length.

We derived the relationship between consumption and income, and the implied univariate stochastic process for consumption. It was shown that the drift parameter of the latter is proportional to the constant term of the income process. Hence, an unanticipated change in the slope of the income line will have as a consequence that the slope of the consumption line will alter. From the empirical analysis we concluded that the univariate process of consumption implied by the theoretical model and the assumption of rational expectations, was in accordance with the sample information. An attractive feature of the model with moving planning horizon is that it does not rely on an ad-hoc assumption about structural change in one of the parameters of the utility function. Surprisingly, the relationship between consumption and income, that is an alternative parameterization implied by the model with moving planning horizon, includes an error correction term. Its presence results from the adjustment of the planning horizon as time goes on. Since in our framework no error is involved on the side of the consumer, we argued that it is more approprlite to speak about a correction term. The model with moving planing horlzon provides an alternative explanation for the appearance of (error) correction mechanisms and shows that the successful implementation of these mechanisms in consumption functions estimated and specifled with aggregate time serles 
data, may have its foundacions in a simple postulate about individual consumer behaviour. The empirical analysis of the specification with correction mechanism, using data on real total consumption per capita showed that the model is in agreement wh the sample information. The emplrical results for real nondurable consumption per capita were not unsatisfactory. The test for heteroscedasticity of the ARCH type in the disturbance term of the consumption function, however, yielded a significant value, whereas the theoretical model and the specified income process imply a homoscedastic process.

In an attempt to remedy the lnconsistency between the inplications of the theoretical model and the empirical evidence, we considered in chapter 5 the influence of inflation effects. The chosen vehicle for incorporating inflation effects was the same as put forward by Deaton (1977). The consumption decision was modelled as a two stage procedure. In the first stage the consumer is assumed to determine total anticipated expenditure for the current period by solwing the intertemporal maximization problem of chapter 4. In the second stage he will take a decision about the anticlpated comnodity demands. The chosen model led to a consumption function which is simllar to that of Davidson et. al. (1978). As in their specification we had to Include inflation, the change in inflation and a correction term as explanatory variables. From the empirical analysis of the resulting model, however, we concluded that incorparating inflation effects did not provide a satisfactory explanation for the inconsistency encountered in chapter 4.

In chapter 6 we considered an alternative extension of the modiels investigated in chapters 2 and 4 . We dropped the assumption of an intertemporally additive utility function, and Investigated more general preference structures. We analyzed the 1 fife cycle model and the model with moving plannimg horizon under rational habit formation. For the Iife cycle model. whth exponential utility function, it was shown that an arbitrary ARTMA process for consumption can be obtained by choosing an appropriate pattern of rational habits. We argued that this general result suggested that ignoring habits might be an explanation of the frequent rejections of the 1 ffe cycle model. The life cycle model under rational hablt formation provides a theoretical framework for interpreting a general category of stochastic processes for consumption. The major advantage of interpreting 
ARIMA processes within the framework of intertemporal decision-making is that it enables one to investigate the effects of pollcy interventions in the rigorous way indicated by Lucas (1976). The results of chapter 6 illustrate how ARIMA schemes can be used for policy analysis.

The model with moving planning horizon was investigated for a special form of rational habits that yields a model in the four period difference operator. We derived the unfvariate stochastic process for the four perlod change in consumption when the annul change in income is generated by an ARMA process and we argued that the interrelationships between the lncome and consumption processes may be of use in the identification stage of a univariate modeling procedure. Moreover, it was shown that the model is capable of reproducing the basic mechanism underlying the consumption function of Davidson, Hendry, Srba and Yeo (1978). More specffically, it was shown that when the annual change in income is generated by an autoregresive process of order 1 , the specification with correction term can be interpreted as if the consumer spends each quarter of a year the same amount as he spent in the corresponding quarter of the previous year, modified by a proportion of the annul change in income and of the change in the annual change in income, and by the correction tern.

In chepter 7 we considered the model with moving planning horizon under a form of rational habit formation that implied an impact of previous consumption on the current consumption declsion. We modelled the effect of habit persistence also by means of past-peak income and by past-peak consumption. The model provides an integrated framework for examining the different hypotheses concerning habit formation orfilnally put forward by Brown (1952), by Duesenberry (1949) and Modigliani (1949), and by Davis (1952) and Brown (1952). Moreover, as a result of adjusting the planning horizon at each period, a correction term as proposed by Davidson et. al. (1978) had to be included in the consumption function. The empirical analysis using data on real total consumption per capita did not suggest the presence of habit persistence and yielded additional confirmative evidence for the model investigated in chapter 4 . The results obtalned for real nondurable consumption per capita on the other hand. Indicated that past-peak consumption has a significant effect. Empirical evidence suggested that neither prevlous consumption nor past-peak income has a significant impact on the current consumption level. The distributional 
and serial correlation properties of the residuals and the predictive performance of the model were very satisfactory. In contrast to the emplrical results for the model whout habits investigated in chapter 4 , the test for heteroscedasticity of the ARCH type in the disturbance term of the consumption function ylelded an insignificant value. This finding was in agreement with the theoretical model. The inclusion of past-peak consumption obviated the inconsistency encountered in chapter 4. The examination of the size and sign of the parameter estimates, however, showed that the impact past-peak consumption reflected habit hysteria. The implication of habit persistence casts serious doubts on the appropriateness of the model.

Chapter 8 was devoted to the 1ssue of modelling quarterly seasonally unadfusted consumption data. Since we do not have quarterly seasonally unadjusted data on labour and transfer income at our disposal, we chose for an analysis within the framework of the life cycle model. In a first stage we speclfied and estimated a structural time series mode1, whereby the life cycle hypothesis with intextemporally additive utility function was used to abtain a model for the trend-cycle component of consumption. Since the information in the data was at variance with the inplications of the theoretical mode1, we followed subsequently a different approach, whereby the seasonality was modelled as a special form of rational habits. We also indicated how the seasonal dummy variables in a madel with a deterministic seasonal pattern may be interpreted as taste-shifters or in the terminology of Hansen and Singleton (1982), as resulting from seasonal shocks to the preferences. The empirical evidence is not fully consistent with the implications of the theoretical model. More specifically, the empirical finding of heteroscedasticity of the ARCH type for the consumption innovation was at variance with the theoretical implications. Since we did not have quarterly seasonally unadjusted data on real disposable labour and transfer income at our disposal, the analysis was necessarily restricted to a unlvariate analysis of the consumption data. The absence of appropriate income data impeded further investigation.

Davidson and Hendry (1981) among others have stressed the (almost) observational equivalence of models based on forward looking behaviour and those based on feedback control rules. The models analyzed in this study provide a new illustration of this observation. Notice however, that the 
models under habit formation effectively established a synthesis between forward and backward looking behaviour. The only possibility to discriminate between the two interpretations seems to occur when structural breaks appear in the forcing variables. When the agents display full capacity of anticipatory behaviour, the model for consumption differs from that of an agent who bases his decision on a feedback rule. The consequences of the structural changes in the life cycle model are different from those in the model with moving planning horizon.

The principal implication of the life cycle model is the separation of the consumption and income profiles. Consequently, the dynamics in consumption are basically determined by the preference structure. For the life cycle model under rational habit formation, it was shown that the parameters of the ARMA process of consumption correspond to the weights attached to past consumption in the utility function. Noting that the consumption innovation is a transformation of the income innovation, it becomes clear that structural changes in the income process will affect pexsistently only the properties of the consumption Innovation. Besides this permanent effect we have also a temporary one resulting from the re-evaluation of life time wealth. This effect will give rise to the introduction of a dummy variable in the consumption model. The analyses carried out in chapters 2 and 8 revealed that an unanticipated change in the drift parameter of the income process leads to a step change in the constant term of the consumption process.

The model with moving planning horizon on the other hand, implies that the dynamics in consumption are closely related to those of income. Structural. changes in the income process have therefore permanent effect on both the innovation and the dynamic structure of the consumption process. In chapter 4. an unanticipated change in the constant term of the income process was shown to imply a persistent change of the drift parameter of the consumption process. This property of the model with moving planning horizon opened up the possibility of relating the decrease in consumption to the observed decline in income in the $1980^{\prime} \mathrm{s}$.

For the length of the planning time span in the model with moving planning horizon investigated in various chapters, we found estimates varying from .01 to 13 quarters. Based on empirical evidence, Friedman (1957) draws a dividing line at a horizon of about 3 years (see p.221) to classify the 
permanent and transitary components of income. Notice that his concept of the horizon differs from ours. Obviously, the empirical results obtalned In our study indicate that the consumer is rather "shortsighted".

Before we can accept the model with moving planning horizon as a viable alternative for the life cycle model, further examination is needed. In this respect the use of panel data may be ultimately the most valuable source of information on consumption patterns. Except for chapter 5, we concentrated on the relationship between income and consumption. We focussed our attention on the incone factor, because it has generally been considered the most important variable in the determination of consumption. An advantage of restricting ourselves to such a limited set-up is that it opens up the posslbility of incorporating the effects of structural changes in the stochastic processes of the forcing variables in a relatively simple way. The results of the empirical analysis showed that it proved possible, at least for aggregate time serles data on total consumption, to obtain a theory-consistent consumption function that was in agreement with the information in the data. In order to take a fuller account of consumption behaviour, the model has to be extended in several directions. A number of issues deserve further inwestigation. In this respect attention should be paid to the assumptions that were maintained throughout the study. In chapter 1 at p.4 they are enumerated.

The extreme form of rational expectations about future labour income is not realistic. In particular, the assumption that the consumer knows the structure and parameters of the income model seems in case of structural changes too demanding. The inclusion of learning processes, possibly along the lines of Fourgeaud, Gourieroux and Pradel (1986), seems therefore not superfluous. Another extension deals with dropping the assumption of a constant real interest rate. Palm and winder (1986) investigate along the IInes of Hansen and Singleton $(1982,1983)$ the 1 ife cycle model for the utility function with constant absolute risk aversion and stochastic interest rates. They show how the restrictions implied by the Euler equations can be incorporated in a bivariate autoregressive process for consumption and the interest rate. However, they were not successful in obtaintng a closed-form solution and consequently, in taking proper account of the structural changes in the income process.

In the models of intertemporal decision-making investigated in chapters 6 
and 7, we introduced additional explanatory variables in the consumption function by extending the preference structure. Another way to obtain a more extensive consumption function is introducing additional constraints In the optimization problem. In this respect the possibility of liquidity constraints is worth mentioning (see e.g. Alessie, Melenberg and Weber $(1987)$ ). In the models investigated in our study we regarded consumption as a composite good. Because of the different character of durable and nondurable goods, the extension towards preference structures that make an explicit distinction between these two goods seems not superfluous (see e.g. Singleton (1985) and Dunn and singleton (1986)) .

Finally, we estimated and tested the models with aggregate data per caplta. obviously, the issues of aggregation over individuals and changing demographic factors deserve special attention (see e.g. Ando and Modigliani (1963) and Alessie and Kapteyn (1986)). We hope that when an attempt will be made to consider possible extensions of the models investigated here, the analysis carried out in this study will be of some use. 
In this appendix ae give the series of the varlous variables used in the study. Quarterly data on dispasable wage - "transfer income and imputed wage Income of the self-employed for 1968(1)-1984(4), on private consumption for $1967(1)+1984(4)$, and on the price index of private consumption for $1968(1)-1984(4)$ are kindly provided by the centraal Planbureau. The price index has been used to calculate the relative change with respect to the previous chapter, which is the inflation variable $\pi_{t}$ used In chapter 5. To obtain per capita figures in 1980 prices for labour and transfer income, $y_{t}$, and total consumption, $c_{t}$, the nominal series have been deflated by the price Index and have been devided by the size of the population.

The quarterly seasonally unadjusted series on nondurable consumption per caplta in prices of 1980, $c_{t}^{*}$ (unadj.), for the period 1967(1)-1984(4) has been computed as the sum of consumption expenditures per capita on food and beverages and on services and other nondurables. Monthly quantity, value and quantity per capita indices on these series are published in Centraal Bureau voor de Statistiek, Maandstatistiek Binnenlandse Handel and Dienstverlening, Staatsuitgeverij, "s Gravenhage. Annual figures on expenditures that are published in Centraal Bureau voor de Statistiek, Nationale Rekeningen, Staatsultgever1], "s Gravenhage, and on the size of the population have been used to transform the indices into monthly expenditures per capita. To incorporate the effects of the revision of the National Accounts in 1977, we used a correction factor deduced from Centraal Bureau voor de Statistiek, Nationale Rekeningen 1980 , Staatsuitgeverij. 's Gravenhage. The price index of nondurable consumption has been used to obtain a series in 1980 prices. The monthly figures have been aggregated into quaterexy data. The observations for the first and fourth quarter of 1975 are replaced by the average of the corresponding quarters in 1974 and 1976. In Centraal Planbureau, Centraal Economisch Plan 1976, Staatsultgeverij, 's Gravenhage, the irregular behaviour in 1975 is explained as an advance of sales in the first quarter from the second and 
third quarters. The high lewel of consumption in the fourth quarter is due to an increase of sales as a result of a change in the exclse tax at the beginning of 1976 .

Similar calculations were carried out to obtain a series on total consumption per capita in 1980 prices. To remove the seasoral pattern in the ratio of nondurable (including services) and total consumption, we have calculated the nondurable consumption shares as a moving average of the ratios. Multiplying $c_{t}$ with these shares yielded the serfes on nondurable consumption per capita in 1980 prices, $c_{t}^{*}$.

Comparing the data on real nondurable consumption per capita $c_{t}^{*}$ and $c_{t}^{*}$ (unadj.) shows that the series exhibit some differences. In particular, the unadfusted series evolves for the perlod 1967-1973 at a higher level than the adjusted series. A possible explanation might be that the adjusted series is constructed from the data on total consumption, which are deflated by the price index of total consumption, whereas the unadjusted series is deflated by the price index of nondurable consumption. It seems. more plausible, however, that the Centraal Planbureau Incorporated the effects of the revision of the National Accounts in 1977 differenty than we did.

Notice that all the consumption series reach their highest level in the fourth quarter of 1979. Income starts to decrease in the second quarter of 1979. Obviously, the fall of income leads that of consumption. Figures 1 and 2 reveal that the timing of the structural change in the drift parameter of the income process in the beginning of the 1970 's is much more troublesome than that at the end of the $1970^{\circ}$.

\begin{tabular}{|c|c|c|c|c|c|}
\hline year & $y_{t}$ & $c_{t}$ & $c_{t}^{*}$ & $c_{t}^{*}$ (unady.) & $\pi_{\mathrm{t}}$ \\
\hline $1967-1$ & & 2232.93 & 1705.51 & 1770 & \\
\hline $1967-2$ & & 2210.42 & 1669.09 & 1785 & \\
\hline $1967-3$ & & 2245.26 & 1693.60 & 1835 & \\
\hline $1967-4$ & & 2289.21 & 1722.75 & 1925 & \\
\hline $1968-1$ & 2273.61 & 2333.39 & 1756.11 & 1830 & -.0004 \\
\hline $1968-2$ & 23466.00 & 2357.89 & 1771.25 & 181.4 & .0036 \\
\hline $1968-3$ & 2368.63 & 2397.50 & 1818.56 & 1892 & .0127 \\
\hline
\end{tabular}




\begin{tabular}{|c|c|c|c|c|c|}
\hline $1968-4$ & 2401.71 & $2449 \cdot 34$ & 1867.62 & 2059 & .0155 \\
\hline $1969-1$ & 2449.07 & 2481.53 & 1898.06 & 1960 & .0206 \\
\hline $1969-2$ & 2491.23 & 2563.88 & 1968.68 & 1990 & .0125 \\
\hline $1969-3$ & 2510.92 & 2597.15 & 1984.35 & 2022 & .0053 \\
\hline $1969-4$ & 2570.62 & 2597.90 & 1978.43 & 2134 & .0150 \\
\hline $1970-1$ & 2633.89 & 2670.27 & 2026.74 & 2076 & .0046 \\
\hline $1970 \cdot 2$ & 2680.90 & 2694.60 & 2029.64 & 2036 & .0126 \\
\hline $1970-3$ & 2691.77 & 2715.16 & 2052.53 & 2052 & .0232 \\
\hline $1970-4$ & 2728.77 & 2772.92 & 2101.18 & 21.98 & .0178 \\
\hline $1971-1$ & 2720.18 & 2724.67 & 2072.11 & 2171 & .0200 \\
\hline $1971-2$ & 2760.28 & 2756.43 & 2114.39 & 2130 & .0209 \\
\hline $1971-3$ & 2821.65 & 2806.22 & 2139.60 & 2164 & .0186 \\
\hline $1971-4$ & 2840.33 & 2802.03 & 2137.18 & 2363 & .0213 \\
\hline $1972-1$ & 281.5 .94 & 2830.64 & 2154.40 & 2266 & .0243 \\
\hline $1972-2$ & 2816.58 & 2827.69 & 2145.02 & 2285 & .0192 \\
\hline $1972-3$ & 2842.15 & 2821.60 & 2138.49 & 2303 & .0196 \\
\hline $1972-4$ & 2899.35 & 2872.22 & 2174.77 & 2381 & .0216 \\
\hline $1973-1$ & 2879.54 & 2898.33 & 2198.17 & 2181 & .0222 \\
\hline $1973-2$ & 2920.63 & 2939.78 & 2226.74 & 2229 & .0252 \\
\hline $1973-3$ & 2947.40 & 2921.51 & 2210.34 & 2239 & .0195 \\
\hline $1973-4$ & 2965.26 & 2974.08 & 2247.66 & 23.39 & .0212 \\
\hline $1974-1$ & 2974.81 & 2958.53 & 2230.29 & 2200 & .0224 \\
\hline $1974-2$ & 3087.85 & 3010.24 & 2272.81 & 2261 & .0237 \\
\hline $1974-3$ & 3067.09 & 3029.84 & 2295.10 & 2312 & .0279 \\
\hline $1974-4$ & 3098.15 & 3028.68 & 2307.78 & 2348 & .0262 \\
\hline $1975-1$ & 3107.75 & 3051.38 & 2334.54 & $22 B 6$ & .0292 \\
\hline $1975-2$ & 3155.43 & 3044.25 & 2333.87 & 2388 & .0183 \\
\hline $1975-3$ & 3228.15 & 3088.02 & 2358.94 & 2413 & .0302 \\
\hline $1975 \cdot 4$ & 3214.35 & 3168.66 & 2407.47 & 2436 & .0200 \\
\hline $1976-1$ & 3244.13 & 3204.90 & 2419.38 & 2371 & .0208 \\
\hline $1976-2$ & 3236.85 & 3232.45 & 2438.80 & 2437 & .0218 \\
\hline $1976=3$ & 3254.95 & 3287.17 & 2465.46 & 2438 & .0141 \\
\hline $1976-4$ & 3254.95 & 3266.46 & 2438.90 & 2524 & .0216 \\
\hline $1977 \times 1$ & 3297.49 & 3331.67 & 2481.10 & 2477 & .0093 \\
\hline $1977-2$ & 3332.14 & 3368.82 & 2500.25 & 2573 & .0186 \\
\hline $1977 \cdot 3$ & 3352.43 & 3406.01 & 2527.52 & 2572 & .0126 \\
\hline
\end{tabular}




\begin{tabular}{|c|c|c|c|c|c|}
\hline $1977-4$ & 3428.42 & 3371.05 & 2502.92 & 2645 & .0085 \\
\hline $1978-1$ & 3402.15 & 3458.05 & 2570.80 & 2588 & .0097 \\
\hline $1978-2$ & 3453.46 & 3495.71 & 2601.07 & 2640 & .0129 \\
\hline $1978-3$ & 3437.98 & 3515.68 & 2625.07 & 2681 & .0128 \\
\hline $1978=4$ & 3546.51 & 3506.63 & 2620.59 & 2723 & .0054 \\
\hline 1979.1 & 3549.29 & 3537.08 & 2652.90 & 2696 & .0086 \\
\hline $1979-2$ & 3536.46 & 3566.44 & 2677.77 & 2728 & .0117 \\
\hline $1979-3$ & 3542.38 & 3588.23 & 2697.36 & 2761 & .0143 \\
\hline $1979-4$ & 3537.88 & 3599.55 & 2717.39 & 2822 & .0165 \\
\hline $1980-1$ & 3512.30 & 3564.22 & 2701.86 & 2705 & .0199 \\
\hline $1980-2$ & 3508.49 & 3550.15 & 2707.97 & 2685 & .0175 \\
\hline $1980-3$ & 3481.40 & 3536.55 & 2711.47 & 2724 & .0184 \\
\hline $1980-4$ & 3432.90 & 3529.48 & 2716.99 & 2770 & .0121 \\
\hline $1981-1$ & 3419.59 & 3469,10 & 2676.93 & 2677 & .0144 \\
\hline $1981-2$ & 3429.93 & 3424.23 & 265.4 .81 & 2638 & .0123 \\
\hline $1981-3$ & 3431.36 & 3422.54 & 2660.17 & 2666 & .0190 \\
\hline $1981-4$ & 3372.27 & 3414.76 & 2659.93 & 2741 & .0226 \\
\hline $1982-1$ & 3436.17 & 3389.52 & 2645.35 & 2629 & .0075 \\
\hline $1982-2$ & 3391.88 & 3364.83 & 2625.32 & 2615 & .0099 \\
\hline $1982-3$ & 3387.05 & 3370.63 & 2628.16 & 2639 & .0096 \\
\hline $1982-4$ & 3366.69 & 3382.98 & 2637.12 & 2702 & .0099 \\
\hline $1983-1$ & 3308.37 & 3394.61 & 2646.52 & 2605 & .0036 \\
\hline $1983-2$ & 3292.71 & 3386.76 & 2642.10 & 2603 & .0054 \\
\hline $1983-3$ & 3286.45 & 3379.80 & 2640.13 & 2632 & .0077 \\
\hline $1983-4$ & 3258.51 & 3356.16 & 2622.76 & 2680 & .0084 \\
\hline $1984-1$ & 3243.06 & 3356.03 & 2624.16 & 2609 & .0075 \\
\hline $1984-2$ & 3228.94 & 3354.28 & 2621.79 & 2570 & .0057 \\
\hline $\mathbb{1} 984-3$ & 3214.24 & 3330.75 & 2588.16 & 2591 & .0042 \\
\hline $1984-4$ & 3232.02 & 3350.63 & 2600.42 & 2649 & -.0004 \\
\hline
\end{tabular}


Eig. 1 Real disposable labour and transfer income per capita $\left(y_{4}\right), 1968(1)$ $1984(4)$.

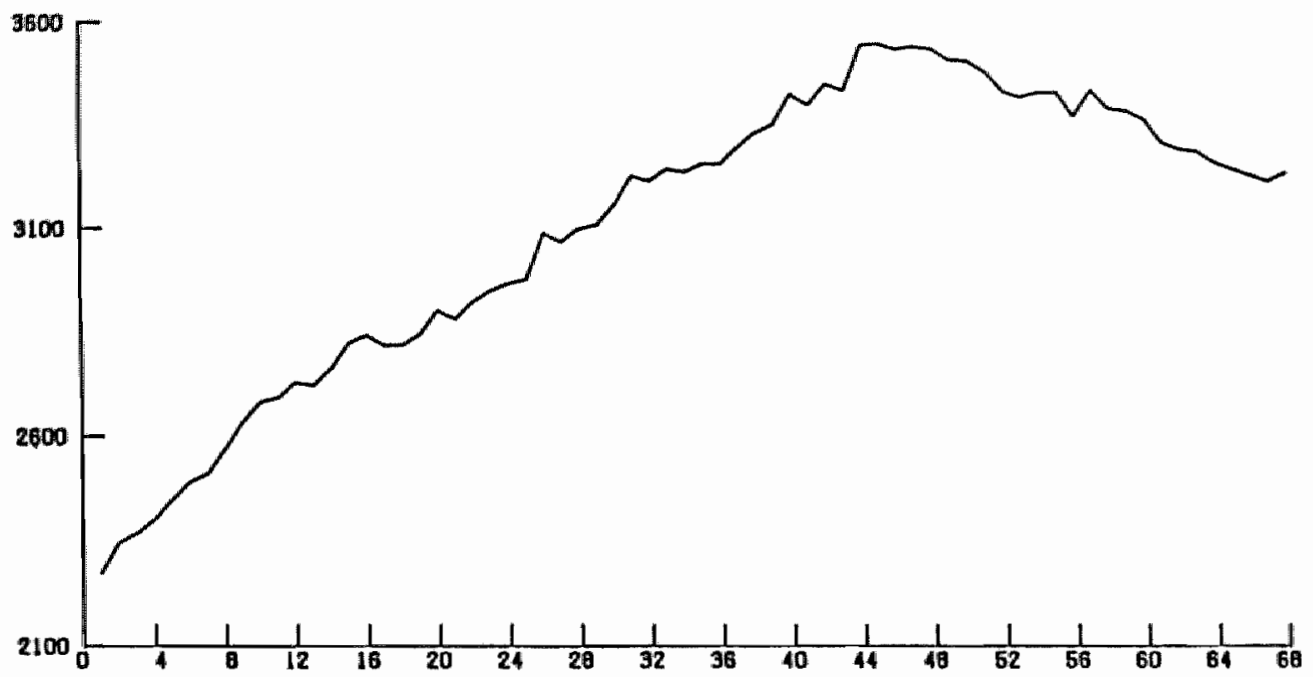

Fig. $2 \Delta$ real disposable labour and transfer income $\left(\Delta y_{t}\right), 1968(2)-1984(4)$.

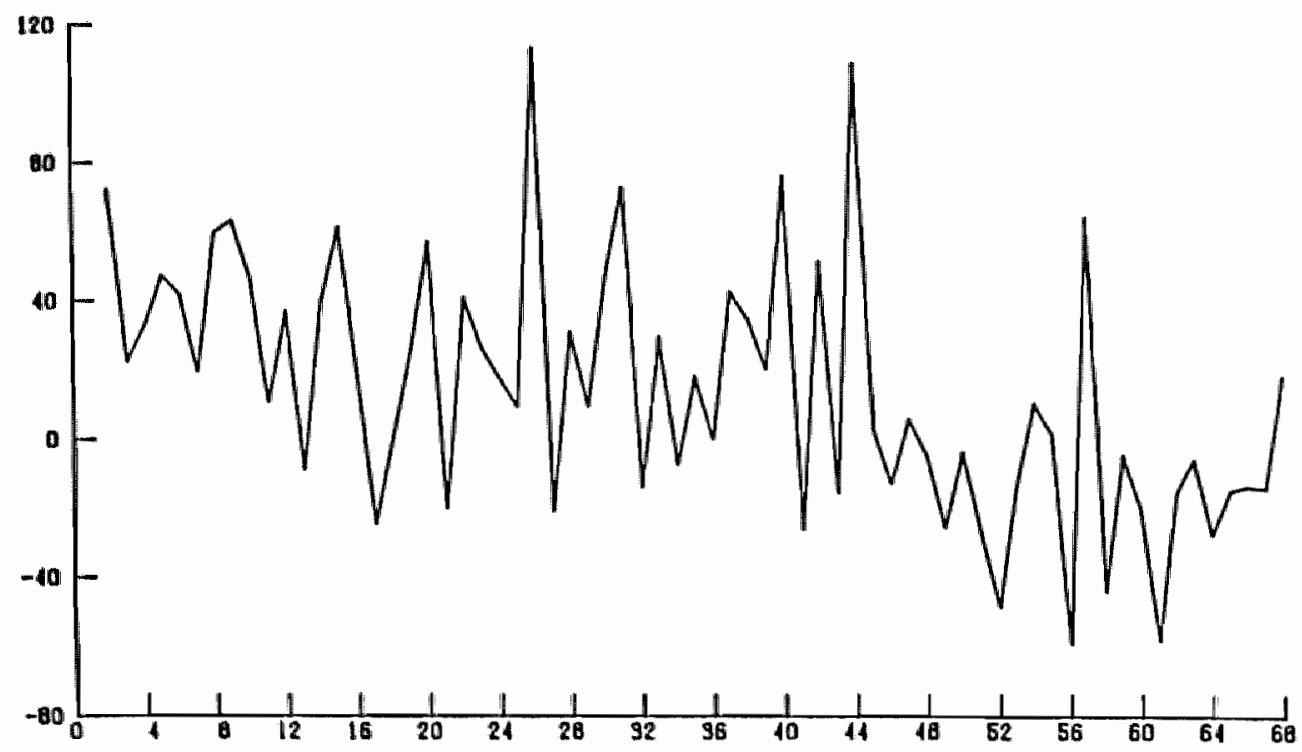


Fig. 3 Real total consumption per capita $\left(c_{i}\right), 1967(1)-1984(4)$.

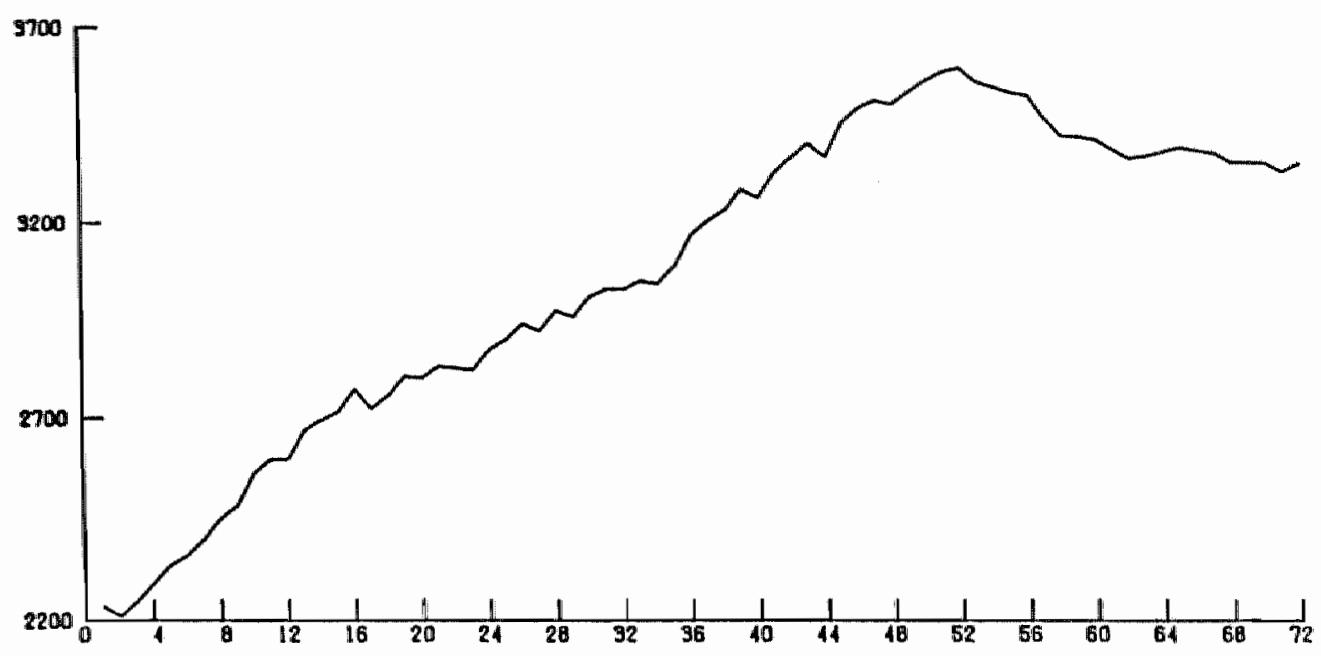

Fïg. $4 \Delta$ real total consumption per capita $\left(\Delta c_{t}\right), 1967(2)-1984(4)$.

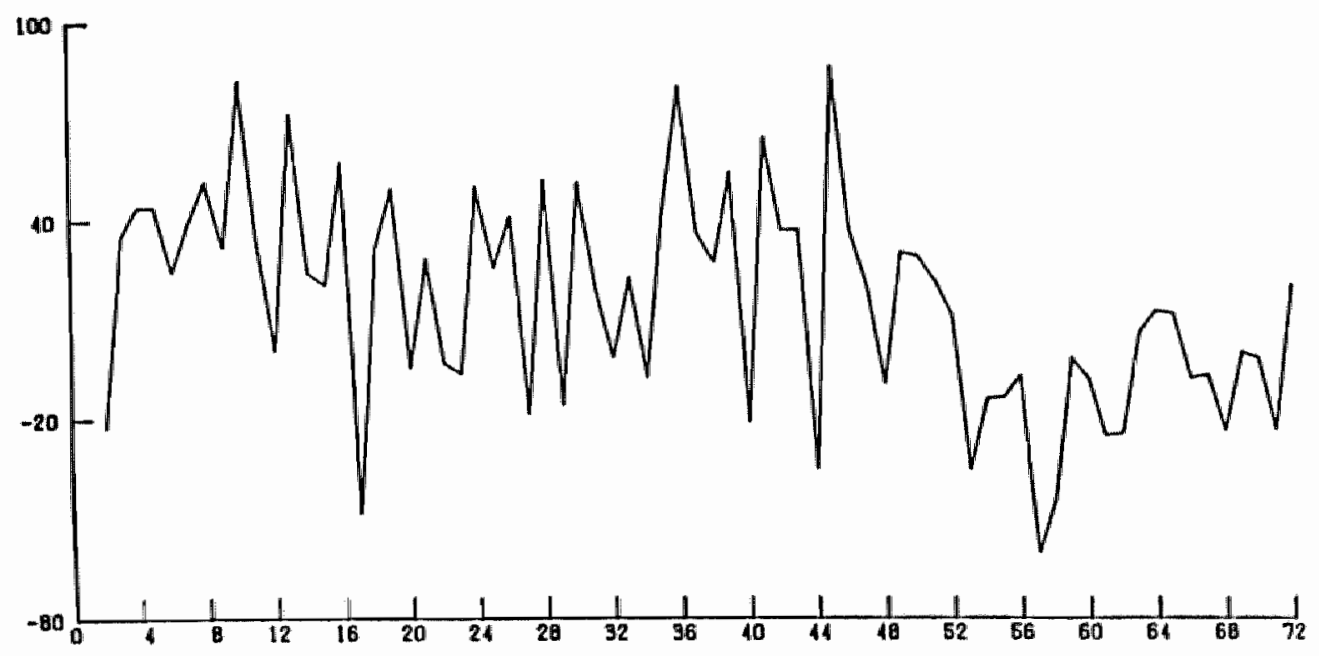


F1g. 5 Real nondurable consumption per capita $\left(c_{i}^{*}\right), 1967(1)-1984(4)$.

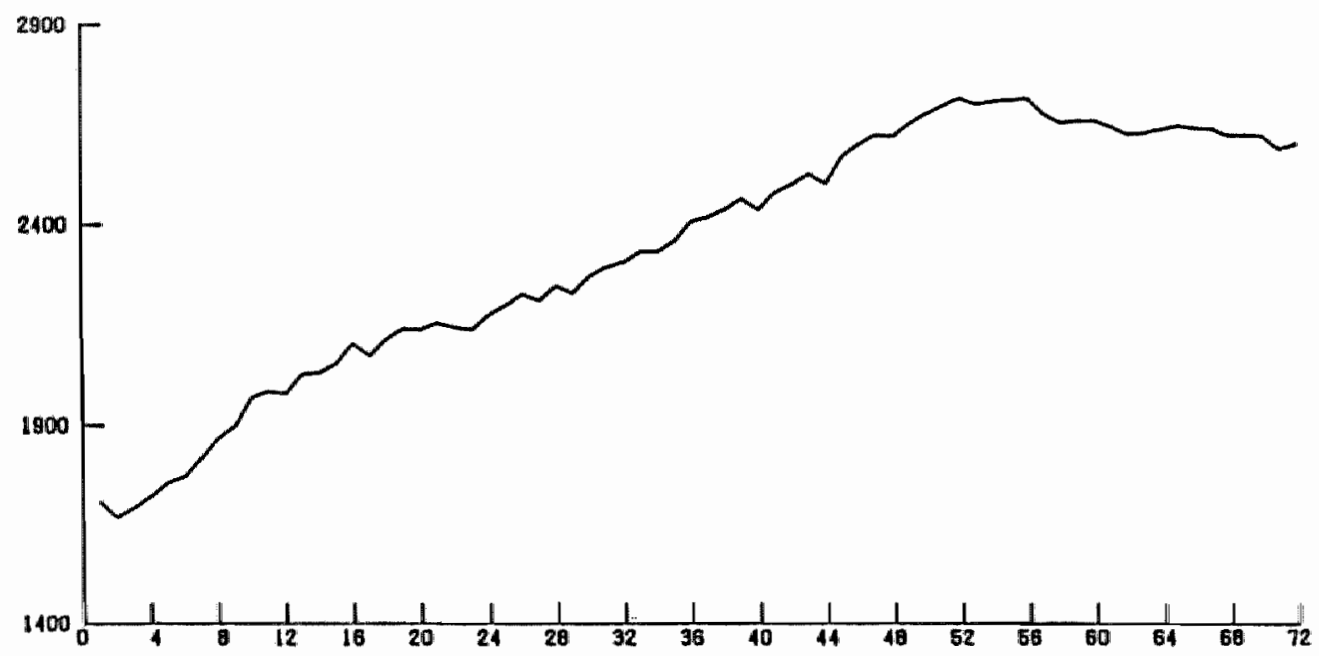

Fig. 6 $\Delta$ real nondurable consumption per capita $\left(\Delta c_{t}^{*}\right), 1967(2)-1984(4)$.

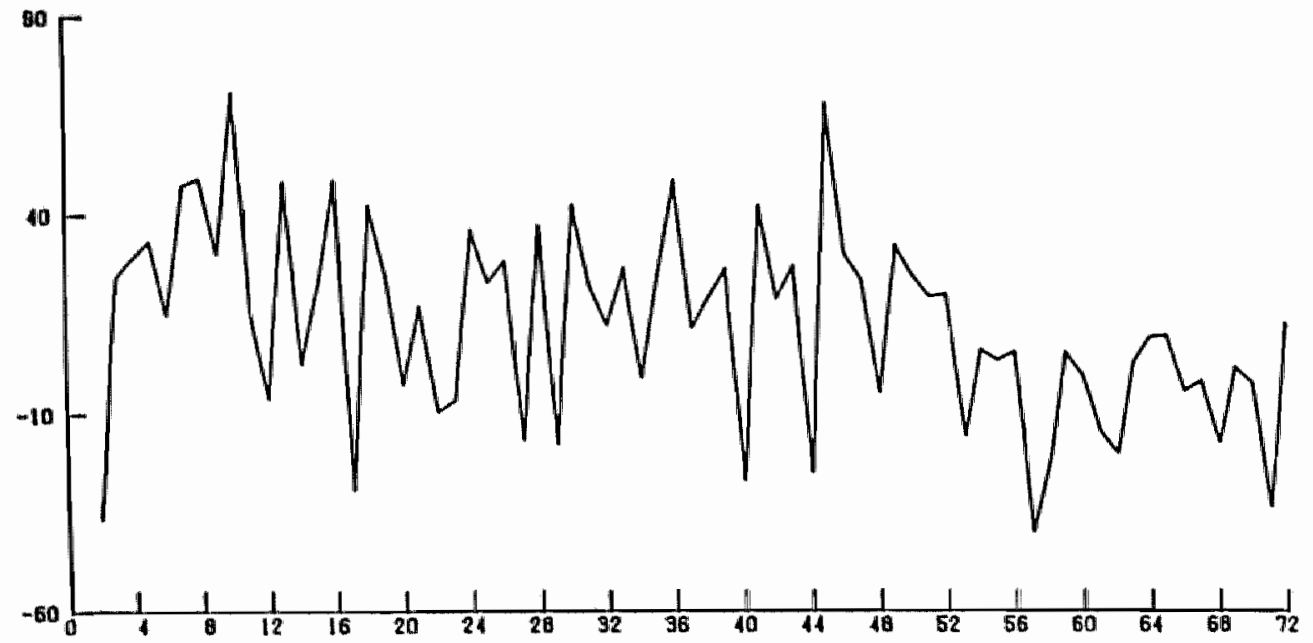


Fig. 7 Seasonally unadjusted real nondurable consumption per capita ( $c_{*}^{*}$

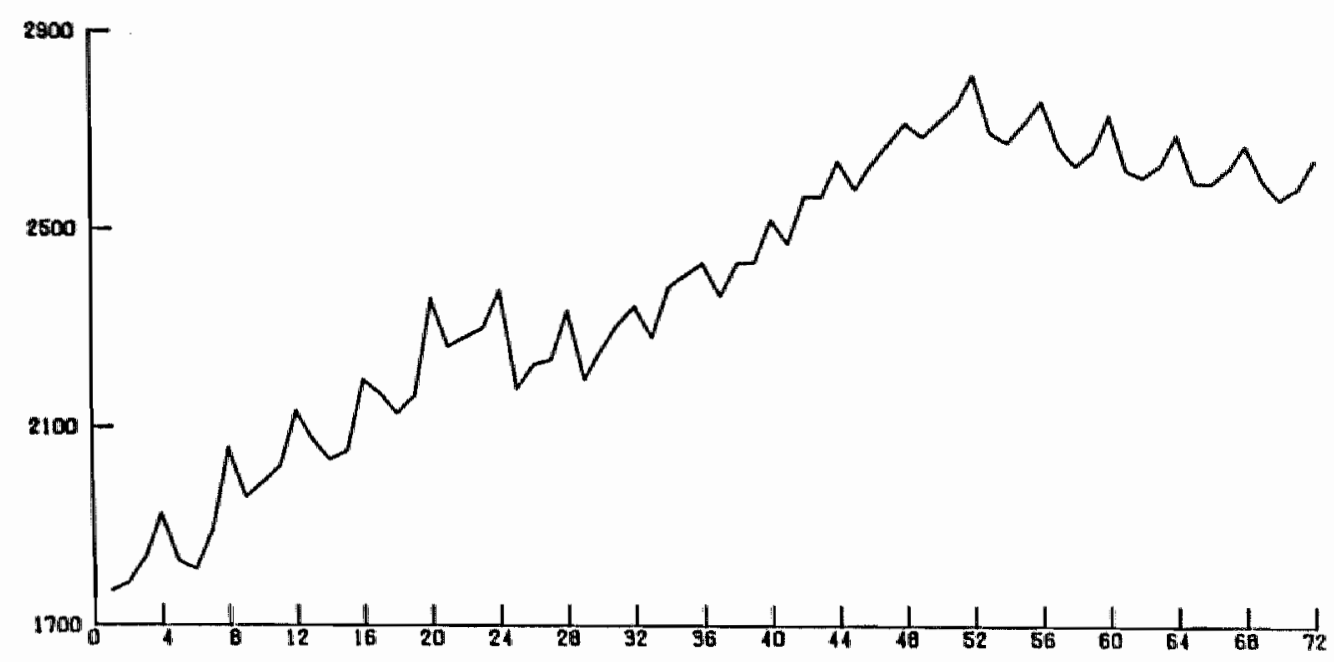

FIg. $8 \Delta_{4}$ seasonally unadjusted real nondurable consumption per capita $\left(\Delta_{4} c_{t}^{*}(\right.$ unadj. $\left.)\right), 1968(1)-1984(4)$.

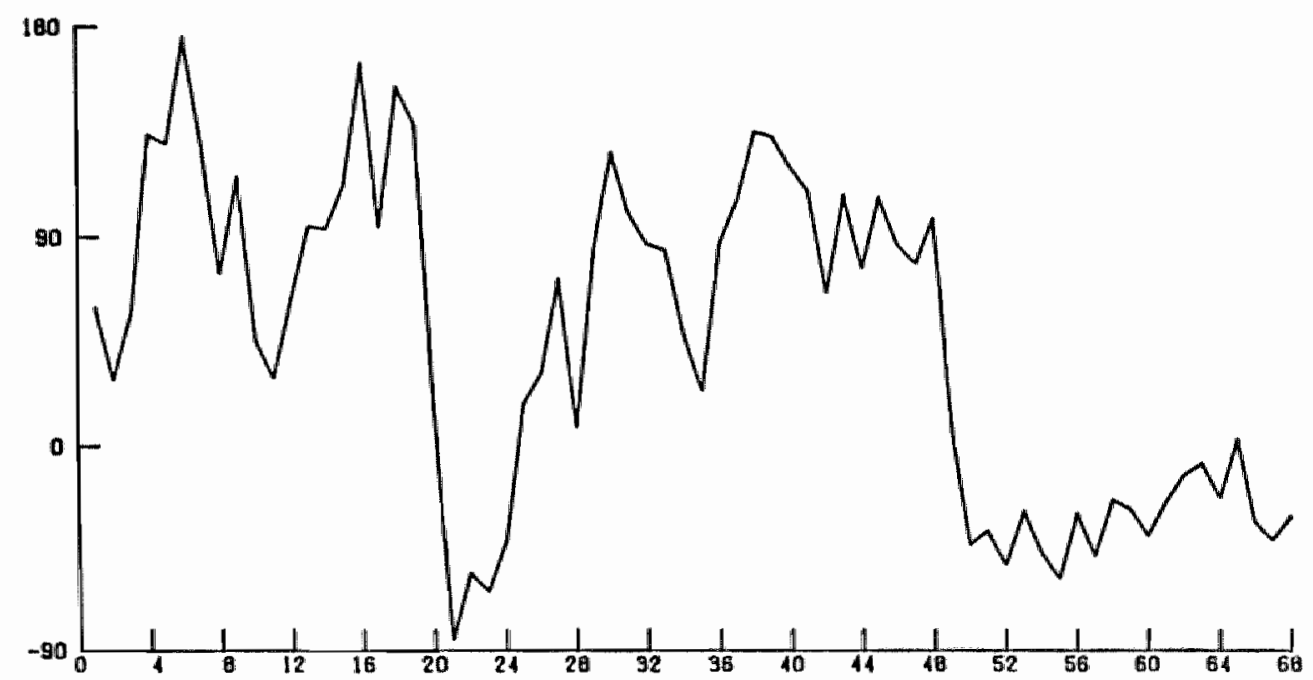


Fig. 9 Inflation $\left(\pi_{t}\right), 1968(1)-1984(4)$.

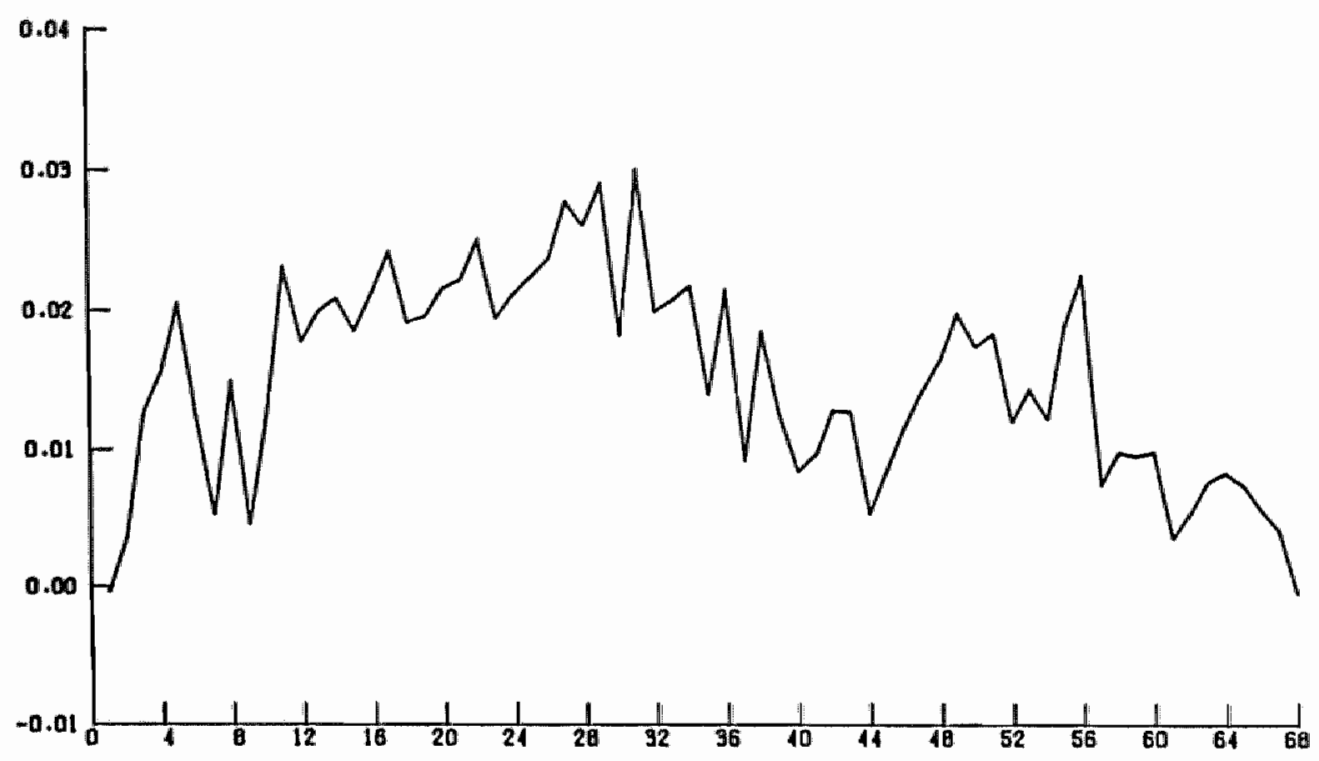




\section{References}

Alessie, R.J.M. and A. Kapteyn (1986): "Consumption, saving and demography". Tilburg University, Tilburg.

Alessie, R.J.M., B. Melenberg and G. Weber (1987): "Life cycle hypothesis with liquidity constraints: an estimable equation" THIburg University, Tilburg.

Anderson, T.W. (1971): The Statistical Analysis of Time Series, New York, John Wley and Sons Inc.

Ando, A. and F. Modigliani (1963): "The life cycle hypothesis of saving: aggregate implications and tests", American Economic Review, 53, 55-84.

Bierens, H.J. (1984): "Model specification testing of time series regressions", Journal of Econometrics, 26, 323-353.

Bilson, J.F. (1980): "The rational expectations approach to the consumption function: a multicountry study", European Economic Review, $13,273-299$.

Blunde11, R. (1986): "Econometric approaches to the specification of lifecycle labour supply and commodity demand behaviour" (with discussion). Econometric Reviews, 5, 89-170.

Box, G.E.P. and G.M. Jenkins (1976): Time Serles Analysis, Forecasting and Control (revised edition), San Francisco, Holden-Day.

Box, G.E.P. and G.C. Tíao (1965): "A change in level of a nonstationary time series", Biometrika, 52, 181-1.92.

Brown, T.M. (1952): "Habit persistence and lags in consumer behaviour", 
Econometista, $20,355-371$.

Campbe11, J.Y. (1987): "Does saving anticipate declining labor income? An alternative test of the permanent income hypothesis". Econometrica, $55,1249-1273$.

Campbe11, J. and A. Deaton (1987): "Why is consumption so smooth?", Princeton University, Princeton, N.J., paper presented at the Econometric Society European Meeting in Copenhagen.

Charpin, F. (1987): "The stochastic life cycle consuraption model: additional theoretical results", University of Paris $X$, Paris, paper presented at the Econometric Soclety European Meeting in Copenhagen.

Currle, D. (1981): "Some long run features of dynamic time series mode1s", The Economic Journa1, 91, 704-715.

d'Autume, A. and $\mathbb{P}$. Michel (1987): "Transversality conditions", budget constraints and the determinacy of a perfect foresight equilibrium in a monetary growth model", European Economic Revilew, 31, 1343-1367.

Davidson, J.E.H. and D.F. Hendry (1981): "Interpreting econometric evidence: the behaviour of consumers' expenditure in the UK" "European Economic Review, 16, 177-192.

Davidson, J.E.H.,D.F. Hendry, F. Srba and S. Yeo (1978): "Econometric modelling of the aggregate time-series relationship between consumers: expenditure and income in the United Kingdom", The Economic Journal, $88,661-692$.

Davis, T.E. (1952): "The consumption function as a tool for prediction", The Review of Econonics and Statistics, $34,270-277$.

Deaton, A. (1977): "Involuntary saving through unanticipated inflation", The American Economic Review, 67, 899-910. 
Deaton, A. (1985): "Life-cycle models of consumption: 1 s evidence consistent with the theory?" Invited paper presented at the Econometric Soclety World Meeting in Boston.

Domowitz, I. and H. White (1982): "Misspecified models with dependent observations", Journal of Econometrics, 20, 35-58.

Duesenberry, J.S. (1949): Income, Saving and the Theory of Consumer Behavior, Cambridge, Mass., Harvard University Press.

Dunn, K.B. and K.J. Singleton (1986): "Modeling the term structure of interest rates under non-separable utility and durability of goods". Journal of Financial Economics,17, 27-55.

Engle, R.F. (1978): "Estimating structural models of seasonality", in A. Zellner (ed, ): Seasonal Analysis of Economic Time Series, U.S. Department of Commerce, Bureau of the Census, 281-297.

Engle, R.F. (1982): "Autoregressive conditional heteroscedasticity with estimates of the variance of United Kingdom inflation", Econometrica, $50,987-1007$.

Engle, R.F. and C.W.J. Granger (1987): "Co-Integration and errorcorrection: representation, estimation and testlng", Econometrica, 55, 251-276.

Engle, R.F., D.M. Lilien and R.P. Robins (1987): "Estlmating time varyinf risk premia in the term structure: the ARCH-M mode1", Econometrica, 55, $391-407$.

Flavin, M. (1981): "The adjustment of consumption to changing expectations about future income", Journal of Political Economy, 89, 974-1009.

Fourgeaud, C., C. Gourieroux and J. Prade1 (1986): "Learning processes and convergence to rationality", Econometrica, 54, 845-868. 
Frledman, M. (1957): A theory of the Consumption Function, Princeton, N.J., Princeton University Press.

Friedman, M. (1963): "Windfalls, the 'horizon', and related concepts in the Permanent-Income Hypothesis", In C. Christ et. al. (eds.): Measurement in Economics: Studies in Mathematical Economics and Econometrlcs in Memory of Yehuda Grunfeld, Stanford, Calif., Stanfard Unlversity Press, 3-28.

Gale, D. (1967): "On optimal development in a multi-sector economy", Review of Economic Studies, $34,1-18$.

Gersch, W. and G. Kitagawa (1983): "The prediction of time series with trends and seasonalitles", Joumal of Business and Economic statistics, 1. $253-264$.

Gourleroux, C., A. Montfort and A. Trognon (1985): "Mofndres carres asymptotiques", Annales de I'INSEE, 58, 91-122.

Ha11, R.E. (1978): "'Stochastic implications of the life cycle-permanent Income hypothesis: Theory and evidence", Journal of Political Economy, $86,971-987$.

Ha11, R.E. (1981): "Comments 'Interpreting econometric evidence" by Davidson and Hendry", European Economic Review, 16, 193-194.

Hal1, R.E. and F.S. MHshiln (1982): "The sensitivity of consumption to transitory income: estimates from panel data on households". Econometrica, $50,461-481$.

Hansen, L.P. and K.J. Singleton (1982): "Generallzed Instrumental varlables estimation of nonlinear rational expectations models" Econometrica, $50,1269-1286$.

Hansen, L.P. and K.J. Singleton (1983): "Stochastic consumption, risk Aversion and the temporal behavior of asset returns" , Journal of 
Political Economy, 91, 249-265.

Harvey, A.C. (1985): "Trends and cycles in macroeconomic time series" Journal of Business and Economic Statistics, 3, 216-227.

Harvey, A.C. and P.H.J. Todd (1983): "Forecasting economic time series with structural and Box-Jenkins models: a case study", Journal of Business and Economic Statistics, 1, 299-315.

Hendry, D.F. (1979): "Predictive fallure and econometric modeliling in macroecomnomics: The transactions demand for money", in P.A. Ormerod (ed): London business school conference on economic modeliling, London, Helneman.

Hendry, D.F. (1983): "Econometric modelling: the "consumption function" In retrospect", Scottish Joumal of Political Economy, 30, 193-220.

Hendry, D.F. and J.F. Richard (1982): "On the formulation of emplrical models In dynamic econometrics", Journal of Econometrics, 20, 3-34.

Hendry, D.F. and J.F. Ríchard (1983): "The econometric analysis of economic time series" (with discussion), International statistical Review, 51, $111-163$.

Hendry, D.F. and T. von Ungern-Sternberg (1981): "Liquiddty and inflation effects on consumers" behaviour", in A.S. Deaton (ed.): Essays in the Theory and Measurement of Consumers' Behaviour, Cambridge, Cambridge University Press.

Jager, A. and K. Neusser (1987): "Excess consumption as a predictor of future income changes", Institute of Advanced Studies "Vienna, paper presented at the Econometric Socity European Meeting in Copenhagen.

King, M. (1984): "The economics of saving. A survey of recent contributions", ESRC Taxation, Incentives and Distribution of Income Program, Working Paper no. 49. 
Kiviet, J.F. (1985): "Hodel selection test procedures in a single linear equation of a dynamic simultaneous system and their defects in small samples:" Joumal of Economerrics, 28, 327-362.

Kloek, T. (1984): "Dynamic adjustment when the target is non-stationary", International Economic Review, $25,315-326$.

Kodde, D.A. and F.C. Palm (1986): "Asymptotic least squares estimation: efficlency considerations", Universtey of Limburg, Maastricht.

Lomnlcki, 2.A. (1961): "Tests for departure from normality in the case of linear stochastic processes", Metrika, 4, 27-62.

Lucas, R.E. (1976): "Econometric policy evaluation: a critique", in $K$. Brunner and A.H. Meltzer (eds.): The Phillips Curve and Labor Markets. Carnegle-Rochester Conference on Public Policy, 1. Amsterdam, North Holland Publishing Company, $19-46$.

Marava11, A. (1985): "On structural time series models and the characterization of components", Joumal of Business and Economic statistics, $3,350-355$.

Miron, J.A. (1986): "Seasonal fluctuations and the life cycle-permanent income model of consumption" Journal of Political Economy, 94, 1258 . 1279 .

Modigliani, F. (1949): "Fluctuations in the saving-income ratio: a problem in forecasting", In Studies in Income and Wealth (Conference on research in lncome and wealth), 11 , New York, National Bureau of Economic Research, $371-438$.

Modigliani, F. (1975): "The 11fe-cycle hypothesis of saving twenty years later", In M. Parkin and A.R. Nobay (eds.): Contempory Issues in Economics, Manchester, Manchester Uniwersity Press. 
Modigliani, F. and R.E. Brumberg (1955): "Utility analysis and the consumption function", in K.K. Kurlhara (ed.): Post - Keynesian Economics, London, George Allen and Unwin.

Modigliani, F. and R. Brumberg (1979): "Utilfty analysis and aggregate consumption functions: an attempt at integration", in A. Abel (ed.): The Collected Papers of Franco Modigliani, vol. 2, Cambridge, Mass., MIT Press, 128-198.

Muellbauer, J. (1983): "Surprises in the consumption function" "The Economic Journal (supplement), 93, 34-50.

Muellbauer, J. (1986): "Habits, rationality, and myopia in the 1ife-cycle consumption function", Nuffield College, Oxford.

Nelson, C.R. and C.I. Plosser (1982): "Trends and random walks in macroeconomic time serles", Journal of Monetary Economics, 10, 139-162.

Nerlove, M., D.M. Grether and J.L. Carvalho (1979): Analysis of Economic Time Series, New York, Academlc Press.

Neusser, K. (1987): "Consumption and changing income uncertainty: first empirical investigation for Austriat, University of Vienna, Vienna.

Palm, F.C. and C.C.A. Winder (1986): "The stochastic 1.fe cycle model: theoretical results and empirical evidence", Free Universtey, Amsterdan, paper presented at the Econometric Soclety European Meeting In Budapest.

Pesaran, M.H. and R.A. Evans (1984): "Inflation, capltal galns and U.K. personal savings: 1953-1981", The Economic Journal, 94, 237-257.

Piexce, D.A. (1978): "Seasonal adjustment when both deterministic and stochastic seasonality are present", in A. Zellner (ed.): Seasonal Analysis of Economic Time Series, U.S. Department of Commerce, Bureau of the Census, $242-269$. 
Pollak, R.A. (1970): "Hable formation and dynamic diemand functions", Joumal of Polltical Economy, 78, 745-763.

Prothero, D.L. and K.F. Wallis (1976): "Modelling macroeconomic time series", Journal of the Royal Statistical Soclety, series A, 139, 468500 .

Salmon, M. (1982): "Error correction mechanfsms" , The Economic Joumal, 92, $615-629$.

Sargent, T.J. (1979): Macroeconomic Theory, New York, Academic Press.

Sargent, T.J. (1981): "Intexpreting economic time series", Journal of Political Economy, 89, 213-248.

Singleton, K.J. (1985): "Testing specifications of economic agents" intertemporal optimum problems in the presence of alternative models" " Journal of Econometrics, 30, 391-413.

Somermeyer, W.H. and R. Bannink (1973): A Consumption-Savings Model and its Applications, Amsterdam, North-Holland Publishing Company.

Steyn, I.J. and A.F. de Vos (1987): "Structural time series models for trends", Free Untversity, Amsterdam, paper presented at the Econometric Soclety European Meting in Copenhagen.

Takayama, A. (1985): Mathematical Economics (second edition), Cambridge, Cambridge University Press.

Tsay, R.S. (1988): "Outliers, level shifts, and variance changes in time serfes", Journal of Forecasting, 7, 1-20.

Wallis, K.F. (1980): "Econometric Implications of the rational expectations hypothesis", Econometrica, 48, 49-73. 
Weiss, A.A. (1984): "ARMA models with ARCH errors", Journal of Time Series Analysis, 5, 129-143.

White, H. (1980): "A heteroscedastic-consistent covariance matrix estimator and a direct test for heteroscedasticity" Econometrica, 48, 817-838.

Wickens, M. and H. Molana (1983): "Stochastic life cycle theory with varying interest rates and prices", The Economic Journal (supplement). 93. $133-147$.

Zellner, A. and F.C. Palm (1974): "Time series analysis and simultaneous equation econometric models" , Journal of Econometrics, 2, 14-54. 
Wederlandse samenvatting (Dutch summary)

\title{
HET MODELLEREM VAN INTERTEMPOREEL CONSUMENTENGEDRAG
}

\author{
Theoretische Resultaten en Empirisch Bewijs
}

Geaggregeexde consumptie is het belangrijkste bestanddeel van het National Produkt. Voor macro-economisch belefd is het dan ook van belang om over betrouwbare voorspellingen van consumptie te beschikken. Voor succesvolle beleidstoepassingen is het daarnaast noodzakelijk inzlcht te hebben in de dynamische structur van de consumptiefunctie. Onderzoekers als Davidson en Hendry hebben benadrukt dat economische theorieen doorgaans enkel informatie leveren over de lange termijn evenwichtsrelaties en dat een econometrische analyse nodig is om de dynamische specificatie van de korte termijn verbanden op te sporen. De klasse van modellen waarin de economische agenten geconfronteerd worden met een dynamisch optimalisatieprobleem is een voorbeeld warin de economische theorie wel uitspraken doet over de dynamische structuru van de gedragsrelaties. In deze studie specificeren we modellen waarin de consument federe periode een intertemporeel nutsmaximalisatieprobleem oplost. De dynamische implicaties van het theoretische model gebruiken we als een leiddraad in de specificatieanalyse. We schatten en toetsen de modellen net geaggregeerde dat vaor de perlode 1968-1984. Gedurende deze periode was de economie aan verschtllende schokken onderhevig. Voorbeelden zijn de twee ollecrises in de jacen ' 70 en de verandering in het overheidsbeletd bij het aantreden van het kabinet Lubbers-Van Aardenne. Deze veranderingen hebben hoogstwarschijnlijk invloed gehad op thet consumentengedrag en hebben bepalde economische gedragsrelaties veranderd. Onderzoekers als Sargent en Lucas hebben benadrukt dat de modellen warin de economische agenten verondersteld worden een intertemporeel maximalisatieprobleem op te lossen, de onderzoeker de mogelijkhefd bieden om de implicaties van structurele breuken op te sporen. 
Een van de belangrijkste doelstellingen van het onderzoek is een bijdrage te leveren aan het verkrijgen van een beter inzicht in de theoretische modelien van intertemporeel consumentengedrag, wanneer structurele breuken in het inkomensproces zich voordoen. Als de ard van de verandering. vastgesteld is, dan geeft het theoretische model aan hoe het consumentengedrag zal veranderen. Wanneer de economlsche modellen verschillen dan zullen de implicaties van die veranderingen doorgaans ook verschillen. Met de empirische analyse beogen we een antwoord te geven op de vraag welke economische theorie het meest in overeenstemming is met de steekproef-informatie.

$\mathrm{Na}$ een inleiding, wasrin we de studie in hoofdlijnen uiteenzetten en een kort literaturuverzicht geven, starten we in hoofdstuk 2 de analyse met het levenscyclusmodel. De gekozen formulering van de levenscyclushypothese is vergelijkbaar met die wan Hall (1978). Het belangrijkste verschil is dat wij veronderstellen dat de consument enkel informatie over het verwachte toekomstige inkomen in zijn consumptiebeslissing verwerkt, terwljl in $H_{a} 11 \mathrm{~s}$ formulering de consument in principe gebrulk makt van alle informatie over het inkomensproces. Onze analyse veralgemenfseert die van Hall omdat w1 aangeven hoe structurele breuken in het inkomensproces verwerkt kunnen worden. De empirische analyse leert ons dat het model een goede beschrifving van de correlatie-structuur van de consumptie-data geeft, mits we bereid zijn te veronderstellen dat een van de parameters die de preferentiestructuur karakteriseren, een verandering heeft ondergaan. Deze veronderstelling is noodzakelifjk om de daling van consumptie in de jaren : 80 te beschrijven. De schattingsresultaten impliceren echter ook dat de consument een zeer korte verwachte levensduur heeft.

In hoofdstuk 3 onderzoeken we het model waarin de consument alle informatle over het inkomensproces gebruikt. Onder de extra veronderstelling dat consumptie normal verdeeld is, leiden we een oplossing af voor de consumptiebeslissing. We laten bovendien zlen dat het geimpliceerde consumptieproces, gegeven het gespecifeerde inkomensproces, niet op basis van informatie in de data te onderscheiden is van het model dat onderzocht is $\mathbb{i n}$ hoofdstuk. 2 .

In hoofdstuk 4 introduceren we het model met meeschuivende planningshorizon. In dit model wordt de consument verondersteld een intertemporeel nutsmaximalisatieprobleem op te lossen, waarbil de 
planningsduur niet samenvalt met de verwachte levensouur. Het lijkt niet denkbeeldig dat hij de gcharse en onbetrouwbare informatie over de verre toekomst zal megeren en zlch zal beperken tot de meer zekere informatie die beschikbaar is over de nabije toekomst. Wanneer de planningsdur niet samenvalt met de levensduur dient het model uitgebreid te worden met een mechanlsme dat de aanpassing van de planningshorlzon bij thet voortschrijden van de tijd beschrijft. We kiezen voor de meest simpele oplossing en veronderstellen dat de consument een planningstermijn van een vast aantal perloden hanteert. We leiden het door het model geimpliceerde univariate stochastische proces voor consumptie af. Het blijkt dat de constante term van dit proces proportloneel is met de constante term van het Inkomensproces. Wanneer de laatste en onverwachte verandering ondergaat, betekent dit dat de constante term van het consumptie-proces ook zal veranderen. Deze elgenschap van het model opent de mogelijkheid om de daling van consumptie in de jaren ' 80 te relateren aan de waargenomen daling van het finkomen. Vit de empirische analyse van het univariate proces voor consumptie concluderen we dat het model met meeschuivende pilanningshorizon een adequate beschrijving van de data geeft. We hoeven niet zoals in het levenscyclusmodel onderzacht in hoofdstuk 2, een ad-hoc veronderstelling dat een van de parameters die het consumptiegedrag karakteriseren verandert, te introduceren.

Het model met meeschuivende planningshorizon leidt tot een verband tussen Inkomen en consumptie dat grote overeenkomst vertoont met andere

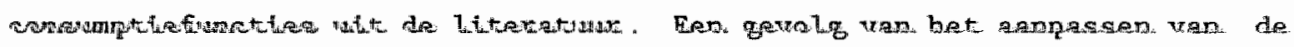
planningshorizon is dat een fouten-correctie mechanisme in de consumptlefunctle opgenomen moet worden. Deze mechanismes zijn eerder met succes toegepast in bijv. de studie van Davidson, Hendry, Srba and Yeo (1978). Het model dat onderzocht wordt in hoofdstuk 4 geeft een Alternatieve verklaring voor die correctie-termen en laat zien dat de succesvolle toepassingen in consumptiefuncties, die geschat en gespecificeerd zijn met geaggregeerde data, mogelifkerwijze terug te voeren zifn op een simpele veronderstelling over individueel consumentengedrag. De empirische analyse van de schattingsvergelfjking met correctiemechanlsme, welke een alternatieve specificatie is die geimpliceerd wordt door het model met meeschuivende planningshorizon, met data voor totale consumptie, laat zien dat de steekproefinformatie in 
overeensteming is met de theoretische implicaties. De resultaten verkregen met niet-duurzame consumptie zijn zeer bevredigend. We vinden echter een aanwijzing van heteroscedasticiteit in de storingsterm van de consumptiefunctie. Dit is in strijd met het theoretische model.

In hoofdstuk 5 onderzoeken we daarom een uitbreiding van het model. We richten onze aandacht op inflatie-effecten. Het mechanisme dat gekozen wordt om inflatievariabelen in de consumptiefunctie te introduceren is vergelijkbaar met dat in Deaton (1977). Uit de empirische resulten concluderen we dat het in ogenschouw nemen van inflatie-effecten echter geen bevredigende verklaring geeft voor de tegenspraak die we tegenkwamen in hoofdstuk 4 .

In hoofdstuk 6 nemen we een andere uitbreiding van de eerder bekeken modellen onder de loep. We analyseren het levenscyclusmodel en het model met meeschuivende planningshorizon, met en preferentiestructuur van de consument die rationele gewoontevorming vertoont. voor het levenscyclusmodel laten we zien dat een willekeurig "autoregressive integrated moving average" (ARIMA) proces voor consumptie verkregen kan worden door de keuze van een geschikt patroon van rationele gewoonten. Het mode1 levert een theoretisch kader waarbinnen we een algemene klasse van stochastische processen voor consumptie kunnen interpreteren en we de effecten van bepalde beleidsscenario's kunnen doorrekenen. Het model met meeschuivende planningshorizon wordt onderzocht voor een speclaal patroon van rationele gewoontevorming, dat een model in jaar-verschillen oplevert. We leiden het univariate stachastische proces voor consumptie af wanneer het jaarlijkse verschli in inkomen gegenereerd wordt door een ARMA proces en argumenteren dat de theoretische relaties tussen het inkomens - en consumptieproces $v a n$ nut kunnen zijn tijdens de identificatiefase wan een univarlate tijdreeksanalyse. Bovendien laten we zien dat het model in staat is om het mechanisme dat ten grondslag ligt aan de consumptiefunctid van Davidson, Hendry, Srba, en Yeo (1978) te reproduceren.

In hoofdstuk 7 beschouwen we het model met messchulvende planningshortzon onder een vorm van rationele gewoonten, die impliceert dat het vorlge consumptieniveau invloed heeft op de huidige consumptiebeslissing. Daarnaast modelleren we de effecten van gewoontevorning door middel van het latste piek-1nkomen en de laatste piek-consumptie. In de consumptiefunctie moeten we als gevolg van de aanpassing van de planningshorizon aok een 
fouter-cormetle term opnemen. Het model dat geanalyseerd wordt in hoofdstuk 7 verschaft ons een geintegreerd theoretisch kader warbinnen de Leeen Wan Duesenberry (1949), Modiglianl (1949), Brown (1952), Davis (1952) en Davidson et. al. (1978) onderzocht kunnen worden. De resultaten van de empirische analyse met data voor totale consumptie leiden tat de conclusie dat er geen aanujzing is dat gewoontevorming een rol speelt. De specifleatie-analyse leidt uiteindelijk tot het model dat onderzocht is in hoofdstuk 4 en bevesitgt de conclustes van dat hoofdstuk. Voor nietduurzame consumptie vinden we daarentegen eren significant effect van de latste piek-consumptie. Uit de misspecificatie-analyse concluderen we dat de steekproefinformatie overeenkomt met de theoretische implicaties van het model. In tegenstelling met de resultaten van hoofdstuk 4 vinden we nu geen Indicatie van heteroscedesticiteit in de storingsterm van de consumptiefunctie. Het in ogenschouw nemen van de effecten van de laatste plek-consumptle lijkt de de eerder gevonden inconsistentie te verhelpen. De evaluatie van de tekens en de orde van grootte van de puntschattingen toont ons echter dat de invloed van de laatste piek-consumptie het tegengestelde is van gewoontevormend. Deze implicatie wekt sterke twijfel over de geschiktheid wan het model.

Voor de lengte van de planningsduur in het modlel met meeschuivende planningshorizon vinden we in de verschillende hoofdstukken schattingen die varieren van 0.01 tot 13 kwartalen. Hierult trekken we de (voorzichtige) conclusie dat de consument betrekkelijk "kortzichtig" is en dat onze resultaten op gespannen voet staan met de uitgangspunten van het levenscyclusmodel.

In hoofdstuk 8 richten we onze aandacht op thet modelleren van niet voor selzoen gecorrlgeerde consumptie-data. Ondat we nite de beschikking hebben over ongecotrigeerde data voor het loon-en ultkeringsinkomen, beperken we ons tot een analyse binnen de context van het levenscyclusmodel. In het eerste gedeelte specificeren we een structureel tijdreeksmodel (zie Harvey en Todd (1983)). Omdat we dit model moeten verwerpen kiezen we vervolgens voor een andere procedure en modelleren het seizoenspatroon als een speclabl geval van gewoontevorming. De empirische resultaten zijn echter niet bevredigend. We vinden wederom heteroscedasticiteit in de consumptieinnowatie die in strijd is met de theoretische implicaties. In een afsluitende paragraaf geven we aan hoe het model eventueel uitgebreid kan 
worden. Vanwege het ontbreken van geschikte inkomensdata zien we af van een nadere analyse.

Hoofdstuk 9 besluit de studie met een samenvatting en een aantal afsluitende opmerkingen. 
CURRICULUM VITAE

Geboren: 26 juli 1958 te Alkmaar

1970-1976: mlddelbaar onderwljs an het Petrus Canisius College te Alkmar juni 1976: Andexamen Atheneum-b

1976-1984: studle aan de Interfacultelt der Actuarlele Wetenschappen en Econometrle van de Universiteit van Amsterdam

14 mel 1979: propedeutisch examen economile (Facultelt der Economische Wetenschappen van de UvA)

30 mei 1979: Kandidaatsexamen econometrle (cum laude)

30 me1 1984: doctoraalexamen econometrie (cum laude)

afstudeerrichting: econometrle

31 october 1984: kandidaatsexamen actuarlaat (cum 1aude). 